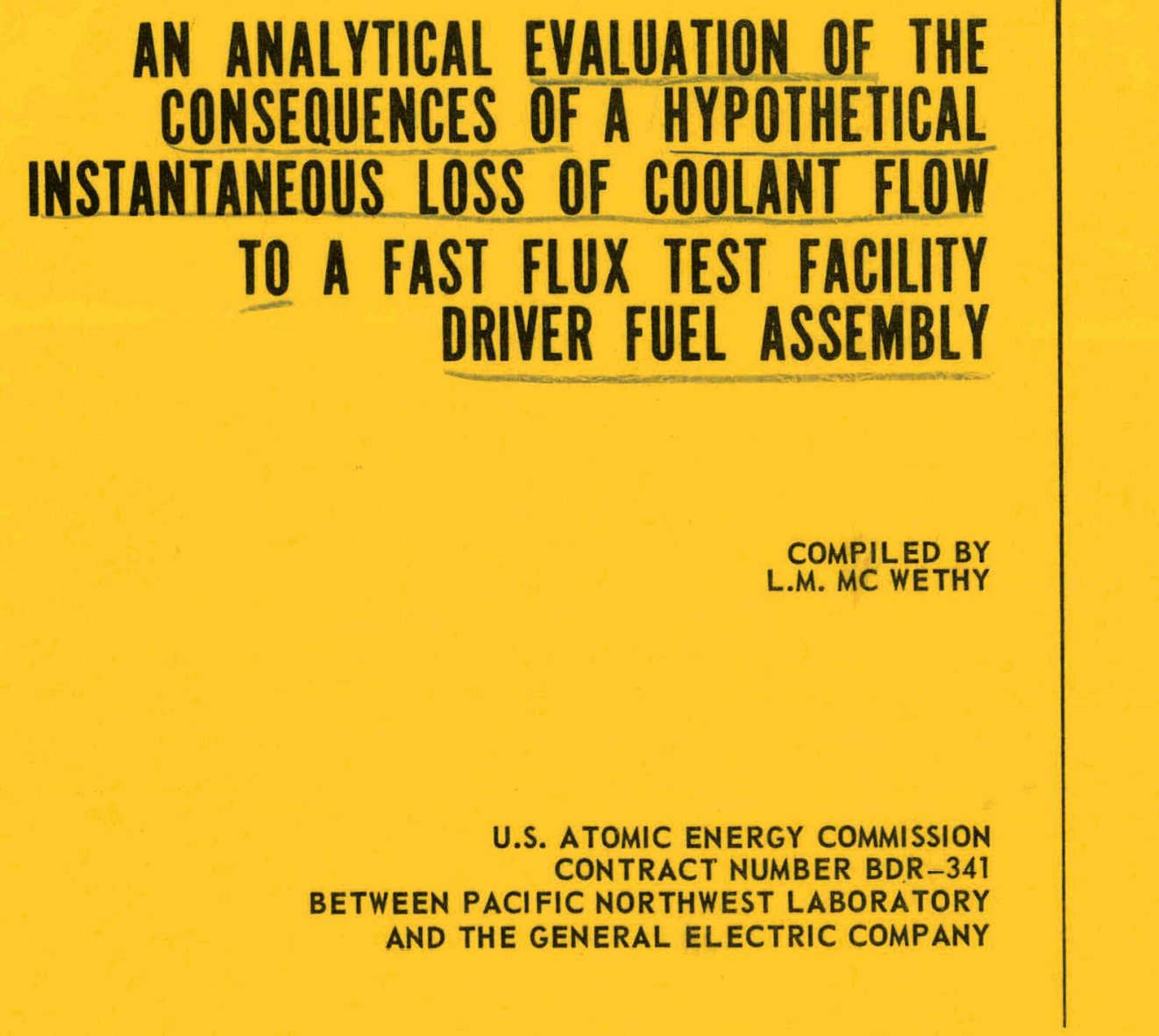

BREEDER REACTOR DEVELOPMENT OPERATION

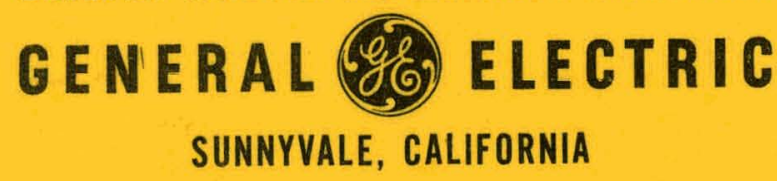




\section{DISCLAIMER}

This report was prepared as an account of work sponsored by an agency of the United States Government. Neither the United States Government nor any agency Thereof, nor any of their employees, makes any warranty, express or implied, or assumes any legal liability or responsibility for the accuracy, completeness, or usefulness of any information, apparatus, product, or process disclosed, or represents that its use would not infringe privately owned rights. Reference herein to any specific commercial product, process, or service by trade name, trademark, manufacturer, or otherwise does not necessarily constitute or imply its endorsement, recommendation, or favoring by the United States Government or any agency thereof. The views and opinions of authors expressed herein do not necessarily state or reflect those of the United States Government or any agency thereof. 


\section{DISCLAIMER}

Portions of this document may be illegible in electronic image products. Images are produced from the best available original document. 


\title{
AN ANALYTICAL EVALUATION OF THE CONSEQUENCES OF A HYPOTHETICAL INSTANT ANEOUS LOSS OF COOLANT FLOW TO A FAST FLUX TEST FACILITY DRIVER FUEL ASSEMBLY
}

\author{
Compiled by L. M. McWethy
}

Approved:

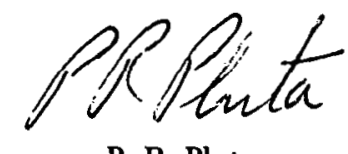

P. R. Pluta

Project Engineer
Approved:

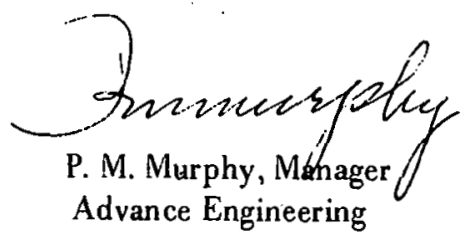

Prepared for the

U. S. Atomic Energy Commission

Under Contract Number BDR-341

Between Pacific Northwest Laboratory and the General Electric Company

Printed in U.S.A. Available from the

Clearing House for Federal Scientific und Technical Information

National Bureau of Standards, U. S. Department of Commerce

Springfield, Virginia

Price: $\$ 3.00$ per copy 


\section{LEGAL NOTICE}

This report was prepared as an account of Government sponsored work. Neitber the United States, nor the Commission, nor any person acting on behalf of the Commission:

A. Makes any warranty or representation, expressed or implied, with respect to tbe accuracy, completeness, or usefulness of the information contained in this report, or that the use of any information, apparatus, method, or process disclosed in this report may not infringe privately owned rights; or

B. Assumes any liabilities witb respect to the use of, or for damages resulting from the use of any information, apparatus, method, or process disclosed in this report.

As used in the above, "person acting on bebalf of the Commission" includes any employee or contractor of the Commission, or employee of such contractor, to the extent that sucb employee or contractor of the Commission, or employee of sucb contractor prepares, disseminates, or provides access to, any information pursuant to bis employment or contract witb the Commission, or bis employment with such contractor.

LN-1 
GEAP-10059

\section{TABLE OF CONTENTS}

1. Introduction . . . . . . . . . . . . . . . . . . 1

2. Summary . . . . . . . . . . . . . . . . . . 4

2.1 Summary of Accident Consequences . . . . . . . . . . . 4

2.2 Results . . . . . . . . . . . . . . . . . . . . . . 6

2.3 Conclusions . . . . . . . . . . . . . . . . 8

3. Fuel Failure Effects . . . . . . . . . . . . . . . 8

3.1 Thermal Transient . . . . . . . . . . . . . . . . . 8

3.2 Clad Kupture Time . . . . . . . . . . . . . . . . 18

4. Coolant Thermal-Hydraulics . . . . . . . . . . . . . 30

4.1 Introduction . . . . . . . . . . . . . . . . . 30

4.2 Initial Voiding and Dryout . . . . . . . . . . . . . . . . . 30

4.3 Heat Transfer in the Core and Plenum, Liquid Sodium . . . . . . 32

4.4 Two-Phase Flow Considerations . . . . . . . . . . . . . . . 35

4.5 Vapor Flow and Heat Transfer Conditions . . . . . . . . . . . 40

4.6 Effect of Fission Gas Release . . . . . . . . . . . . . . . . 40

4.7 Sodium Reentry . . . . . . . . . . . . . . . . . 43

5. Molten Fuel - Sodium Interaction . . . . . . . . . . . . . . . . 46

5.1 Summary of Molten Fuel-Sodium Interaction Approach . . . . . . 46

5.2 Conclusions . . . . . . . . . . . . . . . . . . . 47

5.3 The Heat Transfer Process . . . . . . . . . . . . . . 47

5.4 Work Potential . . . . . . . . . . . . . . . . 51

5.5 Acoustic Energy . . . . . . . . . . . . . . . . 51

5.6 Inertial Energy . . . . . . . . . . . . . . . . . . 54

5.7 Results . . . . . . . . . . . . . . . . . 55

6. Structural Loading Analysis of Fuel Duct . . . . . . . . . . 61

6.1 Shock Loading of Duct . . . . . . . . . . . . . . . 61

6.2 Deflections of An Unirradiated Duct . . . . . . . . . . . 75

6.3 Deflections of An Irradiated Duct . . . . . . . . . . . . . . 80

6.4 The Effect of the Parameters on the Duct Response . . . . . . . 90

6.5 Results Applied to the Loss of Flow Accident . . . . . . . . . . 94 
TABLE OF CONTENTS (Continued)

7. Failure Propagation . . . . . . . . . . . . . . . . 98

7.1 Introduction . . . . . . . . . . . . . . . . . 98

7.2 Analysis . . . . . . . . . . . . . . . . . . 102

8. Recommendations . . . . . . . . . . . . . . . . 123

8.1 Design Implications . . . . . . . . . . . . . . . . . . . . 193

8.2 Implications to System Instrumentation Requirements . . . . . . 123

8.3 Discussion of Development Requirements . . . . . . . . . . . 124

8.4 Experimental Programs . . . . . . . . . . . . . . . . . . 125

\section{APPENDIX}

A. Material Properties . . . . . . . . . . . . . . . . . . . . 129

B. Incipient Superheat Estimate for FFTF . . . . . . . . . . . . . . . 153

C. Plenum Temperatures . . . . . . . . . . . . . . . . . . . . . . 157

C.1 Plenum and Reflector Transienls . . . . . . . . . . . . , 157

C.2 Core and Plenum Transients : . . . . . . . . . . . . . . : 167

C.3 Core Reentry Transients . . . . . . . . . . . . . . . . . 158

D. Slug Voiding and Reentry . . . . . . . . . . . . . . . 174

E. Duct Deflections . . . . . . . . . . . . . . . . . . . 107

Acknowledgments . . . . . . . . . . . . . . . . 198

Distribution . . . . . . . . . . . . . . . . . 198 


\section{LIST OF ILLUSTRATIONS}

1-1 FFTF Geometry and Design Conditions . . . . . . . . . . . . . 3

2-1 Energy Absorption in Duct Wall Versus Time After Flow Blockage . . . . . . . . 7

3-1 Computer Model for Fuel, Clad, and Coolant Temperatures _ . . . . . . . . . . 10

3-2 Steady State Temperatures for the Reference Case . . . . . . . . . . . . . . . 11

3-3 Temperature of the Bulk Coolant Node Initiating Boiling as a Function of Time and Superheat . . . . . . . . . . . . . . . . . . . . . . 12 Average Gap for the Reference Case as a Function of Time and Gap Coefficient . . . . 13 Comparison of Mid-Plane Temperatures as a Function of Time and Gap Conductance . 14

Clad Melt Times for the Reference Case . . . . . . . . . . . . . . . . . . 16" Computer Model for Spacer Wire Temperatures . . . . . . . . . . . . . . . . 20 Spacer, Coolant, and Clad Temperatures . . . . . . . . . . . . . . . . . . Computer Model for Channel Wall Temperatures . . . . . . . . . . . . . . . 22 Channel Wall Temperatures .. . . . . . . . . . . . . . . . . . . . . 23

3-14 Circumferential Variation of Clad Temperatures around a Fuel Pin Adjacent to the Channel Wall .. . . . . . . . . . . . . . . . . . 24

3-15 Temperature Profile Through the Channel Wall after a Flow Blockage . . . . . . . . 25

3-16 Pressure Increase Due to Fission Gas Release for Three Release Modes ～. . . . . . . 27

3-17 Fuel Melt Fraction for the Reference Case . . . . . . . . . . . . . 28

3-18 Ultimate Strength and Hoop Stress as a Function of Time for $0^{\circ}$ Superheat Reference Case for Burnups of 50 and $100,000 \mathrm{MWd} / \mathrm{te}$. . . . . . . . . . . . . . 29

4-1 FFTF-Channel Voiding Versus Time . . . . . . . . . . . . . . . . . . 31

4-2 Laminar Sub-Layer Thickness . . . . . . . . . . . . . . . . . . . . . . 33

4-3 Ratio of Sodium Liquid to Vapor Density at Saturation and Liquid Film Thickness to Fill a Voided Channel . . . . . . . . . . . . . . . . . . . . . 34

4-4. Heat Transferred; Sudden Change in Environmental Temperature . . . . . . . . . 37

4-5 Vapor Bubble Pressures and Clad, Sodium Temperatures Following Voiding . . . . . 37

4-6 Critical Flow Rate in Two-Phase Sodium . . . . . . . . . . . . . . . . 38

4-7 Voiding Times of Core Below Center under Choked Flow . . . . . . . . . . . . 41

4-8 Sodium Change of Phase Limits . . . . . . . . . . . . . . . . . . . . 41

$4-9$ Vapor Pressure Drop at Saturation . . . . . . . . . . . . . . . . . . 42

4-10 Sodium Volding and Reentry at $400^{\circ}$ F Supcrheat . . . . . . . . . . . . 44

4-11 Slug Voiding and Reentry at $240^{\circ} \mathrm{F}$ Superheat . . . . . . . . . . . . . . 45

5-1 Assumed Pressure Wave Generation Characteristics . . . . . . . . . . . . . . 48

5-2 Various Parameters Versus Superheat ... . . . . . . . . . . . . . . 56

5-3 Various Parameters Versus Initial Coolant Temperature . . . . . . . . . . . . . 57

5-4 Various Parameters Versus Initial Fuel Temperature . . . . . . . . . . . . . . 58

5-5 Various Parameters Versus Initial Clad Temperature . . . . . . . . . . . . . . 59

5.6 Variation in Calculated Energy Conversion Versus Variation in Key Parameters . . . . 60 


\section{LIST OF ILLUSTRATIONS (Continued)}

6-1 Reflection and Refraction at the Interface between Two Media . . . . . . . . . . 62

6-2 Energy Reflection and Transmission at Duct Wall . . . . . . . . . . . . . . . 65

6-3 Impulse to Wall and Impact to Liquid . . . . . . . . . . . . . . . . . . . . 66

6-4 Impact on Liquid . . . . . . . . . . . . . . . . . . . . . . . . . . . . 68

6.5 Impulse Versus Energy of Shock Pulse . . . . . . . . . . . . . . . . . . . . 70

6-6 Impulse Versus Energy as a Function of Pressure-Time History _. . . . . . . . . 71

6.7 Equivalence of Peripheral Area of Fuel Cluster to Area of Duct Wall for Shock Wave

Transmission . . . . . . . . . . . . . . . . . . . . . . . 72

6-8 "GASP" Model of Duct . . . . . . . . . . . . . . . . . . . . . . . . 76

6-9 Energy Versus Deflection and Strain in FFTF Cnre Duct, Paramcter Stl 1 . . . . . . 77

6-10 Assumed Stress-Strain Relation . . . . . . . . . . . . . . . . . . . . . . 78

6-11 Energy Vorsus Deflectiun and Strain un H'H'l'H Core Duct, Parameter Set 2 . . . . . . 79

6-12 Cross Section of FFTF Fuel Duct . . . . . . . . . . . . . . . . . . . . . 80

6-13 Pressure-Induced Bending Stress in Duct Wall . . . . . . . . . . . . . . . . . 01

6.14 Bcnding Stress Correction for (Gurvature Effect . . . . . . . . . . . . . . . . 82

6.15 Locations for Fuel Duct Support . . . . . . . . . . . . . . . . . . . . . . 83

6-16 Load Model Assumed for Suggested Duct Analysis . . . . . . . . . . . . . . . 84,

6-17 Energy Absorbed in Duct Versus External Pressure (Duct is simply supported) . . . . 86

6-18 Duct Wall Deflection Versus Differential Pressure for Different Yield Strength . . . . . 87

6-19 Energy Absorbed Per Inch Duct Length Versus Yield Strength with Differential

Pressure as a Parameter . . . . . . . . . . . . . . . . . . . . . . . . . . 88

6-20 Deflection and Energy Absorbed Versus Yield Strength and Static Pressure for

Duct Wall . . . . . . . . . . . . . . . . . . . . . . . . . . . . . . . 89

6-21 Maximum Strain in Duct Wall (Inside at Mid-Corner) Versus Deflection at Middle of

Flat Side . . . . . . . . . . . . . . . . . . . . . . . . . . . . . . 91

6-22 Maximum Strain in Duct Wall (Inside at Mid-Corner) Versus Deflection at Middle of

Flat Side, Extended Deflection Range . . . . . . . . . . . . . . . . . . . . 92

6-23 Some Duct Responses for Two Different Values of Wall Thirkness, Plastic Hinge in Corner and at Middle of Flat Side c . . . . . . . . . . . . . . . . . . . . 93

6-24 Ductility of Duct Wall Versus Time after Flow Dluckage . . . . . . . . . . . . . 95

6-25 Ultimate Strength of Duct Wall Versus Time after Flow Blockage . . . . . . . . . 96

6-26 Rupture Energy of Duct Versus Time after Flow Blockage . . . . . . . . . . . . 97

7-1 Fallure Propagation Modes . . . . . . . . . . . . . . . . . . . . . . . . . 99

7-2 Failure Propagation Modes . . . . . . . . . . . . . . . . . . . . . . . 100

$7-3$ Failure Propagation Modes . . . . . . . . . . . . . . . . . . . . . . 101

7.4 Relation of Pins to Channel Wall . . . . . . . . . . . . . . . . . . . . 103

$7-5$ The Mode of Fuel Pin Loading . . . . . . . . . . . . . . . . . . . . . . . 104

$7-6$ Cladding Deformation Model . . . . . . . . . . . . . . . . . . . 105

7-7 Conditions at tho Inad . . . . . . . . . . . . . . . . . . . . . . 108

$7-8$ Maximum Coolant Temperature for Step Flow Loss . . . . . . . . . . . . . . 109

$7-9$ Duct Melt-Through Model _. . . . . . . . . . . . . . . . . . . . . . 110

7-10 Temperature Response for Melt-Through of Duct Wall . . . . . . . . . . . . . 111

7-11 Vapor Blanketing Thermal Model . . . . . . . . . . . . . . . . . . . . . 112

7-12 Fuel Pin Tcmperature Response for Vapor Blanketing . . . . . . . . . . . . . . 113

7-13 Local Blockage - Top View Showing Nodal Structure and Dimensions . . . . . . . . 116

7-14 Local Blockage - Side View Showing Coolant Conduction Modes . . . . . . . . . 117

7-15 Temperature Rise of Stagnant Sodium Single Channel Blockage . . . . . . . . . . 118

7-16 Temperature Rise of Stagnant Sodium Multi-Channel Blockage . . . . . . . . . . 119

7.17 Channel Types . . . . . . . . . . . . . . . . . . . . . . . . . . . . 120

7-18 Coolant Temperature Rise Across Core for Crushed Bundle . . . . . . . . . . . . 121 


\section{LIST OF ILLUSTRATIONS (Continued)}

A-la Liquid Sodium-Density versus Temperature . . . . . . . . . . . . . . . . . 130

A-lb Liquid Sodium-Specific Heat versus Temperature . . . . . . . . . . . . . . . 130

A-lc Liquid Sodium-Thermal Conductivity versus Temperature . . . . . . . . . . . . 130

A-2a Liquid Sodium-Thermal Diffusivity versus Temperature . . . . . . . . . . . 131

A-2b Liquid Sodium-Viscosity versus Temperature . . . . . . . . . . . . . . . . 131

A-3a Liquid Sodium-Volume Expansion versus Temperature . . . . . . . . . . . . . 132

A-3b Liquid Sodium-Surface Tension versus Temperature . . . . . . . . . . . . . . 132

A-4a Sodium Vapor-Specific Heat versus Temperature . . . . . . . . . . . . . . . 133

A 4b Sodium Vapor-Heat of Vaporization versus Temperature . . . . . . . . . . . . 133

A-5 Sodium Vapor-Vapor Pressure (psia) versus Temperature . . . . . . . . . . . . 134

A-6 Sodium Vapor-Vapor Pressure (atms) versus Temperature . . . . . . . . . . . . 135

A-7 Saturated Sodium Vapor-Specific Volume at Saturation versus Temperature . . . . . 136

A-8a Saturated Sodium Vapor-Viscosity versus Temperature . . . . . . . . . . . . . 137

A-8b Saturated Sodium Vapor-Specific Heat versus Temperature _. . . . . . . . . 137

A-8c Saturated Sodium Vapor-Thermal Conductivity versus Temperature . . . . . . . . 137

A-9 Super Heated Sodium Vapor-Density versus Temperature . . . . . . . . . . . . 138

A-10a Type 316 Stainless Steel-Density versus Temperature . . . . . . . . . . . . . . . 139

A-10b Type 316 Stainless Steel-Specific Heat versus Temperature ～. . . . . . . . . . . 139

A-10c Type 316 Stainless Steel-Thermal Conductivity versus Temperature . . . . . . . . 139

A-1 la Type 316 Stainless Steel-Thermal Diffusivity versus Temperature . . . . . . . . . 140

A-1lb Type 316 Stainless Steel-Poisson's Ratio versus Temperature . . . . . . . . . . . . 140

A-11c Type 316 Stainless Steel-Modulus of Elasticity versus Temperature ～. . . . . . . . 140

A-12a Type 316 Stainless Steel-Volume Expansion versus Temperature . . . . . . . . . 141

A-12b Type 316 Stainless Steel-Coefficient of Expansion versus Temperature . . . . . . . 141

A-13 Type 316 Stainless Steel-Some Mechanical Properties versus Temperature . . . . . . 142

A-14 Type 304 and 316 Stainless Steel-Yield Strength versus Temperature . . . . . . . 143

A-15 Type 316 Stainless Steel-Yield Strength versus Fluence . . . . . . . . . . . . . 144

A-16 Type 316 Stainless Steel-Ultimate Stress versus Temperature . . . . . . . . . . . 145

A-17 Type 316 Stainless Steel-Ultimate Stress versus Fluence . . . . . . . . . . . . . . 146

A-18 Type 316 Stainless Steel-Percent Elongation versus Fluence ． . . . . . . . . . . 148

A-19 Mixed-Oxide Fuel-Thermal Conductivity versus Temperature . . . . . . . . . . 148

A-20 Mixed-Oxide Fuel-Specific Heat versus Temperature . . . . . . . . . . . . . . 149

A-21 Mixed-Oxide Fuel-Linear Thermal Expansion versus Temperature . . . . . . . . . 15U

A-22 Mixed-Oxide Fuel-Volumetric Thermal Expansion versus Temperature . . . . . . . 151

B-1 Incipient Boiling Temperature versus Position in Core . . . . . . . . . . . . . . 155

C-1 Plenum Temperature Model . . . . . . . . . . . . . . . . . . . . . . . . 158

C-2 Voiding Velocity and Displacement $400^{\circ} \mathrm{F}$ Superheat Case PT-2 . . . . . . . . . . 159

C-3 Sodium Temperature in Plenum Region Following Voiding $400^{\circ} \mathrm{F}$ Superheat Case PT-2 . 160

C-4 Clad Temperatures in Plenum Region Following Voiding $400^{\circ} \mathrm{F}$ Superheat Case PT-2 . . 161

C-5 Voiding Velocity and Displacement $100^{\circ} \mathrm{F}$ Superheat Case PT-3 . . . . . . . . . . 162

C-6 Sodium Temperatures in Plenum Following Voiding $100^{\circ} \mathrm{F}$ Superheat Case PT-3 . . . 163

C-7 Clad Temperatures in Plenum Region Following Voiding $100^{\circ}$ F Superheat Case PT-3 . . 164

C-8 Core Temperature Model . . . . . . . . . . . . . . . . . . . 165

C-9 Power Distribution - Core and Plenum Transient . . . . . . . . . . . . . . . . 166

C-10 Sodium Temperatures Case CT-1 $700^{\circ} \mathrm{F}$ Superheat . . . . . . . . . . . . . . . 167

C-11 Clad Average T'emperature Case CT-1 700 $\mathrm{F}$ Superheat . . . . . . . . . . . . . 168

C-12 Voiding Velocity and Displacement $400^{\circ} \mathrm{F}$ Superheat Case CT-2 . . . . . . . . . . . . 169

C-13 Sodium Temperatures Case CT-2 400 $\mathrm{F}$ Superheat . . . . . . . . . . . . . . . 170 


\section{LIST OF ILLUSTRATIONS (Continued)}

Title

C-14 Clad Temperatures Following Voiding $400^{\circ}$ F Superheat Case CT-2 . . . . . . . . . 171

C-15 Reentry Temperature Model . . . . . . . . . . . . . . . . 172

C-16 Reentry Coolant Temperatures . . . . . . . . . . . . . . 173

D-1 Slug Flow Model . . . . . . . . . . . . . . . . . . . . . . . . . . . 174

D-2 Pressure Table for Cases 1 and 2 . . . . . . . . . . . . . . . . . . . . 176

D-3 Coolant Voiding and Reentry $400^{\circ} \mathrm{F}$ Initial Superheat . . . . . . . . . . . . . 177

D-4 Pressure for Cases 3, 4, and 9 . . . . . . . . . . . . . . . . . . . . . . 178

D-5 Coolant Voiding and Reentry $400^{\circ} \mathrm{F}$ Superheat . . . . . . . . . . . . 179

D-6 Reentry from Jet (Case 4), Orifice Coefficient $=1.0 \quad \ldots \ldots$. . . . . . . . . . . 180

D-7 Pressure Table for Case 5 Lower Slug Voiding . . . . . . . . . . . . . . . . . 181

D-8 Case 5: Lower Slug Ejection Reentry Past Core Centerlinc . . . . . . . . . . . . 182

D-9 Cases 6 and 7: Lower Slug Voiding and Reentry . . . . . . . . . . . . . . . . 183

D-10 Voiding at Constant Pressure $\left(10^{7} \mathrm{psi}\right) 400^{\circ} \mathrm{F}$ Initial Superheat . . . . . . . . . . 184

D-1.1 . Pressure Table for Case 10 . . . . . . . . . . . . . . . . . . . 185

D-12 Case 10: Continuation of Case 4, with Core Pressure Increasing 50 psi on Each

Successive Reentry . . . . . . . . . . . . . . . . . . . 186

E-1 Flat Plate Stress Distributions . . . . . . . . . . . . . . . . . . . . . 189

E-2 Flat Plate . . . . . . . . . . . . . . . . . . . . . 191

\section{LIST OF TABLES}

Table

Title

3-1 Summary of Event Times . . . . . . . . . . . . . . . . . 18

3-2 Clad Failure Times fnr the Reference Caso : . . . . . . . . . . . . . . . -26.

5-1 Comparison of Different Calculatinnal Methods for a Roprosontativc Irterautiun . . . . $\quad 4 y$ -

8-1. Recommended Experimental Program . . . . . . . . . . . . . . . . -127- 


\section{INTRODUCTION}

A redirected scope of work under contract BDR-341 was agreed upon between Battelle Northwest Laboratories and the General Electric Company in February 1969 to support the new open lattice, vertical reference core concept described in BNWL-955 FFTF Reference Concept Summary Description (January 1969). The new scope of work consisted of four diverse engineering tasks to be completed in the period of February through June 1969. These other tasks are reported in the following documents.

- GEAP-10056

Conceptual Design Study of Dynamic Sealing Techniques Applicable to the Fast Flux Test Facility Control Rod Drive Mechanism; R. W. Lockhart and P. M. Tschamper (July 1969).

- GEAP-10058

Conceptual Design Study of Axial Fuel Cooling Hardware for the Fast Flux Test Facility Fuel Examination Facility; J. H. Germer (July 1969).

- GEAP-10057

Design Considerations for the Operation of the Fast Flux Test Facility With Fuel Fission Gas Emission; W. R. Gee (July 1969).

The objective of this work was to evaluate the consequences of a hypothetical, instantaneous loss-of-flow accident to a fast flux test facility driver fuel assembly. The circumstances under which the accident could propagate to the adjacent fuel assemblies was of principal concern. An attempt was made to estimate the earliest times at which propagation mechanisms could become credible and relate these times to the instrumentation response requirements. The influence of design parameters, such as fuel duct wall thickness, on the probability of propagation was investigated.

This analysis concerns only the hypothetical situation where there is total and instantaneous loss of flow to the fuel assembly. This is taken as representing an unrealistic extreme case of the family of partial and local flow blockage accidents.

While instructive in providing a bound on the accident consequences, a realistic appraisal of assumed noninstantaneous and less than complete flow blockage situations should be considered in subsequent work in support of FFTF design. For these more credible situations, where accident consequences might influence core and system design, operating conditions, instrumentation and engineered safeguards requirements, the consequences of the accident will be much less severe than the results given in this report.

This analysis has attempted to predict the consequences of the instantaneous loss of flow using rational, but conservative assumptions. The fast breeder industry state-of-the-art for accident analysis was the basis for beginning this study. The lack of a model to describe the molten fuel-sodium interaction required development of the models described in this report to permit a reasonable analysis of this hypothetical accident to proceed. Beyond the point in the accident when significant fuel slumping occurs, the numerical analysis could not profitably be continued due to the lack of a fuel slumping and a molten fuel fragmentation model.

Following a description of the accident in this section and a summary discussion of the accident consequences and conclusions in Section 2, there is a general discussion of this hypothetical accident arranged in the following groupings;

SECTION 3 FUEL FAILURE EFFECTS treats the core thermal transient and initial fuel pin rupture.

SECTION 4 COOLANT THERMAL-HYDRAULICS treats the coolant displacement and temperatures in voiding and reentry.

SECTION 5 MOLTEN FUEL-SODIUM INTERACTION proposes a model to describe the interaction of liquid sodium and hot core materials (steel and mixed oxide).

SECTION 6 DUCT RESPONSE evaluates the partition of energy and treats the effect on the duct of the pressures and impulses expected from this accident.

SECTION 7 FAILURE PROPAGATION treats the effects of mechanical and thermal transients imposed on the adjacent fuel assemblies by the blocked assembly.

SECTION 8 DESIGN AND DE VELOPMENT RECOMMENDA'IIUNS treats the implications to design and development derived from this study. 


\section{ACCIDENT DESCRIPTION AND ASSUMPTIONS}

The accident condition analyzed was the hypothetical, instantaneous total loss of flow of coolant to an FFTF driver fuel assembly. Loss of flow is assumed caused by an object in the main coolant stream becoming lodged over or in the fuel assembly inlet structure. No scram action is assumed to terminate the consequences of this accident. Reactivity and the resultant power changes due to voiding or fuel movement in the blocked assembly have been neglected. Coolant pressure in the reactor core inlet and outlet plenums is assumed unchanged by the flow blockage to a single fuel assembly.
The fuel assembly geometry used in the analysis was that given in BNWL-955 "FFTF Reference Concept Summary Description" January 1969. A fuel assembly at the core center was assumed operating at a peak fuel linear power of $14 \mathrm{~kW} / \mathrm{ft}$ and sodium outlet temperature of $1100^{\circ} \mathrm{F}$. Figure 1-1 summarizes the data pertinent to this study.

A key assumption is that the pressure at the sodium-cover gas interface is atmospheric. This results in a coolant saturation temperature of about $1700^{\circ} \mathrm{F}$. 


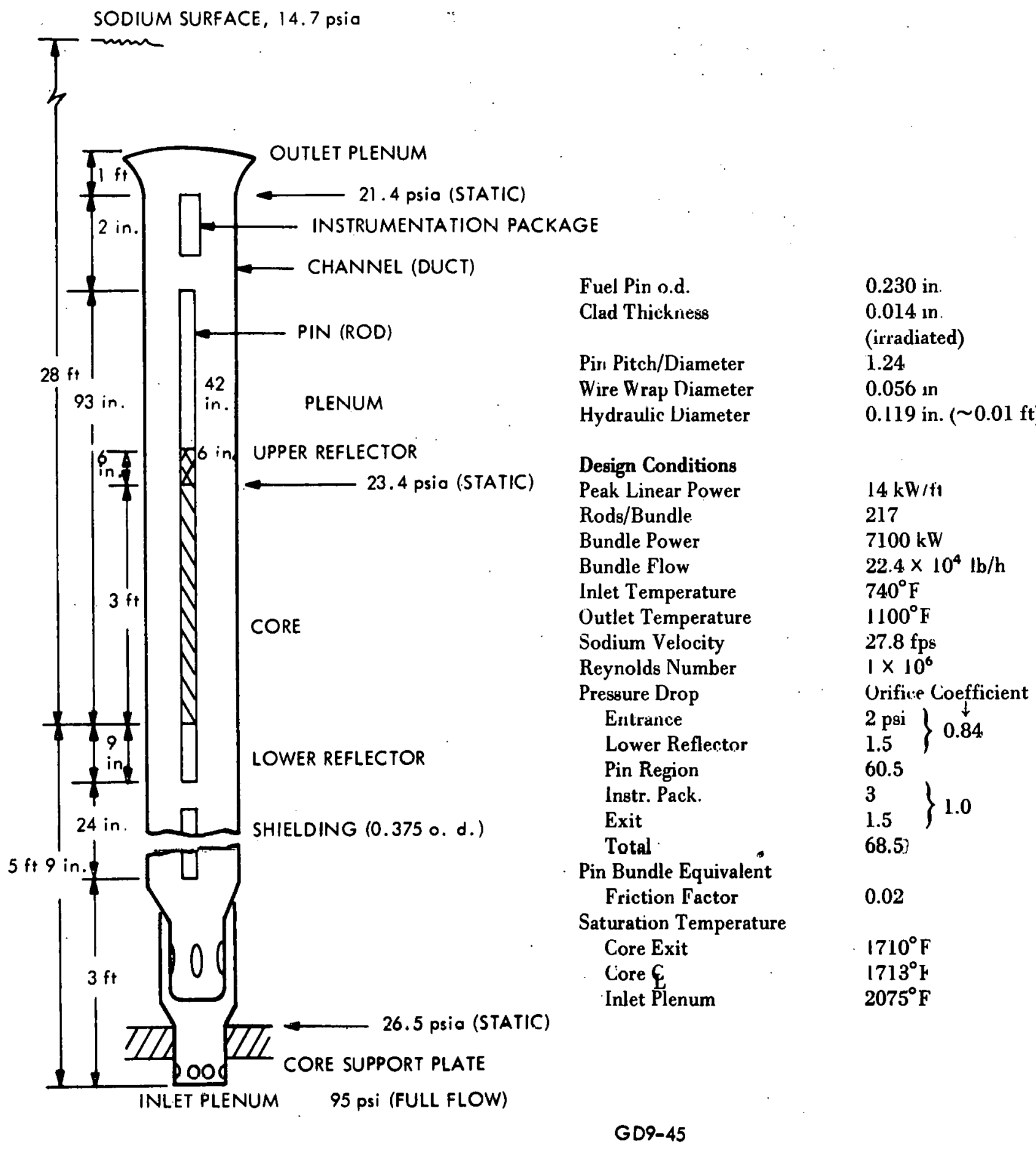

Figure 1-1. FFTF Geometry und Désigni Conditions 


\section{SUMMARY}

\subsection{SUMMARY OF ACCIDENT CONSEQUENCES}

The complete loss of flow through an FFTF fuel subassembly results in a thermal transient of the fuel, clad, and sodium in that subassembly. The resulting chain of events as determined by the conservative analyses given in this report will be summarized qualitatively in this section to give the reader some perspective on the significant features of this hyputhetical accident. The principal features of the transient in the blocked fuel subassembly are (times are given as the delay following the flow blockage):

- Blucked subassembly fuel temperatures increasing at $1000^{\circ} \mathrm{F} / \mathrm{sec}$.

- Coolant boiling near the midpoint of the blocked subassembly fuel region at about 0.75 second.

- Rapid expulsion of the liquid sodium in the top half of the fuel region by sodium vaporization at the center of the fuel region.

- Evaporation of the liquid sodium in the lower half of the fuel region. limited by the thermal transientcomplete dryout at about 2.5 scconds.

- Clad melting beginning at about 1.3 seconds.

- Fuel melting beginning at about 3 seconds.

- Liquid sodium reentry possible near the channel wall after fuel region dryout at about 2.5 seconds.

- Rapid heating of the sodium on contact with the hot fuel pins may result in generation of an acoustic pressure wave capable of rupturing a low ductility, overheated duct.

- Several reentry cycles of sodium contacting the hot fuel region material may produce sufficient pressure pulses to damage and possibly miptore the adjacent fuel assemblies.

- Clad and fuel melting and slumping will contact sodium below the fuel region in the 4 to 6 seconds range.

- Expulsion of the molten clad and fuel may occur on contact with sodium.

- Melt through to the adjacent duct begins in the 10 to 15 seconds range.
A more detailed description of these processes follows

First Phase of the Accident

After the initiating event, a hypothetical total blockage of the inlet of the fuel assembly. the sodium, steel, and fuel in that assembly experience a severe thermal transient. With negligible removal of heat, the power generated in the fuel is absorbed in sensible heat temperature increase and in latent heat. 'I'he axial power profile results in a transient twice as fast at the mid-point of the fuel region as at its ends. Between 0.5 and 1.0 second following blockage, depending on fuel burnup and sodium superheat, the coolant near the direct center will boil. The expected superheat is not sufficient to pressurize the duct to greater than the inlet plenum pressure. The prcssurization due to sudium boiling is relieved by expansion upwards into the reflector and plenum region, working against the over-pressure of about 23 psia.

The accepted models of sodium boiling and expulsion indicate a single bubble will form and eject the liquid between the duct center and exil. This "slug" flow regime lasts for a period from 0.1 to 0.2 second while the heated liquid which was in the top half of the core region of the duct is expelled and cooled rapidly in the reflector and plenum region. The presence of the reflector and plenum steel at an original temperature of $1100^{\circ} \mathrm{F}$ acts as a condenser or heat sink for the ejected sodium liquid and vapor.

When the upper slug is voided, a small amount of liquid just below center (which is still superheated with respect to the ambient over-pressure of 23 psia) flashes to a two phasp mixture and is expelled to the plenum region. This process continues briefly to eliminatc the superheated liquid. The bottom few incheș of liquid in the fuel region, being subcooled, continues a temperature increase limited by the local pnwer generation rate. The liquid-vapor interface then moves downward in the fuel region, the liquid being boiled off and condensed in the upper plenum region. The lower power level and lower initial temperatures at the fuel inlet region result in the boiling temperature being reached at about 2.5 secunds after flow blockage.

Sodium in either liquid, two-phase or vapor form is expelled from the heated region during the time interval of 0.75 to 2.5 seconds following blockage. 
The upper liquid level is forced continually upward to expose "cold" steel and absorb the energy of the expelled sodium. The upper liquid interface is at a pressure of $\sim 23$ psia to balance the static head of liquid above the core. This energy transport into the plenum region effectively buffers the liquid from the nuclear heated region, establishing a region of steel above $1700^{\circ} \mathrm{F}$. This effectively prevents the upper liquid slug from penetrating to the hot core, since penetration results in rapid sodium vaporization and pressurization of the core. The interface probably "chugs" in some fashion, between the heated and cooled regions.

The concern of this study is with possible flow regimes which permit sudden contact of liquid sodium and the overheated fuel assembly materials. The initial voiding and fuel region dryout (up to 2.5 seconds after blockage) does not involve such a condition. Once the fuel region has been boiled dry, the concern is for a re-rntry of liquid into this region. The results of this study support the conclusion thial slug flow re-entry is not credible. However, comparison of these accident conditions with BWR spray cooling tests suggest another flow regime where local re-entry is credible. Previous tests and analysis are limited to geometries with no radial variations, permittıng only one dimensional analysis in the axial direction. The real tube bundle geometry is three dimensional, characterized by the edge flow channels and the cold duct wall. Under these conditions, BWR tests exhibit a flow regime characterized by a downward flow of a liquid film on the duct wall, vaporization by radiation from the hot pins, and upward flow of the vapor. The analogy with this flow blockage accident occurs when the core is dry and the pressure gradient between the core and plenum is relieved. Sodium could flow down the unheated duct wall as liquid, evaporate by radiation or on contact with the heated fuel pins and flow upward as vapor to be recondensed in the plenum.

The possibily exits for a falling film io suddenly make contact with the fuel rods over a significant length. The coolant temperature is characterized by the duct wall temperature with which it is in contact. Because of the slow thermal response of the duct wall, its average temperature increases much more slowly than other components, even in the presence of sodium vapor at $\sim 1700^{\circ} \mathrm{F}$. The sudden contact of cold sodium $\left(<1700^{\circ} \mathrm{F}\right.$.) and hot fuel pins ( $>$ $2000^{\circ} \mathrm{F}$ ) might lead to rapid energy transfer at about 2.5 seconds after blockage.

A conservative model of the thermal and thermodynamic interaction of sodium and hot core materials was developed to study this phenomenon. This model indicates that the thermal energy transferred rapidly to the sodium from hot steel or fuel may be partitioned into three modes:
- sensible heat of the liquid below the saturation temperature

- inertial pressures from expansion of sodium vapor against the liquid head.

- an acoustic wave caused by compression of the sodium when heated faster than a sonic wave can relieve the expansion.

The model assumes the maximum conversion of energy to work on thermodynamic grounds and could be substantially pessimistic. The pressures predicted with this model for both the acoustic and inertial energy waves are sufficiently high to result in damage to structural members. The assumed flow regime, with a "solid" liquid film between the outer row of pins and the duct wall, leads to direct transmission of the pressures of interaction to the duct. The acoustic energy was found to be the dominant energy form from the interaction of sodium and hot core materials. Further analysis showed that the energy of the acoustic wave would be partitioned upon striking the duct wall, with about $20 \%$ being absorbed and $80 \%$ reflected. A negligible amount is transmitted. The duct wall is given an almost instantaneous velocity by the impulse of the acoustic wave. This energy is absorbed as strain energy of deflection in the duct.

The ability of the duct to absorb this energy was studied for both unirradiated and irradiated materials. The stainless steel ductility was found to be the key parameter determining the duct response. An unirradiated duct easily absorbed the incident energy wave without rupture and with negligible deflection. An irradiated duct, particularly when heated, as in this hypothetical transient, suffers local material strains in the corner of the hexagon which exceed the minimum expected ductility of stainless steel at 50,000 $M W d / t e$. Under these conditions of sodium film re-entry after core dryout, the interaction of sodium and clad might generate acoustic pressures sufficient to rupture an overheated, irradiated duct. The same impulse would not be expected to rupture a duct at normal operating conditions. However, a repeating reentry is probable, each of which might result in generation of successively higher energy waves as the hypothetical transient proceeds. This hammering action might accumulate duct wall strain energy to the rupture point for the cold adjacent ducts.

\section{Second Phase of the Accident}

Continuation of the temperature transient beyond clad and fuel melting will result in slumping. Clad will meit and slump to the lower fuel regions freezing on the unmelted 
clad and spacer wires, causing a melting wave to progress duwnward, filling most of the available free volume. The edge fuel pins should remain substantially cooler due to the duct wall and sodium film on the wall. Pressures from 2 to 4 seconds should not be much greater than 23.4 psia ambient. When molten clad reaches the core inlet plane it will contact sodium.

With a removable flow blockage at the duct inlet any molten core material-sodium interaction at the core inlet would probably generate vapor pressures great enough to remove the plug, permitting downward ejection of the trapped liquid sodium and forcing the dispersed core material upward. The weight of the core material is not sufficient to move downward against the sodium pressure gradient of about $60 \mathrm{psi}(1000 \mathrm{lb}$ force over duct cross section).

The interaction of hot pins and a falling sodium film is characterized by relatively high sodium temperatures and the availability of vapor space within the bundle for expansion following interaction. At the core inlet when core slumping occurs a significant amount of highly subcooled liquid would be present and a violent expulsion of the molten steel might follow. The state-of-the-art prevents any definitive quantitative statement about either molten fuel or clad fragmentation or the mechanical energy resulting from the interaction with cold sodium.

\section{Third Phase of the Accident}

Continuation of the thermal transient beyond clad and fuel slumping might result in fuel contact on the duct wall. The time domain when duct melt-through might occur is fully described in Section 7. Assuming the molten fuel and clad are not lost from the core region. by gravity or hydraulic forces, propagation of the fault to the adjacent assemblies might occur by melt-through of the twointervening duct walls in the range from 10 to 15 seconds after bloolkago.

\subsection{RFSIULTS}

The objective of this study was to evaluate the consequences of a hypothetical total instantaneous flow blockage to an FFTF fuel duct. One consequence would be the propagation of the fault to the adjacent fuel assemblies. Propagation in this sense is defined as damage done to the adjacent assemblies leading to loss of coolant flow in an adjacent assembly and a consequent fuel meltdown. The principal damage mechanism leading to propagation is the sudden heating of liquid sodium upon contact with hot or molten core materials. The preceding qualitative description of the accident consequences reflects the conservative analysis performed in order to determine the earliest times when propagation might occur. The end result of this study is a comparison of the possible energy generated due to contact of liquid sodium with hot core materials and the energy loads causing rupture of the hexagonal ducts. The important assumptions leading to this comparison are

- duct temperature calculations following sodium expulsion assumed an insulated duct with temperature relaxing to the sodium saturation temperature.

- clad and fuel were not cooled by expelled sodium.

- a coherent film of sodium was assumed to fall hetween the duct. wall and the adjacent row of fuel pins and suddenly make intimate contact.

- the thermodynamic upper limit on the available work from the sudden heating of the sodium was assumed.

- on contact of the sodium and cladding, film blanketing occurs when the dynamic pressure drops below the interface saturation pressure.

- duct response to the pressure pulse was assumed equal to the response under static pressure conditions.

- no strain concentration factor nor thermal stress influences on duct rupture energies.

These assumptions lead to the result shown in Figure 2-1. The energy loading causing rupture of the duct is shown for times following flow hlockage. The increasing temperatures of the duct cause decreased strength and ductility (as shown in Figure A-18) and result in reductions in the energy absorption that would cause duct rupturc. The heated duct can absorb only about 3 in-lb $b_{f}$ per inch of length at 2.5 seconds after blockage when the first interactiun uf sudlum and córie can credibly occur.

The duct temperiature al this lime is between 1500 and $1600^{\circ} \mathrm{F}$, far above temperaturea whr.re test dala un ductility of irradiated materials is available.

The adjacent duct, being relatively unaffected by the thermal transient of the blocked assembly, is capable of absorbing much more energy per unit length because of its lower temperature. Energy absorption at rupture for the adjacent duct is $55 \mathrm{in}-\mathrm{lb} / \mathrm{in}$ of length assuming that it has been subjected to a fluence of $2 \times 10^{22}$ above $1 \mathrm{MeV}$ and has an assumed ductility of $1 \%$. (The ductility expected under these conditions is 4 to $5 \%$.) 


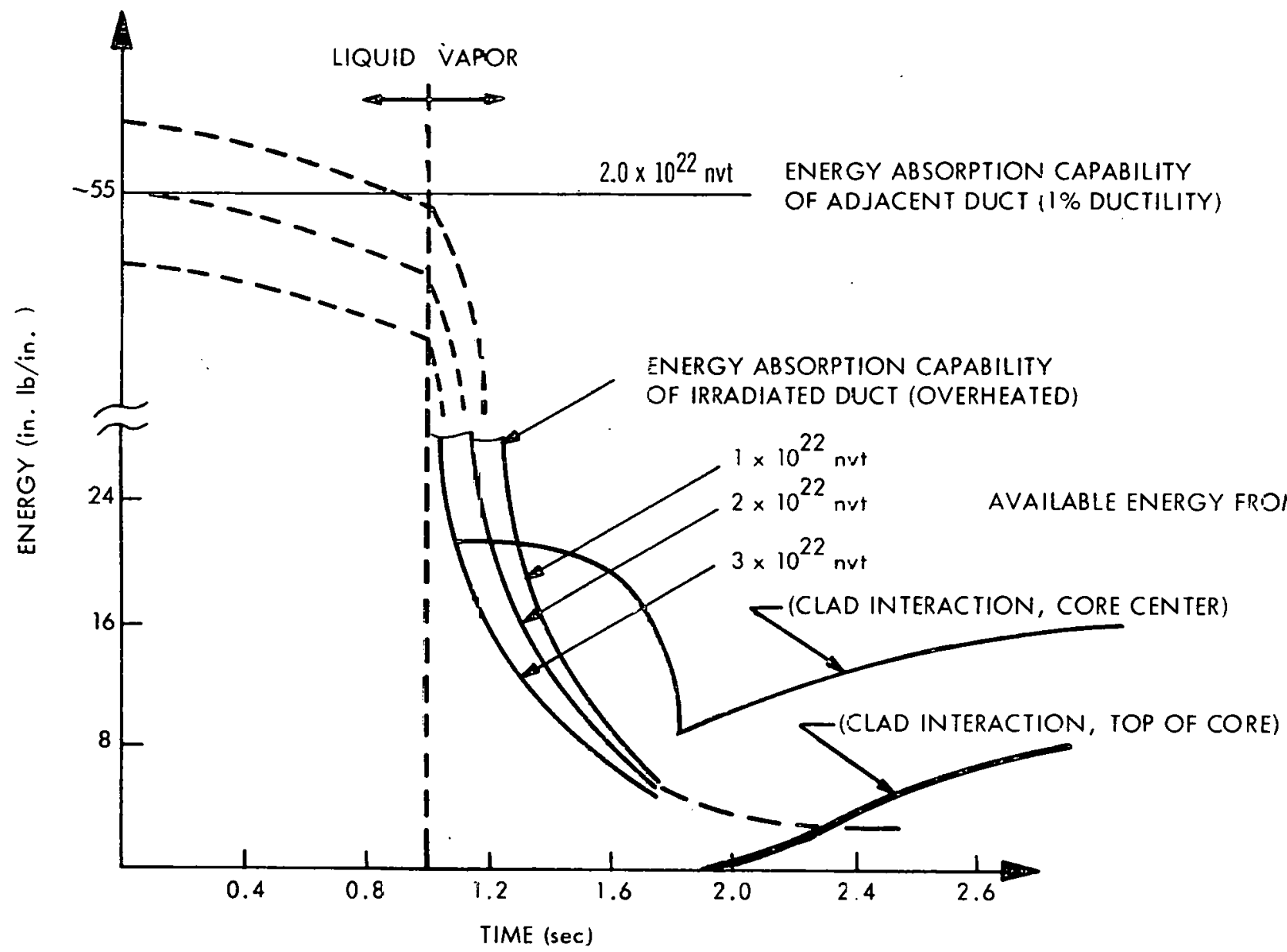


The available energy from interaction of sodium and hot clad is also shown on Figure 2-1 for comparison. The lower curve assumes contact at the top of the core before clad melting has occurred. At 2.5 seconds the available energy is seen to exceed the energy absorption capability of the blocked duct but to be well within than that of the adjacent duct. The top curve (shown for reference) is the energy available if the sodium could contact the molten clad at the mid-point of the fuel region. However, no reasonable mechanism was postulated which would permit sodium to penetrate this deep into the core center before being vaporized by the lower temperature fuel above the centerline.

The available entergies from interaction of sodium with molten fuel or clad under the assumed model show a maximum of about 11 in.-lb $/$ in. $^{2}$ of contact area. Pulses of this magnitude applied to the duet wall result in energy ahsorp. tions of about $33 \mathrm{in} .-1 b_{f} / \mathrm{in}$. of duct length. This is well within the expected capabilities of the cold adjacent ducts. Because of the hypothetical nature of the accident, the conservative nature of this analysis and the uncertainties of materials properties, it is not judged reasonable to speculate on whether these conditions lead to significant mechanical damage to the adjacent ducts.

\subsection{CONCLUSIONS}

This analysis concerns only the hypothetical situation where there is total and instantaneous lnş of flow to the fuel assernbly. This is taken as representing an unrealistic extreme case of the family of partial and local flow blockagc accidents.
While instructive in providing a bound on the accident consequences, a realistic appraisal of assumed noninstantaneous and less than complete flow blockage situations should be considered in subsequent work in suppurt of FFTF design. For these more credible situations, where accident consequences might influence core and system design, operating conditions, instrumentation and engineered safeguards requirements, the consequences of the accident will be much less severe than the results given in this report.

The current state of the art prevents an accurate determination of the consequences of the hypothesized flow blockage accident. The results of this preliminary conscrvative study indicate that the pressure pulses generater by interaction of hot core materials and liquid sodium are of the same order of magnitude as those required to rupture a duct that lias luw ductlityy $(0.5$ to $1 \%$ ) associated with end-of-life burnup. It does not appear that the adjacent ducts will be severely damaged hy the initial pressure pulsc originating from the duct in which the total blockage has .occurred.

The interaction between hot core materials and liquid sodium that could produce these pressure pulses might occur as early as 2 to 3 seconds after total flow blockage occurred. The time required for detection and remedial action (reactor scram) to arrest the progress of this hypo. thetical accldent is about 3 seconds.

Considering the uncertainty of failure mode mechanismis, duct defurmatton añalysiss, material duotility, and the hypothetical nature of the assumed accident, corc dcsign changes (such as increased duct wall thickness) are not rccommended.

\section{FUEL FAILURE EFFECTS}

\subsection{THERMAL TRANSIENT}

This section is concerned with the thermal response of the hottest fuel bundle following a complete tlow blockage. The analysis is divided into three parts.

- the fuel, clad, and coolant associated with the hottest pin,

- the spacer wire associated with the hottest fuel pin,

- the channel wall associated with the hottest bundle.

Most of the analysis was done with the computer code Transient Heat Transfer - Version D, THTD (Ref.1). It was used because of the following capabilities:
- Two dimensinnal conduotion and convcction.

- Variable properties.

- Variable internal heat generation.

- Material phase change with accounting for heat of phase change and different material propertics after phase change.

The major deficiency of THTD for this analysis is a fixed fuel-to-clad gap and thus a constant interface or gap heat transfer coefficient. The computer code FORE-II (Ref. 2) was used to estimate the effect of a continuously variable gap. 
A reference case was established from which the effect of parameter changes could be measured. This reference case has the following design conditions:

Peak linear power $\ldots \ldots \ldots \ldots \ldots \ldots 14 \mathrm{~kW} / \mathrm{ft}$

Pin pitch-to-diameter ratio . . . . . . . . . . . . . 1.24

Bundle power ................. $7100 \mathrm{~kW}$

Coolant inlet temperature $\ldots \ldots \ldots \ldots \ldots \ldots 740^{\circ} \mathrm{F}$

Coolant exit temperature ... $\quad \ldots \ldots \ldots \ldots l 100^{\circ} \mathrm{F}$

Coolant liquid superheat . . . . . . . . . $0^{\circ} \mathrm{F}$

Fuel-to-clad gap heat

transfer coefficient ......... $1500 \mathrm{Btu} / \mathrm{h} \mathrm{ft}^{2}{ }^{\circ} \mathrm{F}$

Clad does not slump.

\subsubsection{FUEL, CLAD AND COOLANT}

The thermal history of the fuel, clad and coolant associated with the hottest pin was determined as a function of liquid superheat, fuel-to-clad gap heat transfer coefficient and clad slumping. In particular, the effect of these parameters on three critical times was noted. These are the initiation times for coolant boiling, clad melting and fuel melting.

The pin was represented by the $36^{\circ}$ segment consisting of 90 nodes as shown in Figure 3-1. Node numbers ending in 0 through 4 are equal volume fuel nodes. The clad is represented by nodes ending in 5 through 7 . The 5 -series nodes are zero volume nodes and indicate the surface temperature on the inside surface of the clad. The clad volume is distributed equally between the 6 and 7 series nodes. The coolant behavior is represented by a 0.0001 inch film with node numbers ending in 8 and by bulk coolant nodes ending in 9. The saturation temperature of the film was set $30^{\circ} \mathrm{F}$ higher than the saturation temperature of the bulk coolant. This allowed the film to "remain" after the bulk coolant vaporized. In addition, the heat of vaporization of the bulk coolant was reduced to model the actual thermal energy required to void a node volume. Each node has a height of 4 inches.

\section{Results}

Figure 3-2 shows the pre-accident, steady-state temperature distribution for a bundle flow rate of $22.4 \times 10^{4} \mathrm{lbm} / \mathrm{hr}$. The term "node series" refers to the column of nodes shown in Figure 3-1, while the value of $X$ indicates the axial position.

When a fluid exists in the liquid state at a temperature higher than the saturation temperature at its associated pressure, it is defined as a superheated liquid. The difference between its temperature and the saturation temperature is called the liquid superheat. The amount of superheat for a specific accident is dependent on many variables including the rate of heating, the coolant purity, and the clad roughness. Superheat, then is a parameter whose value might effect the temperature history. The effect of superheat on the bulk coolant temperature at node 409 , the first node to vaporize, is shown in Figure 3-3. About 0.45 second is required for the coolant to reach 400 degrees of calculated superheat. Because the coolant is assumed to remain in the liquid phase during superheating, coolant temperatures do not increase as rapidly with higher superheats. Thus the initiation times for both coolant vaporization and clad melting are delayed.

The flow of thermal energy from the fuel to the clad and coolant is controlled by the fuel-to-clad gap and its associated interface contact heat transfer coefficient. In reality, there is a circular relationship between the relative thermal expansion rates of the fuel and clad, the contact heat transfer coefficient, and the temperatures in the fuel and clad which must be physically satisfied. Two THTD runs were made with constant gap coefficients of 1500 and $150 \mathrm{Btu} / \mathrm{h}-\mathrm{ft}^{2}{ }^{\circ} \mathrm{F}$. The resulting fuel to clad gaps were calculated and are shown in Figure 3-4. Also shown on Figure $3-4$ is the gap calculated by FORE-II in which the gap coefficient is functionally dependent upon the fuel-to-clad gap. FORE-II predicts an initial maximum gap coefficient of $1847 \mathrm{Btu} / \mathrm{h} \cdot \mathrm{ft}^{2}{ }^{\circ} \mathrm{F}$ and at 1.2 seconds, a minimum gap coefficient of $337 \mathrm{Btu} / \mathrm{h}-\mathrm{ft}^{2}-^{\circ} \mathrm{F}$. Figure 3-4 shows that a gap coefficient of $150 \mathrm{Btu} / \mathrm{h}-\mathrm{ft}^{2}{ }^{\circ} \mathrm{F}$ could not be maintained because the resulting temperatures would cause a zero fuelto-clad gap and therefore, a higher gap coefficient. Figure 3-5 shows the resulting mid-plane temperature Because FORE-II does not account for material phase changes, the results shown for the variable gap coefficient are valid only to the initiation of coolant boiling at 0.74 , seconds. For the reference case, the first coolant node vaporizes at 0.55 seconds and clad melting begins at 1.3 seconds.

Clad temperatures as a function of time are shown in Figure 3-6. Temperatures to the right of the vertical $2550^{\circ} \mathrm{F}$ line on this figure represent vaporized coolant and are representative of the temperatures the molten clad would have if it remained in place after melting. The times for clad melting are shown in Figure 3-7. It could be postulated that the molten clad would flow down the pin and the coolant vapor would contact the fuel surface. This phenomenon was modeled with THTD by replacing the clad properties with coolant properties after clad melting. The effect of this clad slumping is shown in Figure 3-8. Clad slumping has a significant effect on the time required to reach the initiation of fuel melting. Fuel melting at the outside surface of the fuel begins 1.5 seconds earlier when the coolant vapor is in direct contact with the fuel. 


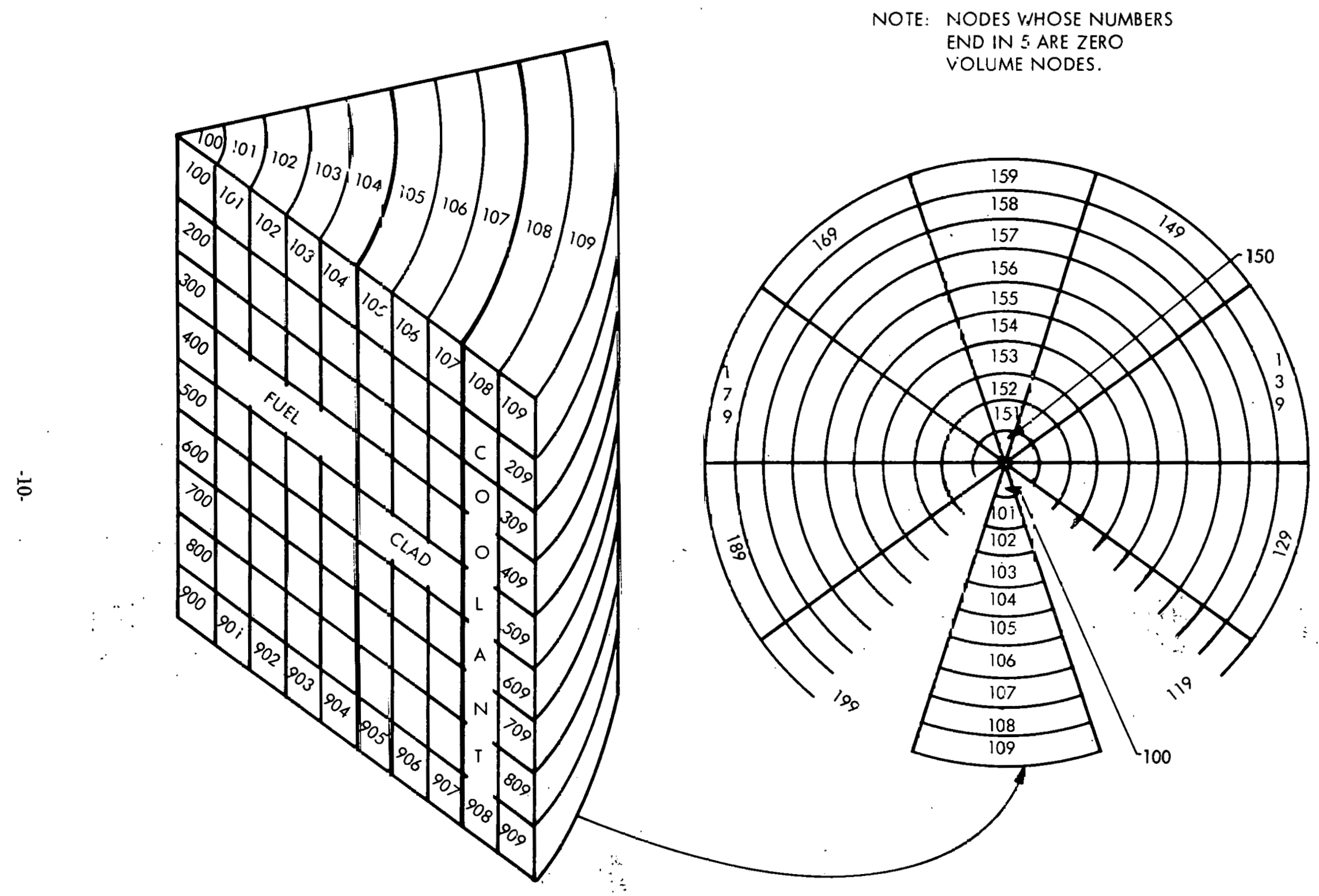

Figure 3-1. Computer Model for Fueh, Clad, and Coolant Temporatures 


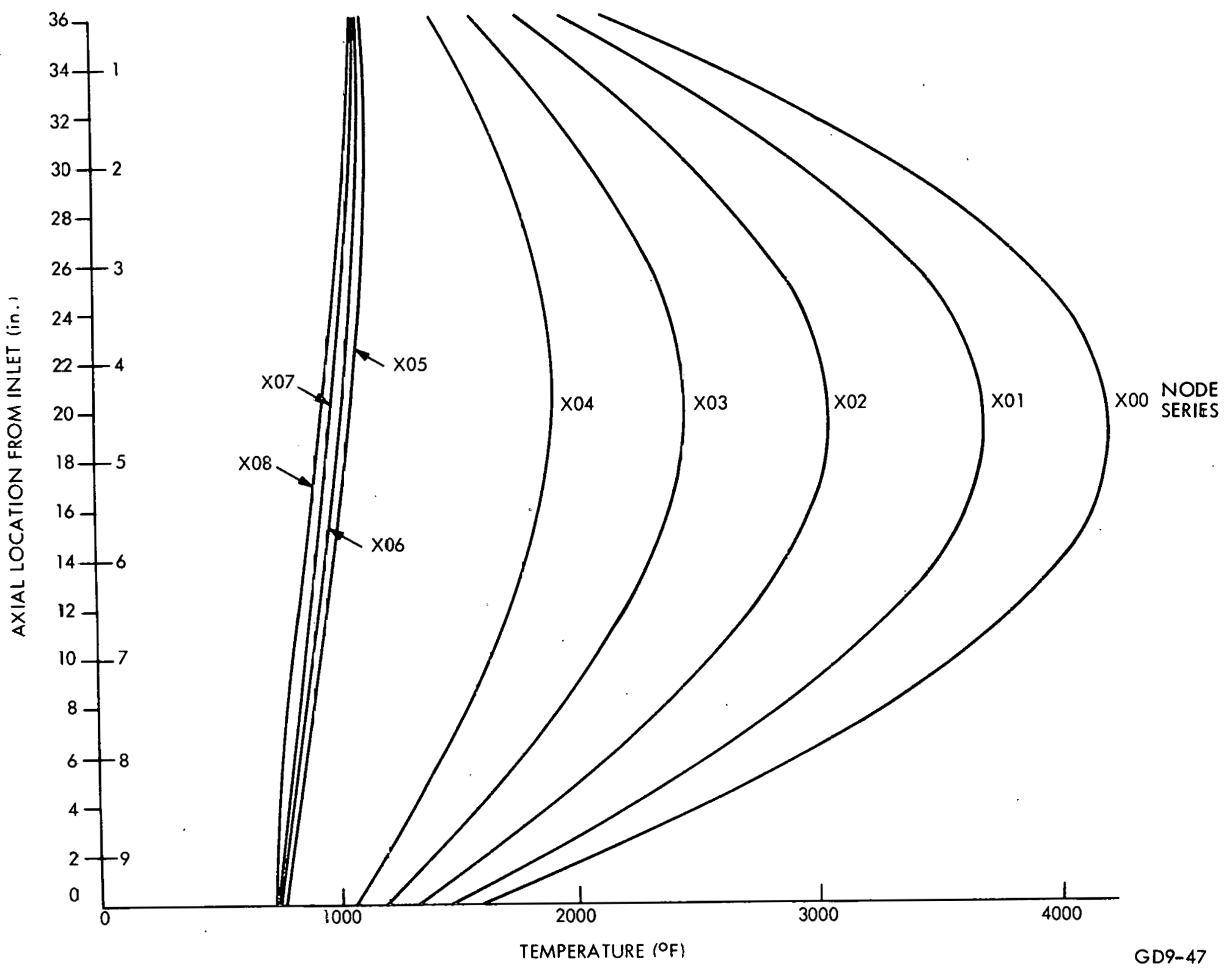




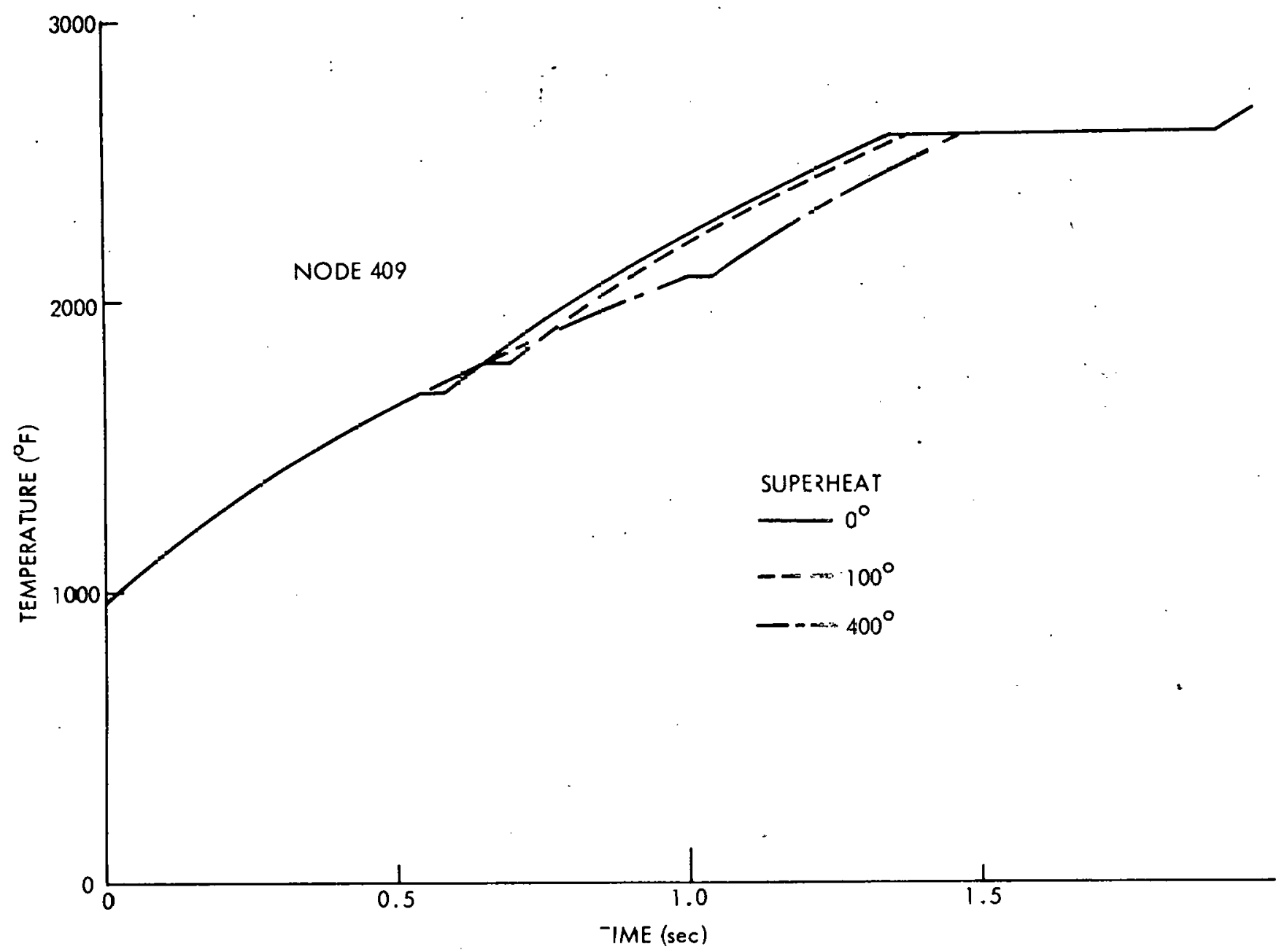

GD9-48

Figure 3-3. Tem, Jerature of the Bulf: Coolant Node Initiating Boiling as a Function of Time and Superheat 


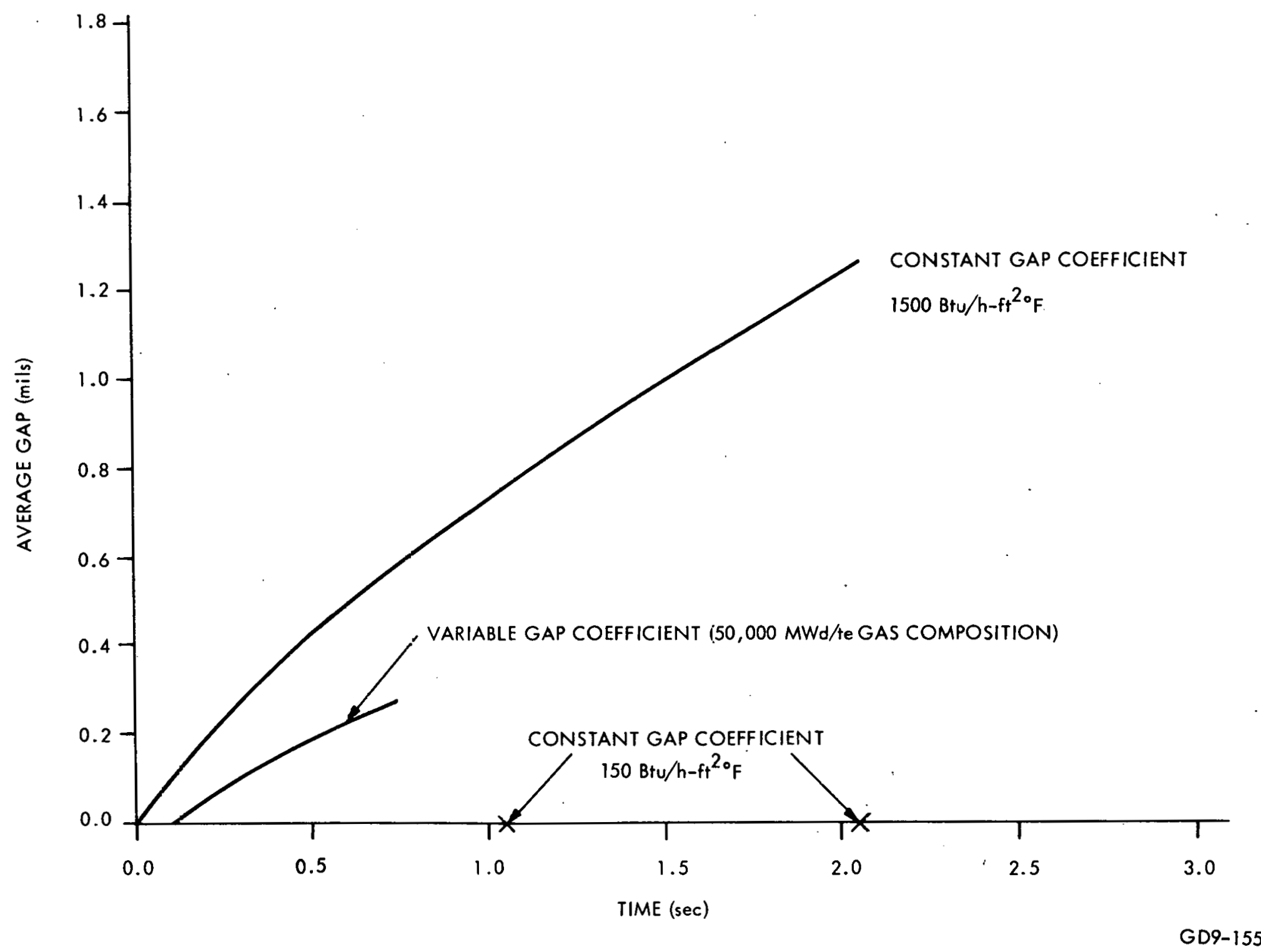

Figure 3-4. Average Gap for the Reference Case as a Function of Time and Gap Coefficient 


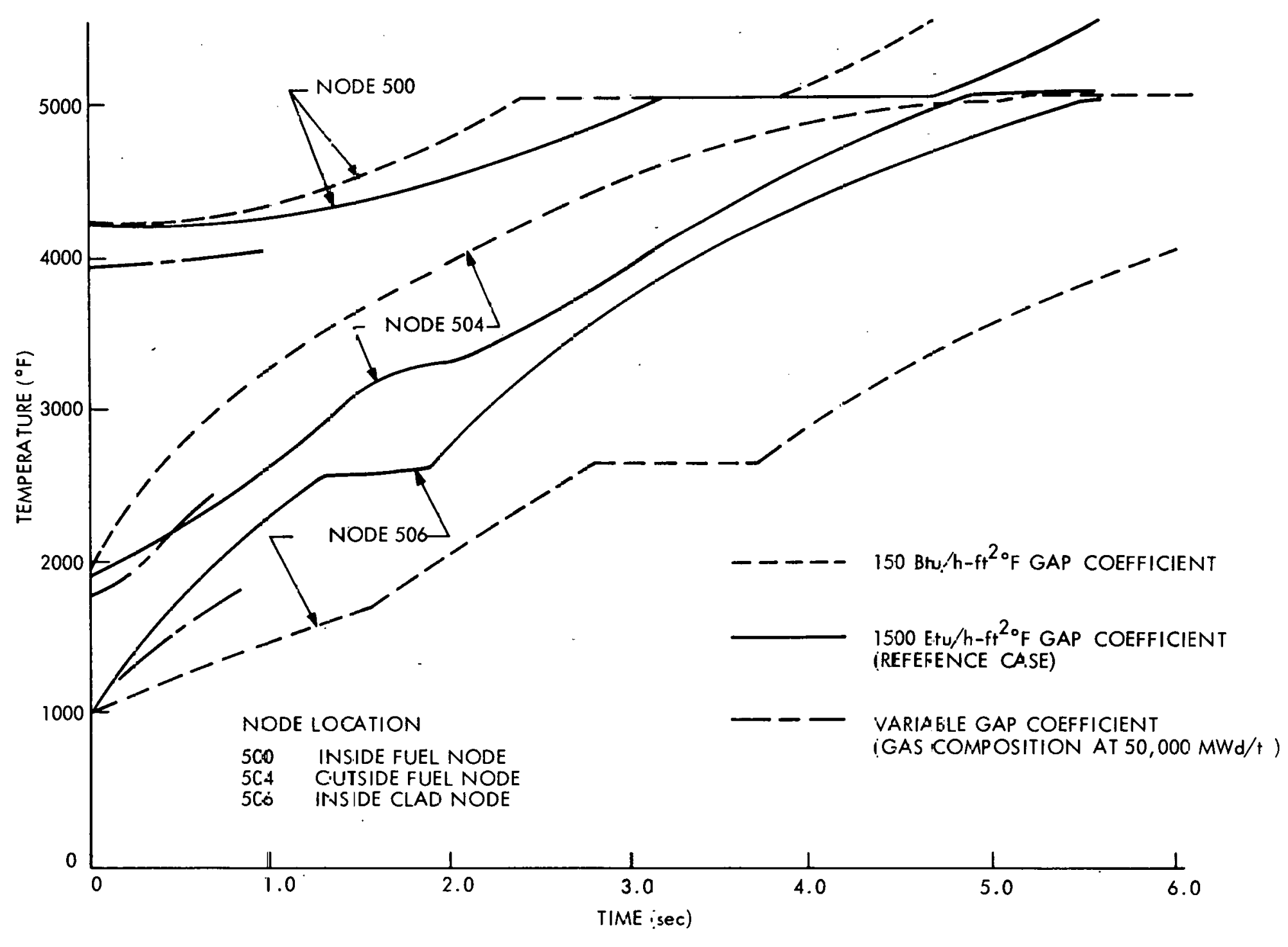

GD9-174

Figure 3-5. Comparison of Mid-Plane Temperatures as a Function of Time and Gap Conductance 


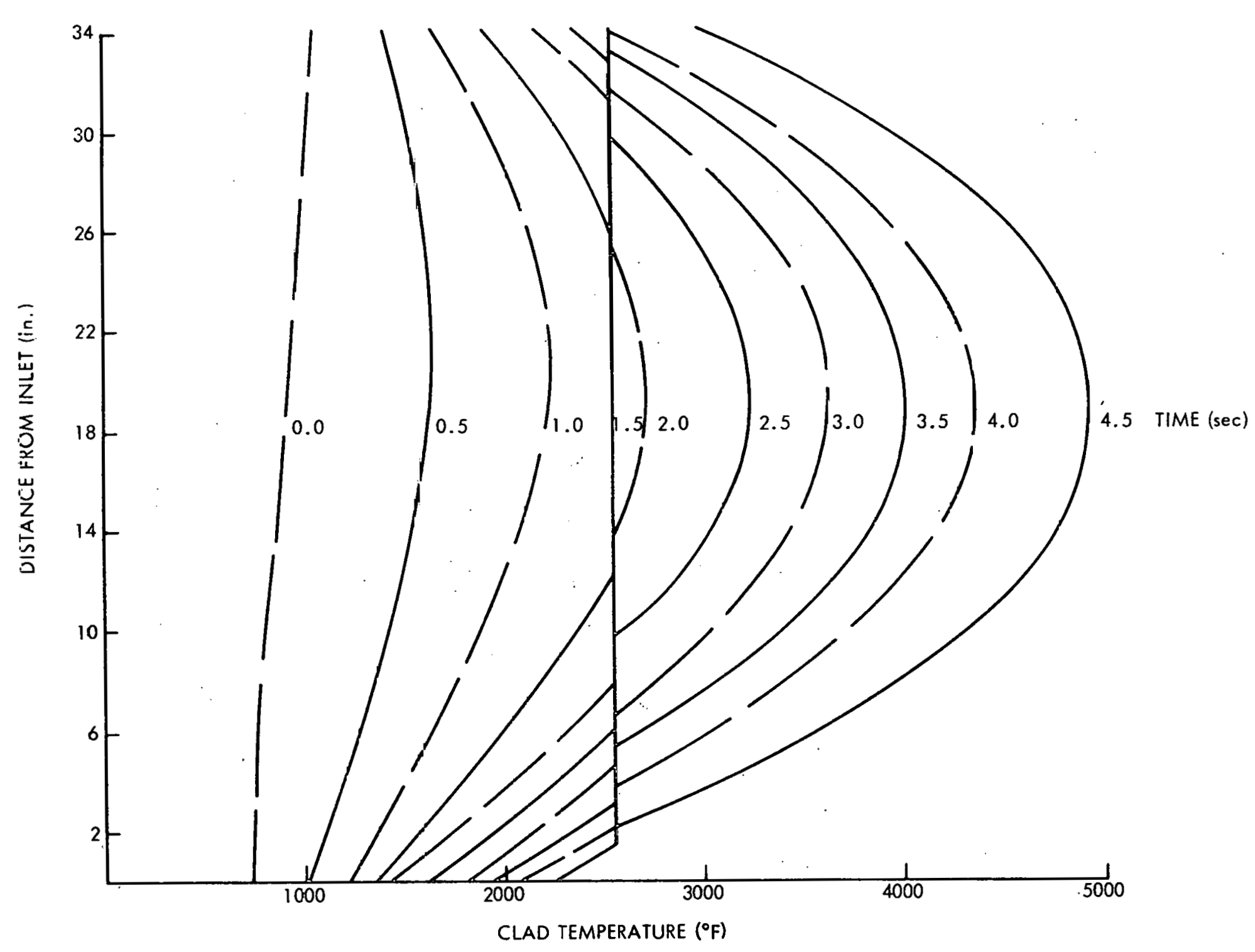

a
0
0
0
0
0
0 


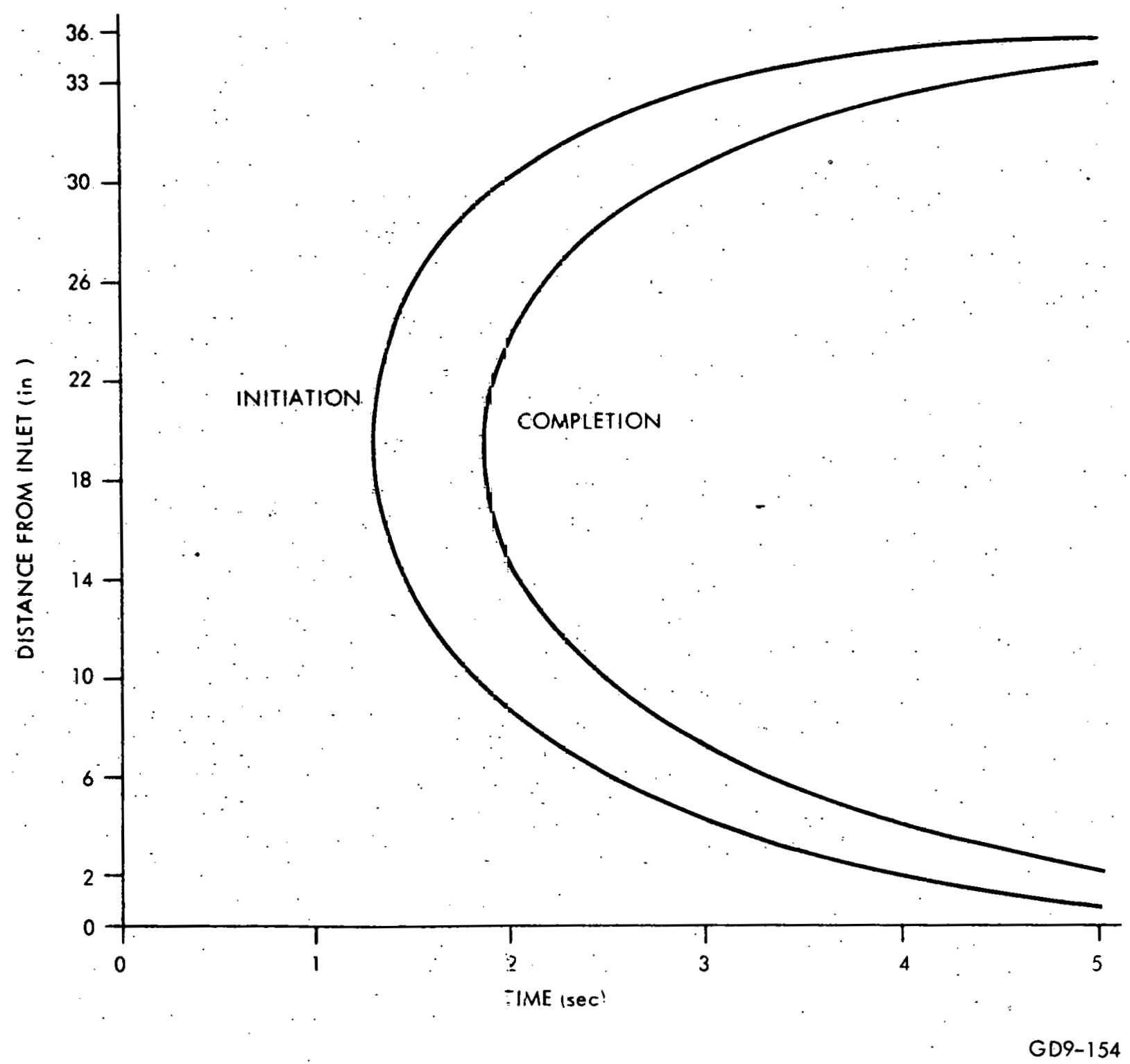

Figure 3-7. Clad Melt Times for the Reference Case 


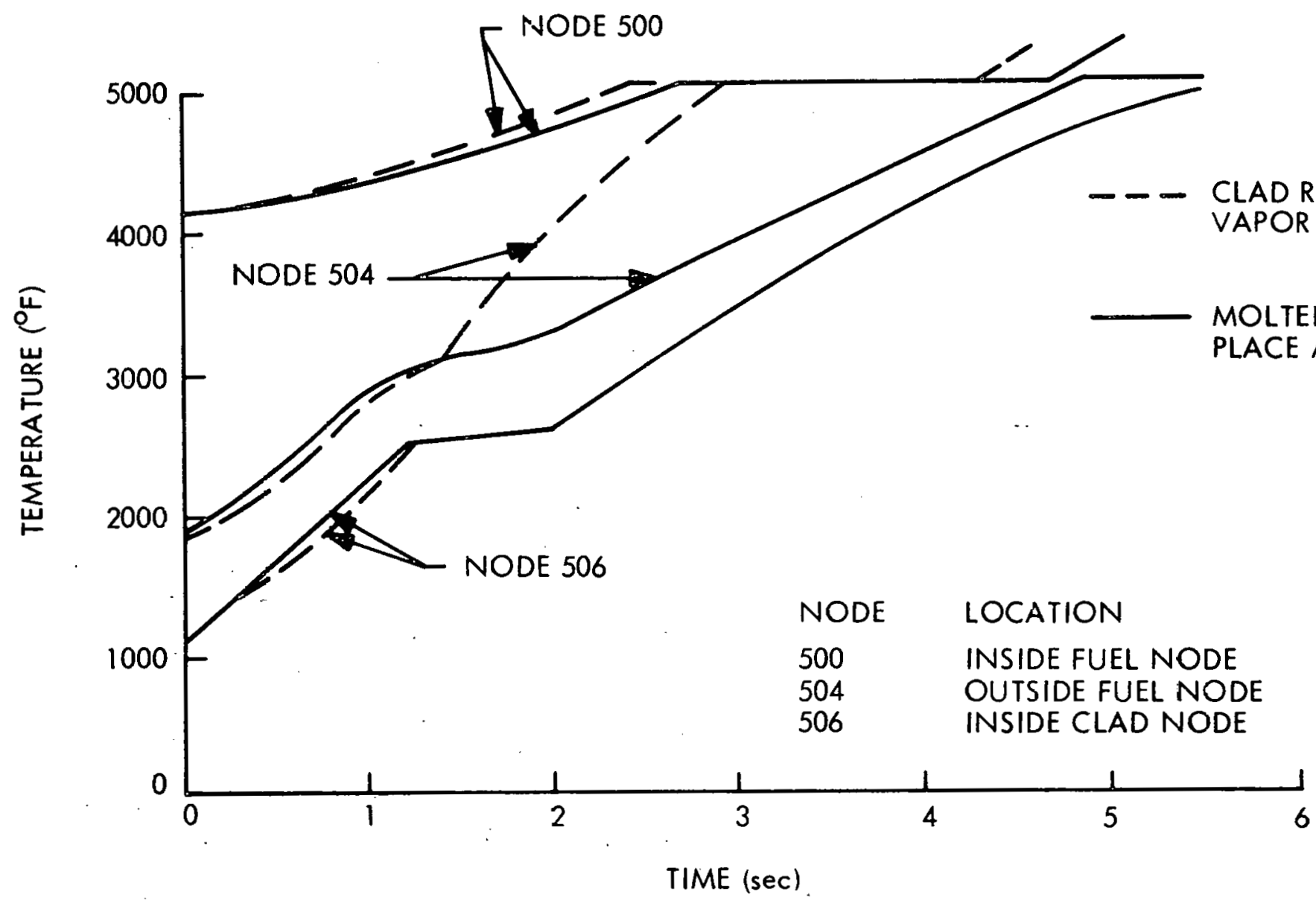


Radial temperature profiles as a function of time for the reference case are shown in Figure 3-9. Table 3.1 summarizes the initiation times for coolant vaporization, clad melting and fuel melting for the various cases considered.

Table 3-1

SUMMARY OF EVENT TIMES

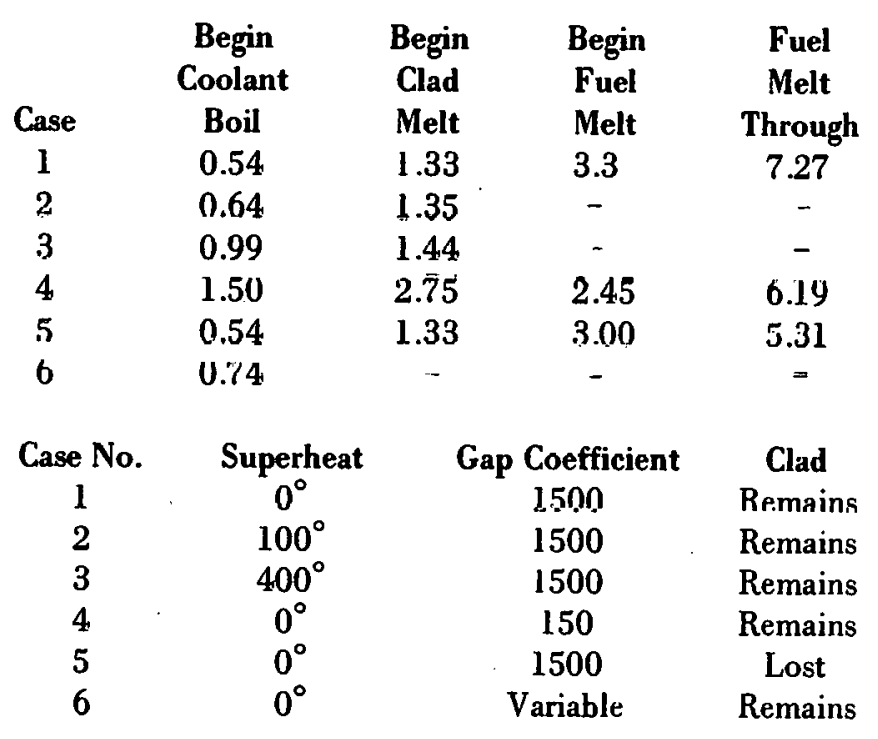

\subsubsection{SPACER WIRE}

Transient temperatures in the spacer wire were also computed by THTD for the $1 / 4$ pin segment shown in Figure $3-10$. The spacer wire was represented by nodes $100-103$, 200-203, and 300-302. The remainder of the outer four nodes represent the coolant. The temperatures of the spacer wire. clad and coolant are shown in Figure 3.11 for the reference case accident. The spacer wire temperatures shown are the average of nodes 101. 102. 201. 202. 301. and 302 . The coolant temperatures are from the circumferential node series $401,501, \ldots, 901$. Clad temperatures are at the clad-coolant interface. The pre-accident temperatures $(t=0)$ show that the clad temperatures under the spacer are higher than the clad exposed to the coolant. Also, the spacer wire is hotter than the bulk coolant. After 0.5 seconds of blocked flow, the clad temperatures under the spacer are cooler than the clad exposed to the coolant, and the spacer wire is cooler than the bulk coolant. This indicates that the spacer wire causes a local hot spot prior to the accident and acts as a heat sink during most of the accident. This is due to the differences in the thermal diffusivity of the clad, spacer wire, and coolant. The coolant was assumed to be in the liquid phase throughout these calculations.

\subsubsection{CHANNEL WALL}

In order to determine the mechanical response of the channel wall, the channel wall temperatures must be known. A section through adjacent channel walls including one fuel pin was used for a THTD analysis. It is shown in Figure 3-12.

Steady-state temperatures were calculated based on a coolant flow velocity of $31 \mathrm{ft} / \mathrm{sec}$. Curves $A$. B, and $C$ of Figure 3-13 show the channel wall and two coolant temperatures for the flow blockage accident. The coolant was kept in the liquid phase. Curve $D$ shows the coolant temperatures at the center of the fuel bundle assuming coolant vaporization dues not occur. Curves $A$ and $D$ are indicative of the radial temperature gradient across the fufl hundle, however, the temperature difference is also due to a slight difference in the flow areas betwecn the modcls uacd in part 1 - fuel, clad, and coolant-and part 3 - channel wall.

The effect of coolant voiding was determined by assuming the tlow area to be totally filied with saturated coolant at 1 second. Node 403 , was allowed to relax to the saturation temperature. The resulting temperatures are shown by curve $\mathrm{E}$.

Circumferential profiles are shown in Figure 3-14 Of particular interest is the gradient caused by the thermal inertia of the wall. T'emperatures in the channel wall were determined from the centroidal temperatures of node 403 and its adjacent nodes. These temperatures are shown in Figure 3-15.

\subsection{CLAD RUPTURE TIME}

The time at which the clad ruptures is dependent upon the fission gas released prior to the flow blockage and the gas temperature. Three modcs of fission gas release were considered:

1. total release of available gas prior to the accident

2. release of gas from fucl experiencing columnar grain growth prior to the accident with the release of the remaining available fission gas as the fuel melts

3. no release prior to the accident with all available fission gas released as the fuel melts.

Rupture was assumed to occur when the hoop stress equaled the ultimate strength.

The available fission gas was calculated for a reference exposure of $50,000 \mathrm{MWd} / \mathrm{t}$ and a fission gas generation rate of 0.23 gas atoms/fission. 


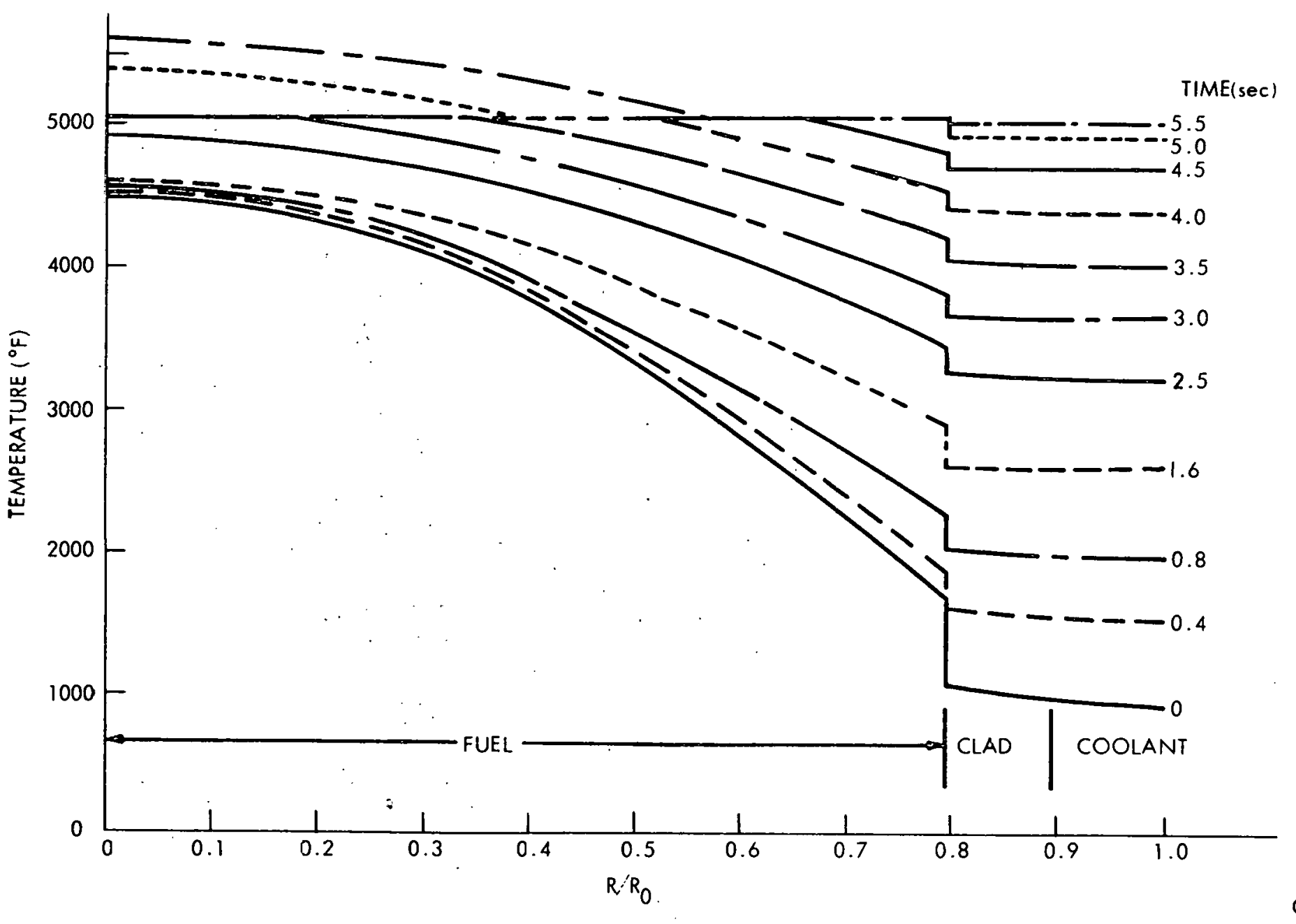




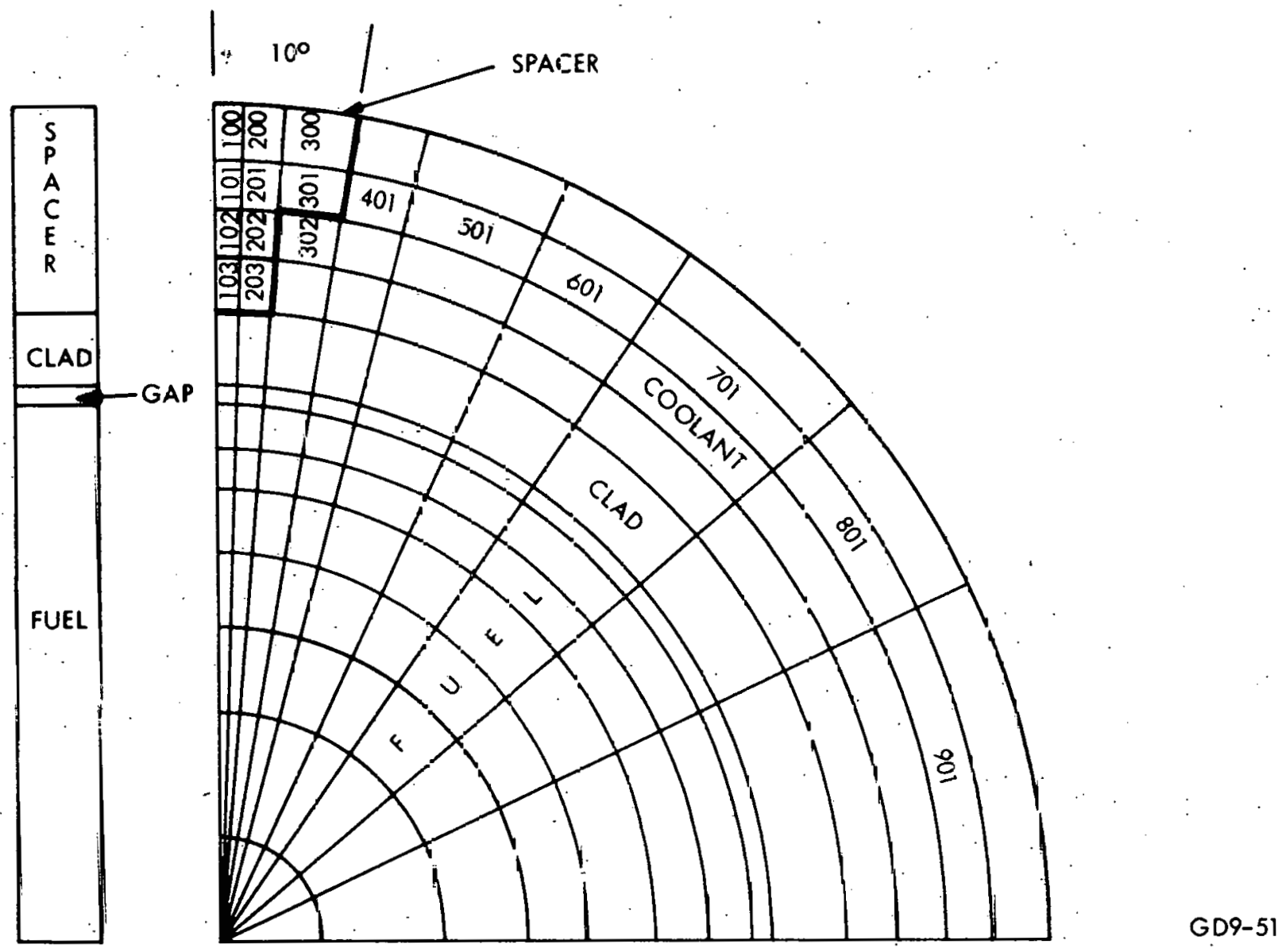

Figure 3-10. Compater Model for Spacer Wire Te mperatures 


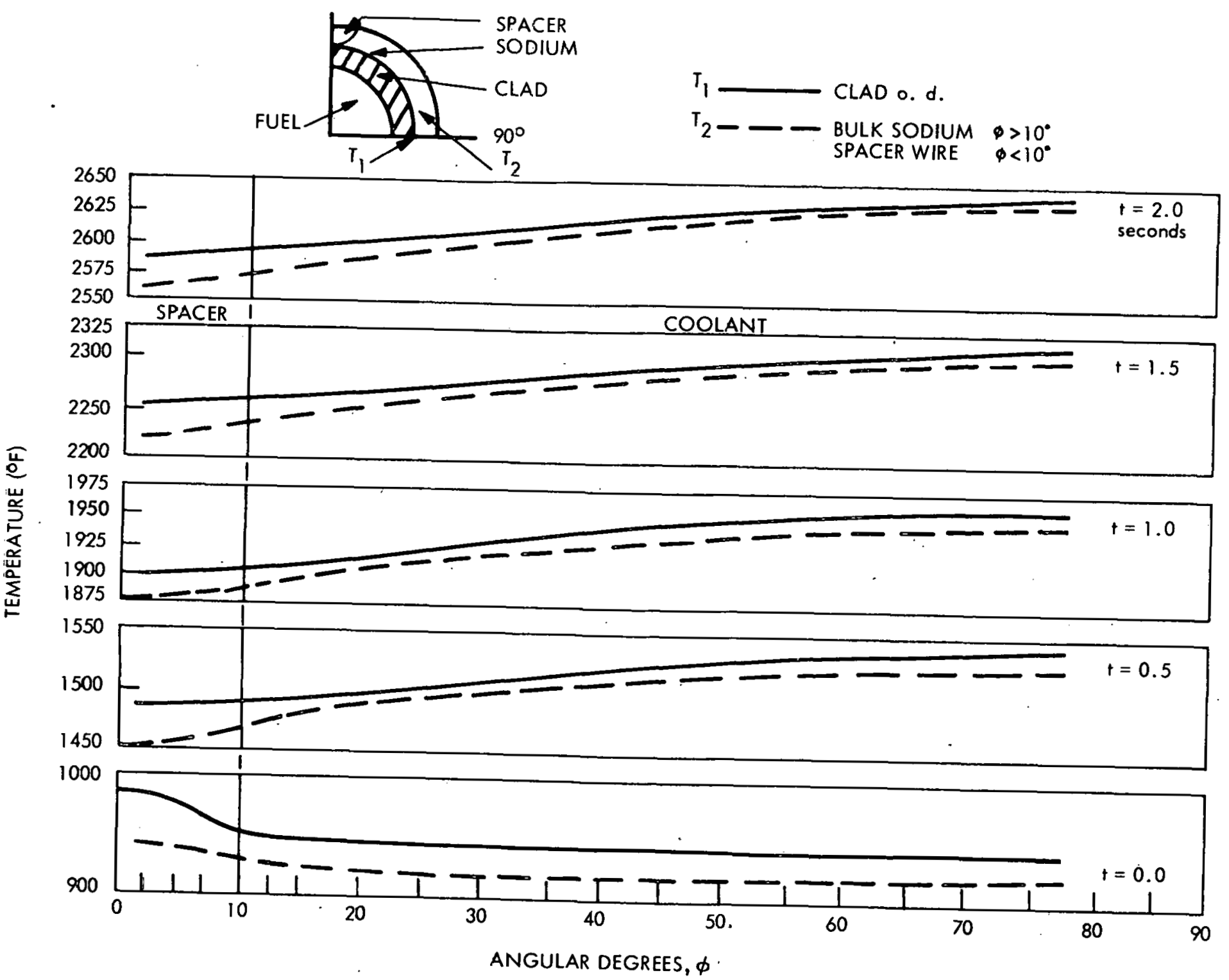


ing

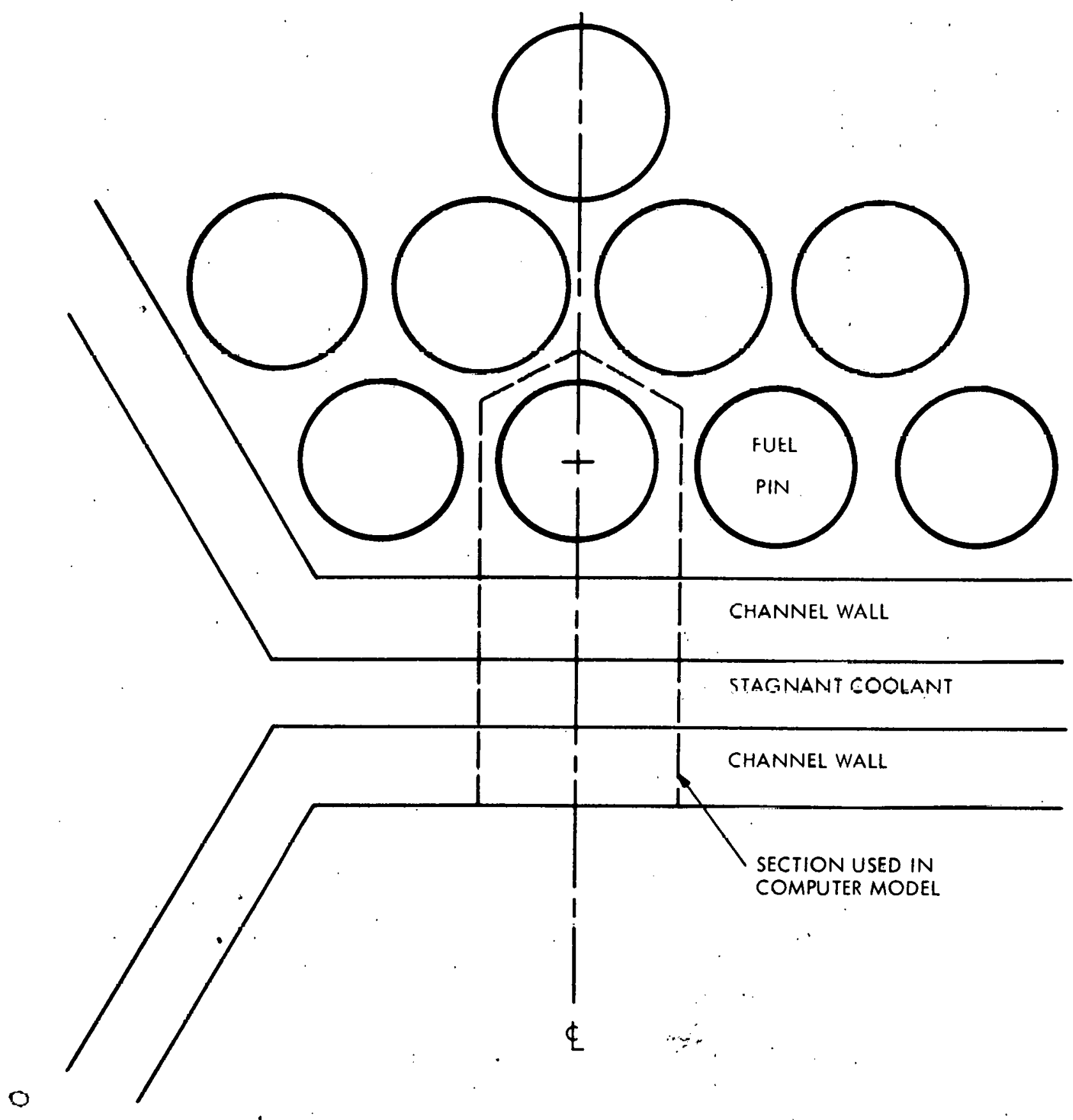

GD9-61

Figure 3-12. Computer Model for Channel Wall Temperatures 

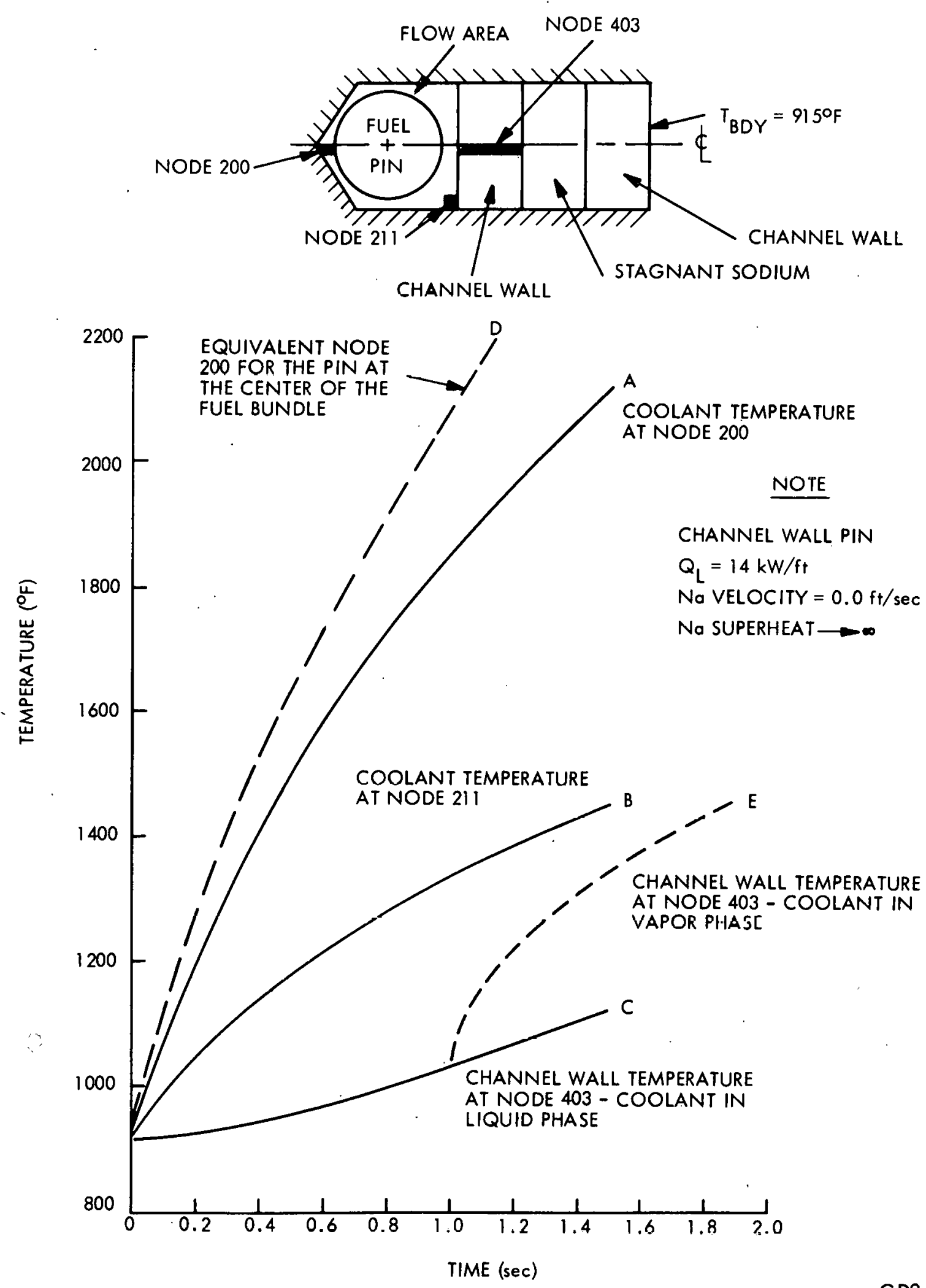

Figure 3-13. Channel Wall Temperatures 


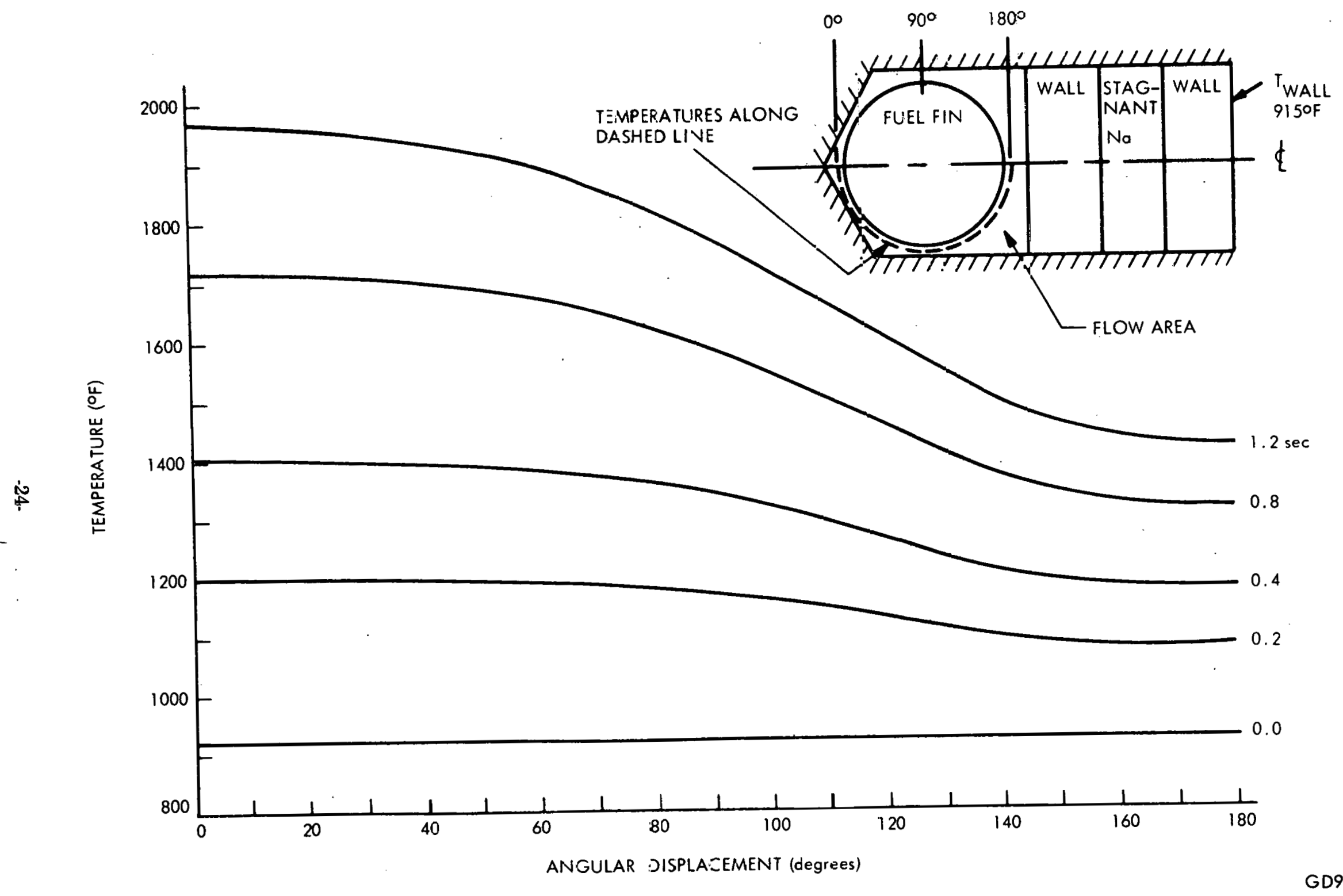

Figure 3-14. Cireuraferential Variation of Clad Temperatures around a Fuel Pin Adjacent to tize Channel Wall 


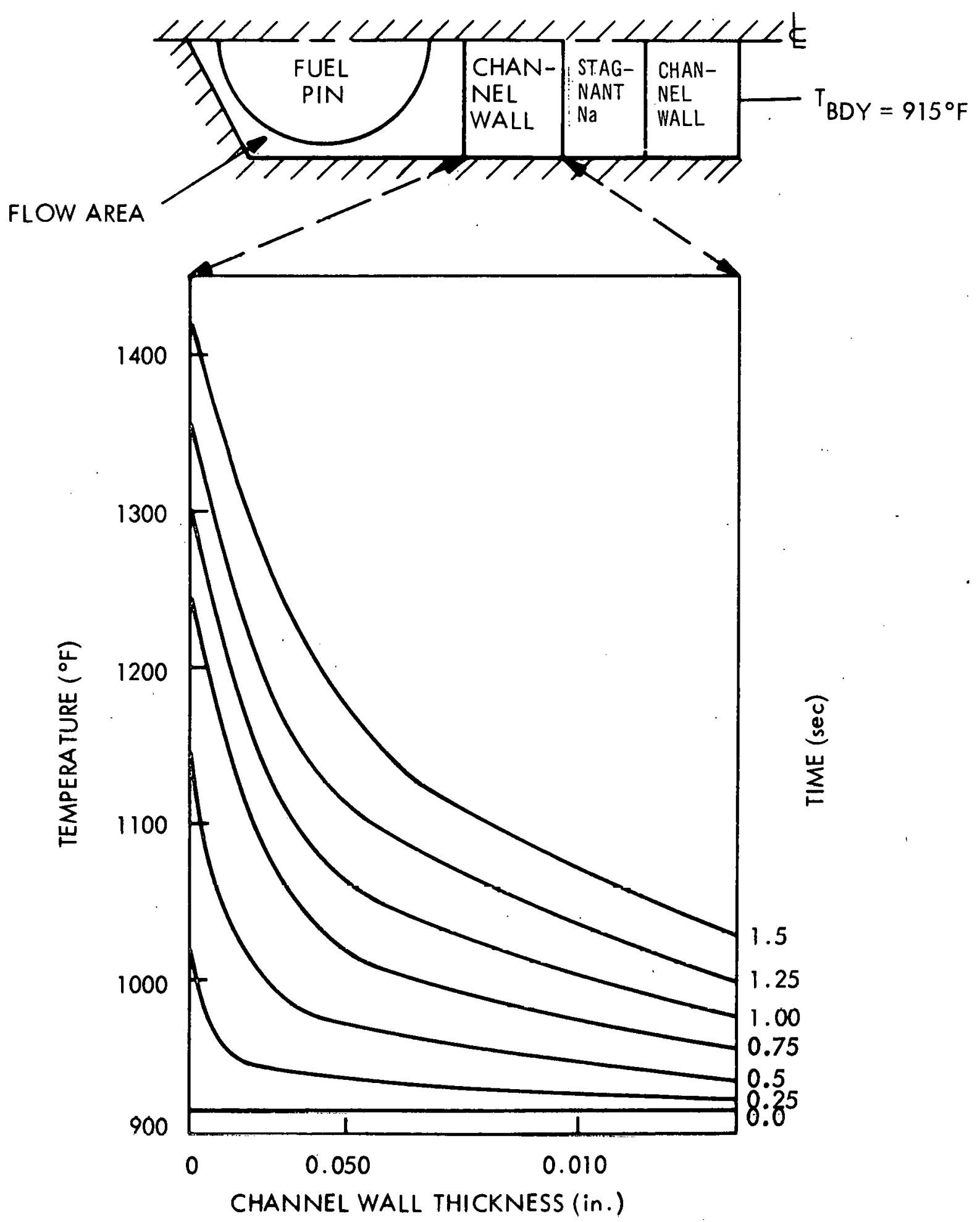

Figure 3-15. Temperature Profile Through the Channel Wall after a Flow Blockage 
Fission density $=\frac{\text { exposure }\left(\frac{\mathrm{MWd}}{\mathrm{t}}\right) \times \text { fuel density }\left(\frac{\mathrm{lb}}{\mathrm{ft}^{3}}\right)}{}$

$$
2.1 \times 10^{-14}
$$$$
=\left(50 \times 10^{3}\right) \times(580.6) / 2.1 \times 10^{-14}
$$$$
=1.38 \times 10^{21} \text { fissions } / \text { in. }^{3}
$$$$
=2.265 \times 10^{22} \text { fissions } / \mathrm{in}^{3}
$$

and the fuel volume is $1.17 \mathrm{in}^{3}$, the number of moles of available fission gas is

$\left(2.265 \times 10^{22} \frac{\text { fissions }}{\text { in }^{3}}\right) \times\left(1.17 \mathrm{in}^{3}\right) \times\left(\frac{0.23 \text { gas atoms }}{\text { fission }}\right) \times$

$\left(\frac{\text { mole }}{6.023 \times 10^{23} \text { gas atoms }}\right)=0.01021$ moles of fission gas.

Assuming a perfect gas relationship, the pressure increase due to the release of all available fission gas is

$$
\begin{aligned}
\mathbf{p} & =\mathrm{NRT} / \mathrm{V} \\
& =\frac{(0.01021 \text { moles }) \times\left(0.08206 \frac{\ell \text {-atm }}{\mathrm{mole}^{\circ} \mathrm{K}}\right)\left(294.11^{\circ} \mathrm{K}\right)}{} \\
& =\left(1.357 \mathrm{in}^{3}\right)\left(0.016387 \frac{\ell}{\mathrm{in}^{3}}\right) \\
& =10.905 \mathrm{ultn.} .
\end{aligned}
$$

at $70^{\circ} \mathrm{F}$ for $50,000 \mathrm{MWd} / \mathrm{t}$.

For a specific release fraction and fission gas plenum temperature, the pressure increase is

$$
\Delta p=161.74\left(X_{\text {release }}\right) \times\left(\frac{T+460}{530}\right) .
$$

For mode 1, total release, the release fraction,

$$
\mathrm{X}_{\text {release }}=1
$$

and for mode 3 , no prior release, the release fraction,

$$
\mathrm{X}_{\text {release }}=\text { the clad melt fraction. }
$$

For mode 2, columnar release, the pressure increase is given by,

$$
\Delta p=\left(35.88+125.59 X_{\text {release }}\right) \times\left(\frac{T+460}{530}\right)
$$

The effect on the pin internal pressure due to the amount of fission gas relcased prior to the accident is shown in Figure 3-16. The fission gas plenum temperature was assumed to be the same as the exit coolant temperature for the reference case. The fuel melt fractlons used to determine curves $B$ and $C$ of Figure 3-16 are given in Figure 3-17.

Figure 3-18 shows the time at which the hoop stress based on Figures 3-16 and 3-17 equals the ultimate strength. Exposures of 50 and $100,000 \mathrm{MWd} / \mathrm{t}$ are considered. The failure times are summarized in Table 3-2. In each case, failure occurs after the initiation of coolant boiling at zero superheat. Due to the rapid decrease of the ultimate strength with temperature, changes in the plenum temperature will have little effect on the failure timcs. The rcsults presented in Figure 3-18 and Table 3-2 represent a lower bound on fuilure timc.

Table 3-2

CLAD FAILURE TIMES FOR THE REFERENCE CASE

\section{TIME TO FAILURE, sec} EXPOSURE, MWd/t

$\begin{array}{llrr}\text { Release Merhanism } & \text {. . . } & 50,000 & 100 ; 000 \\ \text { Total . . . . . . . . . } & 0.78 & 0.59 \\ \text { Columnar . . . . . . } & 1.06 & 0.93\end{array}$

\section{REFERENCES}

1. Skirvin, S.C., User's Manual for the THTD Computer Program (Transient Heat 'Transfer - Version D), June 23, 1966, (PO No. 036-926052-T0602).

2. Fox, J.N., Lawler, B.E., and Butz, H.R., FORE-II - A Computational Program for the Analysis of SteadyState and Transient Reactor Performance, September 1966, (GEAP-5723). 
GEAP-10059

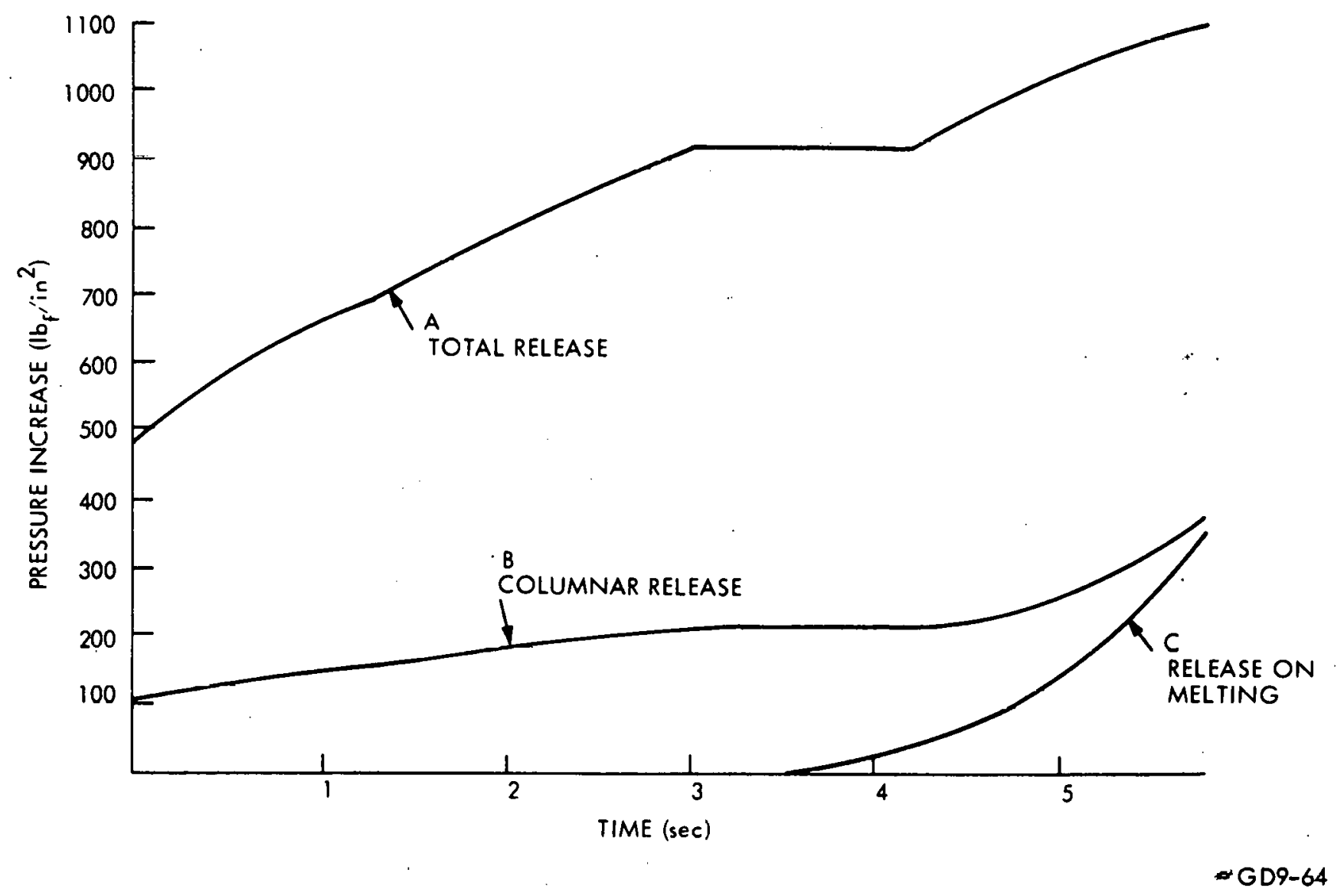

Figure 3-16. Pressure Increase Due to Fission Gas Release for Three Release Modes o 


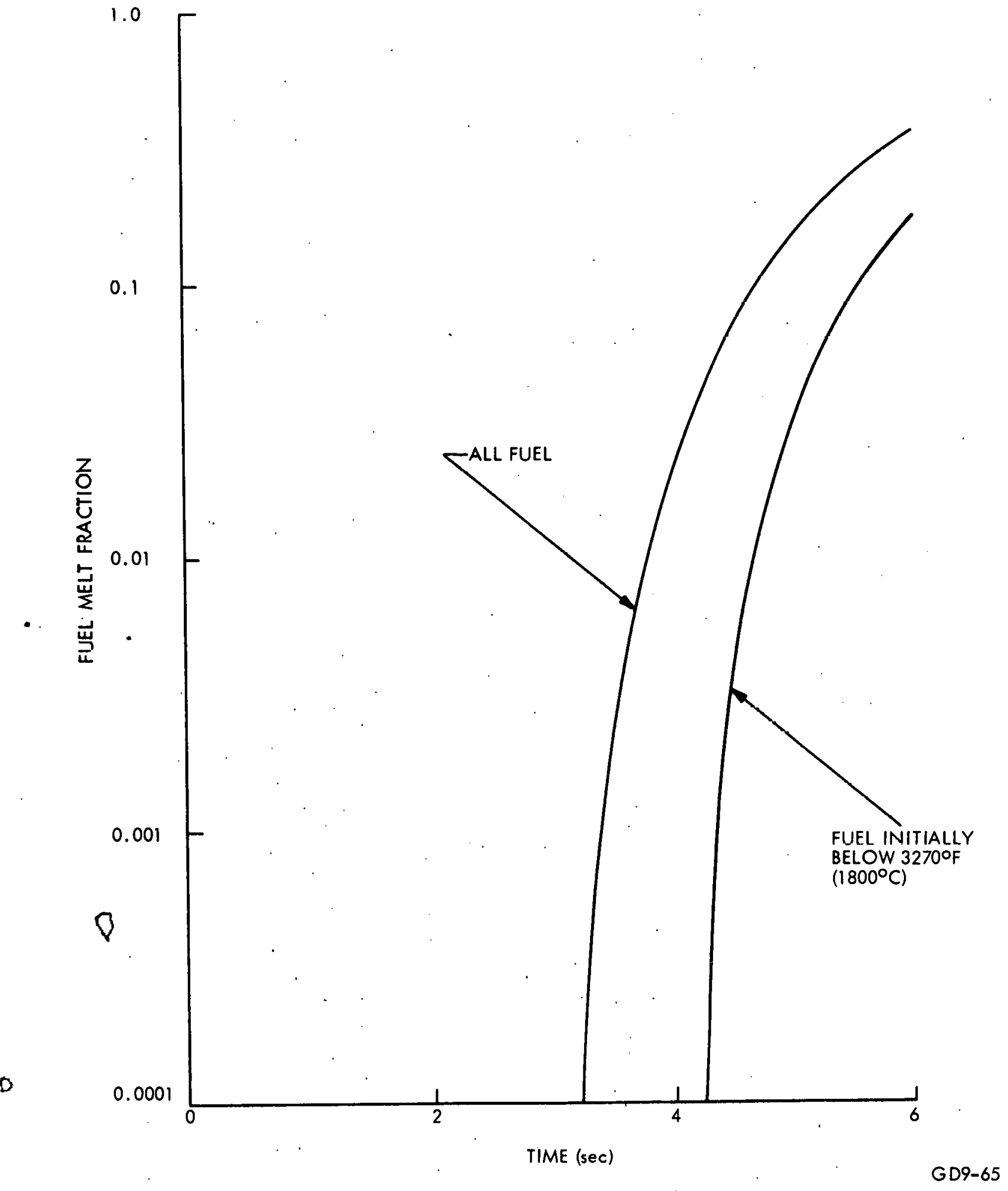

Figure 3-17. Fuel Melt Fraction for the Reference Case 


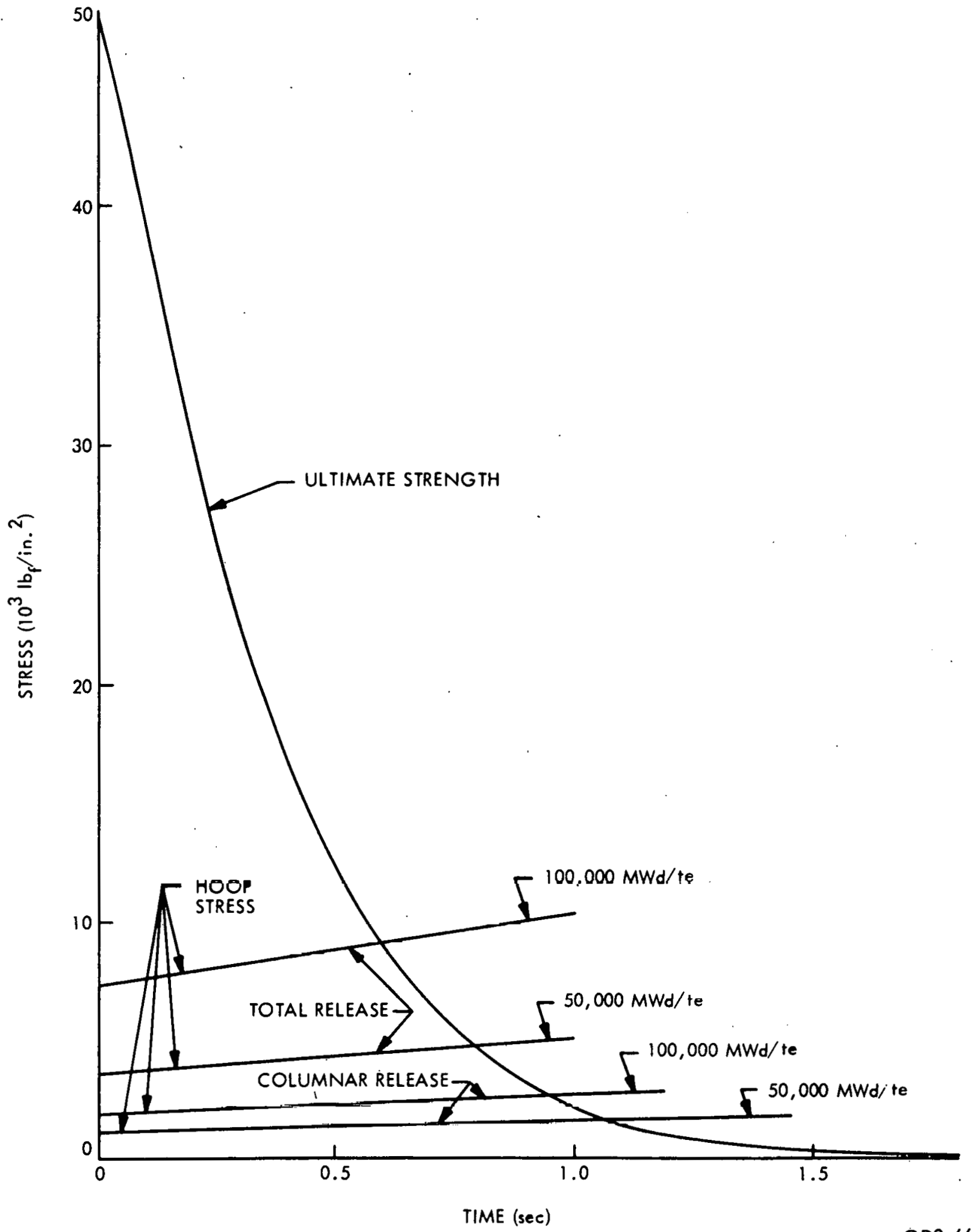

Figure 3-18. Ultimate Strength and Hoop Stress as a Function of Time for $0^{\circ}$ Superheat Reference Case for Burnups of 50 and 100,000 MWd/te 


\section{COOLANT THERMAL-HYDRAULICS}

\subsection{INTRODUCTION}

This section is concerned with predicting the probable behavior of the sodium coolant during the hypothesized loss-of-coolant accident. The principle objective is an estimation of the range of sodium temperatures and velocities when interaction might occur between hot fuel and/or clad and sodium. The two phases of the accident progression used to characterize the coolant thermalhydraulics are:

- Initial duct voiding and evaporation of liquid sodium (dryout)

- Sodium reentry from above the enriched fuel region.

The current understanding of the phenomenon of coolant thermal-hydraulics is well represented by reference 1 .

The main interest in the past has been with power transients. The velocity of initial voiding was important in order to determine reactivity feedback associated with the initial voiding. This aspect of initial voiding has been studied thoroughly and appears adequately described for this loss of flow accident. The consequences of a hypothetical lossof-flow accident are not dependent on more precise analytical tools to predict the initial duct voiding rate. The reference further notes the lack of understanding of the following areas of interest to the loss-of-flow accident:

- Two-phase choking flow

- Void collapse

- Molten fuel - coolant intarantion.

No tools are available to study the combined effects of sodium voiding, reentry and hot or molten material-sodium interaction. The individual phenomenon which contribute to an understanding of the sodium behavior following flow blockage are discussed in the following subsections.

\subsection{INITIAL VOIDING AND DR YOUT}

The object of this subsection is to describe the sodium temperatures and displacements during the initial boiling excursion. The characteristic times associated with the initial voiding and dryout are estimated in order to establish the initial conditions for the subsequent sodium reentry into the core. The principle parameters influencing the initial voiding and dryout are:

- Liquid superheat

- Sodium film thickness on the cladding

- Fission gas

- Type of flow blockagc.

\section{Liquid Superheat}

The maximum liquid superheat expected to be attained before the onset of boiling following complete flow blockage should be less than $240^{\circ} \mathrm{F}$ according to Chen's model (Ref. 2) (see Appendix B). The vapor pressure at this superheat is about $66 \mathrm{psi}$, less than the inlet plenum pressure.

The assumption of a continuing flow blockage due to an inlet obstruction seems credible as the initial vapor pressure would not be sufficient to dislodge a blockage. The test dala confirming Chen's model was generated under flow blockage conditions similar to the FFTF loss-ul-now accident, lending confidence that the model might adequately predict the maximum superheat to he expected.

Two other influences which are important to the potential superheat are entrained gas bubbles and the flow velocity (Ref. 3). Very minute gas bubbles in the system would virtually eliminate superheat. Recent unpublished experiments at BNL also apparently show a marked decrease in superheat as the velocity of the sodium is increased from zero to 1 to $2 \mathrm{fps}$. This becomes significant for the more realistic accident conditions of partial flow blockage (locally or for an entire assembly).

\section{Film Thickness}

The Importance of a liqud film remaining on the heated surface was recognized when early exproriments crhihited higher voiding rates than predicted frum heat transfer considerations. The effect of residual liquid on the cladding is to cause an inertia and friction limited voiding condition that permits ready calculation of the voiding rate using Newton's second law when combined with the single bubble voiding hypothesis and liquid superheat. The details of this analysis are given in Appendix $F$. The results of applying this simplified analysis to the initial voiding are shown in Figurc 4-1, assuniing the pressure acting on the liquid slug is constant and equal to the vapor pressure at the indicated superheat. Only at superheats above $370^{\circ} \mathrm{F}$ does the pressure exceed the inlet plenum pressure and result in downward expulsion as well as upward expulsion.

The slug velocities at the core exit are typically $10 \mathrm{fps}$ and $40 \mathrm{fps}$ for superheats of 50 and $400^{\circ} \mathrm{F}$ respectively. The liquid film thickness remaining on the heated surfaces has been correlated with the laminar sub-layer thickness by $D$. Smidt, et al. (Ref. 4) For the FFTF pin bundle and assuming no influence of the wire wraps, the laminar sublayer thickness was calculated (Ref. 5) and compared to the 


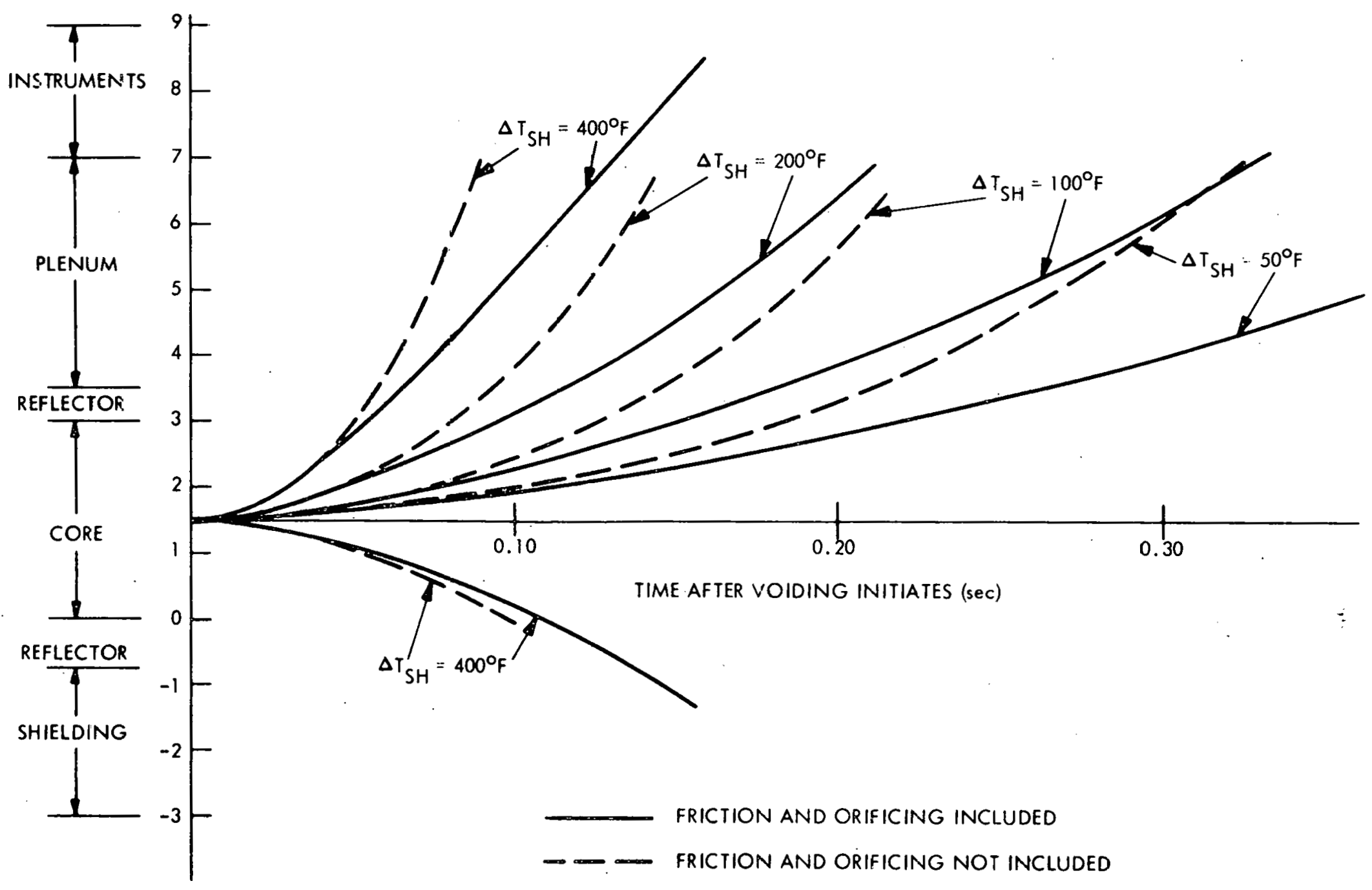


r:xpected surface roughnesses in Figure 4-2. The roughness of supplied cladding is specified to be $32 \mathrm{rms}$ on the PA-10 program and is generally observed to be about $25 \mathrm{rms}$ (Ref. 6). Stainless steel subjected to flowing sodium corrosion tests $\left(1000\right.$ hours at $\left.1300^{\circ} \mathrm{F}\right)$ exhibits surface roughnesses in the range of 0.1 to 0.2 mil (Ref. 7) and a roughness of 0.1 mil might be expected even at the lower temperatures but longer times characteristic of FFTF.

The comparison shown in Figure 4-2 shows that the surface is "rough" for velocities greater than $4 \mathrm{fps}$ even with smooth cladding. The turbulence created by the wire wrap spacers should further decrease the laminar sub-layer thickness. The film thickness remaining after voiding should then be characterized by the clad roughness rather than the laminar sub-layer thickness. The presence of the liquid film is said to provide an almost constant driving force for slug ejection because of the high ratio of liquid to vapor densities. Figure 4-3 shows the film thickness versus saturation temperature at which the liquid film would just fill the voided channel with vapor. For rough surfaces, the film would easily fill the void and provide the driving force for slug ejection, but for a smooth boundary, a superheat of greater than $200^{\circ} \mathrm{F}$ ' could suffer a pressure decrease because of insufficient liquid to fill the voided space. The evaporation from the surface of the liquid filling the lower part of the duct would then determine the degree of pressurc decrease. The wire wraps will cause more liquid to remain in the core, perhaps sufficient to provide an initial constant pressure pulse equal to the liquid saturation pressure. However, the spacer wire transient temperatures discussed in Section 3 will be about $50^{\circ} \mathrm{F}$ cooler than the clad temperature during the loss-of-flow accident, and any liquid film on the wire would evaporate later and at lower pressurc than that on the cladding.

Two other factors that significantly affect the initial voiding rates are the core temperature profiles and the presence of the cold channel wall. Both result in cold surfaces being exposed by the growing vapor bubble, leading to pressure gradients which limit the voiding driving pressure. The next subsection considers the heat transport by the liquid slug being ejected from the top half of the core.

\subsection{HEAT TRANSFER IN THE CORE AND PLENUM, LIQUID SODIUM}

Available transient heat transfer tools do not permit the simultaneous solution of clad and sodium heat transfer when coolant vaporization occurs. The development of the "slug" model at ANL (Ref. 3) will permit the study of the liquid film and slug flow effects. This program should be available in 1969. For this study, the heat transfer and flow conditions were studied separately, permitting only limited parameter studies to be completed.

The principal interest in this transient heat transfer analysis are the time response characteristics of the core and plenum components as well as the coolant. When axial coolant movements occur, the transient heat transfer is closely described as a rapid or step change in surface temperature. The time response of the coolant, clad, spacer, reflector, was calculated for the following conditions:

\section{Geometry:}

Pin diameter, $d$, in. . . . . . . . . . 0.23

Clad thickness, $t$, in. . . . . . . . . . . 0.014

Wire diameter, $\mathrm{d}_{\mathrm{s}}$ in. . . . . . . . . . 0.056

Coolant flow area/pin, in ${ }^{2} \ldots . . . . .0 .0268$

\section{Properties:}

Steel conductivity, Btu/h-ft ${ }^{\circ} \mathrm{F} \ldots \ldots . . . .13$

Sodium conductivity, Btu/h-ft ${ }^{\circ} \mathrm{F}$. . . . . . . 30

Steel specific heat, Btu/lb ${ }^{\circ} \mathrm{F} \ldots \ldots . . . .0 .14$

Sodium specific heat, Btu/lb ${ }^{\circ} \mathrm{F}$. . . . . . . . . 0.30

Sodium heat of vaporization, Btu/lb . . $1675\left(@ 1800^{\circ} \mathrm{F}\right)$

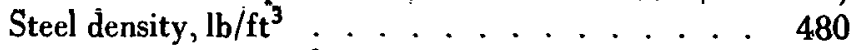

Sodium density, $\mathrm{lb} / \mathrm{ft}^{3}$. . . . . . . . . . . 50

These conditions yield the following heat capacities per unit length, Btu/ft- ${ }^{\circ} \mathrm{F}$ :

Sodium . . . . . . . . . $2.8 \times 10^{-3}$

Clad . . . . . . . . . . . $4.33 \times 10^{-3}$

Spacer wire . . . . . . . . . $1.15 \times 10^{-3}$

Reflector .......... $19.3 \times 10^{-3}$

For FFTF conditions these values yield the ratio of steel to sodium heat capacity within the fuel duct:

$$
\begin{aligned}
& \text { Heat capacity ratio } \frac{\text { clad plus spacer }}{\text { liquid sodium }}=1.95 \\
& \text { Heat capacity ratio } \frac{\text { reflector plus spacer }}{\text { sodium }}=7.32
\end{aligned}
$$

These ratios indicate that in the cxehange of sensible heat during voiding, the sodium temperature changes will at least double the steel temperature changes.

The sensible heat equivalence of the liquid film remaining after slug type voiding is a variable of interest in determining the time required for evaporation. For the expected 0.1 mil thick sodium layer, the latent heat capacity is 0.04 $\mathrm{Btu} / \mathrm{ft}$. This is equivalent to a change in clad temperature of $9.5^{\circ} \mathrm{F}$. This indicates that the liquid film prcsent should be rapidly evaporated with minor effect on the transient clad temperature. At the time of voiding, the transient analysis 


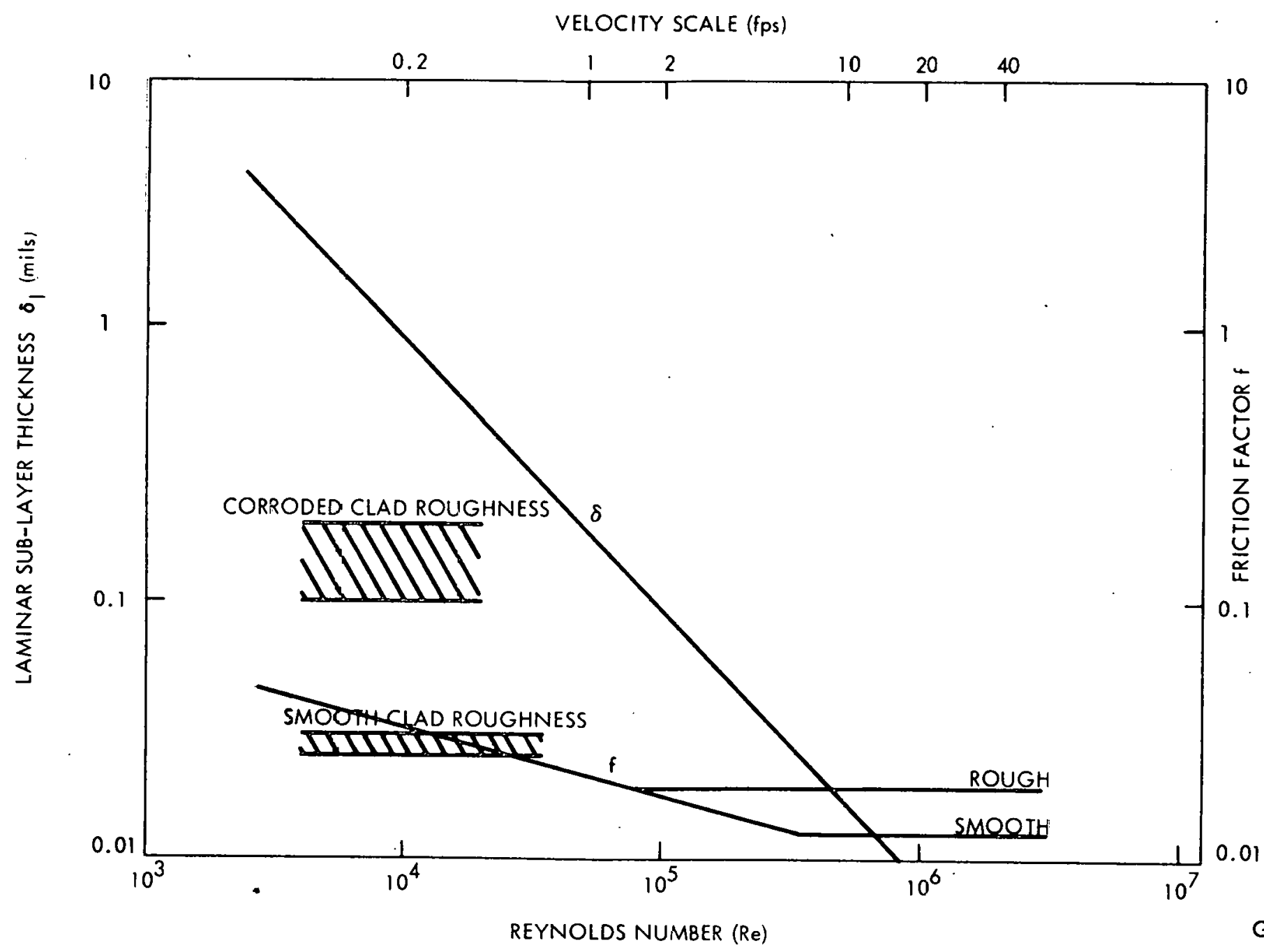

䍂

Figure 4-2. Laminar Sub-Layer Thickness 


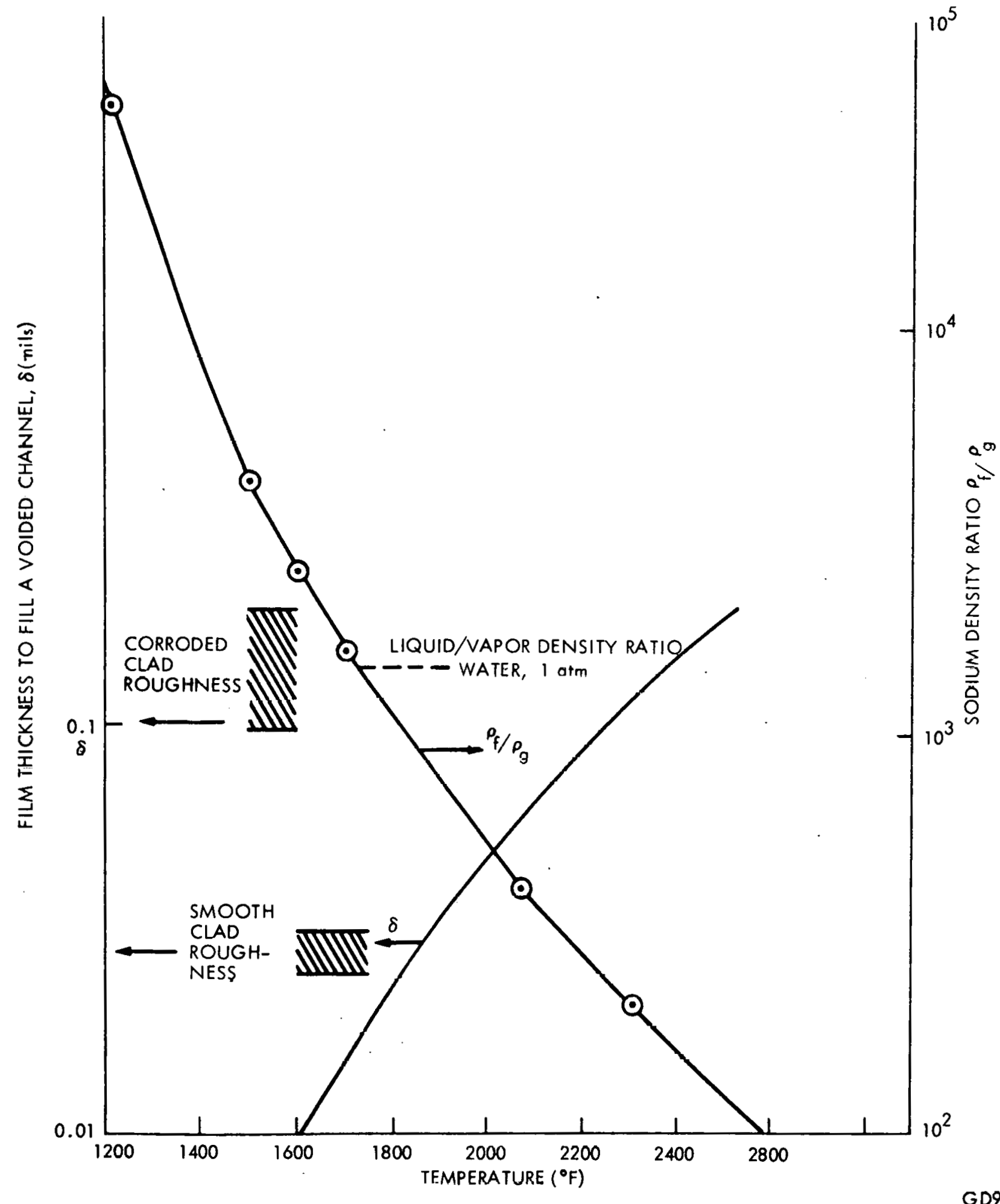

GD9-149

Figure 4-3. Ratio of Sodium Liquid to Vapor Density at Saturation and Liquid Film Thickness to Fill a Voided Channel 
of Section 3 indicates that the heat flux to the sodium is about $200,000 \mathrm{Btu} / \mathrm{h}-\mathrm{ft}^{2}$. The continuation of this heat flux into the liquid film would evaporate a layer $0.1 \mathrm{mil}$ thick in about one millisecond, supporting the contention. of a voiding model at initially constant pressure.

The time response of the core structural components for a step change in surface temperature and no interfacial resistance (infinite Biot modulus) was calculated from Kreith (Ref. 7) and is shown in Figure 4-4. This figure demonstrates that the sodium responds the fastest and the duct the slowest, as expected. The fast response of the sodium together with its lower heat capacity indicates that the sodium will tend to follow closely the steel temperature during voiding and reentry.

Several transient heat transfer cases were studied to characterize the reflector and plenum temperatures following voiding and reentry. The computer code "NAAC" (Ref. 9) was used because of its simplified input allowing rapid turnaround. These cases, detailed in Appendix C, show that the sensible heat carried into the plenum region during voiding quickly raises the steel temperatures at the core exit to near the sodium boiling temperatures $\left(1600\right.$ to $\left.1800^{\circ} \mathrm{F}\right)$, while the temperatures rapidly decrease above the coreplenum interface.

Figure 4-5 shows the plenum temperatures and associated saturation pressures immediately following slug ejection of the sodium in the top half of the core at $400^{\circ} \mathrm{F}$ superheat. The pressure is seen to decrease rapidly above the core reflector interface, whether due to the local clad temperature or the temperature of the lower end of the liquid slug. The saturation pressure corresponding to the average clad temperature exposed to the vapor bubble also decreases rapidly above the core. The presence of this "condenser" results in rapid vapor condensation and decrease in the local pressure causing voiding of the liquid slug. This causes the slug to be driven only part way through the plenum before the velocity decreases to zero.

The following section discusses the next phase of voiding when two-phase flow dominates.

\subsection{TWO-PHASE FLOW CONSIDERATIONS}

Following the voiding of the top half of the core under slug flow conditions, it appears that a two-phase flow regime will follow as described by Le Gonidec, et al. (Ref. 11) and Fauske (Ref. 12). Superheated liquid will be present for a certain length of core as noted in the transient heat transfer results of Section 3. Vaporization at the liquid-vapor interface will cause a dispersed two-phase flow region between the interface and the reflector-plenum "condenser". The limit on the voiding rate may be due to two-phase choking, probably at the core-plenum reflector interface (Ref. 11). However, Fauske (Ref. 3) indicates a heat transfer limit at the interface may also be applicable, based on experiments with Freon II.

The two-phase quality which may be produced at the interface due to flashing of the superheated liquid is found by equating the heat of vaporization to a change in sensible heat of the liquid. At the system pressure of 23 psia, a change of $50^{\circ} \mathrm{F}$ in sodium temperature results in a $1 \%$ quality mixture and a factor of 15 increase in volume. Qualities between 1 and $4 \%$ could be expected immediately following the initial slug expulsion. The limiting flow rates under these conditions are shown in Figure 4-6 after Fauske (Ref. 13). Clearly the flow rates will be lower than the normal liquid flows under design conditions. If choked flow occurs near the liquid-vapor interface at these low qualities, the time to expel the liquid from the lower half of the core is shown in Figure 4.7 and is less than 0.1 sec for the expected qualities. Examination of the temperature profiles below the core centerline reveals that the elevation at which the boiling temperature is reached decreases with time rather slowly. The bottom of the core reaches $1710^{\circ} \mathrm{F}$, the boiling point, at 2.5 seconds after the flow blockage. Since voiding initiates at about 0.75 second the two-phase choked flow can exist at the liquid vapor interface only until the liquid superheat has been relieved. Subsequent voiding will be limited by the temperature transient at the liquid-vapor interface.

Several other conditions influence the rate of voiding, for which no adequate description is available. Above the liquid-vapor interface, continued vaporization will occur because of heat transfer from the hot clad to the two-phase mixture. The effect is an increase in quality, decrease in critical flow rate and significant cooling of the clad.

Within the reflector-plenum region, condensation will tend to maintain a low pressure while the core is continuing at a high saturation pressure. The pressure gradient during this phase of the voiding becomes too complex for hand calculation and requires an integrated heat transfer two-phase flow calculation.

During the later portions of voiding, the quality may approach $100 \%$ on pure vapor flow. These high quality conditions are more amenable to calculation, and were studied brietly. 


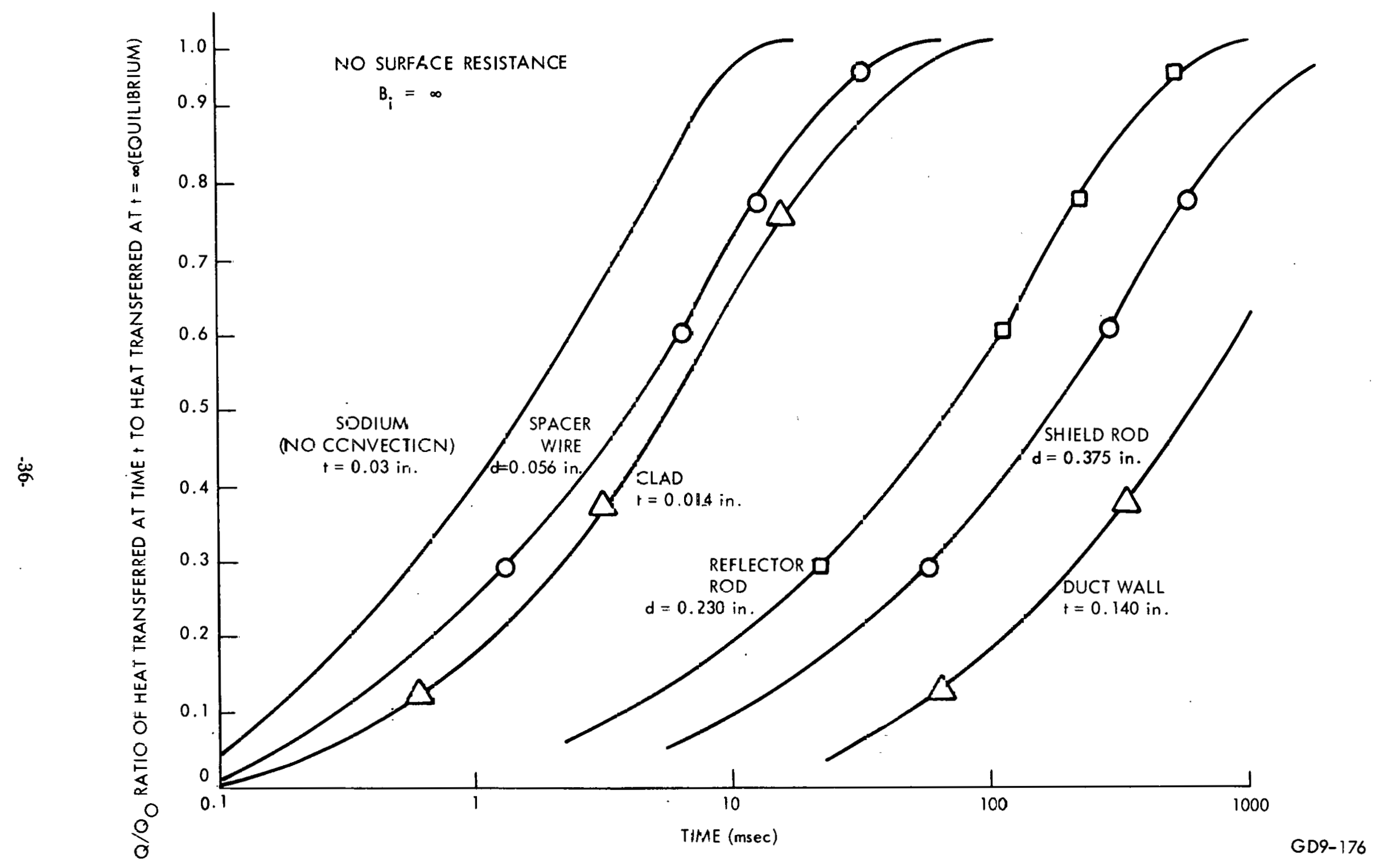

Figure 44. Heated Transjerned; Sudden Change in Envirenmental Temperature 
GEAP-10059

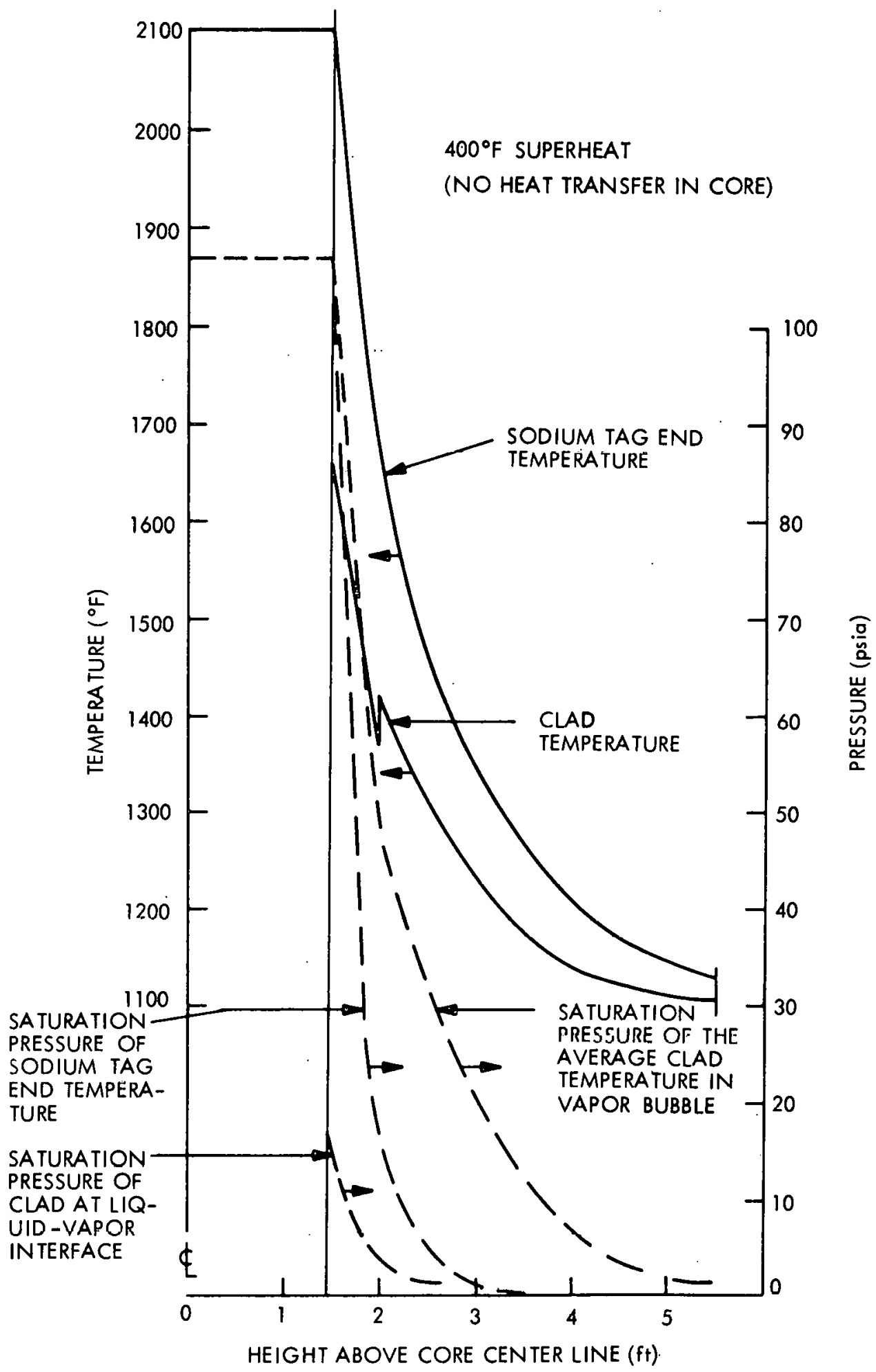

GD9-59

Figure 4-5. Vapor Bubble Pressures and Clad, Sodium Temperatures Following Voiding 
GEAP-10059

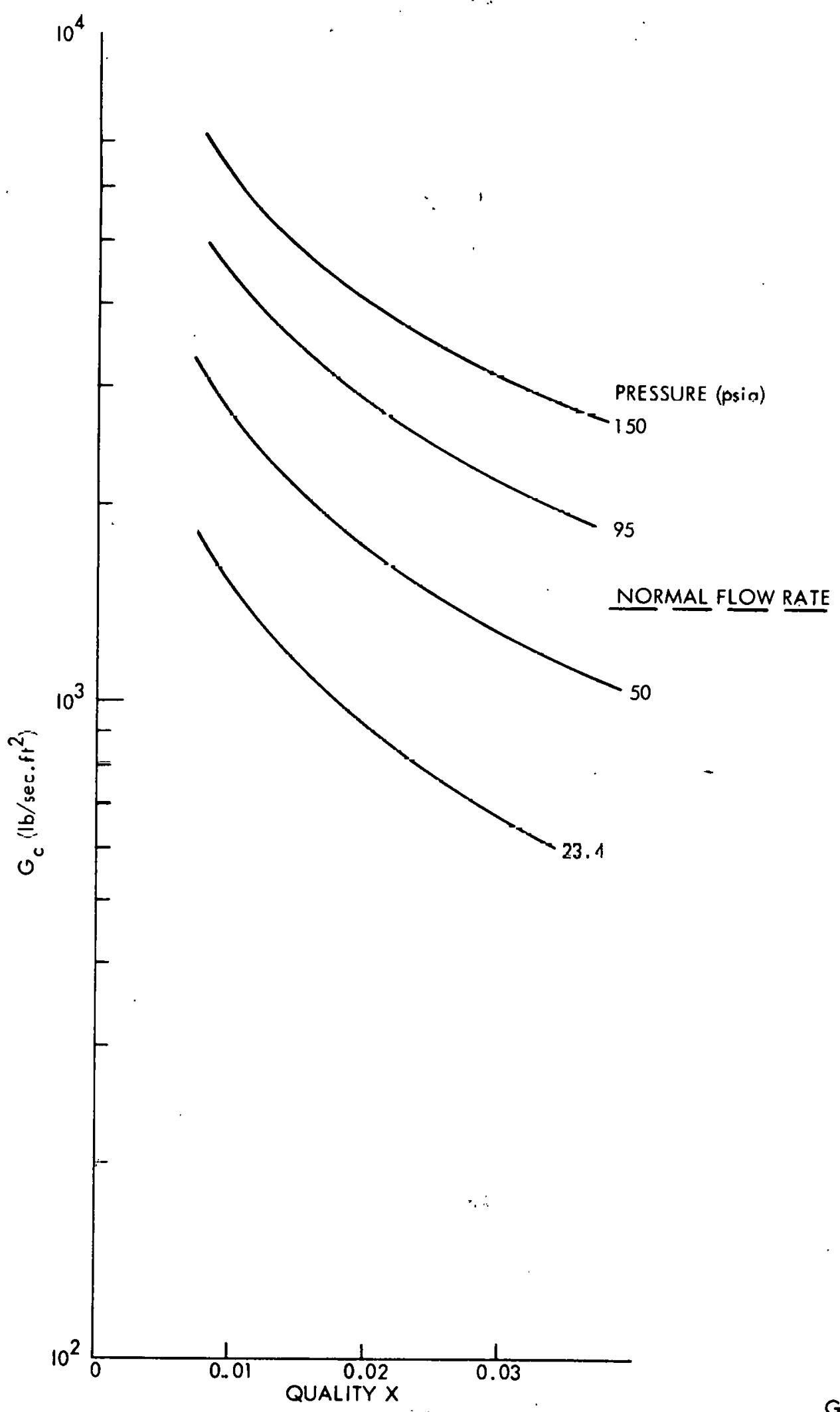

Figure 4-6. Critical Flow Rate in Two-Phase Sodium 


\section{GEAP-10059}

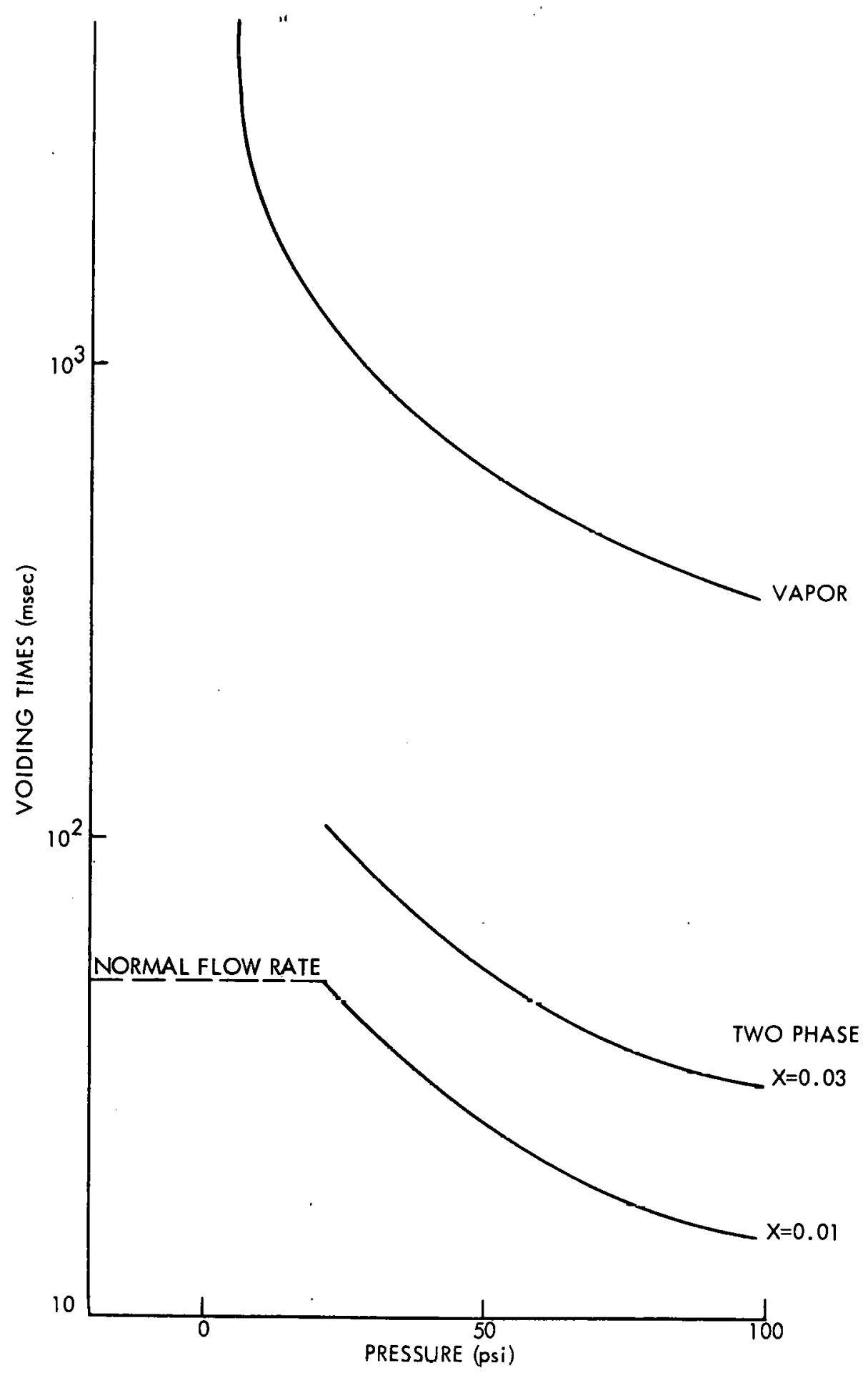

GD9-60

Figure 47. Voiding Times of Core Below Center under Choked Flow 


\subsection{VAPOR FLOW AND HEAT TRANSFER CONDITIONS}

Considering the kinetic theory of gases and the small pin-to-pin spacing in fast reactors, Peppler, et al. (Ref. 10) report that the time constant for pin-to-pin sodium vapor transport is about $4 \times 10^{-6}$ seconds. The vapor should be in equilibrium with the liquid film in the radial direction. This permits analysis of the vapor flow regimes assuming a one-dimensional model of axial variations of temperature. This "heat pipe" regime is then analogous to a condenser problem with a condenser (the reflector and plenum) length to diameter ratio of $\sim 400$. When vapor flow dominates, evapuration from the hot surfaces. and condensation on the colder surfaces leads to axial vapor transport tending to equallze the temperatures and pressures within the sodium vapor bubble.

The limiting rates of vaporization and condensation are shown from kinetic theory to be extremely high for only small differences in liquid and vapor pressures. Figure 4-8 shows the rates of change of film thickness and heat fluxes required under pure vapor conditions. Transient heat transfer between the vapor and clad will not permit sustained high heat fluxes, prohibiting a large pressure difference from developing between a vapor and a wetted wall.

The evaporation and condensation rates are not specifically limited by the sodium phase change phenomenon. Heat flux requirements are much too high to sustain phase change at constant liquid temperatures. The limiting phase change parameter is the steel conductivity for both evaporation and condensation.

Given a change in pressure, a film of sodium will assume a temperature near saturation at that pressure and be evaporated (condensed) by the heat flowing from (to) the steel. A temperature wave proceeds back into the steel to supply (absorb) the phase change energy. The time constant of the clad is quite fast, $\sim 5 \mathrm{~ms}$, and for thin sodium films $(0.1 \mathrm{mil})$ the energy requirements are small $\left(10^{\circ} \mathrm{F}\right.$ change in clad temperature).

After determining that the local radial mass transport rates were apparently determined by heat transfer with the steel, the axial transport of the vapor from the core to the plenum was studied. Figure 4-9 shows the pressure drop due to axial vapor flow through the tube bundle and the critical flow rates. These critical flow rates were used to calculate the time to void the bottom half of the core in pure vapor flow shown on Figure 4-7. The core temperature transient is slow enough to permit even vapor flow during voiding at low pressures. Flow rates during these last stages of voiding will be determined by the thermal transient near the core inlet.

The three regimes of initial core voiding (sub-cooled, nucleate, or film boiling or pure liquid or vapor flow) result in significant axial transport of energy which have not been accounted for in this study for lack of an adequate numerical tool. Qualitatively, the core temperature profile, which is peaked severely under zero flow conditions, may in fact be smoothed markedly by the cooling of the expelled sodium. Clad melting at the center could be delayed until after the core is dry ( $\sim 2.5$ seconds after blockage). The cooling rates depend on the initial superheat, the stability of the sodium expulsion process, and the heat transfer regimes.

To proceed further in this study, the core temperature transient was asșumed undisturherd by the axial heat tranoport due to voiding, establishing the earliest times when hot clad and fuel material would be available for interaction with cold sodium. It is recognized that this conservative assumption may predict grossly incorrect cladding temperatures following core voiding.

\subsection{EFFECT OF FISSION GAS RELEASE}

Irradiated sealed fuel pins at 50,000 MWd/te are expected to fail at between 0.75 and 1.0 second after flow blockage. The primary stress due to fission gas exceeds the material strength in the rangc from $1900^{\circ} \mathrm{F}$ lo $2000^{\circ} \mathrm{F}$. This is the same range as the predicted boiling temperalures, indicating that bursting of irradiatcd pins and voiding will occur nearly simultaneously in this hypothetical accident.

Unirradiated or low burnup pins should not fail until after voiding has occurred. The release of stored fission gas at the core centerline could potentially cause a more rapid ejection of the top liquid slug. Sodium boiling will cease until the core pressure is again below the saturation level. From the results of the single pin fission gas release given in Section 7 , this delay could be of the order of from 0.2 to 0.3 second. After this pressure blowdown time, sodium boiling will commense again, driving the figkion gas upward and out of the fuel assembly.

The reduced sodium condensation on cold surfaces due to the presence of the noncondensible gases is probably more important than this delay in voiding the bottom half of the core. This effect will partially insulate the duct wall and could significantly reduce the duct heat-up rate assumed in Section 3. In addition, the reduced condensation rate should result in a higher liquid level in the plenum region. More "condenser" area must be exposed to absorb the heat transported by sodium two-phase or vapor flow. 
GEAP-10059

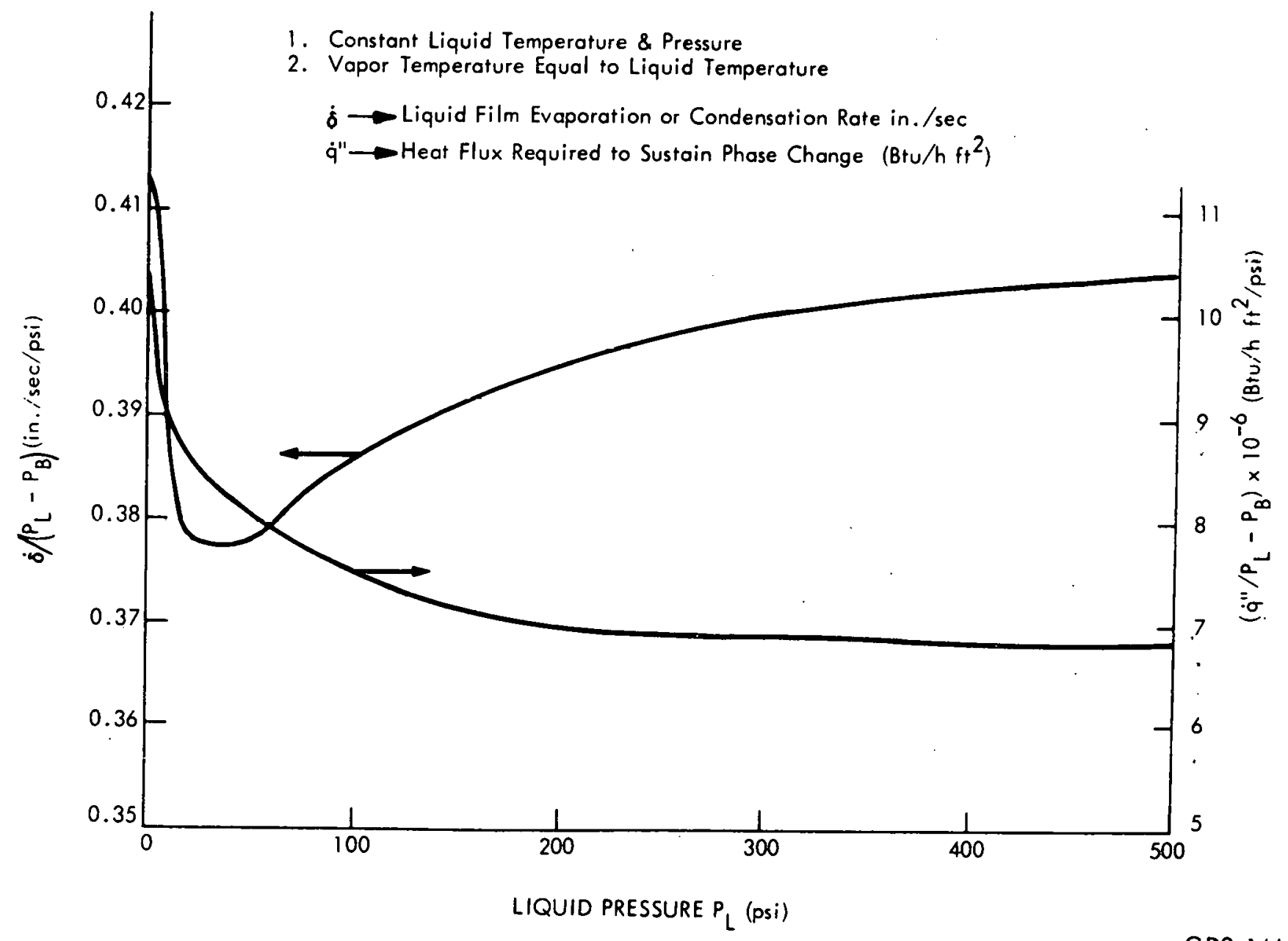

Figure 4-8. Sodium Change of Phase Limits

$-41-$ 


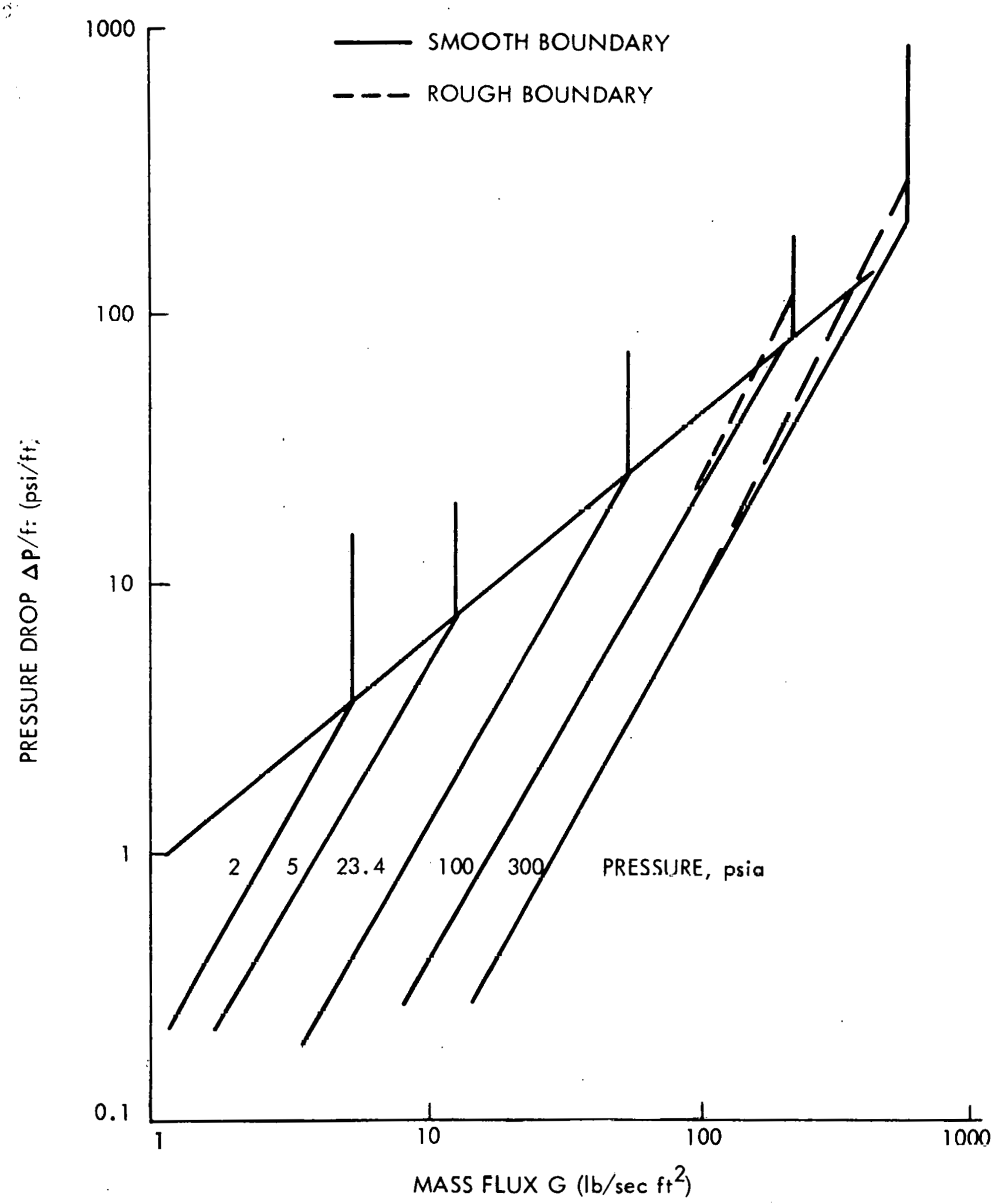

GD9-89

Figure 4-9. Vapor Pressure Drop at Saturation 
The conservative assumption that there is no delay in the heating of the clad or duct due to the presence of the fission gas was made. Development of an overall accident code should include provisions to account for the presence of fission gases.

These remarks concerning the initial core voiding and dryout have been based on several conservative assumptions:

- Neglect the axial heat transport due to core voiding.

- Neglect the presence of fission gases.

- Complete and permanent flow blockage at the inlet.

With the assumptions, it is seen that the core is not dry until about 2.5 seconds after blockage. The first two assumptions will not change this dryout time significantly, but will affect the duct, core and plenum temperature distributions following boiling. The more probable type of accidents involving only partial blockage of flow will always be dominated by two-phase flow regimes because of the continued flow of sodium. The core would never "dry out" and would not be concerned with coolant reentry from the top as in this hypothetical accident analysis.

\subsection{SODIUM REENTRY}

Following core dryout, the possibility exists for a slug flow reentry of sodium into the hot core. A short study was made of voiding and reentry in slug flow for the FFTF geometry. Pressure variations with length above the core center line were estimated from the thermal transients discussed in Appendix C. The results of this study of voiding and reentry are detailed in Appendix D.

The results given in Appendixes $\mathrm{C}$ and $\mathrm{D}$ show that sodium voiding and reentry velocities in slug flow are limitcd.by the frictional and orifice pressure drop above the core. The result is a dampened system in which slug flow "chugging" gradually dies out.

As an example of the calculated reentry behavior an initial superheat of $400^{\circ} \mathrm{F}$ was assumed to show the effect of voiding out both the top and bottom of the core. Pressures acting on the sodium slug were assumed equal to the saturation pressure of the cladding at the liquid vapor interface. Pressures were not changed on subsequent reenteries.

Figure 4-10 shows the velocity and displacement of the liquid-vapor interface as a function of time after boiling starts. Reentry of the liquid slug front proceeds approximately four inches into the enriched fuel region of the core before expulsion starts again. The key assumption for this model is wetting of the hot clad by the sodium, which quickly produces sufficient vapor to pressurize the core. This model also assumes the liquid film in the core has evaporated during the 0.15 second period when the liquid slug is out of the core. This appears reasonable based upon an expected film thickness of $0.1 \mathrm{mil}$.

Considering the most likely superheat and voiding pattern for the blocked flow accident, slug flow reentry might be credible at about 2.5 seconds after blockage. Bccause of the high core temperatures at this time, the assumption of good contact between sodium and hot clad results in essentially zero slug penetration, as shown in Figure 4-11. For this case, the pressure in the reflector and plenum region was assumed to be $4 \mathrm{psi}$ in order to show slug penetration of the core. It is apparent that slug flow will not result in sodium reentry into a hot core.

The coolant thermal-hydraulics study was not continued beyond the slug flow reentry stage because of the lack of a coupled heat transfer, two-phase flow numerical solution. The analysis given in this section has been conservative in the sense of trying to identify the earliest credible times when cold sodium could interact with hot core materials. 


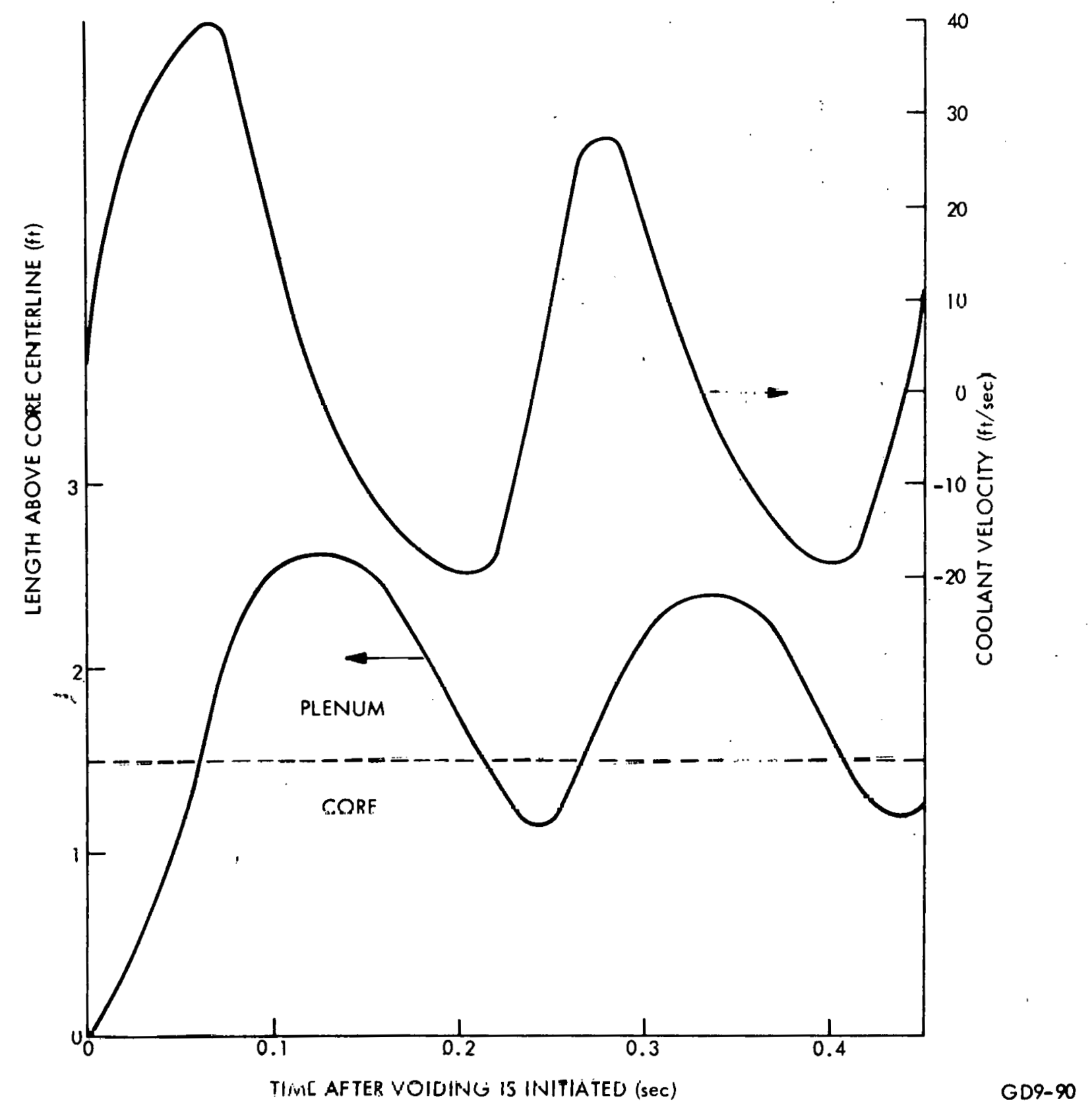

Figure 4-10. Sodium Voiding and Reentry at $400^{\circ} \mathrm{F}$ Superheat 
GEAP-10059

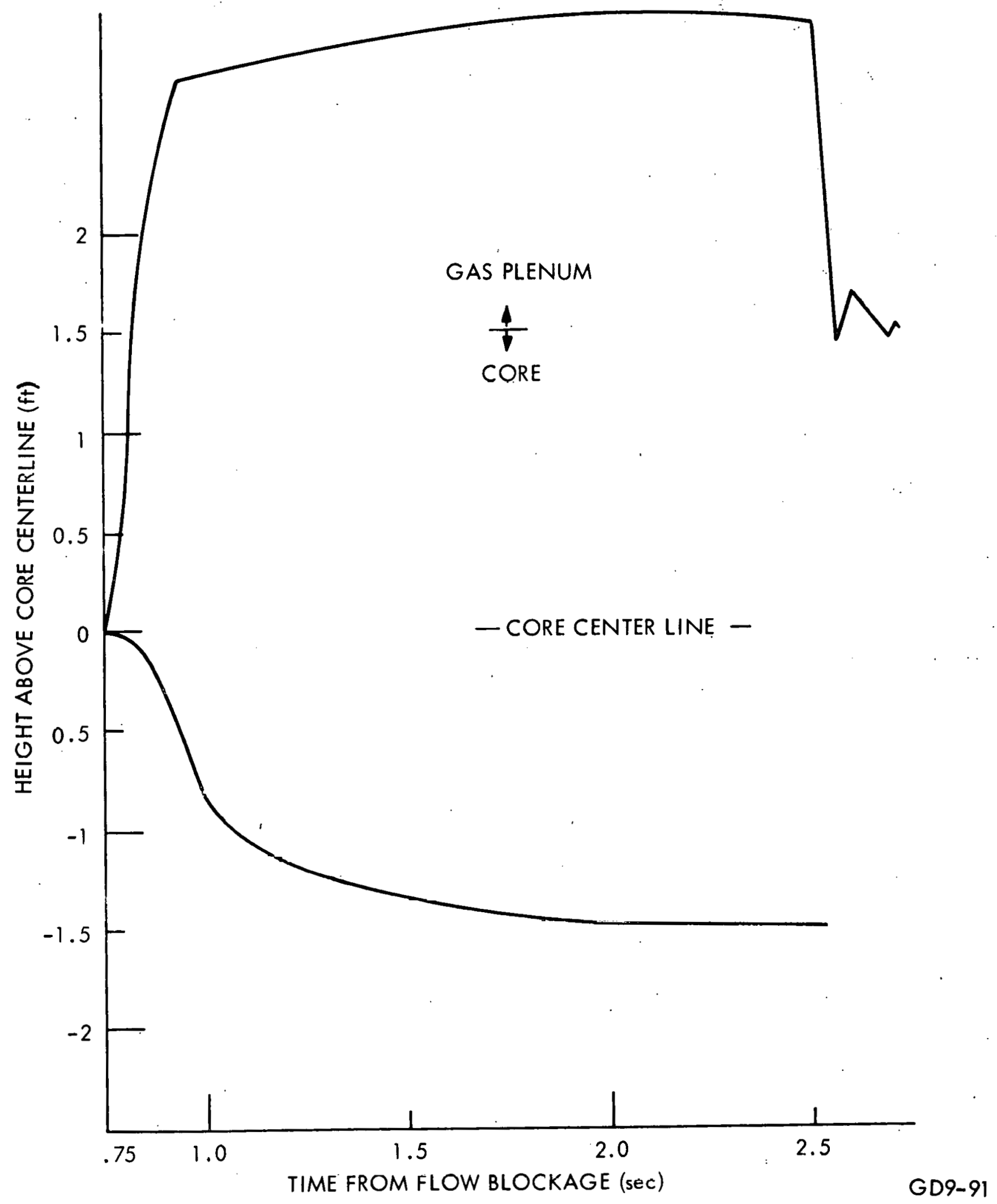

Figure 4-11. Slug Voiding and Reentry at $240^{\circ} \mathrm{F}$ Superheat 


\section{REFERENCES}

1. Fauske, Hans K., Liquid Metal Boiling in Relation to LMFBR Safety Design, Tenth National Heat Transfer Conference, Philadelphia, Penn., August 1968.

2. Chen, J.C., Incipient Boiling Superheats in Liquid Metals, J. of H.T., August 1968, pp. 303-312.

3. Conservation with Hans K. Fauske, Argonne National Laboratory, May 26, 1969.

4. Smith, D., et al., Problems of Sodium Boiling in Fast Reactors, June 1968, (KFK-790).

5. Schlichting, Dr. Hermann. Boundary Lnyer Theory, McGraw-Hill, Inc.., New York, 1960.

6. Conversation with T. Laurizten, General Electric Co., BRDO, May 14, 1969.

7. Conversation with G. Wozadlo, General Electric Co., BRDO, May 20, 1969.
8. Kreith, F., Principles of Heat Transfer, International Textbook Co., Scranton, 1961.

9. Fast Ceramic Reactor Development Program, Seventeenth Quarterly Report, (GEAP-5098), pp. 7-18.

10. Peppler, W., et al., Sodium Boiling and Fast Reactor Safety, International Conference on Fast Reactor Safety, Aix-en-Provence, September 19-22, 1967.

11. LeGonidee, et al., Experimental Studies on Sodium Boiling, International Conference on Fast Reactor Safety, Aix-en-Provence, September 19-22, 1967.

12. Argonnc National Laboratory, Reactor Development

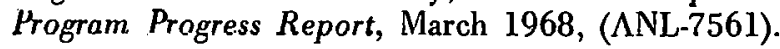

13. Fauske, Hans K., Two-Phase Compressibility in Liquid Metal Systems, International Conference on Fast Reactor Safety, Aix-en-Provence, September 19-22, 1967.

\section{MOLTEN FUEL - SODIUM INTERACTION}

The analysis presented in this section is an attempt to define the upper limit to the energy which may be converted to work during the interaction between hot core materials and the sodium conlant. A great many acoumptions have been made. However, they have all been selected to provide conservative results. Subsequent work in this area, to refine the model, should result in less conservative values.

\subsection{SUMMAR Y OF MOLTEN FUELSODIUM INTERACTION APPROACH}

In analyzing this accident, it is assumed that heating of the core material is accomplished in the absence of coolant and that the hot core materials and coolant are suddenly brought into intimate contact. The liquid hammer effect associated with the deceleration of the coolant is not considered. Immediately upon contact, heat is transferred from the hot core malerial to the coolant. The rate at which this energy is transferred depends upon the thermal properties of the components and the initial temperature difference. Initially, assuming no conțact resistance, the rate of heat transfer will be vcry high and the resulling temperature gradients very steep. Because of this, the heat affected zone will he narrow and, except for extromoly omall "hot particles", treating the system as a one dimensional, semi-infinite solid with constant initial temperatures appears reasonable.

The assumption that the contact resistance is zero, i.e., the coolant immediately wets the hot core material, yields very conservative results. It has not yet been demonstrated that this condition could not exist given the proper circumstances. It appears that this should be a local effect and gross energy transfer under these conditions is highly unlikely. Becausc of this, the heat transfer area will be treated as a parameter and judgment and subsequent experimental evidence can be applied to yield realistic gross results, as discussed in Section 6.

The thermal energy transferred to the coolant can be converted to mechanical energy through two mechanisms. The first of these is the increase in kinetic and potential energy of a thin layer of liquid coolant resulting from the rapid heating of the coolant adjacent to the interface. This energy pulse is very short and is strongly dependent upon the acoustic behavior (compressibility) of the coolant. The energy associated with this pulse is referred to as "acoustic energy" and because of its short duration, is expected to behave in a manner similar to a shock wave. The second mechanism is related to the vapor 
expansion which will result as the initial pressure wave travels away from the interface and the local pressure falls below saturation for the local temperature. The rate of vapor expansion is strongly dependent upon the flow channel geometry and the local temperature gradients. However, it will be orders of magnitude slower than in the case of the acoustic wave. For the vapor to expand, the volume of coolant between the superheated fluid and a free surface, must be set in motion. This motion is inertia limited and the energy available from the vapor expansion is referred to as "inertial energy."

In both cases, work is a path function and cannot be evaluated without a knowledge of the exact process. However, an upper limit to the quantity of work can be determined by investigating the change in entropy and internal energy of the coolant between its initial and final stages (both entropy and internal energy are point functions and do not depend upon the process). This is the approach used to determine the maximum work potential in this analysis.

The work which may be obtained from the expanding coolant is limited by the total heat added during the heat transfer process. This implies that some cut-off mechanism exists which will limit the amount of energy associated with each pulse. The cut-off mechanism chosen for this analysis is the formation of a vapor blanket between the hot core material and coolant. This vapor is assumed to form when the interface pressure drops below saturation. The formation of this vapor phase severely restricts the rate at which heat can be added to the expanding liquid. The reader is referred to reference 1 , plate XII for evidence of this vapor formation. Alternately, the energy added below a minimum pressure will be incapable of performing work on the surrounding structure and, therefore, only the energy added above a minimum threshold pressure is effective in performing work.

The exact shape of the pressure pulse is unknown, but the average pressure behind the pressure front can be obtained. As long as the pressure wave retains the classical pressure wave shape (and there is no reason to believe this should be different), the pressure at the interface will be less than the average pressure (Figure 5-1). Using the average pressure as the interface pressure will result in a conservative estimate of the amount of energy transferred.

The acoustic and inertial energies calculated by this method represent the maximum energy which can be converted to work under ideal conditions for a system operating between the given limits. The actual amount of energy available to do work will be less than this by the degree of irreversibility of the process.

\subsection{CONCLUSIONS}

A number of preliminary conclusions can be drawn from the work in this section. These include:

- The energy which can be converted to work by the coolant will be significantly less than that calculated by the other techniques presently being used (Table 5-1).

- The acoustic pulse (shockwave) has the potential for delivering considerably more energy to the structure than is possible with the inertial pulse (expanding vapor). The reason for this is that the severe temperature gradients result in relatively small quantities of coolant being heated to temperatures greater than saturation during periods of high local pressure. This is not to say that the shock wave will necessarily deliver this greater amount of energy. However, the potential is clearly indicated. (Table 5-1.)

- The potential for transferring energy to the coolant is greater for the case of a clad-coolant system than for a fuel-coolant system because of the higher cladding thermal conductivity.

\subsection{THE HEAT TRANSFER PROCESS}

The heat transfer analysis begins by considering a one dimensional semi-infinite solid with the initial temperature in the fuel region $(X<0)$ equal to $\mathrm{T}_{\mathrm{F}_{\mathrm{o}}}$ and the initial temperature in the coolant region $(X>0)$ equal to $\mathrm{T}_{\mathrm{C}_{\mathrm{o}}} \cdot$ 
FUEL $\longrightarrow$ COOLANT
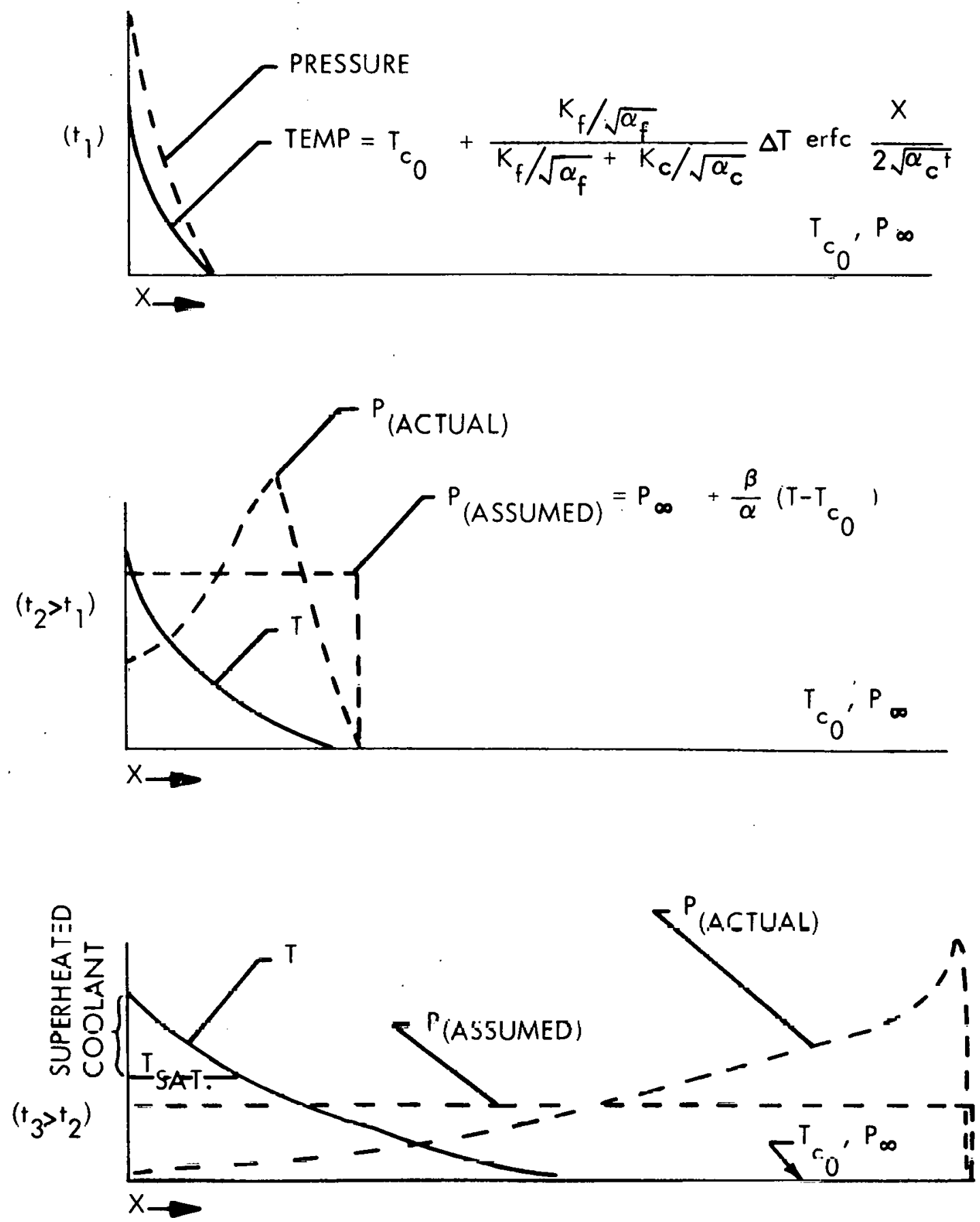

Figure 5-1. Assumed Pressure Wave Generation Characteristics 


\section{Table 5-1}

COMPARISON OF DIFFERENT CALCULATIONAL METHODS

FOR A REPRESENTATIVE INTERACTION

\author{
This Analysis \\ (Fuel Sphere Radius $=0.0016$ in.) \\ $0^{\circ} \mathrm{F}$ Superheat \\ $250^{\circ} \mathrm{F}$ Superheat
}

Peak

Acoustic

Pressure

1,015 atm

1,015 atm

$520 \mathrm{~atm}$

100,000 atm

Peak

Serondary

Pressure

$33 \mathrm{~atm}$

33 atm

$520 \mathrm{~atm}$

7,500 atm

Acoustic

Encrgy . . 160 in.-lb/gm Fuel

290 in.-lb/gm Fuel

$2710 \mathrm{in} .-\mathrm{lb} / \mathrm{gm}$ Fuel

17,700 in.-lb/gm TNT

Inertial

Energy . . . 14 in.-lb/gm Fuel

25 in.-lb/gm Fuel

$2710 \mathrm{in} . \mathrm{lb} / \mathrm{gm}$ Fuel

14,150 in.-lb/gm TNT

Initial

Time

Scale ... $4.6 \times 10^{-7} \mathrm{sec}$

$1.5 \times 10^{-6} \mathrm{sec}$ $\sim 10^{-4} \mathrm{sec}$

It is necessary to set up solutions to the energy equations of the type $(3)$

$$
\begin{aligned}
& \mathrm{T}_{1}=\mathrm{A}_{1}+\mathrm{B}_{1} \operatorname{erf} \frac{|\mathrm{X}|}{2 \sqrt{\mathrm{a}_{1} t}} \mathrm{X}<0 \\
& \mathrm{~T}_{2}=\mathrm{A}_{2}+\mathrm{B}_{2} \text { erf } \frac{\mathrm{X}}{2 \sqrt{\mathrm{a}_{2} t}} \mathrm{X}>0
\end{aligned}
$$

These solutions satisfy the differential equations for heat conduction in their respective regions. The constants $A_{1}, B_{1}, A_{2}$, $B_{2}$ are chosen to satisfy the initial and boundary conditions.

The former give

$$
\begin{aligned}
& A_{1}+B_{1}=T_{F_{o}} \\
& A_{2}+B_{2}=T_{c_{0}}
\end{aligned}
$$

The latter give

$$
\begin{aligned}
& A_{1}=A_{2} \\
& B_{1} k_{1}\left(a_{1}\right)^{-1 / 2}=-B_{2} K_{2}\left(a_{2}\right)^{-1 / 2}
\end{aligned}
$$


Where $\mathrm{a}=$ Thermal Diffusivity and $\mathrm{k}=$ Thermal Conductivity.

Solving these equations and substituting into the original equations gives

$$
\begin{aligned}
& \mathrm{T}_{\mathrm{F}}=\Phi\left(\mathrm{T}_{\mathrm{F}_{o}}-\mathrm{T}_{\mathrm{c}_{o}}\right)\left[\mathrm{l}+\frac{\mathrm{k}_{\mathrm{c}} / \sqrt{\mathrm{a}_{c}}}{\mathrm{k}_{\mathrm{F}} / \sqrt{\mathrm{a}_{F}}} \operatorname{erf}\left(\frac{\mid \mathrm{X} L}{2 \sqrt{\mathrm{a}_{\mathrm{F}} \mathrm{t}}}\right)\right]+\mathrm{T}_{\mathrm{c}_{o}} \\
& \mathrm{~T}_{\mathrm{c}}=\Phi\left(\mathrm{T}_{\mathrm{F}_{o}}-\mathrm{T}_{\mathrm{c}_{o}}\right)\left[\operatorname{erfc}\left(\frac{\mathrm{X}}{2 \sqrt{\mathrm{a}_{c} t}}\right)\right]+\mathrm{T}_{c_{o}}
\end{aligned}
$$

where

$$
\Phi \equiv \frac{k_{F} / \sqrt{a_{F}}}{k_{F} / \sqrt{a_{F}}+k_{c} / \sqrt{a_{c}}}
$$

The coolant temperature, $\mathrm{T}_{\mathrm{c}}$, is thus defined in time and space as a function of the initial temperature and thermal properties. Equation 2 can be solved for the fuel-coolant interface temperature by setting $X=0$.

$$
\mathrm{T}_{\text {interface }}=\Phi\left(\mathrm{T}_{\mathrm{F}_{\mathrm{o}}}-\mathrm{T}_{\mathrm{c}_{\mathrm{o}}}\right)+\mathrm{T}_{\mathrm{c}_{\mathrm{o}}}
$$

From this it can be seen that the interface temperature is constant for all $t>0$.

Equation 2 can also be manipulated to yield the average coolant temperature between the fuel-coolant interface and a point a distance $\bar{X}$ from this interface.

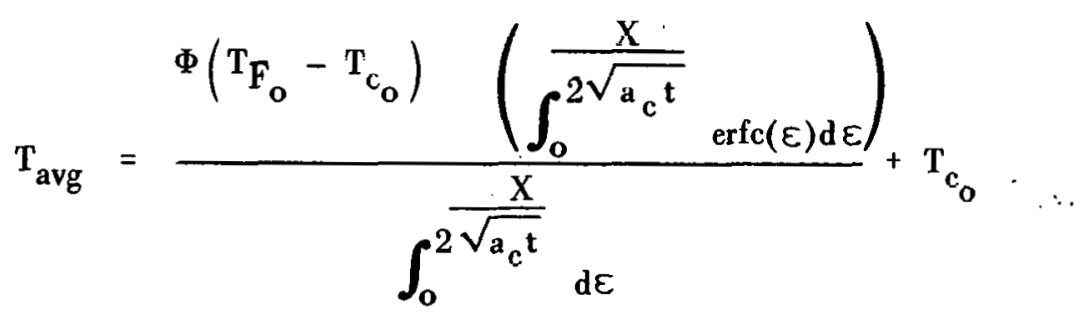

Two other useful relationships can be developed by observing that

$$
\operatorname{erfc}\left(\frac{X}{2 \sqrt{a_{0} t}}\right) \rightarrow 0 \text { as }\left(\frac{X}{2 \sqrt{a_{c} t}}\right) \rightarrow 4
$$

The thickness of the "heated coolant" layer at any time " $t$ " is given by

$$
X_{\text {Film }}=8 \sqrt{a_{c} t}
$$

The velocity of propagation of the "heated front" at time " $t$ " is given by

$$
\frac{d x}{d t}=4 \sqrt{\frac{d a c}{t}}
$$




\subsection{WORK POTENTIAL}

Equations one through six define the thermal behavior of the coolant as long as the contact coefficient between the fuel and coolant is infinite. For most practical cases, the interface temperature (Equation 3) is above the saturation temperature for the ambient pressure, $\mathrm{P}_{\infty}$. However, because the velocity of propagation of a pressure wave in the sodium is not infinite, the local pressure will be greater than $\mathbf{P}_{\infty}$ until the pressure wave reaches the coolant boundary. The average local pressure can be estimated as follows:

$$
\begin{aligned}
& \left(\frac{d p}{d T}\right)_{V}=\frac{(\partial v / \partial T)_{P}}{(\partial v / \partial T)_{T}} \\
& P_{A v g}-P_{\infty}=\frac{(\partial v / \partial T)}{(\partial v / \partial P)}\left(T_{A v g}-T_{c_{o}}\right) \\
& P_{A v g}=\frac{(\beta)}{(a)}\left(T_{A v g}-T_{c_{o}}\right)+P_{\infty}
\end{aligned}
$$

Where $\frac{1}{v}\left(\frac{\partial v}{\partial T}\right)=$ Thermal Expansion Coeff. $(\beta)$

$$
-\frac{1}{v}\left(\frac{\partial v}{\partial \mathrm{P}}\right)=\text { Compressibility }(a)
$$

The rapid increase in coolant temperature, near the fuel, is expected to result in the formation of a pressure wave. Initially, the propagation velocity of the "heated front", Equation 6 , is greater than the "sonic velocity" in the coolant. This results in the formation of a very high local pressure. Eventually, the shock wave velocity will exceed the "heated front" velocity and the local pressure will decrease. When the pressure at the fuel-coolant interface drops below saturation, voiding is initiated and heat transfer to the coolant severely reduced.

For the purpose of this analysis, it is assumed that following voiding, no heat is transferred into the coolant nor is any heat allowed to flow down the very steep temperature gradient in the coolant. Also, it is assumed that the pressure everywhere ahead of the shock front is equal to $P_{\infty}$ while the pressure everywhere behind the shock front is equal to $P_{\text {avg }}$, (where $P_{\text {avg }}$ is a function of time). Roth of these assumptions are felt to be conservative (i.e., result in a high estimate of energy input to the coolant.) The latter may be overly conservative and deserves some further analysis, (Figure 5-1).

\subsection{ACOUSTIC ENERGY}

From the first law of thermodynamics, the work $d^{\prime} w$, done when a system performs any infinitesimal process. reversible or irreversible, between two equilibrium states, is:

$$
d^{\prime} \mathbf{w}=-d u+d^{\prime} \mathbf{q}
$$

That is, the energy converted to work is equal to the heat provided by reservoirs with which the system is in contact and which gives up a quantity of heat $d^{\prime} q$, minus the increase in the internal energy of the system.

The quantitics $d^{\prime} w$ and $d^{\prime} q$ are inexact differentials, which is another way of saying, that $w$ and $q$ are not properties of the system and that the integrals of $d^{\prime} w$ and $d^{\prime} q$ cannot be expressed as the difference between two quantities which depend only on the end poinls of the path of integration. 
The expression for the maximum amount of work that can be obtained when a system undergoes a process between two equilibrium states can now be derived. In this case, it is assumed that the system (the coolant) exchanges energy with a single reservoir (the fuel) at the interface temperature. ( $\left.\mathrm{T}_{\text {interface }}\right)$.

From the principle of increase of entropy, the sum of the increase of entropy of the system, ds, and that of the surroundings, $\mathrm{ds}_{\mathrm{o}}$, is equal to or greater than zero.

$$
\mathrm{ds}+\mathrm{ds} \mathrm{o}_{\mathrm{o}} \geqq 0
$$

$\ldots, \cdot r$

Since $\mathbf{d}^{\prime} \mathbf{q}$ represents heat flowing out of the reservoir, the entropy change of the reservoir is

$$
\begin{aligned}
& d s_{0}=-\frac{d^{\prime} q}{T_{\text {interface }}} \\
& d s-\frac{d^{\prime} q}{T_{\text {irterface }}} \geqq 0 \\
& T_{\text {interface }} d s \geqq d^{\prime} q
\end{aligned}
$$

Therefore, from the first law:

$$
d^{\prime} w \leqq T_{\text {interface }} d s-d u
$$

Where the quantities $u$ and $s$ (internal energy and entropy respectively) are properties of the system and $\mathrm{T}_{\text {inlerface }}$ is a constant.

Since entropy is a property of the system, the change in entropy of the coolant will depend only upon the end points. The average temperature of the coolant behind the shock front, at the time the local pressure reaches saturation, can be obtained from Equation 4. The same final conditions (temperature and pressure) will be obtained if sufficient heat were added to increase the temperature of the coolant behind the shock front by $\left(\mathrm{T}_{\mathrm{avg}}-\mathrm{T}_{\mathrm{c}_{0}}\right)$ in a constant volume process. The entropy change is therefore:

$$
d s=C_{v} \frac{d T}{T}
$$

The internal energy change "du" is also a property of the system. The increase in internal energy at the end of the constant volume heat addition is:

$$
\mathrm{du}_{1}=\left(\frac{\partial \mathrm{u}}{\partial \mathrm{T}}\right)_{\mathrm{v}} \mathrm{dT} \text {. }
$$

The coolant is in a compressed state and a portion of this energy can be converted to useful work in the shock wave. The change in internal energy for an isentropic expansion is given by:

$$
\begin{aligned}
& d u_{2}=\left(\frac{\partial u}{\partial T}\right)_{v} d T+\left(\frac{\partial u}{\partial v}\right)_{T} d v \\
& d T=\left(\frac{\partial T}{\partial v}\right)_{s} d v \\
& d u_{2}=\left(\frac{\partial u}{\partial v}\right)_{T} d v+\left(\frac{\partial u}{\partial T}\right)_{v}\left(\frac{\partial T}{\partial v}\right)_{s} d v
\end{aligned}
$$


The total increase in internal energy is, therefore, given by:

$$
\begin{aligned}
& d u=d u_{1}+d u_{2} \\
& d u=\left(\frac{\partial u}{\partial T}\right)_{v} d T+\left[\left(\frac{\partial u}{\partial T}\right)_{v}\left(\frac{\partial T}{\partial v}\right)_{s}\right] d v+\left(\frac{\partial u}{\partial v}\right)_{T} d v
\end{aligned}
$$

Substituting

$$
d u=c_{v} d T+c_{v}\left(-\frac{c_{p}-c_{v}}{\frac{\beta}{\rho} c_{v}}\right) d v+\left(\frac{c_{p}-c_{v}}{\frac{\beta}{\rho}}-p\right) d v
$$

$d u=c_{v} d T-p d v B t u / l b m$

Equation 8, therefore, becomes:

$$
d^{\prime} w \leqq T_{\text {interface }} d s-c v^{d T}+p d v
$$

Integrating:

$$
\begin{aligned}
& w \leqq T_{\text {interface }} c_{v} \ln \left(T_{\text {avg }} / T_{c_{o}}\right)-c_{v}\left(T_{\text {avg }}-T_{c_{o}}\right)+\int_{v_{1}}^{v_{2}} \text { pdv } \\
& w \leqq T_{\text {interface }} c_{v} \ln \left(T_{\text {avg }} / T_{c_{o}}\right)-c_{v}\left(T_{\text {avg }}-T_{c_{o}}\right)+\frac{P_{\text {sat }}-P_{\infty}}{2} \Delta v \\
& w \leqq T_{\text {interface }} c_{v} \ln \left(T_{\text {avg }} / T_{c_{o}}\right)-c_{v}\left(T_{\text {avg }}-T_{c_{o}}\right)+\frac{P_{\text {sat }}-P_{\infty}}{2} \frac{a}{\rho}\left(P_{\text {sat }}-P_{\infty}\right)
\end{aligned}
$$

Since pressure is a function of the temperature, Equation $y$ can be written as:

$$
w \leqq T_{\text {interface }} c_{v} \ln \left(\frac{\frac{P a}{\beta}+T_{c_{o}}}{T_{c_{0}}}\right)-c_{v}\left(\frac{P a}{\beta}\right)+\frac{P}{2(778)}\left(\frac{P a}{\rho}\right) \frac{B t u}{\mathrm{lbm}}
$$

Where $P=$ saturation pressure $-P_{\infty}\left(l b / f^{2}\right)$

$$
\begin{aligned}
\beta & =\frac{1}{v}\left(\frac{\partial v}{\partial \mathrm{T}}\right)_{\mathrm{P}} 1 /{ }^{\circ} \mathrm{F} \text { (Coefficient of Thermal Expansion) } \\
a & =\frac{1}{\mathrm{v}}\left(\frac{\partial \mathrm{v}}{\partial \mathrm{P}}\right)_{\mathrm{T}} \mathrm{ft}^{2} / \mathrm{lb} \text { (Compressibility) } \\
\mathrm{T} & =\text { Temperature }{ }^{\circ} \mathrm{R}
\end{aligned}
$$


The work calculated above results in the acceleration of the coolant in a very thin layer adjacent to the fuel. Initially, this disturbance propagates at velocities greater than the sonic velocity in the coolant. Since the coolant is not able to accommodate this expansion instantaneously, high local pressures are generated. The high pressures associated with this compression are relieved by an intensive pressure wave and an outward motion of the coolant. The resulting steep fronted wave is described as the "shock wave."

\subsection{INERTIAL ENERGY}

As the shock wave travels away from the fuel-coolant interface, the local pressure is reduced. When the initial coolant temperature is high enough, this reduction in pressure will result in partial vaporization of the coolant.

It has been assumed that heat transfer into the coolant is interrupted at the onset of vaporization, therefore, the maximum heat available to vaporize the coolant is equal to the coolant internal energy in excess of the internal energy at saturation:

$$
d^{\prime} \mathbf{q}=d \mathbf{u}
$$

Suhstituting

$$
\begin{aligned}
& \mathbf{d}^{\prime} \mathbf{q}=c_{v} \mathrm{dT}+\left(\frac{\beta \mathrm{T}}{a}-\rho\right) \mathrm{dv} \\
& \left.\mathbf{q}=c_{\mathbf{v}}\left[\mathrm{T}_{(\mathrm{avg}}>\mathrm{T}_{\text {sat }}\right)-\mathrm{T}_{\text {sat }}\right]+\left(\frac{\left.\beta \mathrm{T}_{(\mathrm{avg}}>\mathrm{T}_{\text {sat }}\right)}{a}-\rho\right) \Delta \mathrm{v}_{\mathrm{f}} B \mathrm{Btu} / \mathrm{lbm}
\end{aligned}
$$

The amount of coolant that can be vaporized by the addition of this amount of heat is given by:

$$
X=\frac{q}{\underline{h}_{f g}}
$$

The work performed by the expanding vapor is given by:

$$
w=\int_{v_{f}}^{v_{g}} P d v
$$

Since internal energy is a property of the system and $q$ is equal to $\Delta u$, this equation may be replaced by:

$$
\begin{aligned}
& w=\left(u_{f o}-u_{f}\right)+\left(u_{f}-u_{g}\right) \\
& w=u_{f o}-u_{g}
\end{aligned}
$$

In this case, it can be seen that the work depends only upon the end status and not the path. In other words, any process between the same end points will result in the same quantity of work being performed. If it is assumed that the process con-

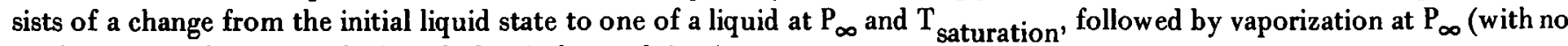
work being performed in the liquid phase) the work is:

$$
w=P_{\infty}\left(v_{g}-v_{f}\right)_{P_{\infty}}
$$


For a quality $\chi$ :

$$
w=\frac{P_{\infty} \cdot \chi\left(v_{g}-v_{f}\right)}{778} P_{\infty} \frac{B t u}{l b m}
$$

\subsection{RESULTS}

Several cases were investigated in which the initial temperatures, superheat and material properties were varied. The results of this investigation are presented in Figures 5-2 through 5-5.

Figure 5-2 illustrates the effect of coolant superheat on the quantity of energy which can be converted to work by the expanding liquid. As the superheat increases, the time required for vapor formation increases and as a result, a larger quantity of heat is added to the coolant. It is important to notice that the average pressure behind the shock front (at the time vapor formation begins) is quite low for high values of superheat. This implies that a large portion of the energy is available at very low pressure and may not be capable of performing work on the structure.

Figure 5-3 demonstrates the effect of varying initial coolant temperature. As can be seen, a reduction in the initial coolant temperature results in an increase in the energy available to do work. Here again, the final average pressure is very low for low initial coolant temperatures and it is doubtful that the acoustic energy shown in Figure 5-3, for very low coolant temperatures, will actually be available to do work on the reactor structure.

Figures 5-4 and 5-5 illustrate the effect of initial fuel and clad temperature. From those curves, it can be seen that clad material is more effective than fuel at generating significant acoustic energy pulses. The flattening of the acoustic energy curve at high initial fuel and clad temperature is attributed to the rapid increase in vapor pressure which results in a reduction of the time during which energy is being transferred.

Several cases were analyzed in which the sensitivity of results to variations in key parameters was determined. The purpose was to determine if minor variations in a particular parameter could result in large variations in the calculated maximum energy. The results of this study are presented in Figure 5-6. It can be seen that fuel parameters have the smallest effect on the energy input while the coolant heat capacities $C_{p}$ and $C_{v}$ ) have the greatest influence.

\section{REFERENCES}

1. Cole, R.H., Underwater Explosions, Princeton University Press, Princeton New Jersey, 1948.

2. Hicks, E.P., and Menzies, D.C., Theoretical Studies on the Fast Reactor Maximum Accident, October 1965, (ANL-7120).
3. Carslaw, H.S. and Jaeger, J.C., Conduction of Heat in Solids, Oxford Press, London, 1959.

4. Lee, J.F., and Sears, F.W., Thermodynamics, Addison-Wesley Publishing Co. Inc., Reading, Massachusetts, 1.956. 


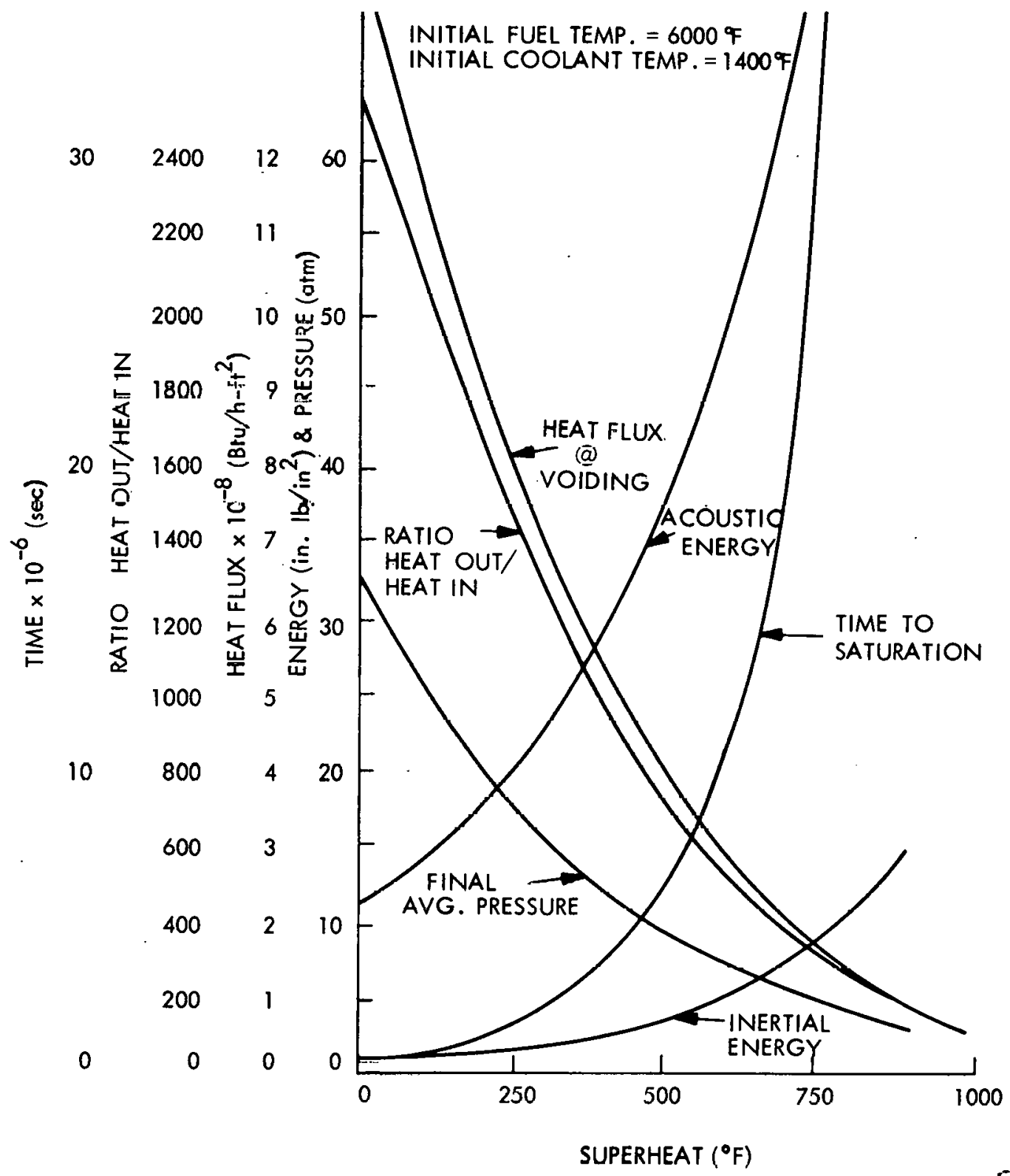

GD9-150

Figure 5-2. Various Parameters Versus Superheat 
GEAP-10059

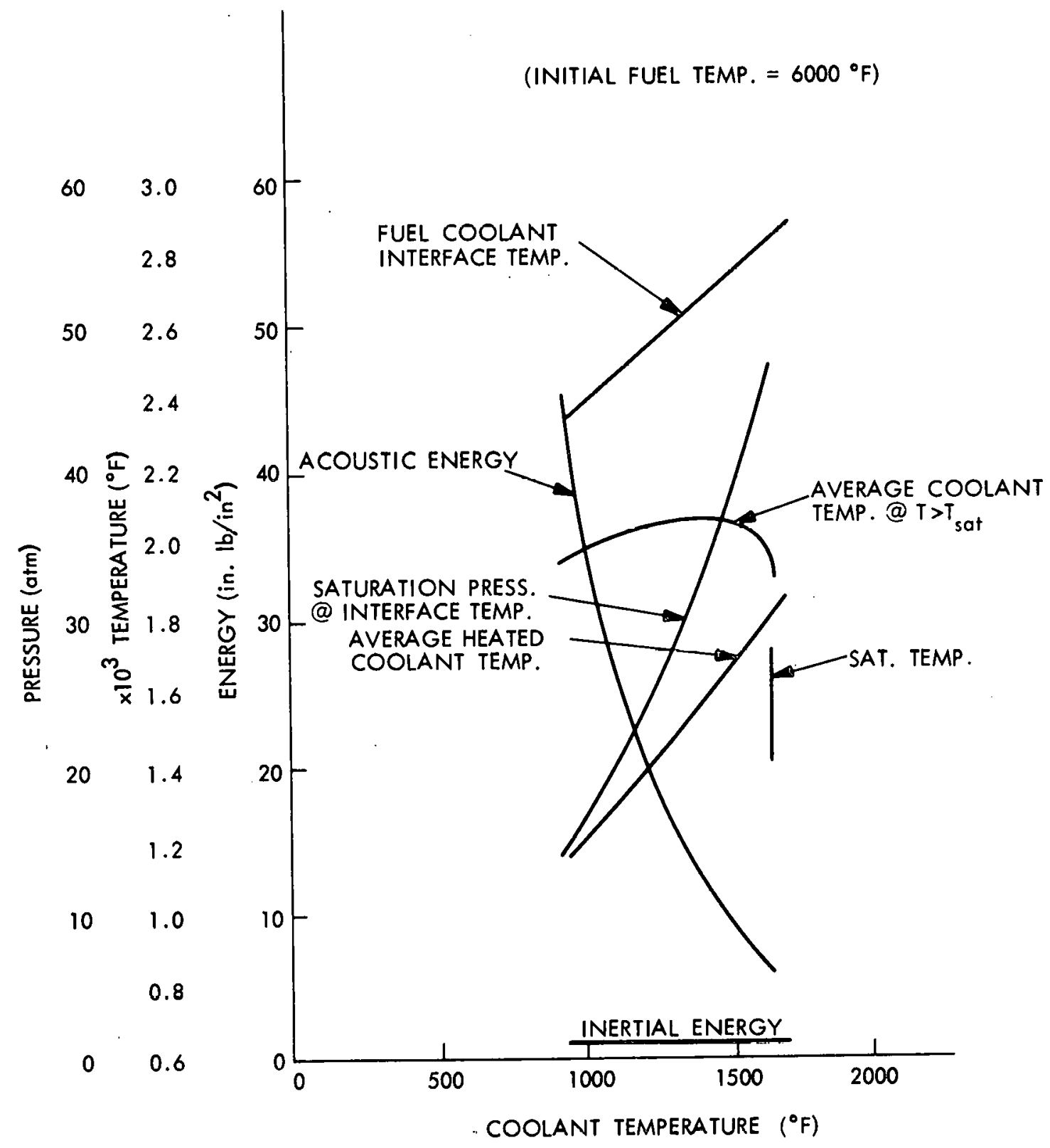

GD9-93

Figure 5-3. Various Parameters Versus Initial Coolant Temperature 


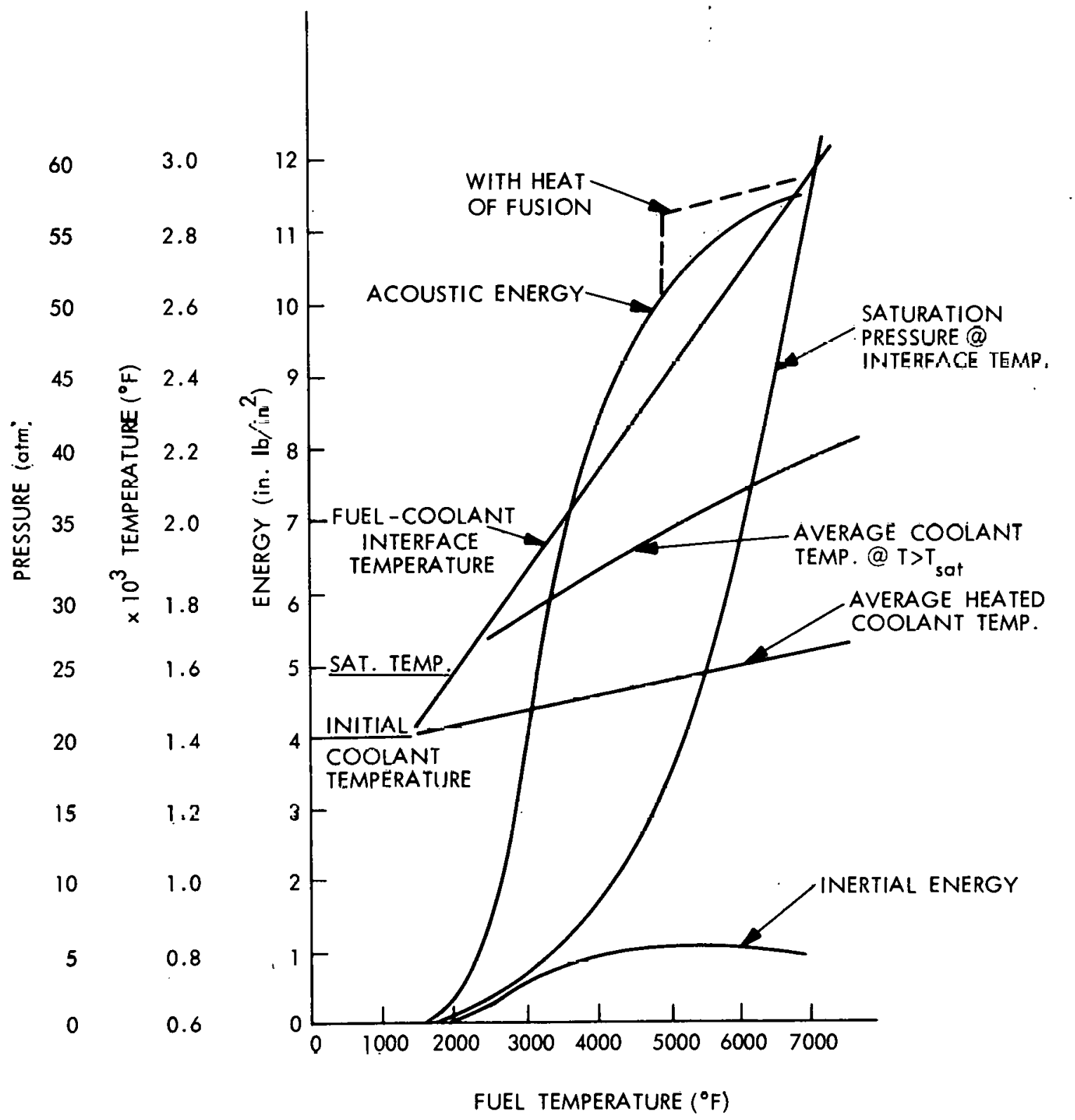

G.59-179

Figure 5-4. Various Parameters Versus Initial Fuel Temperature 


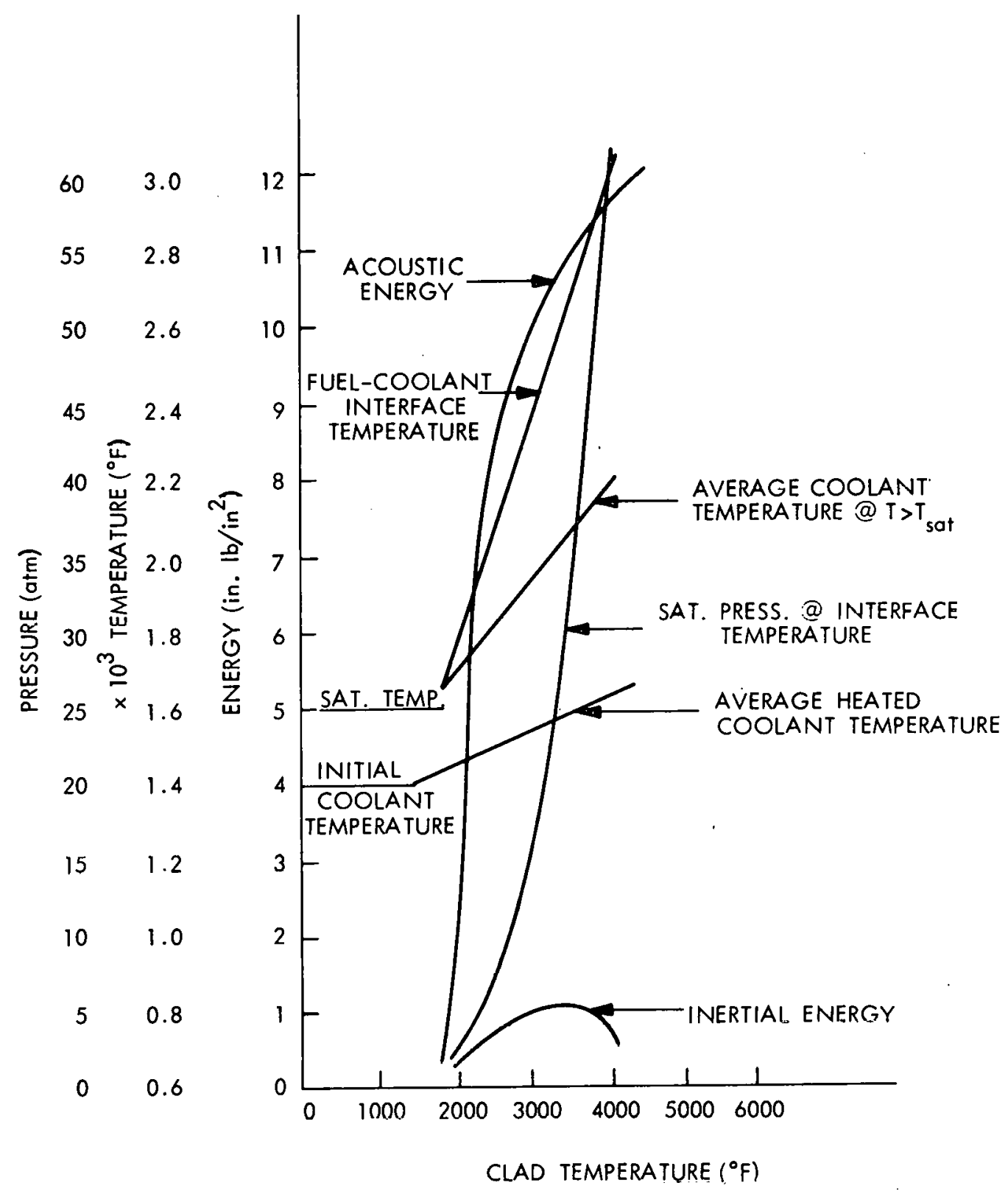

GD9-94

Figure 5-5. Various Parameters Versus Initial Clad Temperature 


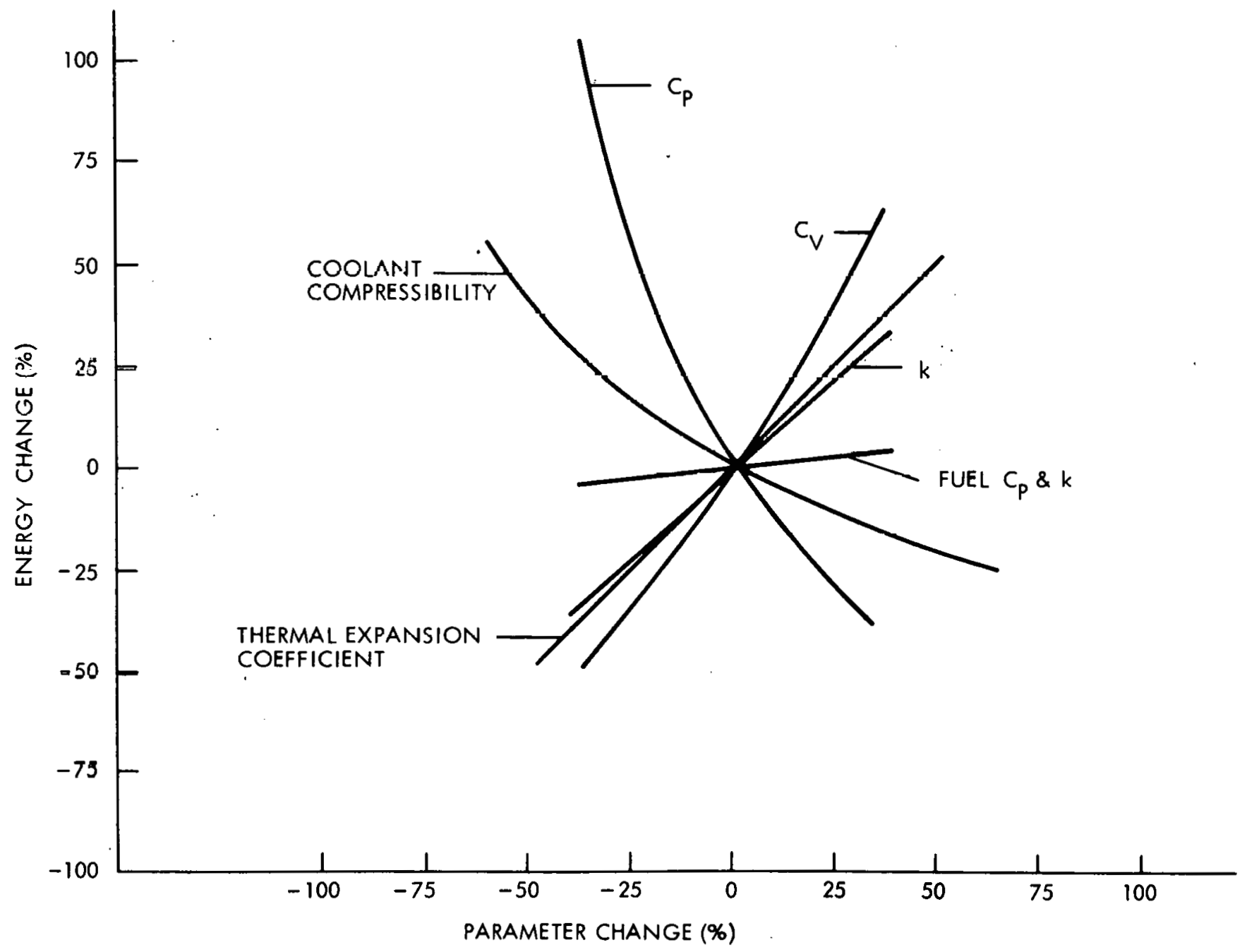

GD9-95

Figure 5-6. Variation in Calculated Energy Conversion Versus Variation in Key Parameters 


\section{STRUCTURAL LOADING ANALYSIS OF FUEL DUCT}

Analysis of the FFTF fuel duct response to the hypothetical flow blockage accident considered the following aspects:

- Shock loading of duct

- Deflection of an unirradiated duct

- Deflections of an irradiated duct

The duct deflection analysis has assumed a uniformly loaded duct wall and uniform temperatures. Deflection calculations assume a static load on the duct.

The derivation of the acoustic energy generated from interaction of hot core materials and cold sodium, described in Section 5 , forms the starting point for this duct analysis. Beginning with the partition of this energy to the wall, the analysis has shown the deflections to be expected in general and applied the results to the FFTF duct for this particular hypothetical accident.

\subsection{SHOCK LOADING OF DUCT}

The intense heating at the contact surface between re-entrant sodium and hot core material may result in a shock pulse from the rate of thermal expansion at this surface as described in Section 5. If this pulse is intense and reaches the duct walls, it may deform or even rupture them with consequent damage to the adjacent ducts and the possibility that the fault may propagate. To assess this possibility, it is first necessary to study the mechanics of the shock wave transmission, reflection and absorption. Existing technology offers a dual approach to the solution of this problem and it is judged that a combination of the two approaches will offer a bounding magnitude to the loading of the duct.

The initial investigation in this study was the energy partition of reflection, absorption and transmission of the shock wave at the duct wall in order to assess the dynamic loading of the duct.

The complex internal arrangement of fuel pins is apt to be disturbed in the explosive reaction and the reflections, diffractions and refractions within the interior are judged too difficult to model. The impulse and energy are assumed to emanate from the edge of the fuel cluster and impinge on the duct wall.

There appear to be at least two mechanisms involved in the interaction of the sodium and the duct,wall under the wave impulse of compression associated with shock loading. One is the reflection, absorption and transmission of near sonic velocity waves at the boundaries of differing media when the media are considered semi-infinite in extent. The other concerns the impulse Inad delivered to the duot wall by the reflected wave when the wall is consldered as a flexible boundary. In order to make the problem more tractable, the model will be treated as one dimensional, illustrated in Figure 6-1, with the shock wave travelling from left to right, originating in the fluid sodium passing through the duct wall and continuing in the fluid sodium. In this simplified model the boundaries will be considered normal to the direction of pulse velocity. For the energies and impulses associated with shocks that the duct may be able to absorb, it is judged that elastic waves at near sonic velocities can be expected. In order to characterize the shock wave, it will be necessary to know either the initial energy and impulse of the wave, or the pressure-time history of the pulse.

Acoustic theory permits the assessment of reflection and transmission at the interface between two media and is probably valid when the pressure in the pulse docs not greatly exceed the elastic strength of the medium and does not have a gross effect on the density. It is expected that the shock wave in the duct may be categorized this way. 
(1) (2) (3)
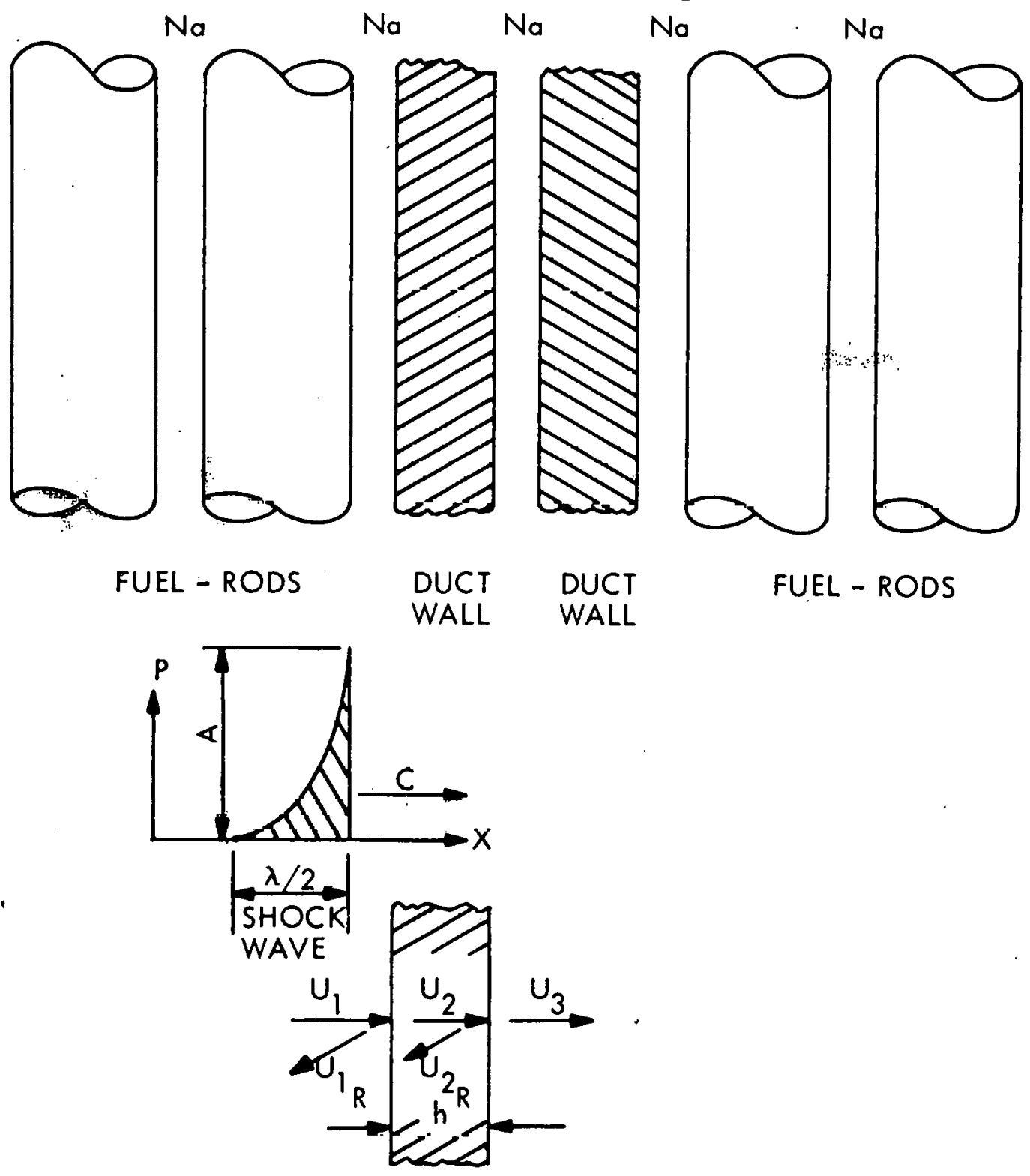

GD9-96

Figure 6-1. Reflection and Refraction at the Interface between Two Media 
Kolsky (Ref. 1) shows that the plane interface of differing media for normal incidence of a dilatational wave, the relation between the incident wave amplitude $\left(A_{1}\right)$ and the reflected wave $\left(A_{R}\right)$ is:

(a) $\mathrm{A}_{\mathrm{R}}=\mathrm{A}_{1}\left(\rho_{2} \mathrm{C}_{2}-\rho_{1} \mathrm{C}_{1}\right) /\left(\rho_{2} \mathrm{C}_{2}+\rho_{1} \mathrm{C}_{1}\right)$

and the transmitted wave $\left(\mathrm{A}_{\mathrm{T}}\right)$ is:

(b) $\mathrm{A}_{\mathrm{T}}=\mathrm{A}_{1}\left(2 \rho_{1} \mathrm{C}_{1}\right) /\left(\rho_{2} \dot{\mathrm{C}}_{2}+\rho_{1} \mathrm{C}_{1}\right)$

where:
$\rho=$ density of the media and the subscript identifies the medium.
$\mathrm{C}_{1}=$ the velucity of propagation of dilatation in the media and the subscript identifies the medium.

\section{For a Solid}

(c)

$$
c=\sqrt{\frac{\mathrm{k}+4 / 3 \mu}{\rho}} \text { (dilatation) }
$$

(d) $\mathrm{k}=$ bulk modulus $=\frac{\mathrm{E}}{3(\mathrm{l}-2 \nu)}$.

(e) $\mu=$ rigidity modulus $=\frac{E}{2(1+\nu)}$

$\mathrm{E}=$ modulus of elasticity

$\nu \quad=\quad$ Poisson's Ratio
For a Liquid

$\mathrm{C}=\sqrt{\mathrm{k} / \rho}$

'The ratio of reflected to incident energy at an interface is given by McGonnagle (Ref. 5) for semi-infinite media as:

$$
\text { (f) } \frac{\mathrm{Ur}}{\overline{\mathrm{U}}_{\mathrm{i}}}=\left(\frac{\rho_{1} \mathrm{C}_{1}-\rho_{2} \mathrm{C}_{2}}{\rho_{1} \mathrm{C}_{1}+\rho_{2} \mathrm{C}_{2}}\right)^{2}
$$

or for finite media where (for $h \leq \lambda$ )

$$
\text { (g) } \frac{\mathrm{U}_{\mathrm{r}}}{\mathrm{Ui}}=\frac{\left(\frac{\rho_{1} \mathrm{c}_{1}}{\rho_{2} \mathrm{c}_{2}}-\frac{\rho_{2} \mathrm{c}_{2}}{\rho_{1} \mathrm{c}_{1}}\right)^{2}}{4 \mathrm{Cut}^{2}\left(\frac{2 \pi \mathrm{h}}{\lambda}\right)+\left(\frac{\rho_{1} \mathrm{c}_{1}}{\rho_{2} \mathrm{c}_{2}}+\frac{\rho_{2} \mathrm{c}_{2}}{\rho_{1} \mathrm{c}_{1}}\right)^{2}}
$$

$$
\left\{\begin{array}{l}
\lambda=\text { wave length (in.) } \\
h=\text { extent of medium }
\end{array}\right.
$$


Equation (g) is employed for a medium through which the wave travels for a wave length or less. Maximum transmission occurs when $h$ is equal to an integral number of half wave lengths. Minimum transmission will occur when $h$ (extent of medium) is an odd number of quarter wave lengths.

By computing the reflection at the interfaces in turn an assessment of the energy reflected, transmitted and absorbed in the duct wall can be obtained, see example in Figure 6-2.

Supplementing the acoustic theory by considering the impulse delivered to a finite extent of wall such as the duct, it is reasoned that the reflection of the shock wave at the initial sodium to steel interface will result in a pressure of some duration that will result in motion of the wall. The initial velocity imparted to the wall will then be retarded by impact upon the sodium at the next interface and finally by the strength of the wall resisting deformation. The velocities are much below the speed of sound in this phase so that the shock pulse travels on unaffected.

If the impulse, I, of the incident wave is added to that of the reflected wave, their effect on the wall is to impart an almost instantaneous velocity to the wall if the period of the wall is large compared to the time of the pulse.

The pressure of the incident wave is nearly doubled on reflection, see Figure 6.3 , so that the impulse ( $(\mathrm{Pdt}$ ) of the wave pressure acting on the wall is also nearly doubled. The integral of the pressure-time of the wave, or the impulse, will impart motion to the duct wall if the duration of the pressure is much less than the natural period of vibration for the wall, or will act as a quasi-static pressure if the duration is much larger than the period of the wall. For durations approximating the period of the duct wall, the reaction is more complex, but this regime is not of interest for the flow blockage accident. In those shocks of relatively short duration that are of interest, the impulse may be equated to momentum imparted to the wall, determining the initial velocity of the wall and the consequent energy transfer, see Figure 6-3. $\mathrm{I}=\mathrm{Pt}=\mathrm{mv}$, the resultant energy is $E=\mathrm{mv}^{2} / 2=\mathrm{I}^{2} / 2 \mathrm{~m}$. The resultant motion of the wall will impact the sodium on the opposite side of the duct sending a pressure pulse through the liquid and extracting some of the kinetic energy from the duct wall. Timoshenko (Ref. 4) has treated the impact of solid rods and a modification of this procedure can be employed for the one dimensional model. In the development of this treatment, it is assumed that a stress, $\dot{\sigma}$, is suddenly applied to the boundary of the medium causing a wave of compression traveling through the medium with the speed of sound, $C$. The particles of the medium will receive a velocity, $v$, due to the compressive stran. In thus instance

$$
\varepsilon \quad=\frac{\mathrm{o}}{\mathrm{k}} \text { and } \delta=\frac{\mathrm{o}}{\mathrm{k}} \text { ct } \therefore \mathrm{v}=\frac{\delta}{\mathrm{t}}=\frac{\mathrm{cor}}{\mathrm{k}}
$$

where $\quad \varepsilon=$ strain, in. per in.

$\delta=$ deformation in.

and the other symbols are as previously defined. By equating the impulse of the stress, $\sigma$, to the momentum of the compressed fluid, $\rho$ vct, the velocity of wave propagation, $\mathrm{c}$, is found:

$$
\text { (h) } \begin{aligned}
\text { ot } & =\rho \mathrm{vct} \\
\frac{\sigma}{\rho \mathrm{v}} & =\mathrm{c}=\frac{\sigma}{\rho \frac{\mathrm{co}}{\mathrm{k}}}=\frac{\mathrm{k}}{\rho \mathrm{c}} \text { or } \mathrm{c}^{2}=\frac{\mathrm{k}}{\rho} \therefore \mathrm{c}=\sqrt{\frac{\mathrm{k}}{\rho}}
\end{aligned}
$$

Continuing a parallel to Timoshenko's development, the strain energy would be:

(i) $\mathrm{E}_{\mathrm{s}}=\frac{\sigma^{2} \mathrm{ct}}{2 \mathrm{k}}$ 


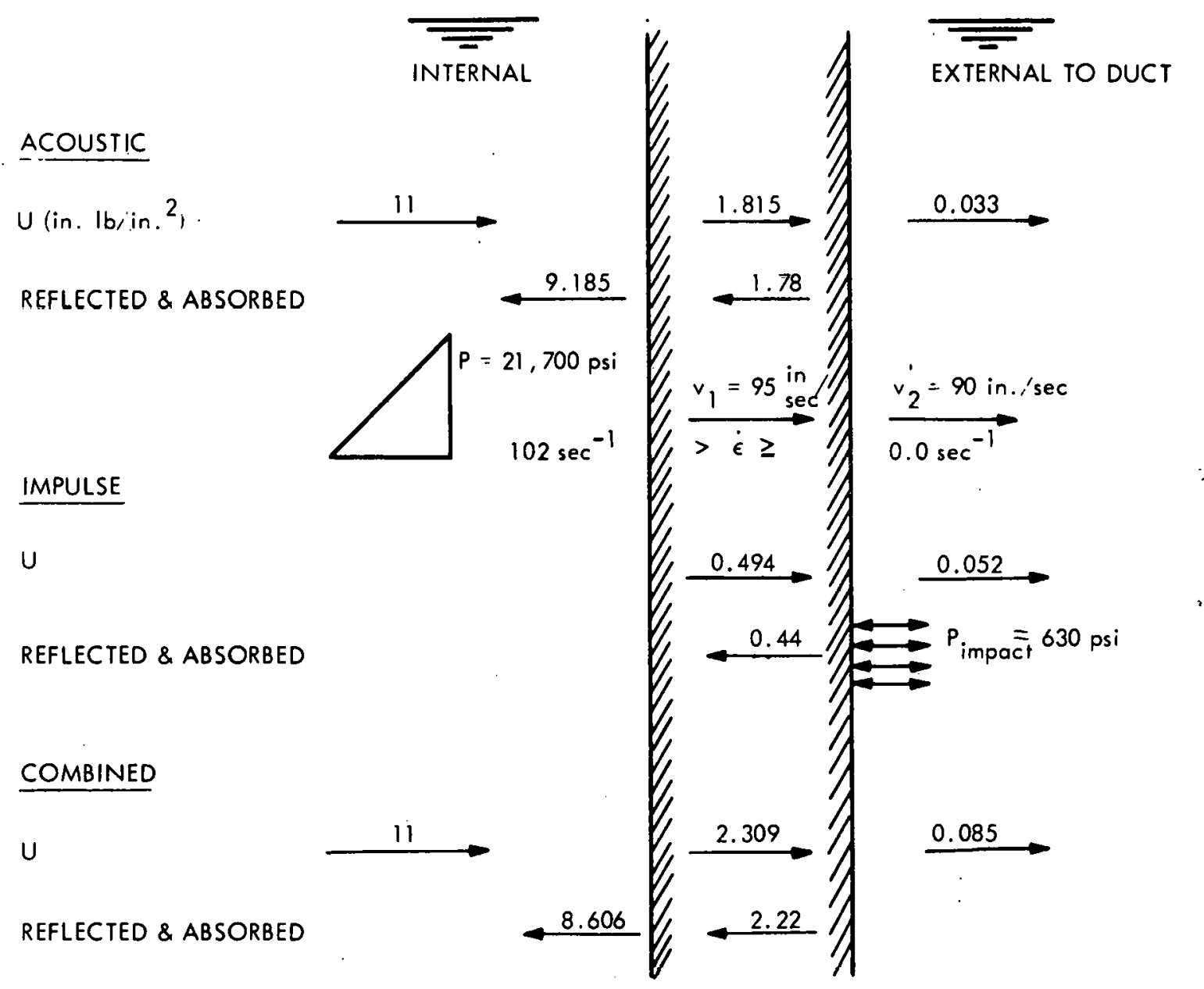

GD9-97

Figure 6-2. Energy Reflection and Transmission at Duct Wall 


$$
\begin{aligned}
& U_{\epsilon}=\frac{\sigma^{2} C_{t}}{2 k} \\
& U_{v}=\frac{C t \rho v^{2}}{2}=\frac{\sigma^{2} C t}{2 k} \\
& U=\frac{\sigma^{2} C t}{k}
\end{aligned}
$$

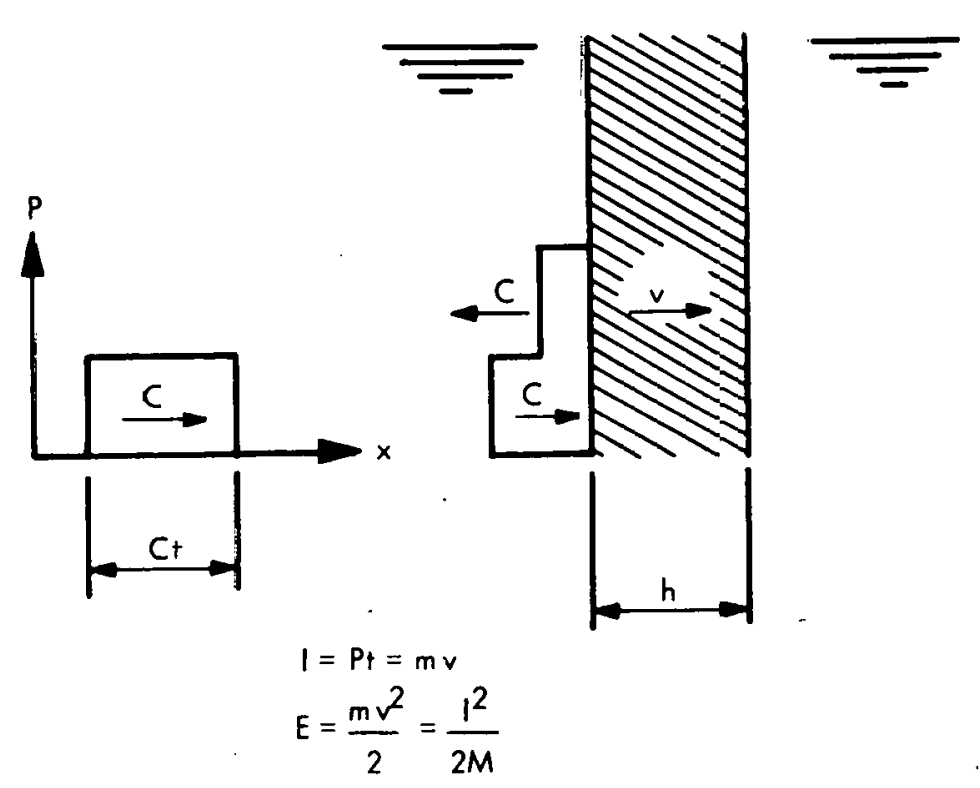

$\epsilon=\frac{\sigma}{k}$

$\theta=\frac{\sigma}{k} C_{t}$

$v=\frac{\sigma}{t}=\frac{\sigma C}{k}$

$a t=p_{r} C_{1}$

$z=\frac{\sigma}{\rho v}=\frac{k}{\rho C} \therefore C^{2}=\frac{k}{\rho}$

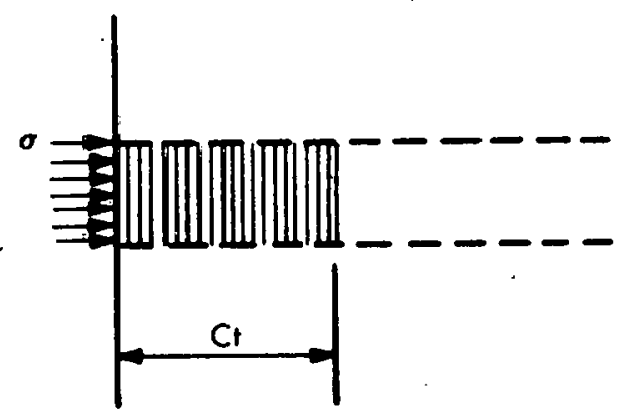

GD9-98 
and the kinetic energy equal to:

$$
\text { (j) } \mathrm{E}_{\mathrm{k}}=\frac{\mathrm{ct} \rho v^{2}}{2}=\frac{\mathrm{ct} \rho}{2}\left(\frac{\sigma}{\rho \mathrm{c}}\right)^{2}=\frac{\mathrm{ct} \sigma^{2}}{2 \rho \mathrm{c}^{2}}=\frac{\sigma^{2} \mathrm{ct}}{2 \mathrm{k}}
$$

with a total energy of:

$$
\text { (k) } E_{T}=\frac{\sigma^{2} c t}{k}
$$

then considering impact of a plate on fluid, as in Figure 6-4, at the beginning of the first interval, $2 \mathrm{~h}_{1} / \mathrm{C}_{1}(\mathrm{determined}$ by time of travel of reflected wave in the wall to traverse the wall and return to the impact surface, $v_{1}-v_{1}^{\prime}=v_{2}^{\prime}$.

Assuming the fluid initially at rest, the particle velocity of the fluid and the plate must be equal to maintain contact and the accelerating stress must be equal for equilibrium at the wave front:

$$
\begin{aligned}
& \text { (l) } \mathrm{v}_{1}^{\prime}=\frac{\sigma}{\sqrt{\mathrm{k}_{1} \rho_{1}}} \text { and } \mathrm{v}_{2}^{\prime}=\frac{\sigma}{\sqrt{\mathrm{k}_{2} \rho_{2}}}=\mathrm{v}_{1}^{\prime} \sqrt{\frac{\mathrm{k}_{1} \rho_{1}}{\mathrm{k}_{2} \rho_{2}}} \\
& \text { (m) } \mathrm{v}_{1}-\mathrm{v}_{1}^{\prime}=\mathrm{v}_{1}^{\prime} \sqrt{\frac{\mathrm{k}_{1} \rho_{1}}{\mathrm{k}_{2} \rho_{2}}} \\
& \text { (n) } \mathrm{v}_{1}=\mathrm{v}_{1}^{\prime}\left(1+\sqrt{\frac{\mathrm{k}_{1} \rho_{1}}{\mathrm{k}_{2} \rho_{2}}}\right) \\
& \text { (c) } \sigma_{1}=\mathrm{v} \sqrt{\mathrm{kp}_{1}}=\mathrm{v}_{2}^{\prime} \sqrt{\mathrm{k}_{2} \rho_{2}}=\mathrm{v}_{1}^{\prime} \sqrt{\mathrm{k}_{1} \rho_{1}} \\
& \text { (p) } \sigma_{1}=\frac{\mathrm{v}_{1} \sqrt{\mathrm{k}_{2} \rho_{2}} \sqrt{\mathrm{k}_{1} \rho_{1}}}{\sqrt{\mathrm{k}_{2} \rho_{2}}+\sqrt{\mathrm{k}_{1} \rho_{1}}} .
\end{aligned}
$$

The energy transmitted

$$
\text { (q) } \begin{aligned}
\Delta \mathrm{U} & =-\frac{\mathrm{m}_{1} \mathrm{v}_{1}^{2}}{2}+\frac{\mathrm{m}_{1} \mathrm{v}_{2}{ }^{2}}{2} \\
& =-\frac{\mathrm{m}_{1} \mathrm{v}_{1}^{2}}{2}+\frac{\mathrm{m}_{1}}{2} \mathrm{v}_{1}{ }^{2} \frac{\mathrm{k}_{1} \rho_{1}}{\mathrm{k}_{2} \rho_{2}} \\
& =-\frac{\mathrm{m}_{1} \mathrm{v}_{1}^{2}}{2}+\frac{\mathrm{m}_{1}}{2}\left(\frac{\mathrm{k}_{1} \rho_{1}}{\mathrm{k}_{2} \rho_{2}}\right)\left(\frac{\mathrm{v}_{1} \sqrt{\mathrm{k}_{2} \rho_{2}}}{\sqrt{\mathrm{k}_{1} \rho_{1}}+\sqrt{\mathrm{k}_{2} \rho_{2}}}\right)^{2} \\
& =-\frac{\mathrm{m}_{1} \mathrm{v}_{1}^{2}}{2}\left(1-\frac{\mathrm{k}_{1} \rho_{1}}{\mathrm{k}_{1} \rho_{1}+2 \sqrt{\mathrm{k}_{1} \rho_{1}} \sqrt{\mathrm{k}_{2} \rho_{2}}+\mathrm{k}_{2} \rho_{2}}\right)
\end{aligned}
$$


(r) $\frac{\Delta \mathrm{l}:}{\widetilde{U}}=1-\frac{\mathrm{k}_{1} \rho_{1}}{\mathrm{k}_{1} \rho_{1}+2 \sqrt{\mathrm{k}_{1} \rho_{1}} \sqrt{\mathrm{k}_{2} \rho_{2}}+\mathrm{k}_{2} \rho_{2}}$

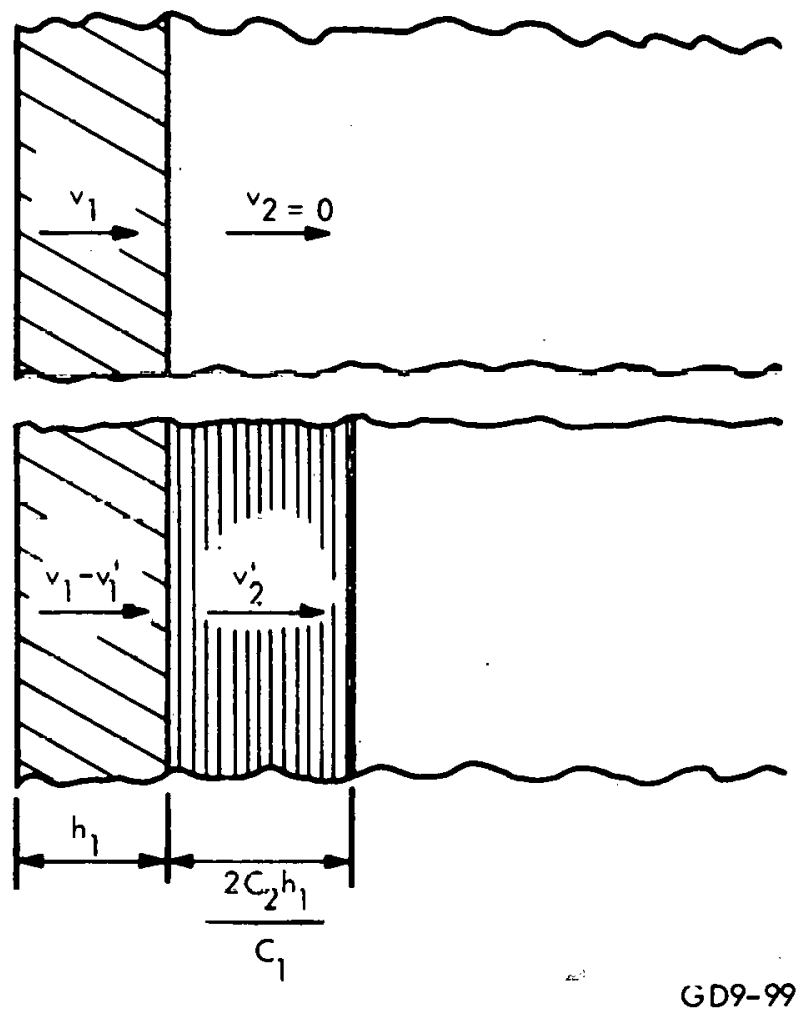

Figure 6-4. Impact on Liquid

To properly categorize a shock wave (Ref. 2,3 ) it is necessary to know either the pressure-time history of the pulse, or at least the energy and impulse (momentum) associated with the shock. All are difficult to assess and the present study has yielded only estimates of the energy, peak pressure and decay time in the wave so further assumption must be made to evaluate the impulse. For conventional explosive and nuclear explosive shock waves the attenuation can be approximated by an exponential decay from the shock front pressure and there is some evidence that such decay would be appropriate.

For a decay curve decreasing from a peak pressure where the curve is concave with respect to the peak pressure and the area under the curve and the limits of integration are held constant the moment of the area under the curve

$$
\left(M=A \bar{y}=\int_{0}^{x} \frac{y^{2} d x}{2}\right)
$$

will increase with increasing curvature. As energy is a function of the pressure squared and impulse is a function of pressure, the same will hold true for these parameters, see Figure 6-5. In a shock wave, it is normal for the pressure to degrade at a faster rate at the higher pressure and more slowly as the pressure returns to ambient. It therefore appears that a linear decay would be an adequate bounding case for the relation of impulse to energy for a shock wave. In Figure 6-6 a relation has been graphed for a number of shapes including an exponential in the portion of the curve with slight curvature to illustrate the limiting approximation. The triangular distribution was employed in the computations as a bounding assumption that was conservative, but the available evidence indicates that an exponential decay is probable, with higher peak pressure and lower 
impulse loading than would be observed in a linear decay. In employing the linear decay, the energy of the wave is equated to the energy in the triangular wave form $\left[u=\left(C P^{2}{ }_{\max } t_{1}\right) / 3 k\right]$ and solved for the peak pressure $\left(P_{\max }\right)$. The impulse is then computed from $\mathrm{I}=\mathrm{Pt} / 2$. In the duct it is assumed that the pressure pulse originates at the perimeter of the outer row of fuel rods and that the heat transfer surface at this boundary is equivalent to the surface area of the duct exposed to the shock front. The maximum energy of a shock wave for either maximum temperature of fuel or maximum temperature of clad is indicated in Figures 5-4 and 5.5 to be approximately $11 \mathrm{in.} \mathrm{lb} / \mathrm{in}^{2}{ }^{2}$ of heat transfer area. The complex geometry of the fuel cluster discourages an attempt to relate the effective heat transfer area exposed to the duct wall with the reflections and absorptions in the interior of the cluster contributing a time delay to further cloud the picture. Figure 6-7 illustrates the adopted concept of equilibrating the peripheral area of the fuel cluster to the adjacent duct wall area on a one to one basis for computational purposes. From this assumption it is estimated that the incident energy of the shock wave is 11 in. lbs/in. ${ }^{2}$, and the corresponding impulse is $5.42(10)^{-3} \mathrm{lb} . \mathrm{sec} / \mathrm{in}^{2}{ }^{2}$ delivered to the duct wall as shown below.

$$
\Delta u=\frac{p^{2} c \Delta t}{k}
$$

(s) $u=\frac{c}{k} \int_{0}^{t_{1}} p^{2} d t=\frac{c}{k} \int_{0}^{t} 1\left(\frac{P t}{t_{1}}\right)^{2} d t$

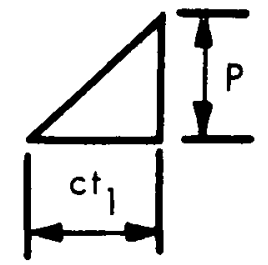

$$
\begin{aligned}
&=\frac{\mathrm{cP}^{2}}{\mathrm{kt}_{1}^{2}} \int_{0}^{t_{1} t^{2} \mathrm{dt}} \\
&=\frac{\mathrm{cP}^{2} \mathrm{t}_{1}}{3 k} \\
& \mathrm{P}^{2}=\frac{3 \mathrm{ku}}{\mathrm{ct}}=470.1(10)^{6} . \\
& \mathrm{P}=21681 \mathrm{psi}=1475 \mathrm{Atm} . \\
& \mathrm{I}=\frac{\mathrm{P}}{\mathrm{t}_{1}} \int_{0}^{\mathrm{t}_{1}} \mathrm{tdt} \\
&=\frac{\mathrm{Pt}_{1}}{2}=\frac{21681}{4(10) 6}=0.00542 \mathrm{lb} \text { sec. } \\
& t_{1}=5(10)^{-7} \text { sec. }
\end{aligned}
$$


Triangular distribution of pressure results in largest ratio of impulse to energy of wave for indicated shape.

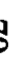
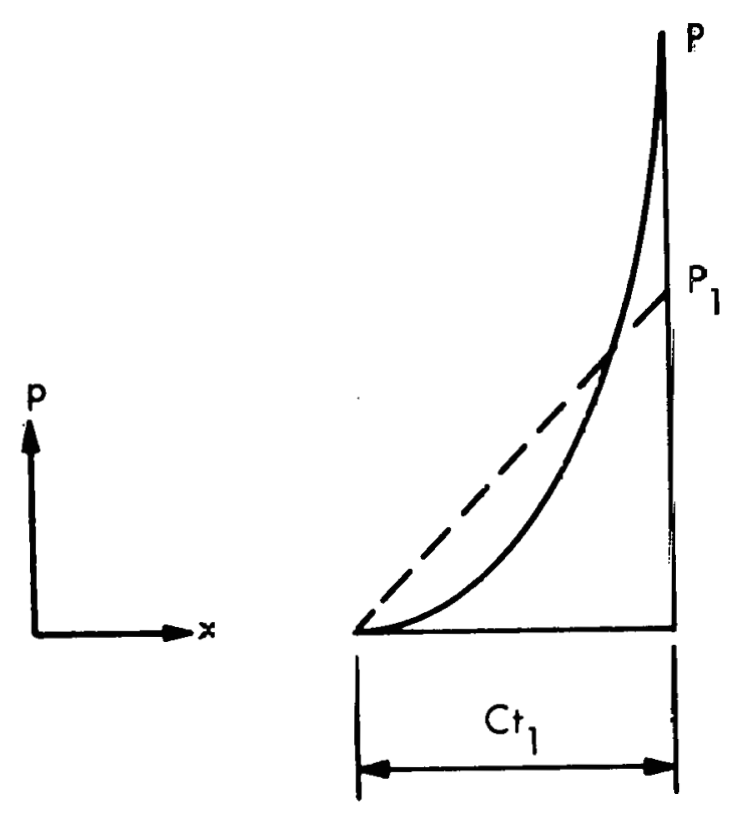

or $P_{1}^{2}=\frac{3 k U}{E t_{1}}$

and $I=\int_{0}^{t_{1}} P \Delta t=\frac{P_{1}}{t_{1}} \int_{0}^{t_{1}} t d t=\frac{P_{1}}{t_{1}}\left[\frac{t^{2}}{1} \frac{}{2}\right]$

$=\frac{P_{1}{ }^{\dagger} 1}{2}=1 / 2 \sqrt{\frac{3 k U_{1} 1}{C}}$ 

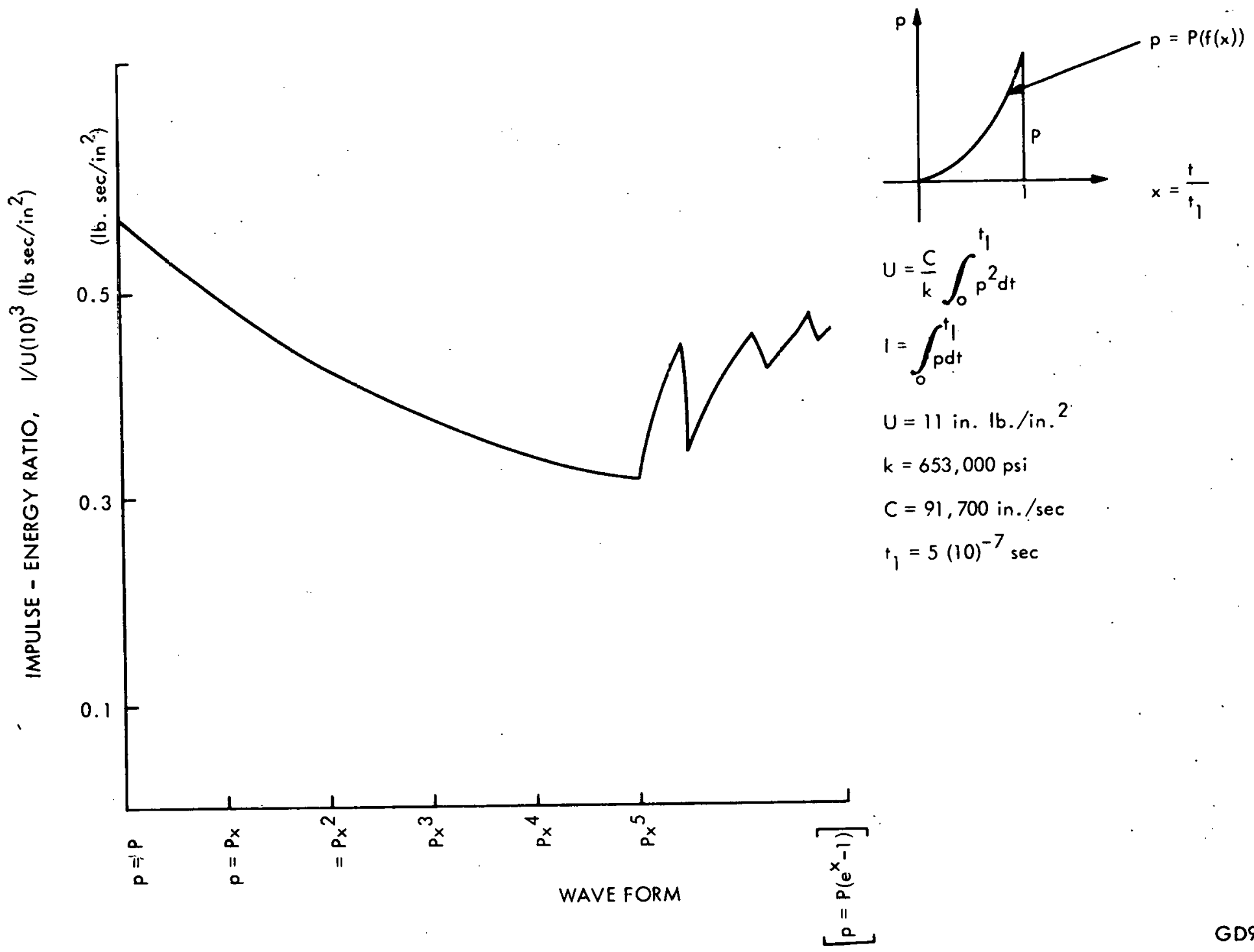$$
U=\frac{C}{k} \int_{0}^{t_{1}} p^{2} d t
$$$$
1=\int_{0}^{t} \mathrm{~d} d t
$$$$
U=11 \text { in. } 16 . / \text { in. }^{2}
$$$$
k=653,000 \mathrm{psi}
$$$$
C=91,700 \mathrm{in} . / \mathrm{sec}
$$$$
t_{1}=5(10)^{-7} \mathrm{sec}
$$ 


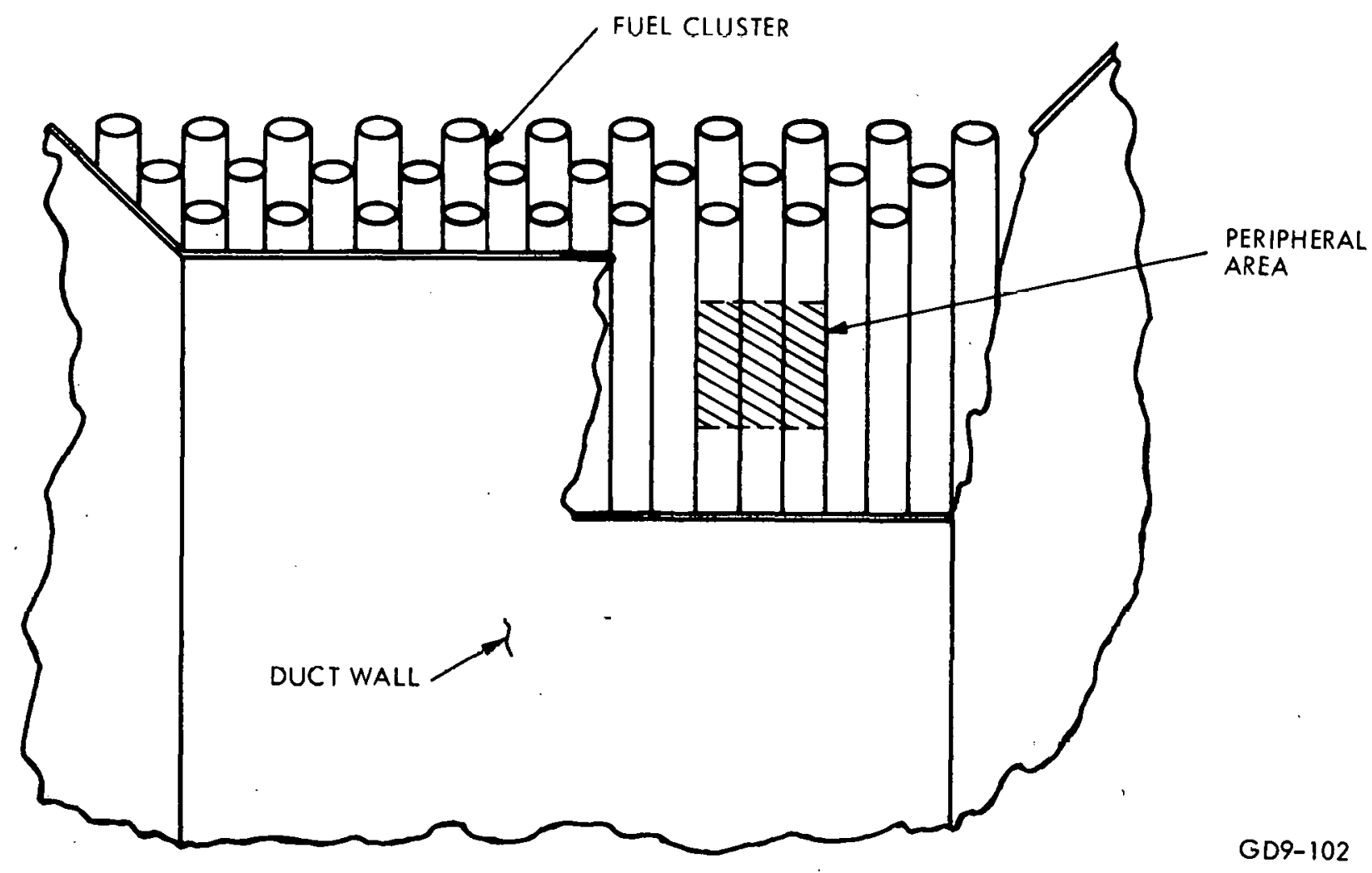

Figure 6-7. Equivalence of Peripheral Area of Fuel Cluster to Area of Duct Wall for Shock Wave Transmission

Using expected properties of the FFTF envirumment and similar gcometry we may compute as an illustration:

$$
\mathrm{T}=1000^{\circ} \mathrm{F}
$$

\begin{tabular}{|c|c|c|c|}
\hline Property & SS 304 & $\mathrm{Na}(6)$ & Units \\
\hline$\rho=$ density & $7.772(10)^{-4}$ & $7.7044(10)^{-5}$ & lb- $\sec ^{2} /$ in. 4 \\
\hline$c=$ velocity of sound & 199,600 & 90,400 & in./sec \\
\hline$k=$ bulk modulus & $19,170,000$ & 636,500 & lb/in. ${ }^{2} /$ in. $^{3}$ \\
\hline$\mu=$ rigidity modulus & $8,846,000$ & & $\mathrm{lb} / \mathrm{in}^{2}$ \\
\hline$E=$ modulus of elasticity & $23,000,000$ & 763,800 & $\mathrm{lb} / \mathrm{in}^{2}$ \\
\hline$\nu=$ Poisson's ratio. & 0.3 & 0.3 & \\
\hline $\mathbf{b}=$ compressibility & $5.22(10)^{-8}$ & $1.571(10)^{-6}$ & in. $3 / \mathrm{lb} / \mathrm{in}^{2}$ \\
\hline
\end{tabular}


Reflection at the inside surface of the duct:

$$
\begin{aligned}
\mathrm{A}_{\mathrm{R}_{1}} & =\mathrm{A}_{1}\left(\rho_{2} \mathrm{C}_{2}-\rho_{1} \mathrm{c}_{1}\right) /\left(\rho_{2} \mathrm{c}_{2}+\rho_{1} \mathrm{c}_{1}\right) \\
& =\mathrm{A}_{1}\left[7.772(10)^{-4}(199,600)-7.7044(10)^{-5}(90,400)\right] /(155.13+6.96) \\
& =0.914 \mathrm{~A}_{1}
\end{aligned}
$$

Transmitted:

$$
\begin{aligned}
A_{T_{1}} & =A_{1}\left(2 \rho_{1} c_{1}\right) /\left(\rho_{2} c_{2}+\rho_{1} c_{1}\right) \\
& =A_{1}(2)(6.96 / 162.09) \\
& =0.086 A_{1}
\end{aligned}
$$

Reflection at the outside surface of the duct:

$$
\begin{aligned}
A_{R_{2}} & =0.086 A_{1}(6.96-155.13) / 162.09 \\
& =-0.079 A_{1}(\text { Tension Wave) }
\end{aligned}
$$

Transmitted:

$$
\begin{aligned}
\mathrm{A}_{\mathbf{T}_{2}} & =0.086 \mathrm{~A}_{1}(2)(155.13) / 162.09 \\
& =0.165 \mathrm{~A}_{1}
\end{aligned}
$$

The corresponding energies of reflection and transmission would be:

$$
\begin{aligned}
\frac{\mathrm{U}_{\mathrm{R}_{1-2}}}{U_{\mathrm{I}}} & =\left(\frac{\rho_{1} \mathrm{c}_{1}-\rho_{2} \mathrm{c}_{2}}{\rho_{1} \mathrm{c}_{1}+\rho_{2} \mathrm{c}_{2}}\right)^{2} \\
& =\left(\frac{7.7044(10)^{-5}(90,400)-7.772(10)^{-4}(199,600)}{6.96+155.29}\right)^{2} \\
& =0.835
\end{aligned}
$$

$$
\frac{\mathrm{U}_{\mathrm{R}_{2-3}}}{\mathrm{U}_{\mathrm{I}}}=(1-0.835) \frac{\left(\frac{\rho_{2} \mathrm{c} 2}{\rho_{3} \mathrm{c}_{3}}-\frac{\rho_{3} \mathrm{c}_{3}}{\rho_{2} \mathrm{c}_{2}}\right)^{2}}{4 \cot ^{2}\left(\frac{2 \pi \mathrm{h}}{\lambda}\right)+\left(\frac{\rho_{2} \mathrm{c}_{2}}{\rho_{3} \mathrm{c}_{3}}+\frac{\rho_{3} \mathrm{c}_{3}}{\rho_{2} \mathrm{c}_{2}}\right)^{2}} \quad(\mathrm{~h}<\lambda)
$$




$$
\begin{aligned}
&=(0.165) \frac{\left(\frac{7.772(19.96}{7.7044(0.904)}-\frac{7.044(0.904)}{7.772(19.96)}\right)^{2}}{4 \cot ^{2}\left(\frac{2 \pi(0.14)}{(10)^{-6}(199,600)}\right)+\left(\frac{7.772(19.96)}{7.7044(0.904)}+\frac{7.7044(0.904)}{7.772(19.96)}\right)^{2}} \\
&=(0.165)(0.964)= 0.162 \text { Reflected and absorbed } \\
& \frac{0.835}{0.997} \text { Reflected }
\end{aligned}
$$

$$
\frac{\mathrm{U}_{\mathrm{T}_{2-3}}}{\mathrm{U}_{\mathrm{I}}}=1-0.997=0.003 \text { Transmitted }
$$

If $\mathrm{U}_{\mathrm{I}}=11.0,{ }^{*} \mathrm{U}_{\mathrm{T}_{2-3}}=0.033, \mathrm{U}_{\mathrm{A}}=1.78$ (in. $\mathrm{lb} / \mathrm{in}^{2}$ )

For the impulse energy delivered as a result of the initial reflection, assume I, specific impulse, is equal to $0.542(10)^{-2} \mathrm{lb}$. sec. per in. ${ }^{2}$. (This is an upper bound, computed from triangular pressure distribution.)

$$
\begin{aligned}
& \mathrm{U}_{\mathrm{I}}=\frac{(1.914 \mathrm{I})^{2}}{2 \mathrm{~m}}=\frac{\left[1.914(0.542)(10)^{-2}\right]^{2}}{2(7.772)(10)^{-4}(0.14)}=0.494 \mathrm{in} . \mathrm{lb} / \mathrm{in} .^{2}
\end{aligned}
$$

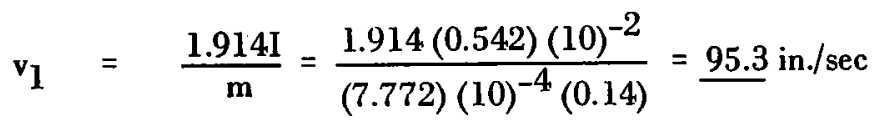

$$
\begin{aligned}
& \sigma_{2}=\frac{\mathrm{v}_{1} \sqrt{\mathrm{k}_{2} \rho_{2}} \sqrt{\mathrm{k}_{1} \rho_{1}}}{\sqrt{\mathrm{k}_{2, \rho_{2}}}+\sqrt{k_{1} \rho_{1}}}=\frac{95.3 \sqrt{636500(7.704)(10)^{-5}} \sqrt{19.17(10)^{6}(7.772)(10)^{-4}}}{7.00+122.06}=631 \mathrm{psi} \\
& \mathrm{v}_{2}^{\prime}=\frac{\sigma}{\sqrt{\mathrm{k}_{2} \rho_{2}}}=\frac{631}{7.00}=90 \mathrm{in} . / \mathrm{sec} \\
& v_{1}^{\prime}=\frac{\sigma}{\sqrt{\mathrm{k}_{1} \rho_{1}}}=\frac{631}{122.06}=5.17 \mathrm{in} . / \mathrm{sec} \\
& \frac{\Delta u}{u}=1-\frac{k_{1} \rho_{1}}{\left(\sqrt{k_{1} \rho_{1}}+\sqrt{k_{2.2} \rho_{2}}\right)^{2}}=1-\frac{19.17(10)^{6}(7.772)(10)^{-4}}{(7.00+122.06)^{2}} \\
& =1-0.894=\underline{\underline{0.106}} \text { Energy transmitted } \\
& 0.894 \text { Energy absorbed in duct. } \\
& \left.\mathrm{U}_{\mathrm{R}}=0.835(11)=9.185, \quad \mathrm{U}_{\mathrm{A}}=0.894(0.494)+1.78 \text { (in.lb/in. }{ }^{2}\right) \\
& \mathrm{U}_{\mathrm{T}}=0.106(0.494)+0.033=0.085 \quad \mathrm{U}_{\mathrm{I}}=\Sigma \mathrm{U}=11.49>11.0
\end{aligned}
$$

* Section $V$ indicates this energy level per sq. in. of fuel surface for a clad or fuel temperature near melting. It is judged that a one-to-one relation between the exterior of the fuel cluster and the duct surface is the maximum effective in transferring energy. The complex reflection and absorption in the interior of the cluster appears intractable. 
The excess in the $\Sigma u$ is explained by the conservative assumption of the impulse loading and neglecting the decrease in reflected energy due to the flexibility of the wall.

This example has been worked for a duct temperature of approximately $1000^{\circ} \mathrm{F}$ with corresponding material properties, but it is hoped will illustrate the loading mechanism and barrier properties of the duct under an internal impulse load. Figure 6-2 shows the reflections and transmission estimated for this case.

\subsection{DEFLECTIONS OF AN UNIRRADIATED DUCT}

The next problem investigated is the ability of the duct to absorb the energy deposited by the shock wave. A limitation that is imposed is that the strain in the duct must be less than the ductility expected to prevent fracture and subsequent energy transfer to adjacent ducts.

It is reasoned that the shock wave imparts an impulsive load to the duct both by the pressure of the reflection at the inner surface and the reflection of part of the transmitted wave at the outer surface. The wave travels at the speed of sound and the two impulses are almost coincident. It is considered conservative to neglect the hysteresis losses inherent in the internal wave as well as the multiple reflections that may occur during the impulsive motion of the wall. As mentioned above, the question of considering the shock energy as an impulsive loading resulting in an initial velocity of the wall to be restrained by the ability of the wall to absorb energy by plastic deformation, or as a quasi-static sustained loading that must be resisted by the strength of the wall; is a function of the duration of the pulse and the natural frequency of vibration of the duct wall. If the duration of the pulse is short relative to the period of the wall, the wall does not have time to respond, and the impulsive load results in an initial velocity of the wall that must be accommodated. The duration of the pulse is estimated to be $5(10)^{-7}$ seconds and the period of the duct wall is computed as about 1.4 (10 $)^{-4}$ seconds so that it is expected that the shock will result in an impulsive load. The duration of the pulse results in a wave length of about 0.2 inch in the steel duct wall and the wall thickness of 0.14 inch is neither an integral number of half wave lengths or an odd number of quarter wave lengths necessary for maximum or minimum transmission.

In order to estimate the ability of the duct to absorb this energy input, it is assumed that the energy is dissipated by deformation of the duct in a pattern similar to that for an internal pressure. The duct is then analyzed for a series of increasing pressure loads and the cncrgy absorbed is compared to the deformations and strains resulting. A computer solution of plane stress problems for bodies of arbitrary variation of material properties, shape and loading is employed. The program, "GASP", (Ref. 7) is a finite element solution that by iteration will solve problems of plasticity where the stress-strain law can be approximated by a two-slope idealization. Noting that there are six axes of symmetry for the hexagonal duct and that symmetrical boundary conditions can be imposed, it is possible to analyze $1 / 12$ of the perimeter of the duct for an internal pressure, see Figure. $6-8$. The duct has little ability to absorb energy in the elastic range so that the duct must be analyzed for plastic deformation.

With this method of solution the procedure is to obtain successive solutions with increasing pressure loads, obtaining the deflections and energy absorbed for the successive solutions. With this information it is possible to plot a curve of maximum deflection versus energy absorbed that can be employed to relate the two. This relationship is then utilized to assess the ability of the duct to absorb the energy imposed by the shock wave. The deformation to contact adjacent ducts and the ductility of the metal are employed as limiting parameters in this assessment.

The multiplicity of pnssible loading conditions, initial conditions, prior history and material properties, make an investigation mapping the entire field prohibitive for the purpose of this study. Many of the accompanying loadings producing initial stress, strain and deformation are not readily assessable for combination and comparison with failure limits. In order to furnish some insight, the duct has been investigated for representative accident conditions early in life when the metal is weak, but ductile and also latc in life when irradiation has changed the properties of the metal to strong and brittle.

The analysis for early in life when the metal is weak can also be employed for later in life if loss of ductility is not accompanied by irradiation hardening, but appropriate limits must be imposed on the allowable ductility in this case. These extremes may indicate bounds of the problem. Unfortunately not enough information is availale to bound all of the combining loadings and all of the temperatures. 

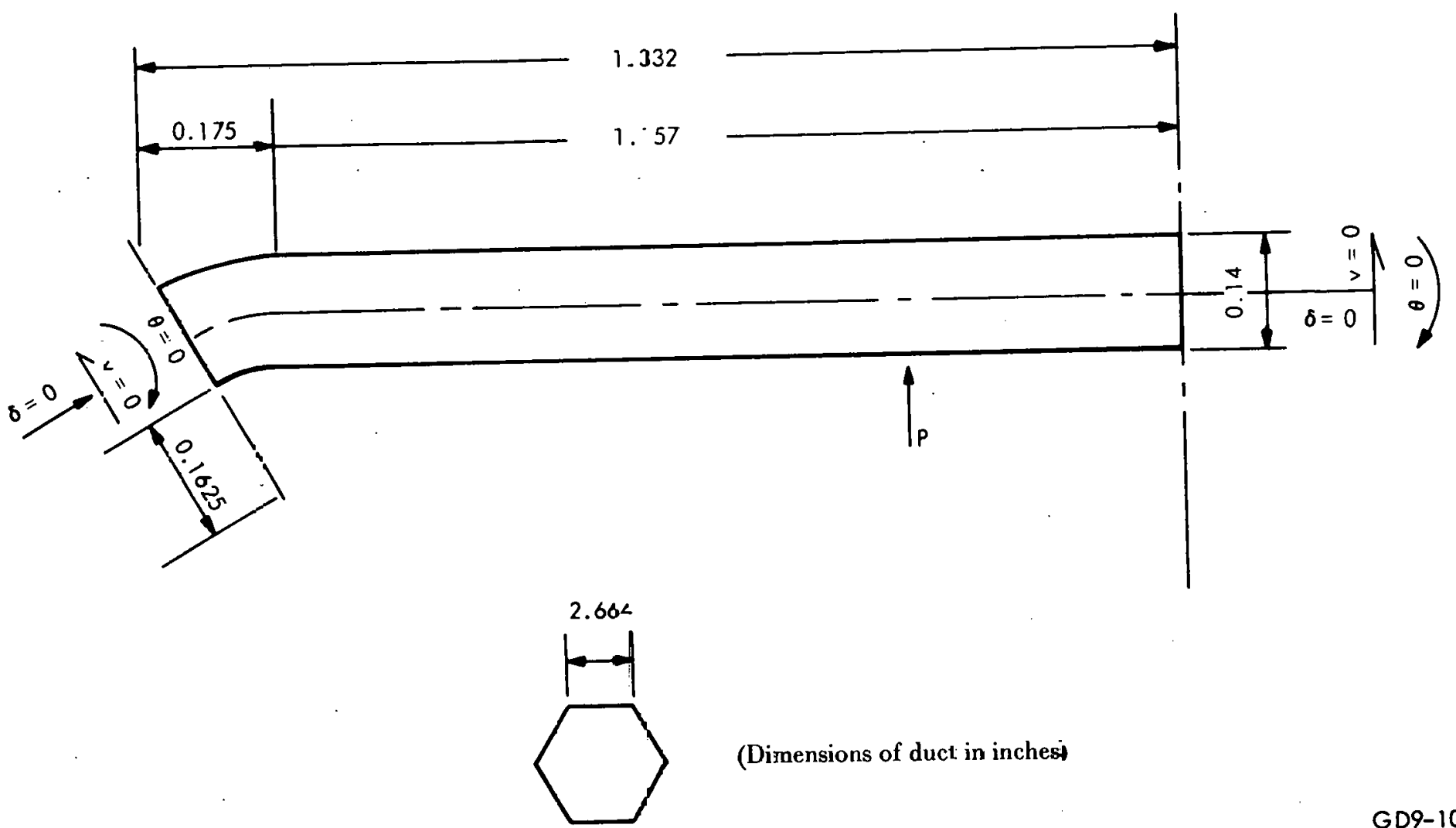
The early life condition assumes metal properties for temperatures approximating $1000^{\circ} \mathrm{F}$. The material of the duct is assumed as ASTM A-213, Type 304, with properties at $1000^{\circ} \mathrm{F}$ of Young's Modulus, $\mathrm{E}=23(10)^{6} \mathrm{psi}$, Poisson's ratio, $\nu=0.3$, a yield strength of about $14,000 \mathrm{psi}$ and an elongation of about $42 \%$. A series of solutions from the pressure of $100 \mathrm{psi}$ (incipient yielding) to $300 \mathrm{psi}$ (gross plastic deformation) yields information on the maximum deflection, strain, and energy absorption which have been plotted in Figure 6.9 showing curves constructed from these points. The stress-strain relation assumed for these solutions is $E=23(10)^{6}$ psi up to the yield strength of $14,000 \mathrm{psi}$ and then a strain hardening of $\mathrm{E}^{*}=$ $1.05(10)^{5}$ psi.

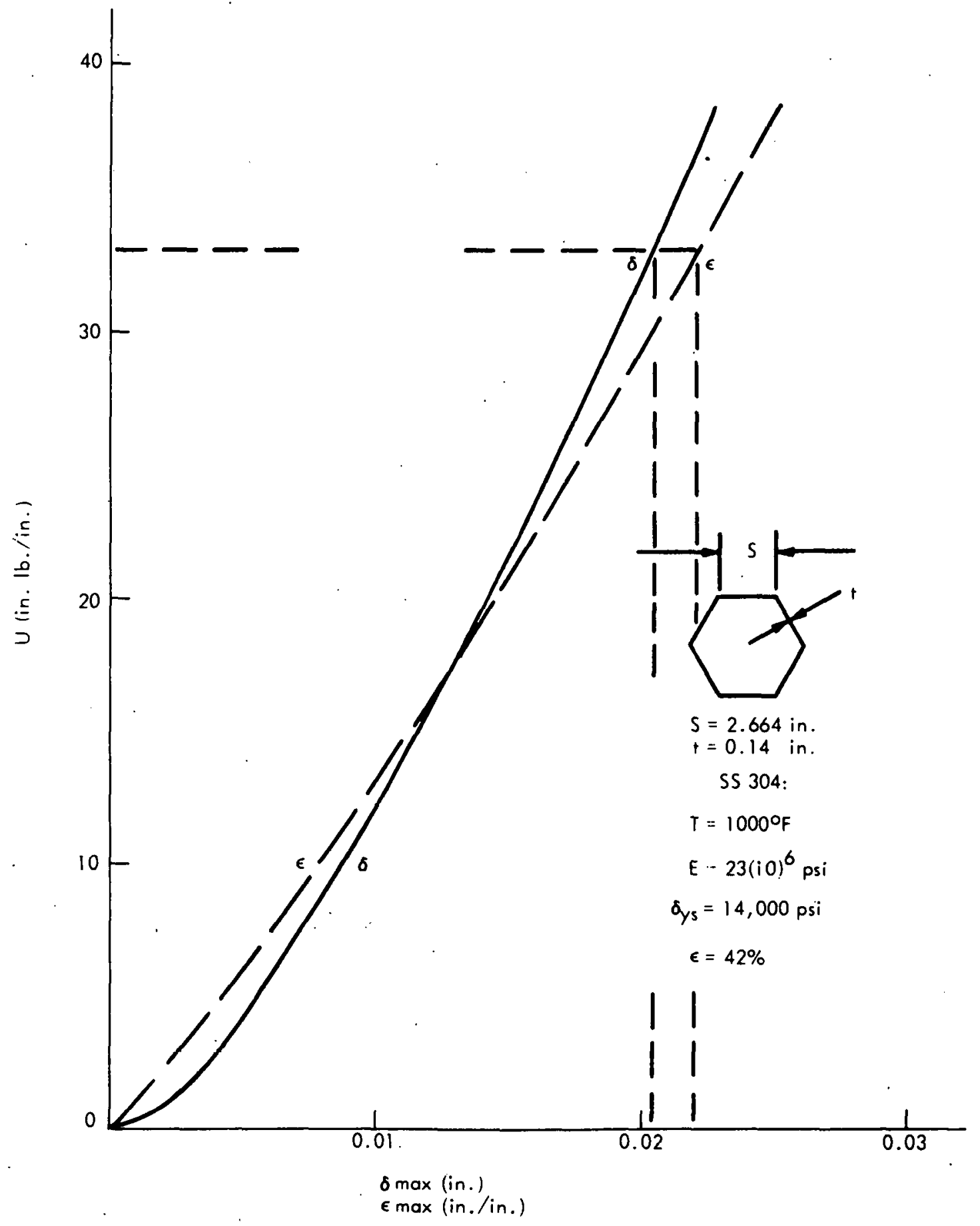

Figure 6-9. Energy Versus Deflection and Strain in FFTF Core Duct, Parameter Set 1 
The two slope idealization of the stress-strain law employed in the compuler solution is illustrated in the Figure 6.10.

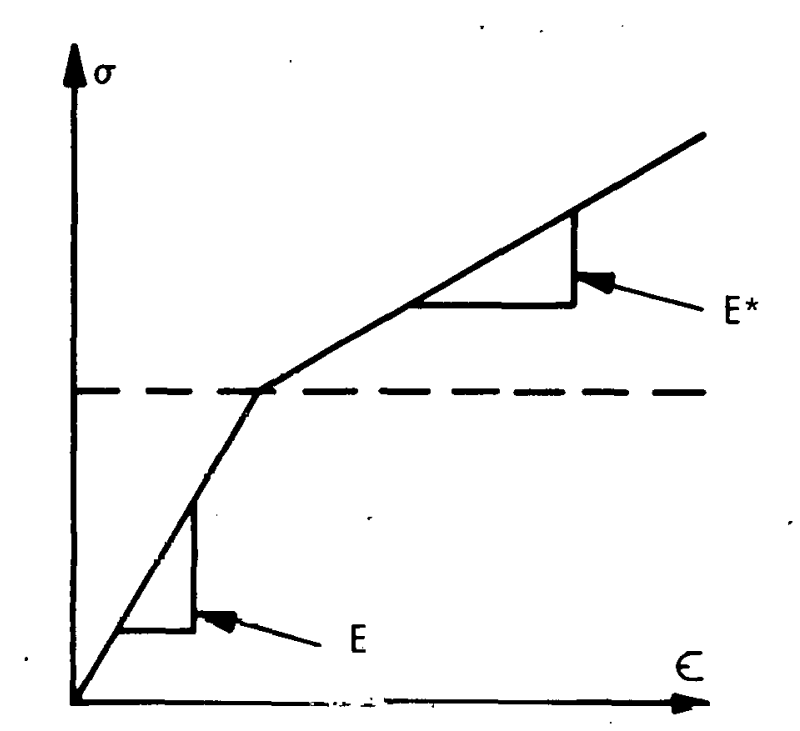

Figure 6-10. Assumed Stress-Strain Relation

The late in life conditions are similar except that irradiation has increased the yield strength to $40,000 \mathrm{psi}$ and decreased the elongation to $1 \%$. Figure 6-11 indicates the relation between strain, energy and maximum deflection for the duct and material after lengthly exposure to radiation. The pressures employed in this series of analyses range from 200-500 psi.

The shock loading of the duct indicates a maximum energy input of about $2.2 \mathrm{in.lb} / \mathrm{sq}$ in. for the accident loading which is equal to $2.2(14.9) \approx 33$ in.lb/in. of duct. Figure 6-9 would indicate that such an input would result in a maximum deflection of about $0.02 \mathrm{in.}$ and a maximum strain of $0.02 \mathrm{in}$./in. These values of deflection and strain are easily accommodated by the dur.t in early life, but at this strain level the duct wall is almost entirely in the plastic regime.

The same input of energy in later life, from Figure 6.11, would result in maximum deflection of 0.014 in. and maximum strain of $0.009 \mathrm{in}$./in. The maximum deflection can be tolerated but the maximum strain of 0.009 is very near the material capability and could fail the duct. The duct would have marginal chance of surviving the shock load near the end of life.

An assessment of the strain rate can be obtained from the initial velocity of the duct wall resulting frum the impulsc loading from the shock pulse. It can be reasoned that the strain rate is proportional to the deformation rate and therefore the strain rate can be obtained as the maximum strain divided by the maximum deflection as a ratio multiplier of the initial velocity of the duct wall. The assumption is made here that the strain to deformation remains constant throughout the travel of the wall. The strain rate as well as the deformation rate degrade from their initial values down to zero when the wall comes to rest. On this basis the maximum strain rate would occur for the irradiation hardened material and would be approximately 102 in./in./ sec and degrade to zero. This is a comparatively modest rate compared to the speed of sound $(200,000 \mathrm{in} . / \mathrm{sec})$ and the duct would respond to the deformation in a uniform pattern without delay time due to inertial restraint.

The strains from the shock loading are additive to the strains from other loadings of the duct, but the large plastic strains from absorbing the energy of the shock dwarf the ordinary elastic strains. But the accompanying severe radial temperature gradient results in a strain of about $0.25 \%$ which may be significant late in life. 
GEAP.10059

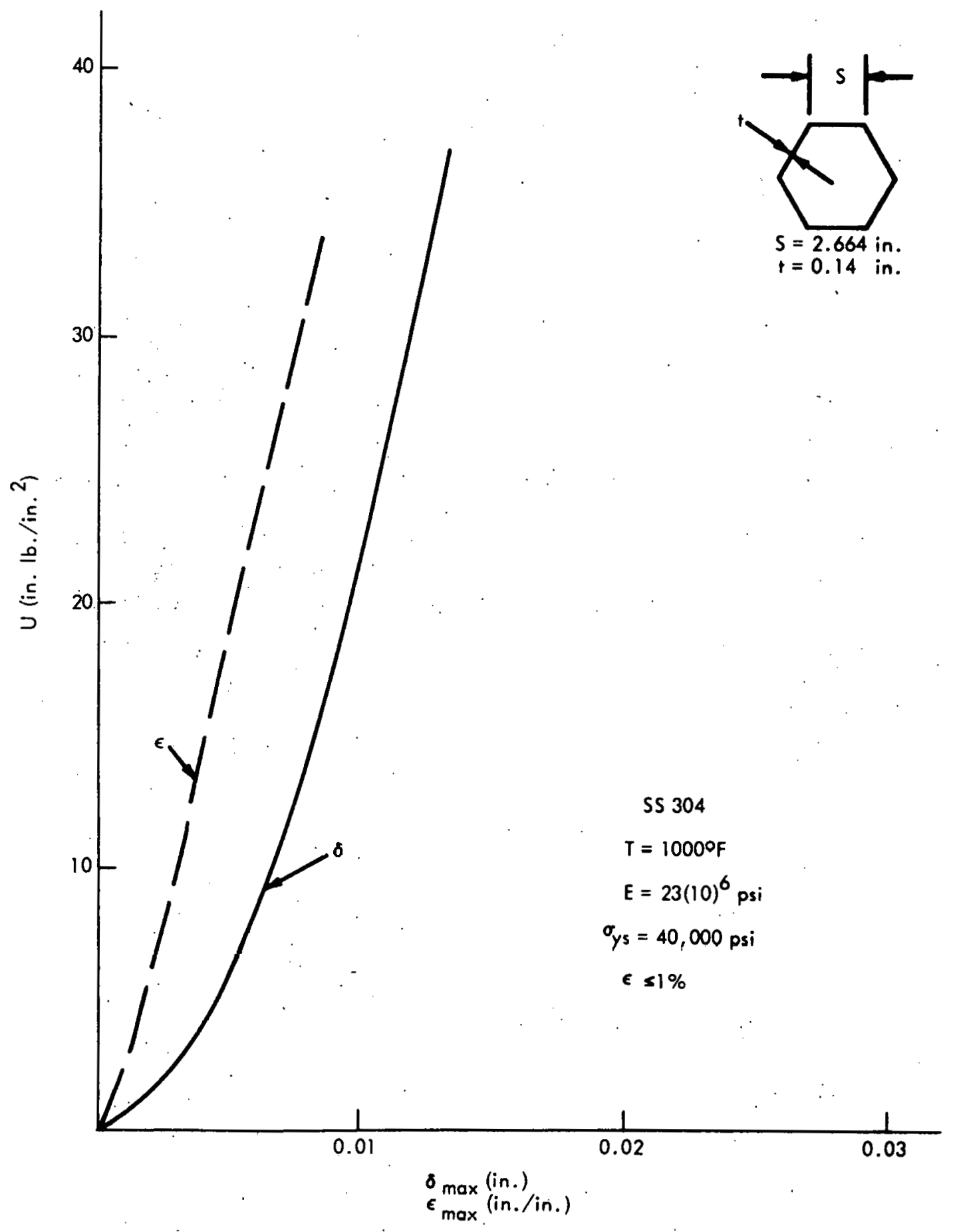

GD9-105

Figure 6-11. Energy Versus Deflection and Strain in FFTF Core Duct, Parameter Set 2

.79. 


\subsection{DEFLECTIONS OF AN IRRADIATED DUCT}

The preceding part of Section 6 has dealt with shock loadings and elastic-plastic deflection early in duct life, where the ductility permits large deflections and high strains. The following is an attempt to determine the duct response late in duct life when irradiation has significantly reduced elongation and increased ultimate strength and yield strength.

In attempting to determine the duct response characteristics it is essential to know the maximum pressure, duration and shape of the forcing impulse, in order to establish if the load will produce either impulse-, dynamic-, or approximate static loading conditions. Information presently available on the load characteristics is insufficient to precisely determine the type of duct response. However, preliminary results indicate that the duration of load was long compared with the period of the duct. The static load procedure was chosen for the analysis reported in this subsection.

Three areas were investigated.

- elastic deflections of the duct wall

- elastic deflections of the assembly

- elastic-plastic deflections of the duct wall.

\subsection{1 bilastic Meflestions, Hexagonal Duct}

Analysis was performed to accurately define the elastic limit of the hexagonal duct. 'The following assumptions are used in this analysis:

- Hook's Law applies.

- Effect of axial pressure variation is negligible.

- Channel-thickness-to-diameter ratio is small enough to be considered thin wall (membrane).

- Nonlinear stress distribution near corners does not affect moment distribution determined by energy methods.

- Shear stresscs are negligible.

The cross section of the duct to which the analysis is applited is given in Figurc 6-12.

$$
0-\frac{A}{2}-\frac{T}{2}=(4.615-0.14) 0.5=2.2375 \text { inches }
$$

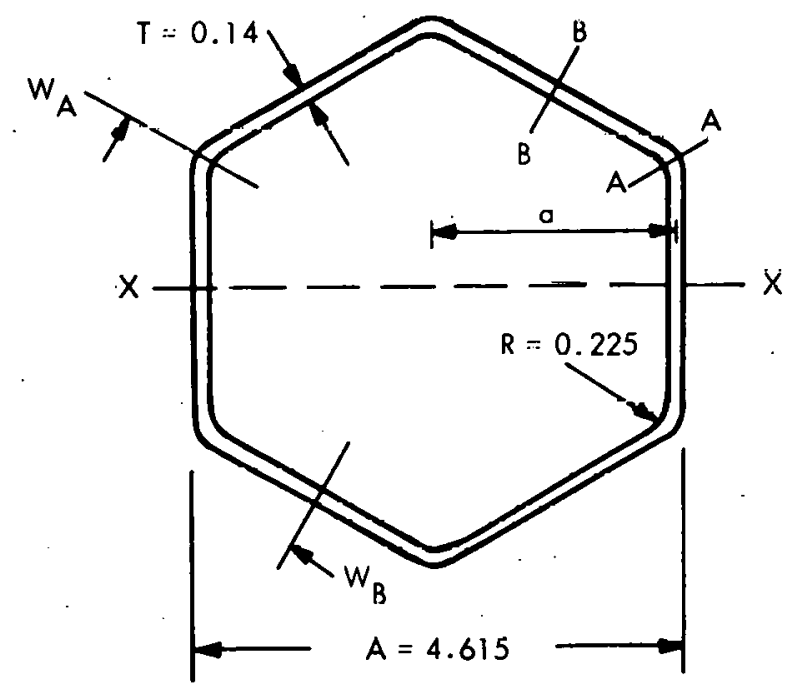


Using the geometry and nomenclature of Figure 6-12, the membrame stresses in the duct wall are:

$$
\begin{aligned}
& \sigma_{\text {mem A }}=W_{A} / T=18.206 \cdot p \\
& \sigma_{\text {mem B }}=W_{B} / T=16.239 \cdot p
\end{aligned}
$$

The total stresses at location $A$ and $B$ are:

$$
\begin{aligned}
& \sigma_{\text {tot A }}=203.10 \cdot \mathrm{p} \\
& \sigma_{\text {tot B }}=99.10 \cdot \mathrm{p}
\end{aligned}
$$

A complete derivation of these formulas is found in Appendix E.

A graphic presentation of the maximum wall stresses are shown in Figure 6-13 as a function of the differential pressure, p.

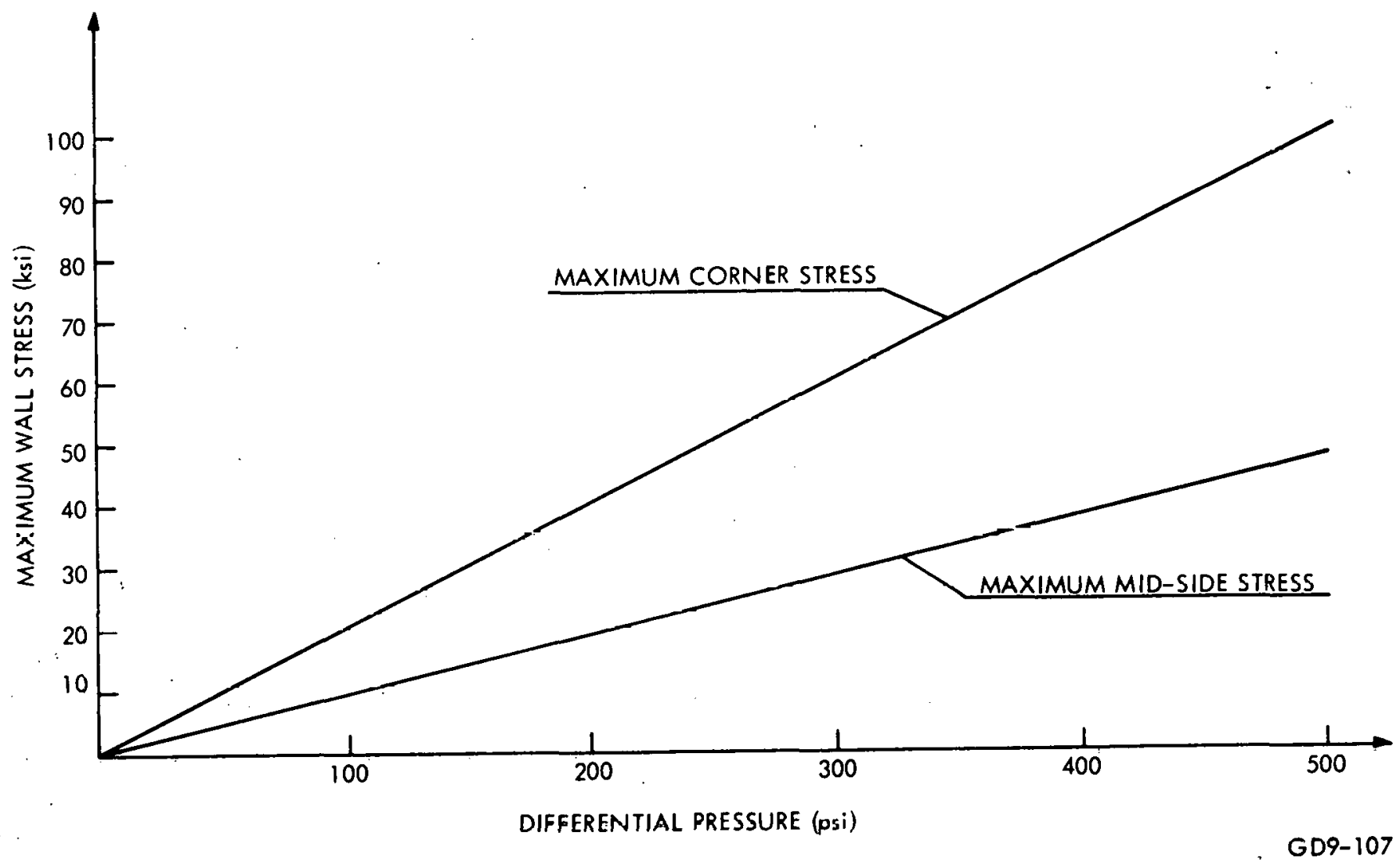

Figure 6-13. Pressure-Induced Bending Stress in Duct Wall 
Figure 6-14 indicates (Ref. 11) that maximum bending stress in the duct corner is $27.2 \%$ higher for the existing geometry of the duct than the equivalent stress in a flat plate.

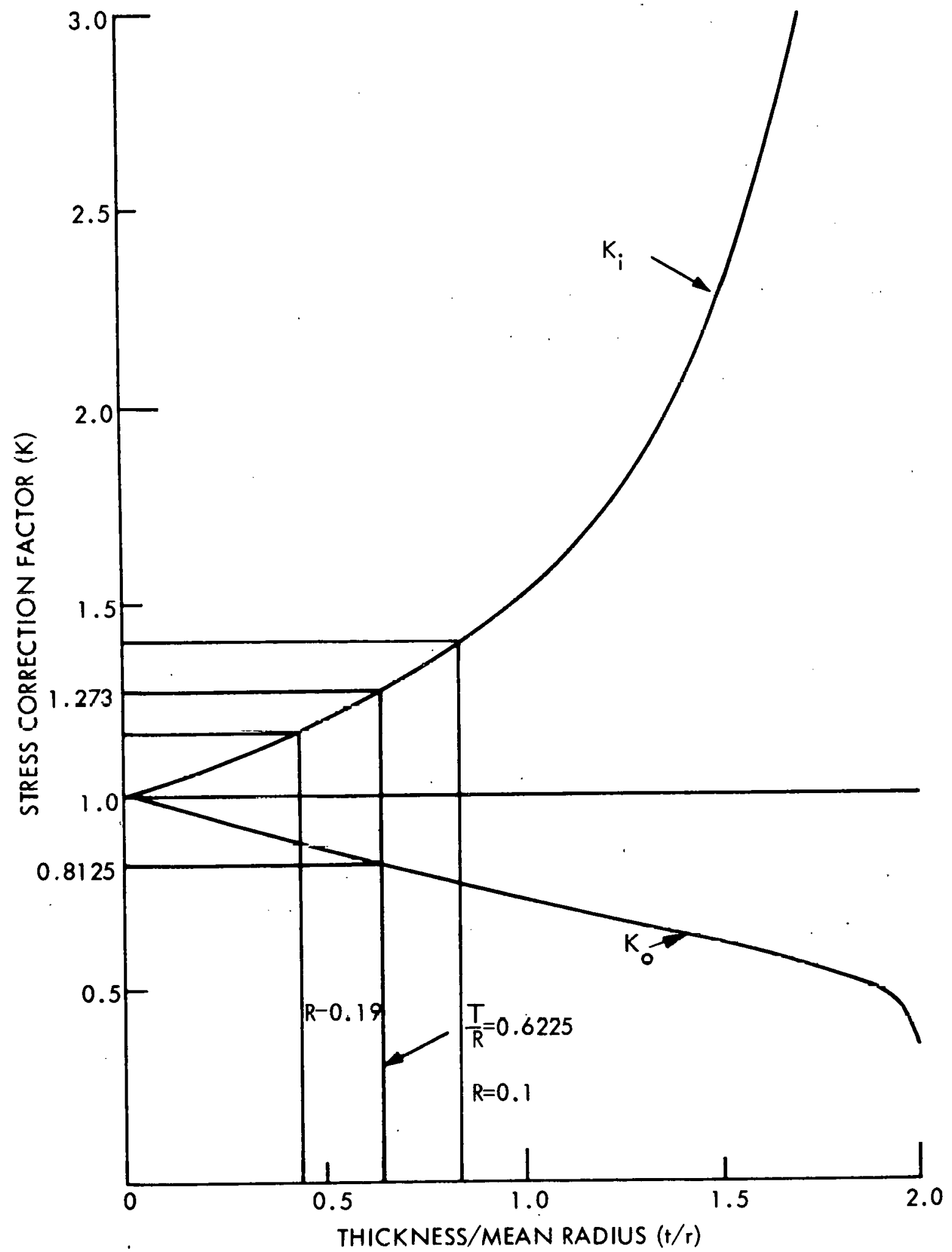

Figure 6-14. Bending Stress Correction for Curuature Effect 
One way to decrease the corner stress is to remove the six corner pins and increase the mean corner radius to 0.720 . This make's $\mathrm{T} / \mathrm{R}=0.195$ which according to Figure 6-14 gives a stress increase due to the corner effect of approximately $7 \%$. This is a $15.7 \%$ decrease of the maximum wall stress.

\subsubsection{Fuel Assembly Deflections}

The deflections and energy absorbed in a duct when bent between supports as a simply supported beam was analyzed assuming locations of support for the fuel assembly as shown in Figure 6-15.

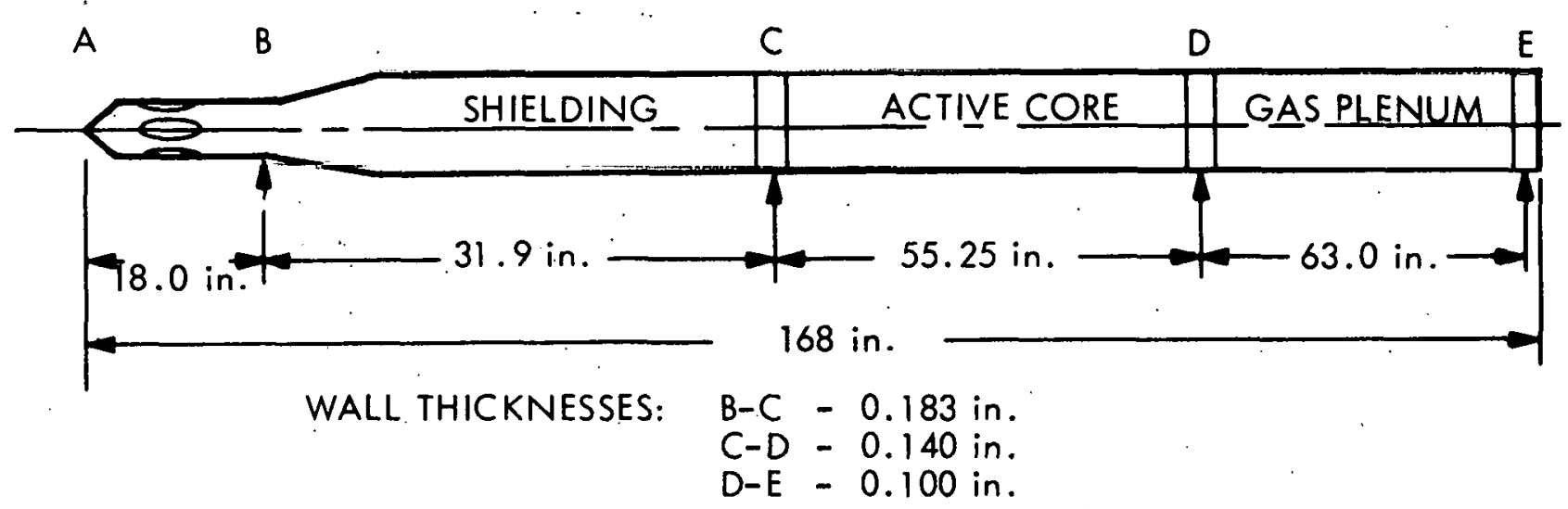

GD9-127

Figure 6-15. Locations for Fuel Duct Support

Since the type of failure investigated in this report will occur in the core section, only this section (C-D) will be considered.

The following assumptions are used in this analysis:

- Hook's Law is valid.

- The cross-section does not change when duct is deflected.

- Shear stresses are negligible.

- Bending does not occur.

- Simple support at the clamps.

- No support from the fuel pins.

The calculational model is shown in Figure 6-16. 


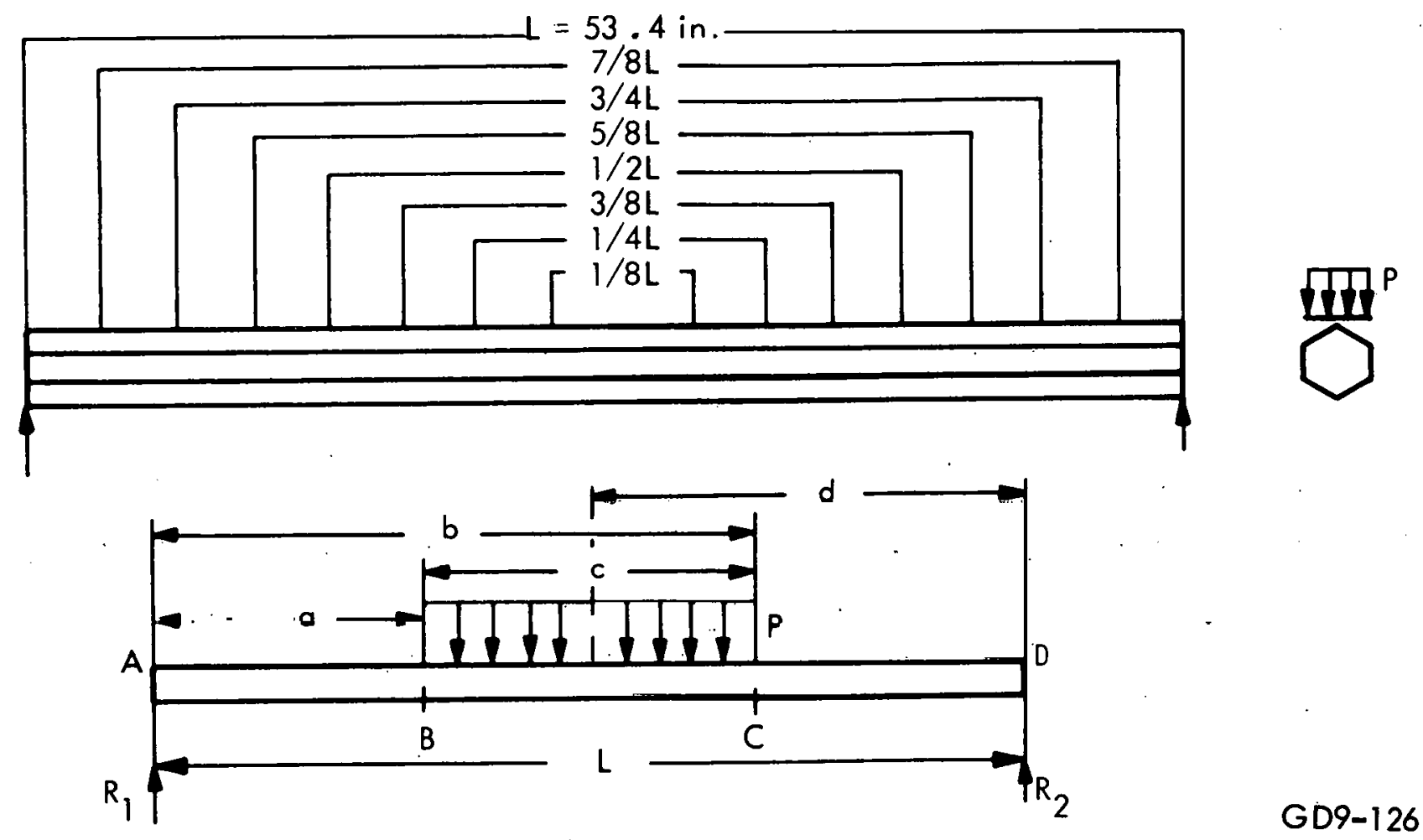

Figure 6-16. Laad Model Assumed for Suggested Duct Analysis

The formulas used for moment and deflection are given in Reference 10.

$$
\begin{aligned}
& \mathrm{R}_{1}=W \cdot \frac{d}{L} \quad W=P \cdot c \\
& R_{2}=\frac{W}{L}\left(a+\frac{1}{2} c\right) \\
& A-B: \quad M=R_{1} X \\
& B-C: \quad M=R_{1} X-W \frac{(X-a)^{2}}{2 c} \\
& C-D: \quad M=R_{1} X-W\left(X-\frac{1}{2} a-\frac{1}{2} b\right)
\end{aligned}
$$

\section{Deflection:}

$$
\begin{aligned}
& A-B \quad y=\frac{1}{48 E I}\left\{8 R_{1}\left(X^{3}-L^{2} X\right)+W x\left[\frac{8 d^{3}}{L}-\frac{2 b c^{2}}{L}+\frac{C^{3}}{L}+2 C^{2}\right]\right\} \\
& B-C \quad y=\frac{1}{48 E I}\left\{8 R_{1}\left(X^{3}-L^{2} X\right)+W X\left[\frac{8 d^{3}}{L}-\frac{2 b c^{2}}{L}+\frac{C^{3}}{L}+2 C^{2}\right]-2 W \frac{(X-a))^{4}}{C}\right\} \\
& C-D \quad y=\frac{1}{48 E I}\left\{8 R_{1}\left(X^{3}-L^{2} X\right)+w X\left[\frac{8 d^{3}}{L}-\frac{2 b c^{2}}{L}+\frac{C^{3}}{L}\right]-8 W\left(X-\frac{1}{2} a-\frac{1}{2} b\right)^{3}+W\left(2 b c^{2}-C^{3}\right)\right\}
\end{aligned}
$$


The procedure to calculate the energy absorbed in the duct is similar to the one used for the duct wall.

$$
U=\frac{1}{2}\left[\left(\frac{y_{n}+y_{n+1}}{2}\right) \cdot p \cdot d x\right]_{x=0}^{x=c / 2}
$$

the bending stress in the beam is given by:

$$
S_{B}=\frac{M \cdot k}{I}
$$

where $\mathrm{K}=2.6188$

and $I=6.043$

Figure 6-17 shows duct responses when a duct is bent by external pressure in the mode indicated on the figure. When the stresses reach the yield stress, the duct will buckle and the part of the graph above this specific stress is no longer valid.

Without analytic proof, it is expected that the pressure load is too rapid for the relatively heavy fuel duct to respond as indicated on Figure 6-17. It is more likely that the duct wall deforms locally in the same mode as when pressurized internally. This same (secondary) duct is assumed to be at normal operating temperature $915^{\circ} \mathrm{F}$ and should absorb more energy than the initial duct before failure.

\subsubsection{Elastio-Plastic Deflection of Duct Wall}

Duct wall deflection was analyzed when the imposed pressures result in partially plastic deformation. The corner and possibly the middle of the flat develop plastic hinges with the intermediate material being either elastic or partially plastic. The maximum material strain in the corner is in the range of the minimum expected ductility of irradiated ducts (1\%). This analysis permitted a more extensive parameter study of this region than time permitted with the "GASP" code used for the ductile material cases.

The principle assumption permitting analysis of the wall in the plastic regime is the straight beam approximation.

The equivalent straight beam is taken as having a length equal to the duct wall neutral axis between adjacent corners when the corner radius is zero. This permits integration of the deflection of the beam and ealculation of the energy absorbed during the elastic and plastic deflection. Appendix $\mathrm{E}$ develops the equations for the beam deflections.

The derived expressions for deflection of the elastic-plastic beam are used to numerically integrate the energy absorbed in the beam:

$$
U=\frac{1}{2} \sum_{x=0}^{x=L / 2}\left[\left(\frac{y_{n}+y_{n+1}}{2}\right) \cdot p \cdot d x\right]
$$

The result using this procedure is presented in Figure 6-18 showing wall deflection, and 6-19 showing energy absorbed versus yield strength and applied pressure.

Figure 6-20 is calculated for 6 different values of modulus of elasticity ranging from $E=23 \times 10^{6}$ to $28 \times 10^{6}$ to illustrate the effect of the modulus of elasticity on the results. Pressure is adequate to develop a plastic hinge in the corner and at the middle of the flat side. 


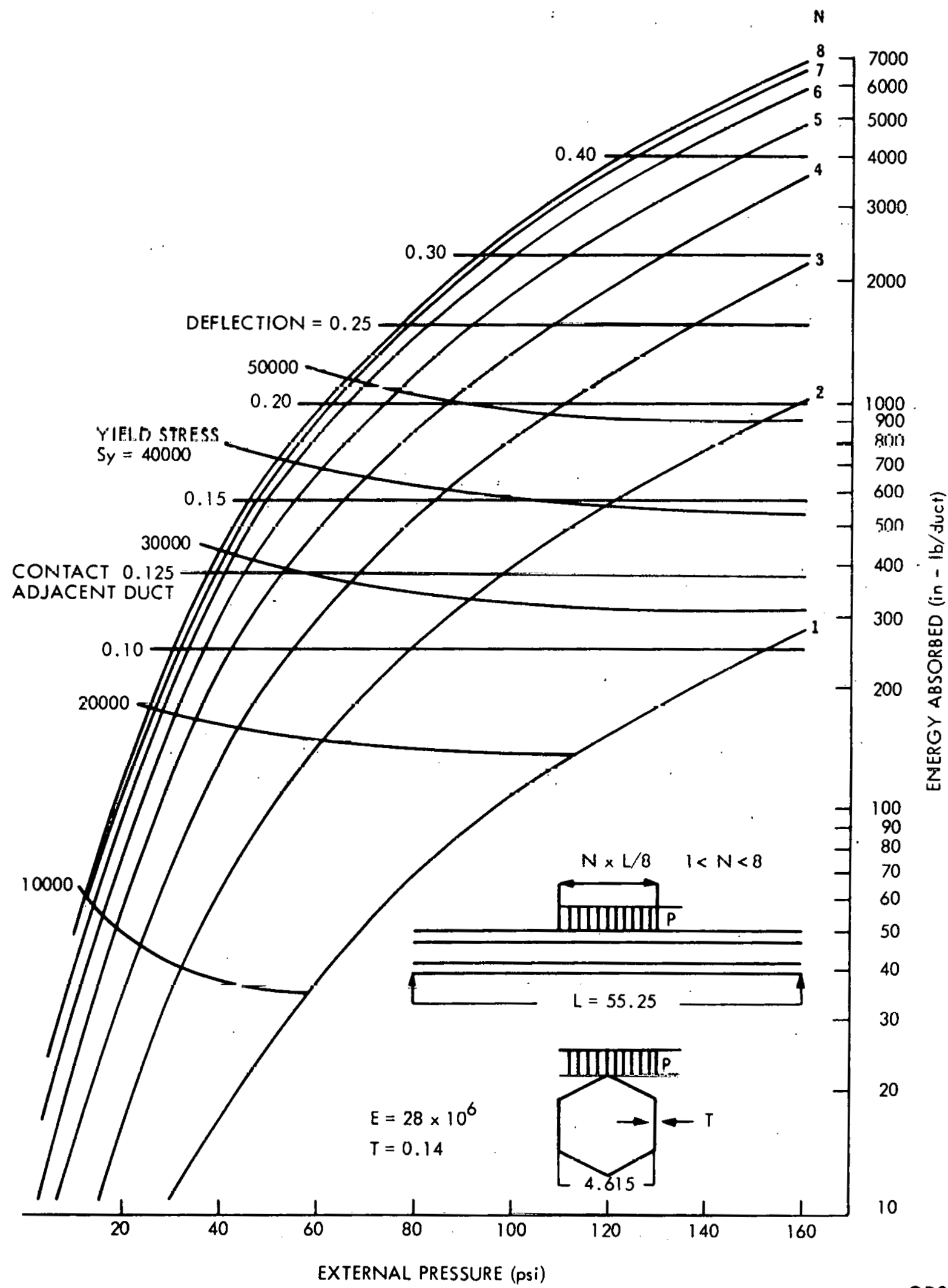

Figure 6-17. Energy Absorbed in Duct Versus External Pressure (Duct is simply supported) 


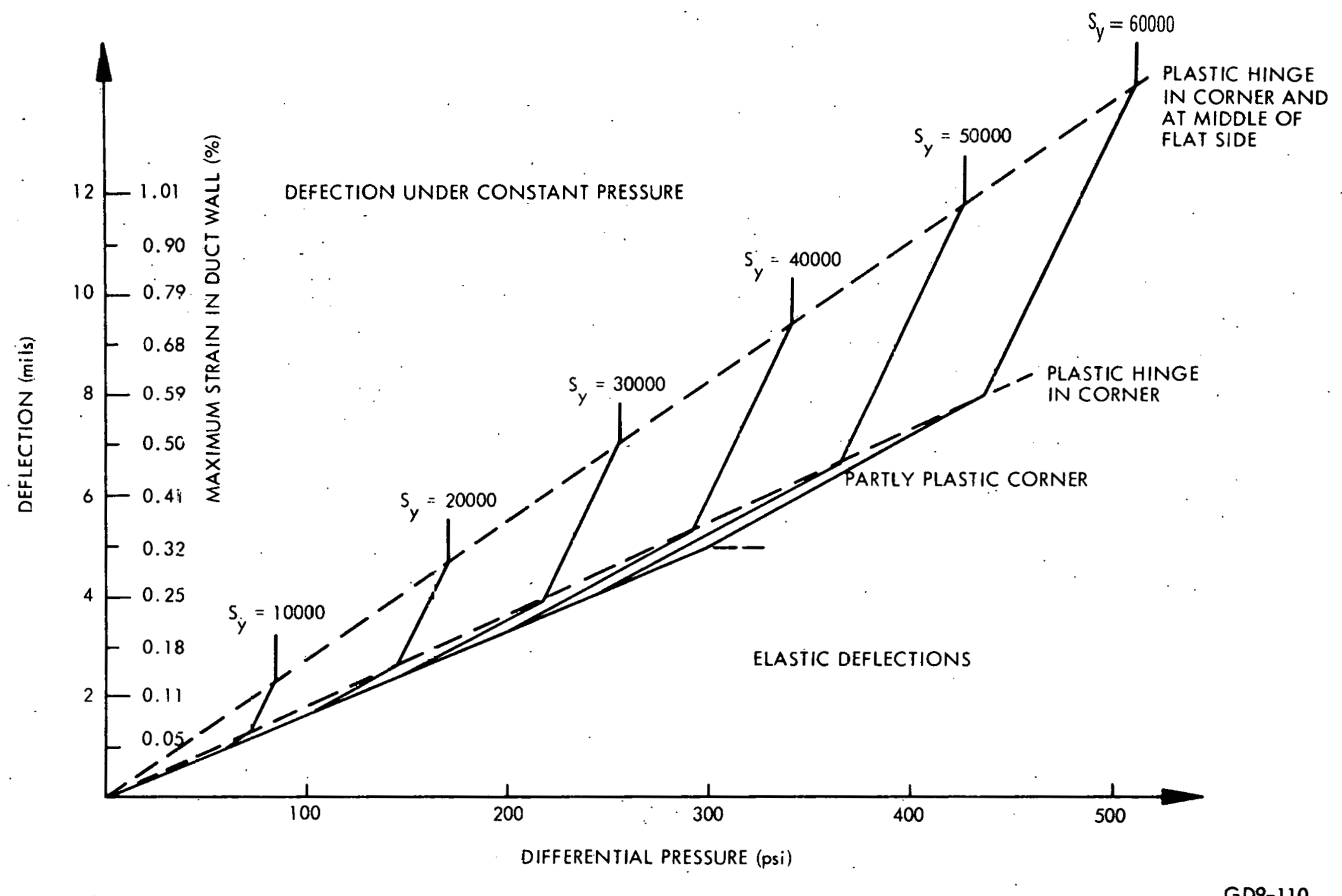




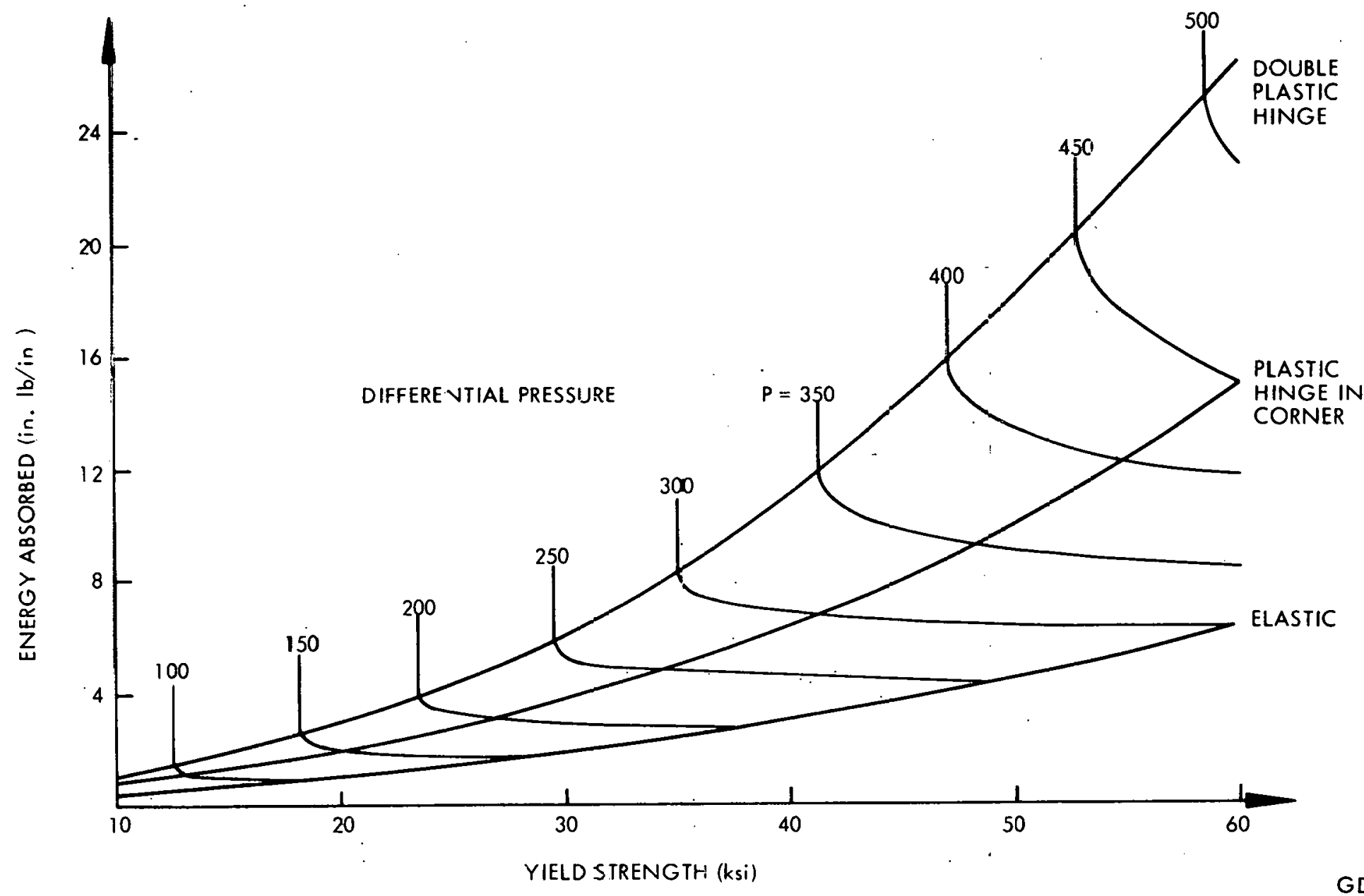

Figure 6-19. Energy Absorbed Per Inch Dust Length Versus Yield Strength with Difïerential Pressure as a Parameter 


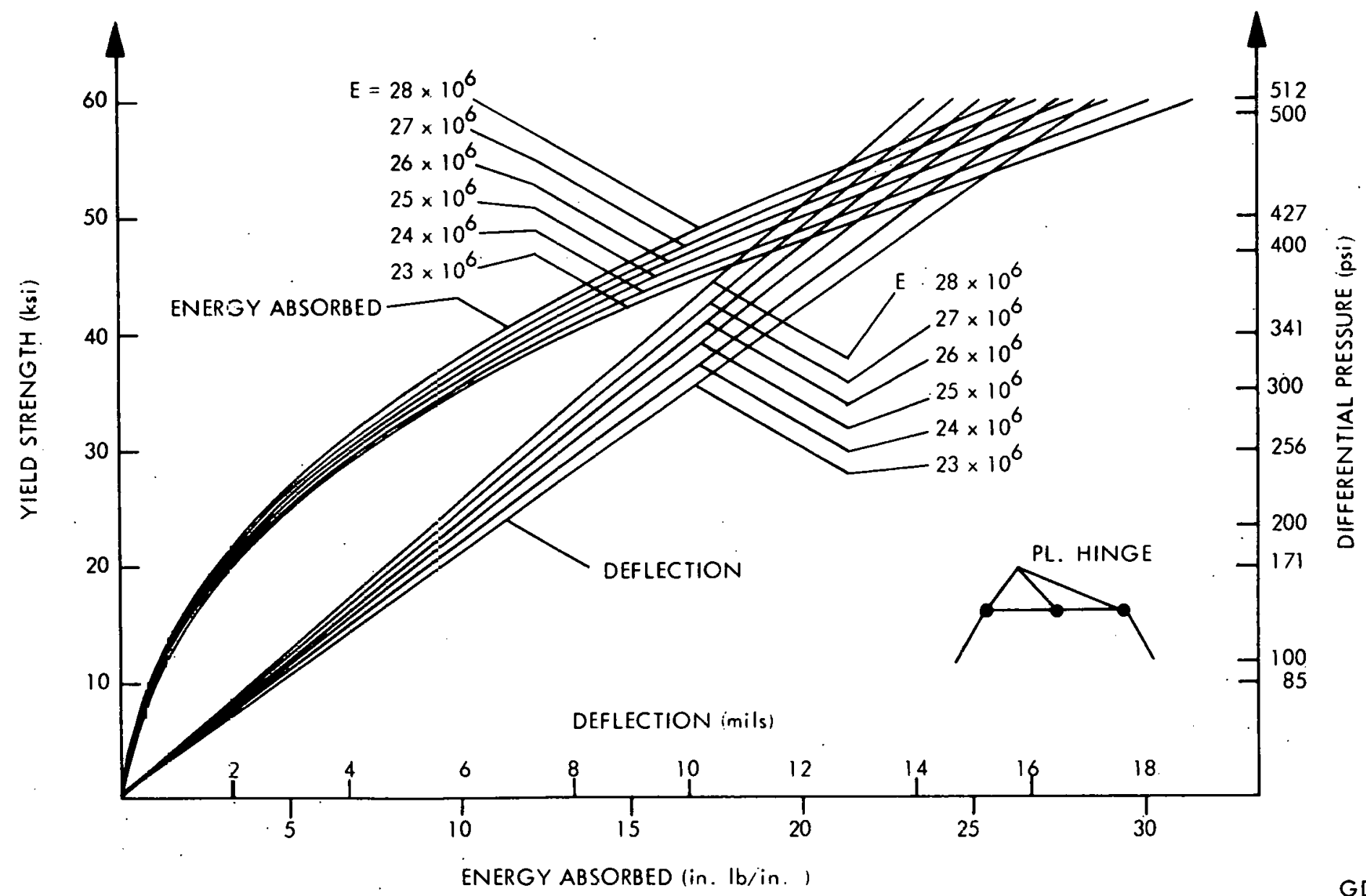




\subsubsection{Expected Accuracy}

The elastic part of this analysis is expected to be within 5\% accuracy. Two different procedures have been compared and the correlation is excellent. The plastic calculations contain more uncertainties due to the facts that the assumptions and the straight beam model introduce greater errors in the plastic regime. However, some arbitrary points on Figure 6-18 and 6-19 have been checked by substituting the corresponding values for $E, P, S_{y}$ into GASP. This computer code should be accurate for elastic or slightly plastic deformations. The points that were checked indicated a maximum deviation from GASP results for plastic conditions in corners of less than $10 \%$ and for double plastic hinges less than $20 \%$. Because strain hardening is not accounted for in this analysis, the relative error will increase for an increase in wall deflection beyond the double plastic hinge condition.

The relationship between mid-wall deflection and maximum strain in duct corner plotted on Figures 6-21 and 6-22 was obtained from several GASP runs. The results were used to add the strain shown on Figures 6-18 and 6-23.

\subsection{THE EFFECT OF THE PARAMETERS ON THE DUCT RESPONSE}

\subsubsection{Wall Thickness}

To establish the dependency of the wall thickness on the duct-damage some calculations have been carried out for two different wall thickness, 0.14 in. and 0.19 in. The results are shown in Figure 6.23 which gives strains and duct responses when both ducts contain a pressure sufficiently high to develop plastic hinges in the corner and at the middle of the flat side. Assuming the same yield strength for the two ducts, Figure 6.23 indicates that by increasing wall thickness from 0.14 to 0.19 the ability of the duct to contain a static pressure increase approximately $70 \%$. Energy absorbed shows a slight increase and deflection shows a minor decrease. (For a given deflection the maximum strain will. increase with wall thickness in the ratio $T_{1} / T_{2}$ where $T_{1}>T_{2}$, in this case $E_{1}=E_{2} \cdot 0.19 / 0.14=1.36 \cdot E_{2}$.) It does not appear that an increase in wall thickness will contribute significantly to the capability of the duct to absorb energy.

\subsection{Flat to Flat Outside Dimenșions}

The above results are based on a flat to flat outside dimension of 4.615 in. By increasing this value to 4.8 inches the deflection will increase by the ratio $\mathrm{L}^{4} / \mathrm{L}_{1}{ }^{4}=4.8^{4} / 4.615^{4} \cong 1.16$ assuming the same diffcrential pressure in both cases. Uitferential pressure to produce a specific stress in the duct wall will decrcase by the ratio $L^{2} / L_{1}{ }^{2}-1.8^{2} / 1.615^{2}=1.08$. Energy absorbed which is a function of deflection $x$ pressure will increase by the ratio $1.16 / 1.08=1.075$.

\subsubsection{Corner Radius}

The possible range for the internal corner radius is 0.10 to 0.25 . The reference FFTF value used is 0.155 . The effect of this radius is tabulated in Figure 6-14 in terms of a stress correction factor $\mathrm{K}_{\mathrm{i}}$ and $\mathrm{K}_{\mathrm{o}}$ which represent the ratio of the aclual stress to stress computed by ordinary flexure formula for a flat beam. $K_{i}$ refers to inside and $K_{0}$ outside of the duct.

Assuming constant wall thickness ' $\mathrm{I}$ ' $=0.14$ inches, the ratio:

$$
\begin{array}{ll}
\frac{\mathrm{T}}{\mathrm{r}_{1}}-\frac{0.14}{0.1+0.07}=\frac{0.14}{0.17}=0.023 & \mathrm{r}=0.1 \\
\frac{\mathrm{T}}{\mathrm{r}_{2}}=\frac{0.14}{0.25+0.07}=\frac{0.14}{0.32}=0.437 & \mathrm{r}=0.19
\end{array}
$$

which gives respectively,

$$
\begin{aligned}
& \mathrm{K}_{\mathrm{i}}=1.40 \\
& \mathrm{~K}_{\mathrm{i}}=1.17
\end{aligned}
$$

compared with $\mathrm{K}_{\mathrm{i}}=1.273$ for the reference geometry. 


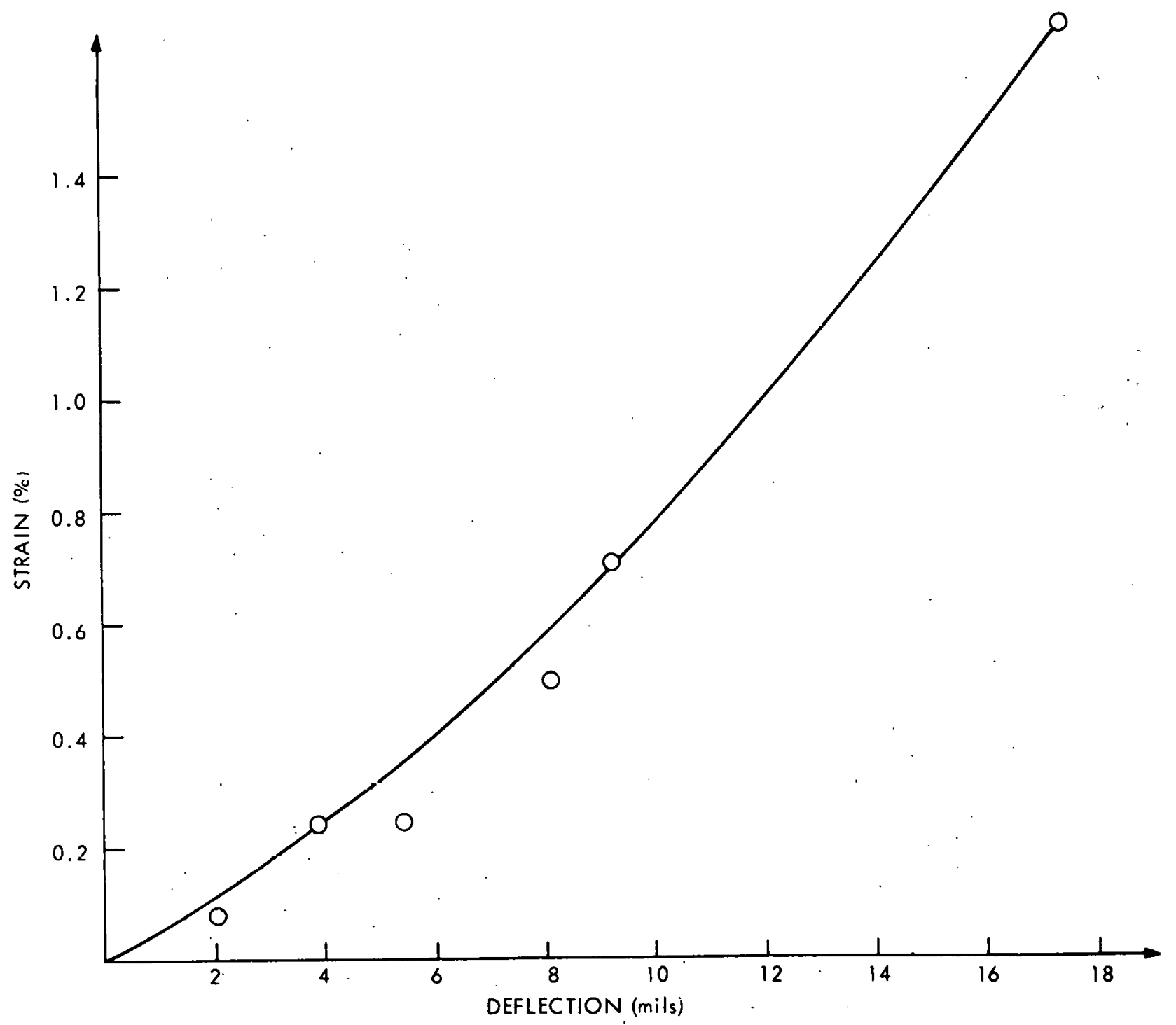

GD9-113

Figure 6-21. Maximum Strain in Duct Wall (Inside at Mid-Corner) Versus Deflection at Middle of Flat Side 
GEAP-10059

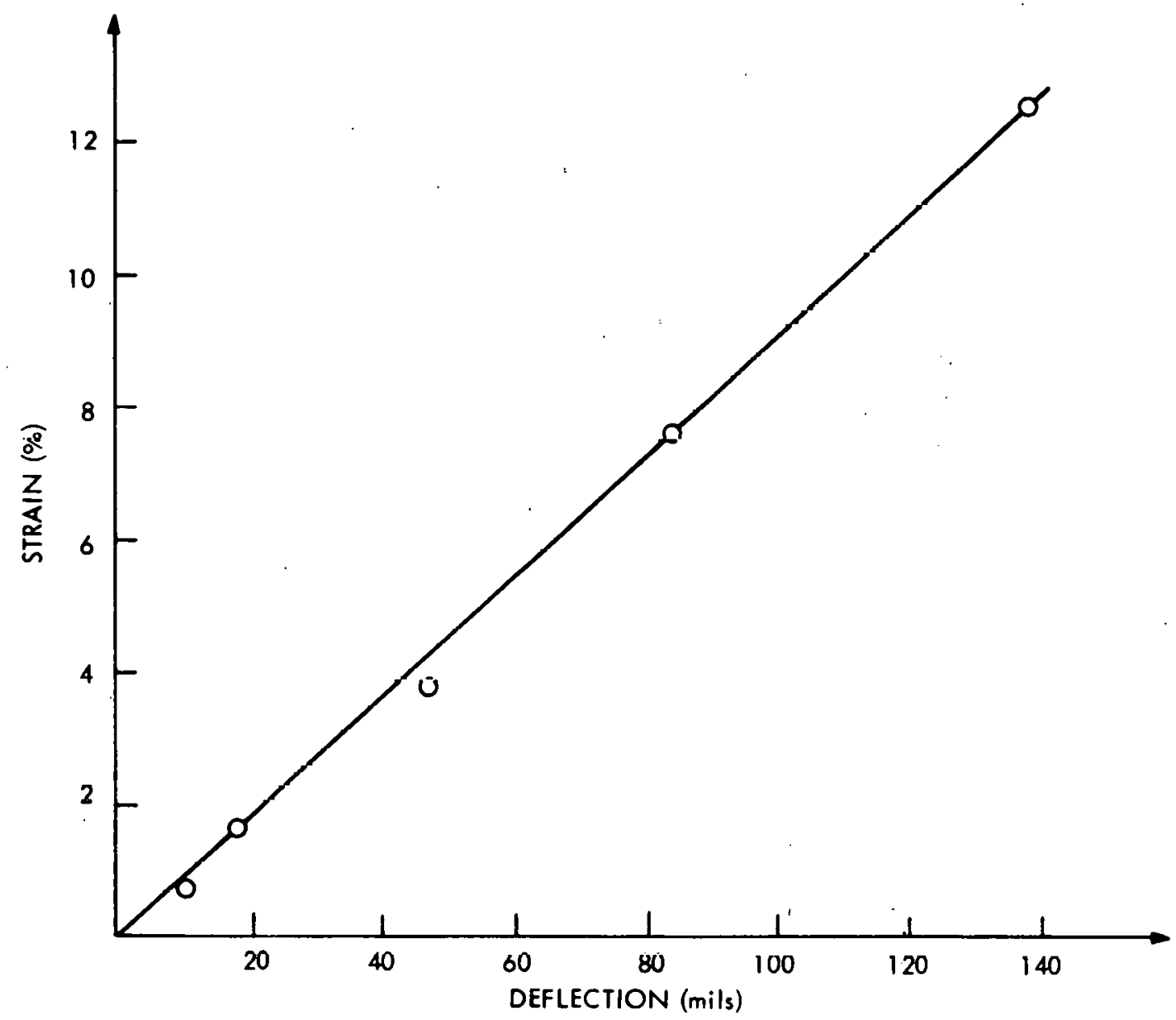

GD9-114

Figure 6-22. Maximum Strain in Duct Wall (Inside at Mid-Corner) Versus Deflection at Middle of Flat Side, Extended Deflection Range

-92- 


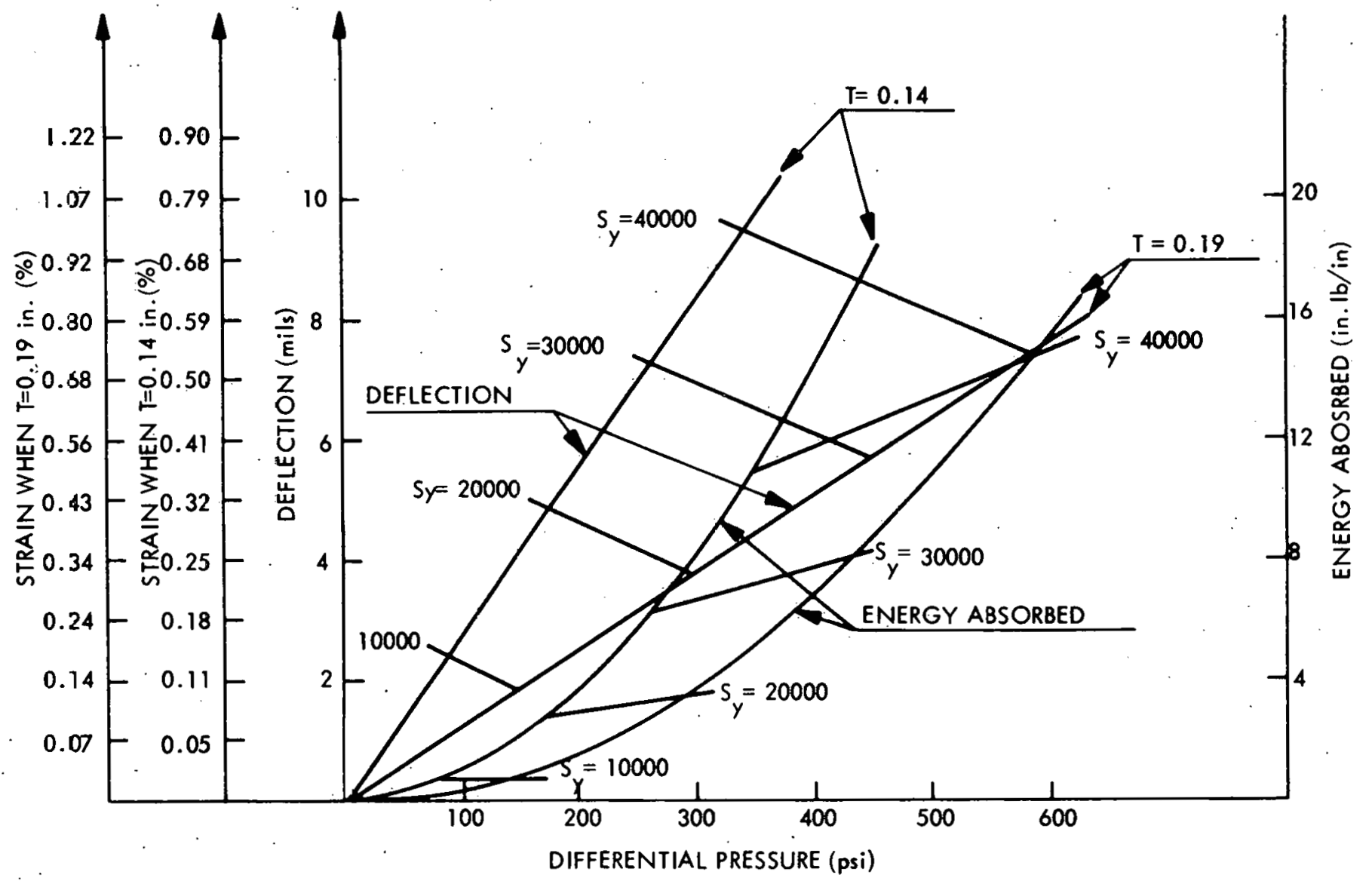

Figure 6-23. Some Duct Responses for Two Different Values of Wall Thickness, Plastic Hinge in Corner and at Middle of Flat Side 
This represents a stress increase of $10.0 \%$ and a stress reduction of $8.1 \%$, respectively.

\subsection{RESULTS APPLIED TO THE LOSS OF FLOW ACCIDENT}

Figure 6-24 shows the ductility of duct wall for different fluences above $1 \mathrm{MeV}$ and Figure 6-25 shows ultimate strength of the duct wall as a function of time after the hypothetical flow blockage. As expected a significant reduction in both properties occurs after $\sim 1$ second when vapor is formed in the duct and a steep rise in duct temperature takes place.

The basis for the time-temperature relationship after flow blockage is given in Section 3 and material properties in Appendix A.

Figure 6-26 gives the calculated energy absorbed in duct wall as a function of time after flow blockage. The dotted part of this figure is extrapolated from other graphs and is shown only to indicate order of magnitude and trends. For a fluence of 2 $\times 10^{22}$ the graph indicates energy absorption capability in the duct wall to be $\sim 55 \mathrm{in} \mathrm{lb} / \mathrm{in}$. at normal operating conditions. When flow blockage occurs the temperature starts to rise, causing a reduction in duct strength, and ductility, which in turn lowers the energy required before failure. At about 2.0 to 2.5 seconds after the initial flow blockage the possible energy deposited in the duct wall equals or exceeds the energy absorption capability. This means that after $\sim 2.5$ seconds the initial duct may crack open for this hypothetical accident. This permits the pressure in the duct to be relieved into the space between the ducts. To analytically establish a reliable magnitude and history of this pressure between the ducts is extremely difficult. It is believed however that the pressure build-up is too rapid for the relatively heavy fuel bundle to respond in the sense that it deflects like a beam between the clamps. Due to a higher natural frequency the duct wall will probably deflect in the same manner as when bent by internal pressure. This makes it possible to find energy absorbed in the initial and adjacent duct based on the same analysis, if pressure and duct temperature are known.

The two important factors that determine the damage on the adjacent ducts are energy released and ductility. Assuming normal operating conditions the two ducts nearest the crack should be capable of absorbing all the energy released in the initial interaction without themselves failing.

Calculations given in Section 4 indicate that the pressure pulses may be of a repeating nature due to repeated reentry. In a qualitative manner this type of loading may have a strengthening effect on the duct, in the sense that repeated pressure pulses gradually convert the hexagonal shape to a stronger cylindrical section in which fairly uniform hoop strains are produced. The static analysis ilescribed above is based on a quasi-static pressure, and does not account for possible shock-wave ly pie pirissuires.

\section{REFERENCES}

1. Kolsky, H., Stress Waves in Solids, Dover, 1963

2. Cole, Underwater Explosions, Dover, 1965.

3. Glasstone, The Effects of Nuclear Weapons, USAEC, 1962.

4. Timoshenko and Goodier, Theory of Elasticity, McGraw-Hill, 2nd Edition, 1.951.

5. McGonnagle, Nondestructive Testing, Gordon \& Breach, 2nd Edition, 1961.

6. Golden, Tokar and Miller, Thermo-Physical Properties of Sodium - Recommended Values, Reactor \& Fuel Processing Technology Quarterly, 11, No. 1, AEC by Argonne National Laboratory, Winter 1967-68.
7. Wilson, E.L., 'GASP', A Digital Computer Program for the Finile Elemeni Anulysis of Sulids with Nonlinear Material Properties, Aerojet-General Technical Memnrandum No ?.3, 196.5

8. Flowers, C.D., Structural Analysis of a Hexagonal Tube or Ring under Internal Pressure, June 1966, (BNWL-263).

9. Timoshenko, Strength of Materials Part II, D. Van Nustrand Cunpany, Inc., 3rd Edition, 1956.

10. Roark, R.J., Formulas for Stress and Strain, 3rd Edition, 1954.

11. Safety and Economic Characteristics of a $1000 \mathrm{MWe}$ Fast Sodium Cooled Reactor Design, December 1965, (GEAP-4939). 


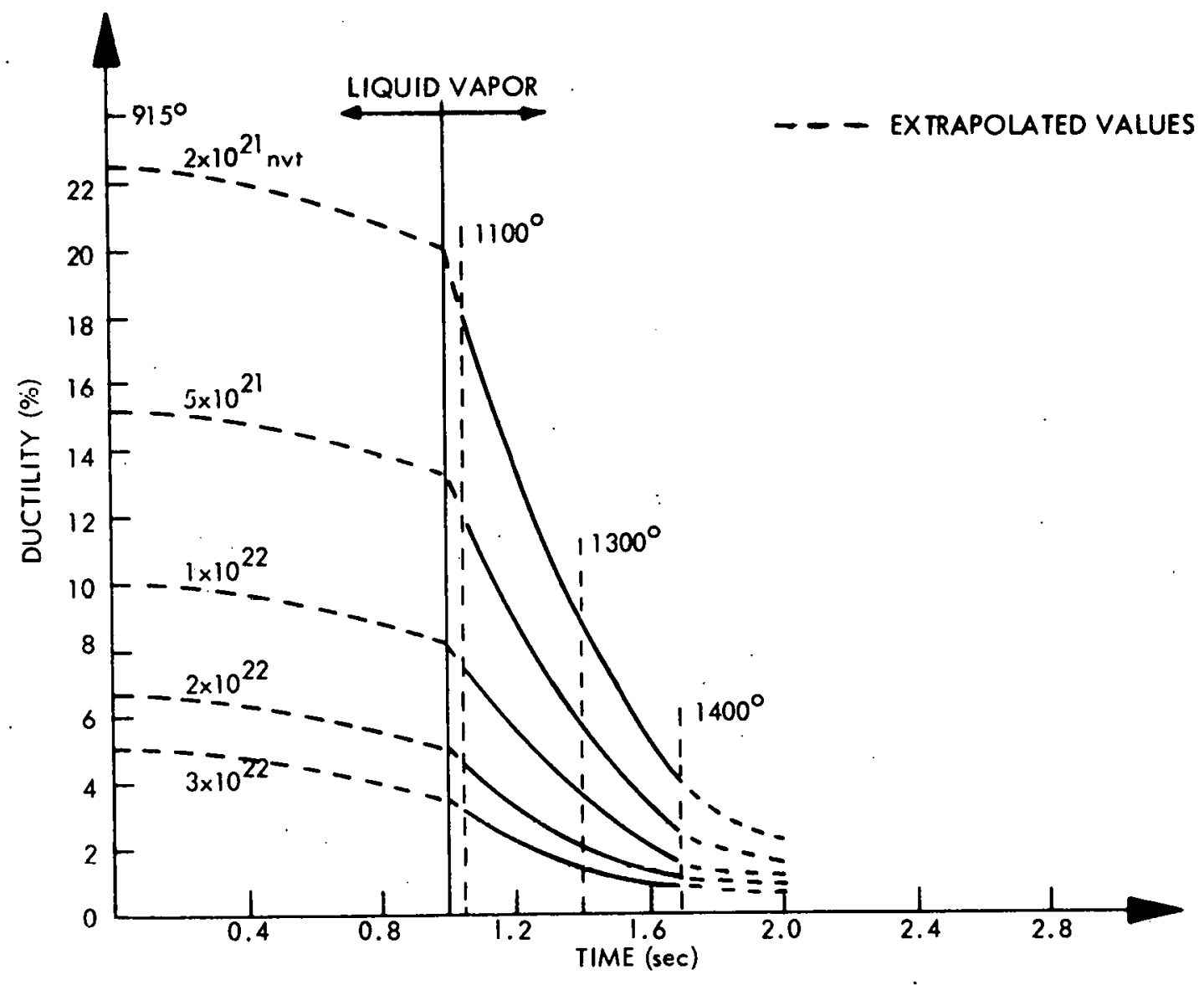

GD9-116

Figure 6-24. Ductility of Duct Wall Versus Time ufter Flow Blockage 


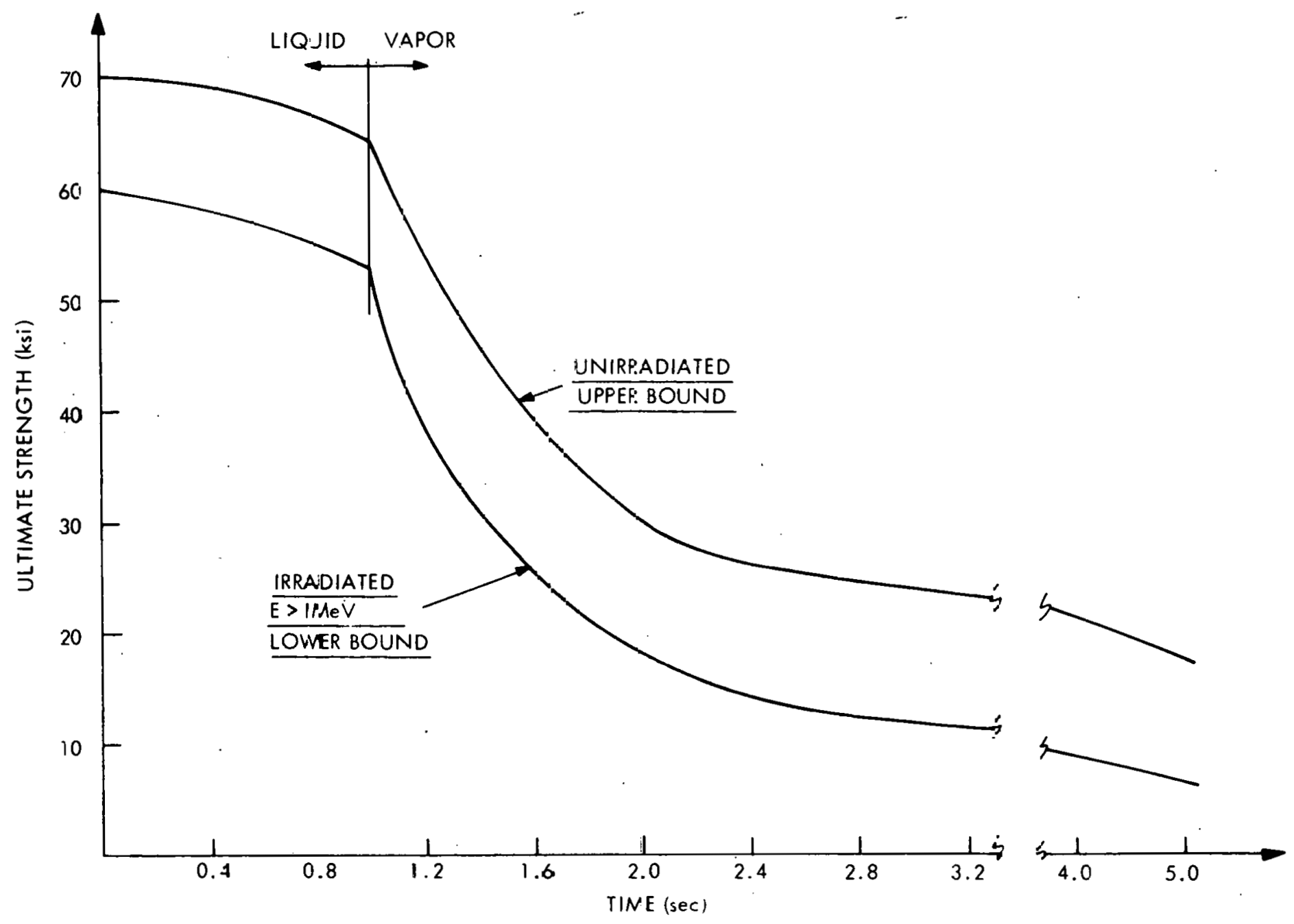

Figure 6-25. Ultimate Stregeth of Duct Wall Versus Time after Flo x: Blockoge 


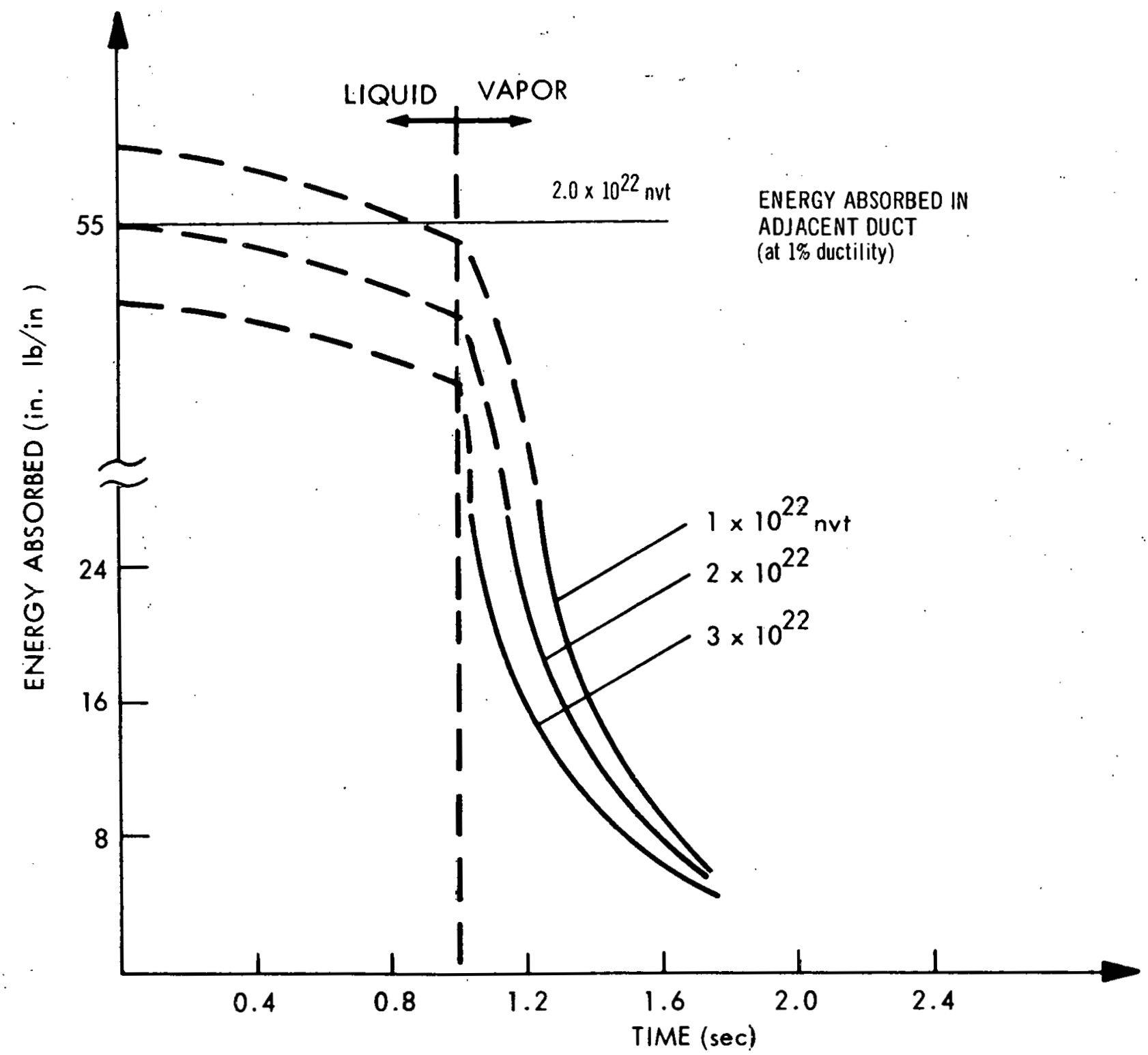




\section{FAILURE PROPAGATION}

\subsection{INTRODUCTION}

The objective of this section is to examine the mechanisms for the propagation of failure between fuel bundles, and to determine the range of mechanical and thermal conditions that will inhibit failure propagation.

Assuming a loss of flow accident in the primary bundle, the following conditions in the primary bundle would result and could affect the performance of the adjacent fuel bundles:

- Generation of significant pressures and quantities of vapor.

- Release of solid debris, such as pieces of clad, wire wrap and fuel.

- Release of molten fuel.

The first step is to identify the possible modes of bundle failure. This is shown in Figures 7-1, 7-2, and 7-3, where the conscquences of these three conditions are traced through the adjacent bundle to either a new equilibrium point or else bundle failure (i.e., loss of sufficient cooling).

At issue is the determination of when the thermal performance of the bundle has been sufficiently impaired to cause failure. The causes of departure from design thermal conditions have been grouped into the categorics of mechanical dantage to the bundle, thermal propagation from the primary bundle, or injection of foreign material into the bundle.

In many instances, a definite conclusion on failure cannot be given, since enough quantitative information on the condition causing the failure is not available, or else is a parameter depending on conditions in the primary bundlcs. This, for example, would include magnitude and duration of applied pressures, volume of vapor injected into the bundle, size and quantity of debris injected, etc. In this case, it has only been possible to draw conclusions based on the driving function as a parameter. Alsu, in instances where failure is indicated, time constants from initiation of the accident to failure condition havc been determined to indicate the time available to react to the situation and prevent the failure.

Referring again to Figures 7-1 through 7-3, the following individual categories were identified as considerations in the failure of the adjacent bundle.

1. Resistance of the duct wall to failure due to external pressure loadings (See Section 6).

2. Response of the fuel pin array to loading through a broken or deflected duct wall.

3. Coolant temperature response to a partial loss of flow caused by plugging of the bundle inlet.

4. Melt through of the channel wall by molten finel from the primary bundlo. Poosibility of südium voiding In the adjacent bundle due to the interbundle heat flux.

5. Interaction of fuel and sodium (see Section 5).

6. Blanketing of fuel pins by vapor or fission gas, injected into the bundle from the primary bundle.

7. Coolant temperature around a local blockage in a coolant channel:

8. Coolant temperature response to a reduction in pitch to diameter ratio, caused by bundle compaction from applied external pressures.

9. Duration of vapor blanketing of a pin due to fission gas release and resulting clad temperature rise. 


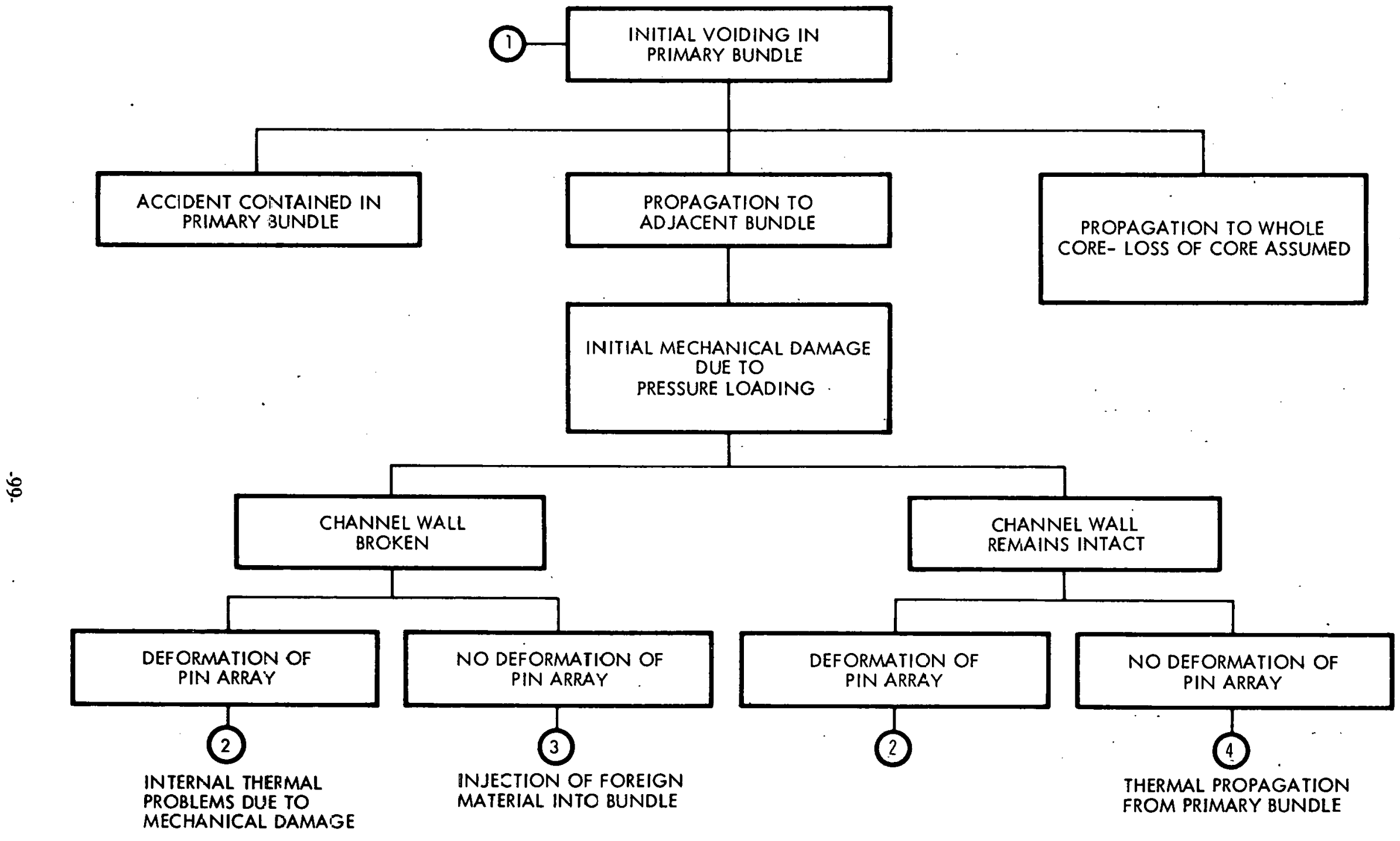




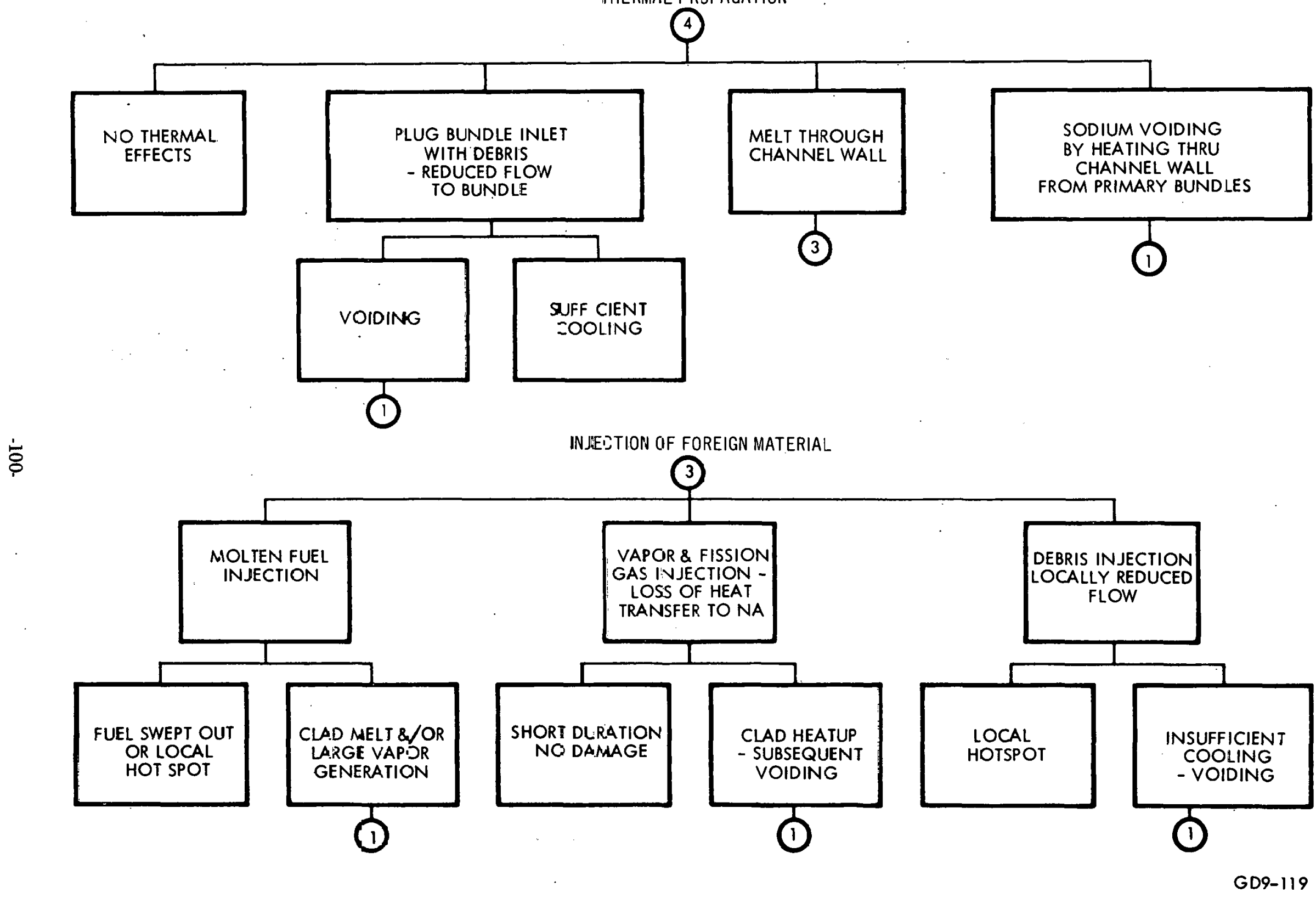

Figure 7-2. Failure Propagation Modes (b) 


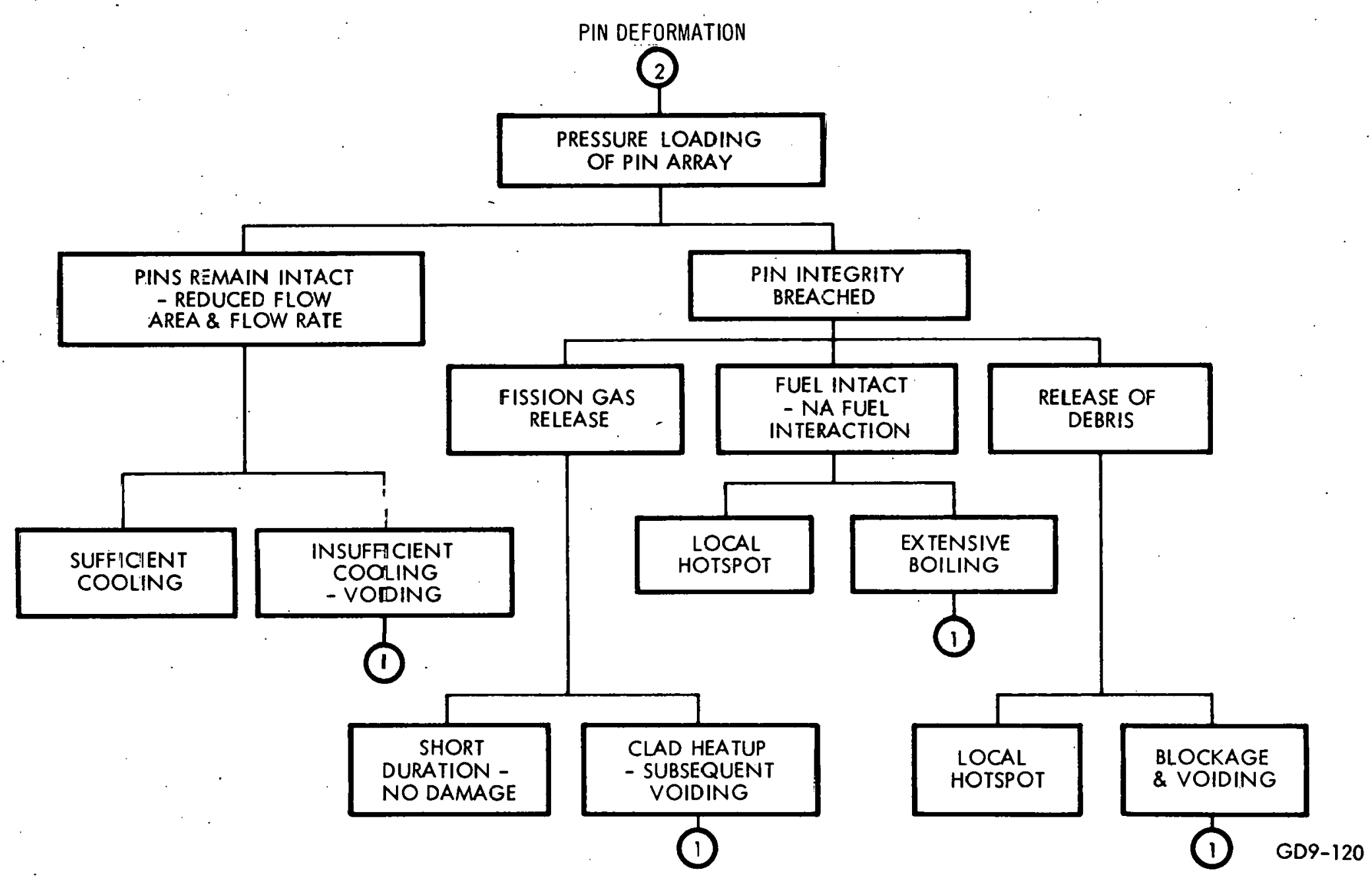

Figure 7-3. Failure Propagation Modes (c) 


\subsection{ANALYSIS}

\subsubsection{Response of the Fuel Pin Array to Loading}

By loading the channel wall with an external pressure, these forces can be transmitted to the fuel pin array as the duct wall either deflects inward or else is sheared off and driven inward by the pressure. Due to the presence of the wire wrap the forces are applied to the pins at the point where the wire wraps are in contact between the wall and the pin or else in mutual contact between two pins.

Referring to Figure 7-4, at the edge of the bundle each pin is required to support an area of the channel wall equal to

$$
A_{w_{p}}=P_{p} P_{w}
$$

wherc $A_{w_{p}}=$ area of channel wall supported by a point of contact of the wire wrap

$$
\begin{aligned}
& P_{p}=\text { pitch of the pin array } \\
& P_{w}=\text { pitch of the wire wrap }
\end{aligned}
$$

These forces are then transmitted inward into the bundle as shown in Figure 7-5. Relating the applied external pressure, $P_{E X T}$, to the force per edge pin, $F_{e}$,

$$
\mathrm{F}_{\mathrm{e}}=\mathrm{A}_{\mathrm{w}_{\mathrm{p}}} \mathrm{P}_{\mathrm{EXT}}
$$

and relating $F_{e}$ to the forces on the internal pins, $F_{i}$,

$$
\begin{aligned}
& 2 \mathrm{~F}_{\mathrm{i}} \cos 30^{\circ}=\mathrm{F}_{\mathrm{e}} \\
& \mathrm{F}_{\mathrm{i}}=\frac{\mathrm{F}_{\mathrm{e}}}{2 \cos 30^{\circ}}
\end{aligned}
$$

Thus each internal pin will see forces due to $\mathrm{P}_{\mathrm{EXT}}$, as shown in Figure 7-5, equal to

$$
F_{i}=\frac{A_{w_{p}}{ }{ }_{E X T}}{2 \cos 30^{\circ}}
$$

To determine the transient response of the pins to this loading is a difficult analytical problem beyond the scope of this study. Therefore, it was decided to evaluate the limiting cases of atcady atate defoumation of the ping to the indicated loading. In steady state, the fuel pellet has negligible resistance to deformation due to its plastic nature at high temperatures. Thus the major static structural characteristics of the bundle are determined by the cladding. Since the applied force, $F_{i}$, is a very localized effect, it was assumed that a fuel pin could be modeled as a thin, infinite cylinder with a single force applied over a small arca, as shown in Figure 7-6. 

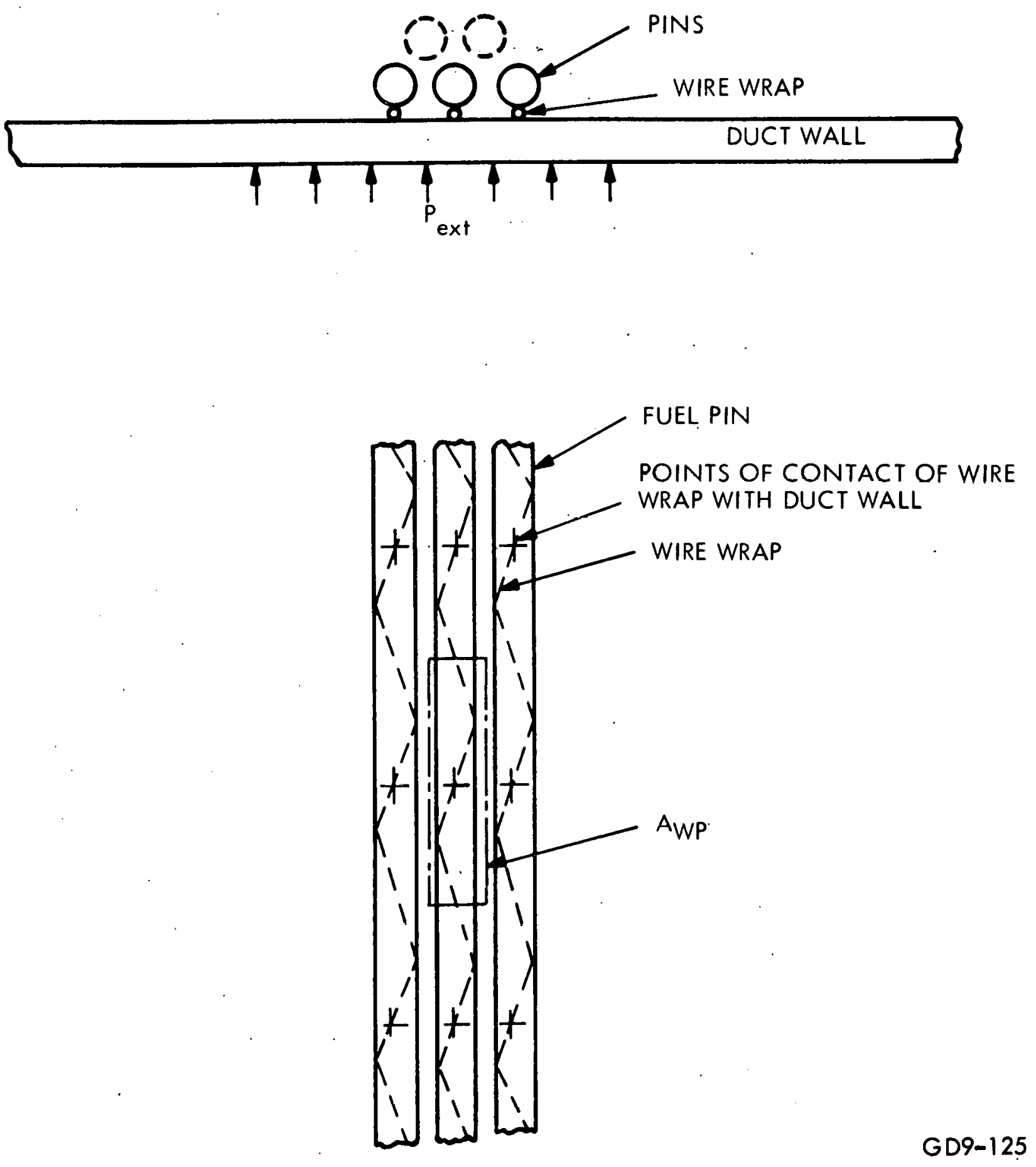

Figure 7-4. Relation of Pins to Channel Wall 

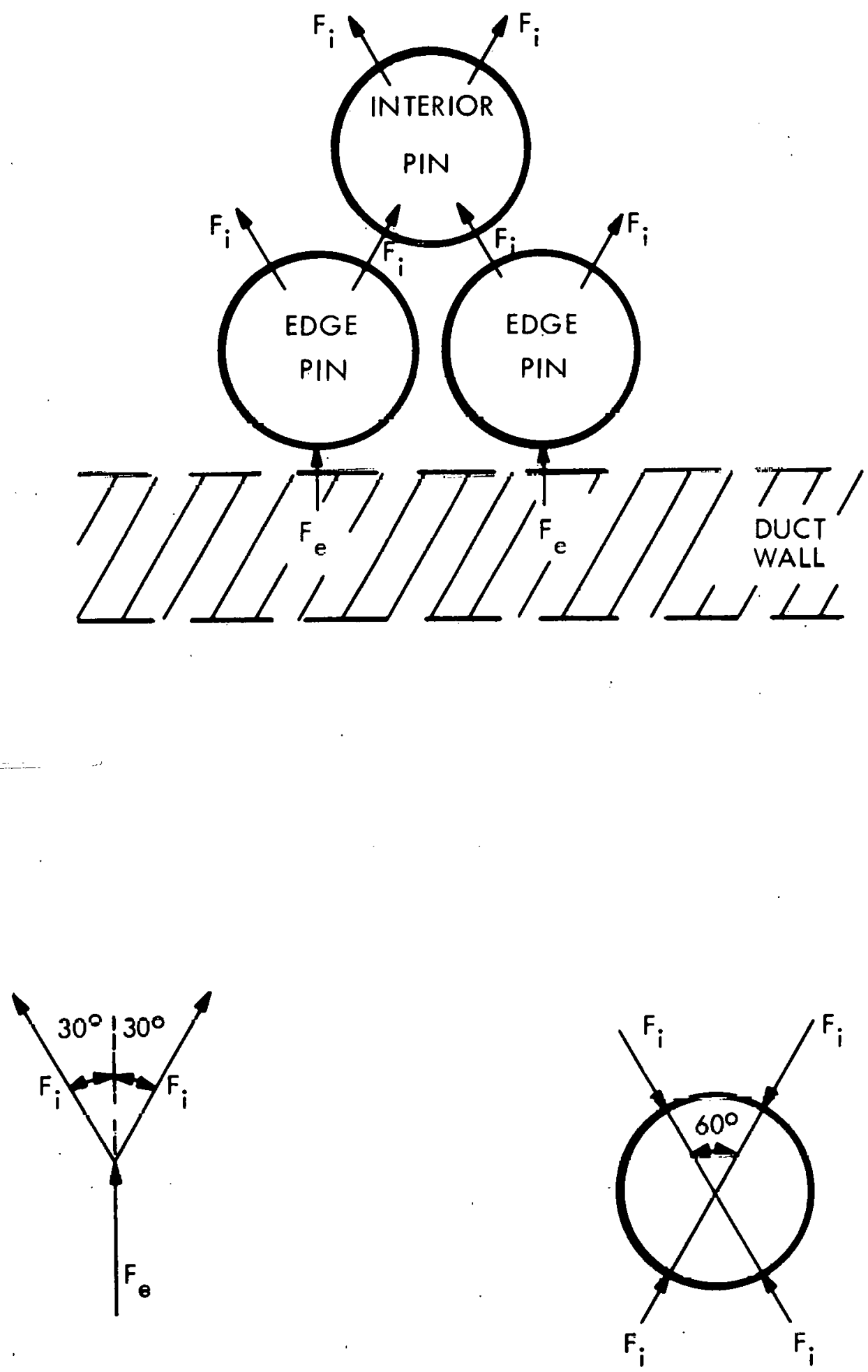

GD9-122

Figure 7-5. The Mode of Fuel Pin Loading 

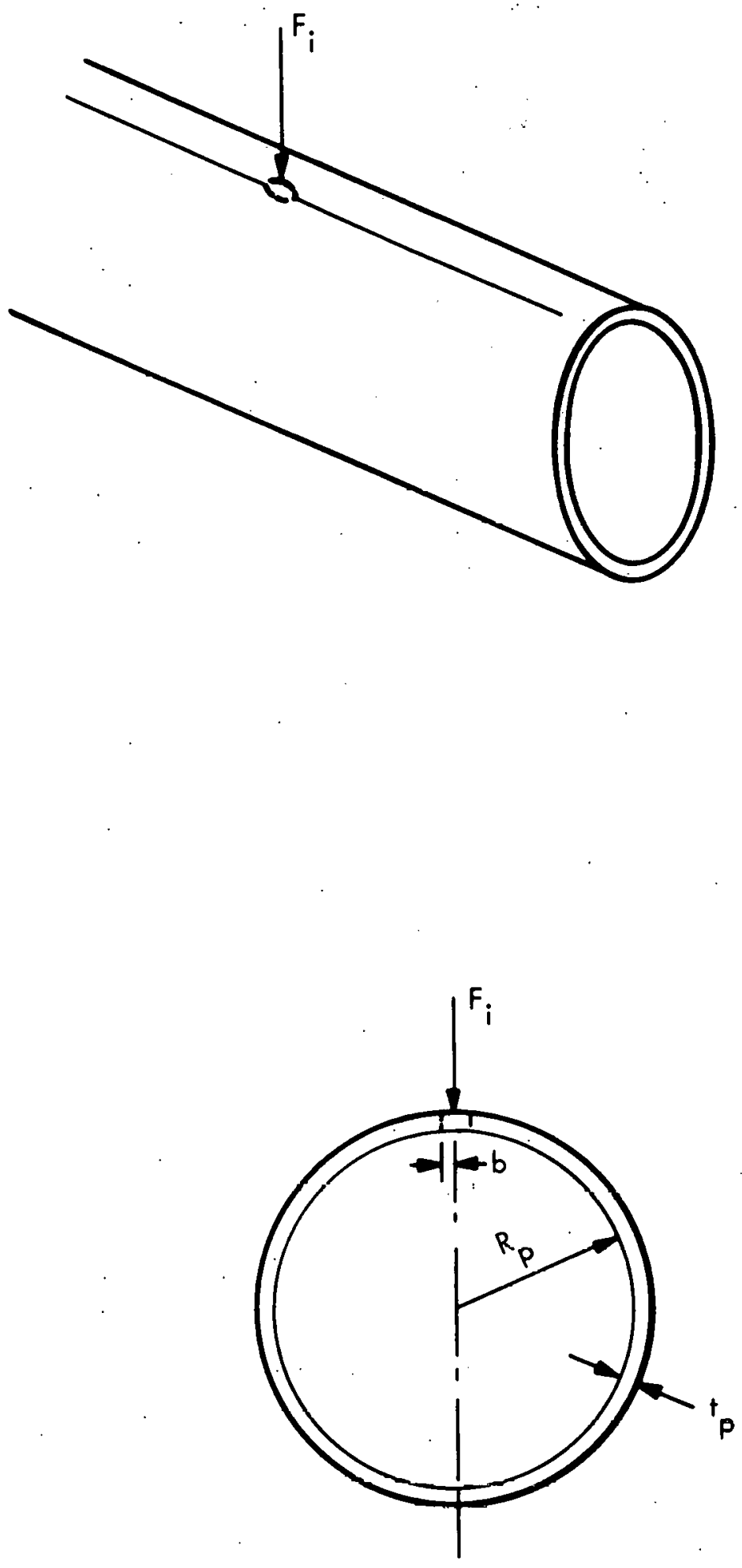

GD9-123

Figure 7-6. Cladding Deformation Modol 
In this situation, the maximum stress is developed at the load, and is given by the following formulation from Roark (Ref. 1).

$$
\sigma=\frac{-\mathrm{F}_{\mathrm{i}}}{\mathrm{t}_{\mathrm{p}}^{2}}\left[0.42 \ln \left(\frac{0.215 \mathrm{R}_{\mathrm{p}}}{\mathrm{b}}\right)+\frac{6}{4 \pi}\right]
$$

where

$$
\begin{aligned}
& \sigma=\text { circumferential bending stress } \\
& \mathbf{R}_{\mathbf{p}}=\text { clad radius } \\
& \mathbf{t}_{\mathbf{p}}=\text { clad wall thickness } \\
& \mathbf{b}=\text { radius of the area over which } \mathrm{F}_{\mathbf{i}} \text { acts }
\end{aligned}
$$

The radial deflection at the load is

$$
\mathrm{U}_{\mathrm{r}}=\frac{-0.135 \mathrm{~F}_{\mathrm{i}} \mathrm{R}_{\mathrm{p}}^{2}}{\mathrm{~F}_{\mathrm{p}} \mathrm{H}_{\mathrm{p}}^{3}}
$$

where

$$
\begin{aligned}
& \mathrm{E}=\text { Young's modulus } \\
& \mathbf{U}_{\mathbf{r}}=\text { radial deflection }
\end{aligned}
$$

Tu determine $b$, the area over which the load acts, a model of two cylinders in contact at right angles was used. In this situation, the area of contact is an ellipse, whose major and minoi semi-axcs are, from Koark (Ref. 1);

$$
\begin{aligned}
& c=a^{3} \sqrt{\left(F_{i}\right)\left(\frac{4 R_{p} R_{w}}{R_{p}+R_{w}}\right)\left(\frac{1-\nu^{2}}{E}\right)} . \\
& d=\beta c
\end{aligned}
$$

where

$$
\begin{aligned}
& R_{w}=\text { radius of the wire wrap } \\
& \nu=\text { Poisson's ratin } \\
& a, \beta=\quad \text { tabulated parameters depending on the ratio } R_{p} / R_{w}
\end{aligned}
$$


Since the area of an ellipse is ( $\pi \mathrm{cd})$, the equivalent circle radius, $b$, is given by

$\mathbf{b}=\sqrt{\mathbf{c d}}$

Lsing the following values

$$
\begin{aligned}
& R_{p}=0.11 \text { inches } \\
& P_{p}=0.28 \text { inches } \\
& t_{p}=0.014 \text { inches } \\
& E=28 \times 10^{6} \mathrm{psi} \\
& \nu=0.30
\end{aligned}
$$

The bending stress at the load, $\sigma$, and the radial deflection at the load, $\mathrm{U}_{r}$, were calculated and are plotted in Figure 7-7 as a function of the loading, $F_{i}$.

Using an ultimate strength for the clad of 50,000 psi at $1000^{\circ} \mathrm{F}$ (Ref. 2), this would imply a load, $\mathrm{F}_{\mathrm{i}}$, of about 5.5 pounds. Relating this back to an extcrial pressure, via the fourth equation, the maximum tolerable pressure would be $\mathrm{P}_{\mathrm{EXT}}=2.9 \mathrm{psi}$.

$$
\because \because "
$$

\subsubsection{Coolant Temperature Response to a Loss of Flow}

Assuming destruction and breakup of the primary bundle, the possibility exists that the coolant inlet of the adjacent bundle may be partially or totally plugged by debris, causing a reduction in the heat removal capability in the bundle.

Therefore, a series of transients were examined, determining the coolant temperature for various step flow losses. This indicated the degree of flow loss that could be tolerated and still maintain subcooled sodium in the bundle. For the flow losses where the boiling temperature was exceeded, the results indicated the length of time required to reach this condition, and thus the allowable time available to react to the situation and prevent voiding. The calculations were run on the NAAC code, which is a model of a fuel pin and its associated coolant annulus, and permits the pin to be broken into various axial sections, with fuel, clad and coolant temperature calculations in each axial section. Allowable forcing functions input to the code as functions of time are coolant flow rate and inlet temperature, and power generation rate.

Using the following geometric description of a fuel pin and its associated coolant annulus,

fuel pellet radius $=0.101 \mathrm{in}$.

clad thickness $=0.014$ in.

coolant annulus radius $=0.1495$ in.

step flow loss transients. were run for $25 \%, 50 \%, 75 \%$ and $100 \%$ flow loss for a pin operating at a linear power of $10.9 \mathrm{~kW} / \mathrm{ft}$ and initially having flow at $30 \mathrm{ft} / \mathrm{sec}$.

The maximum coolant temperature, as a function of time, is plotted in Figure 7-8 for the four transients. 


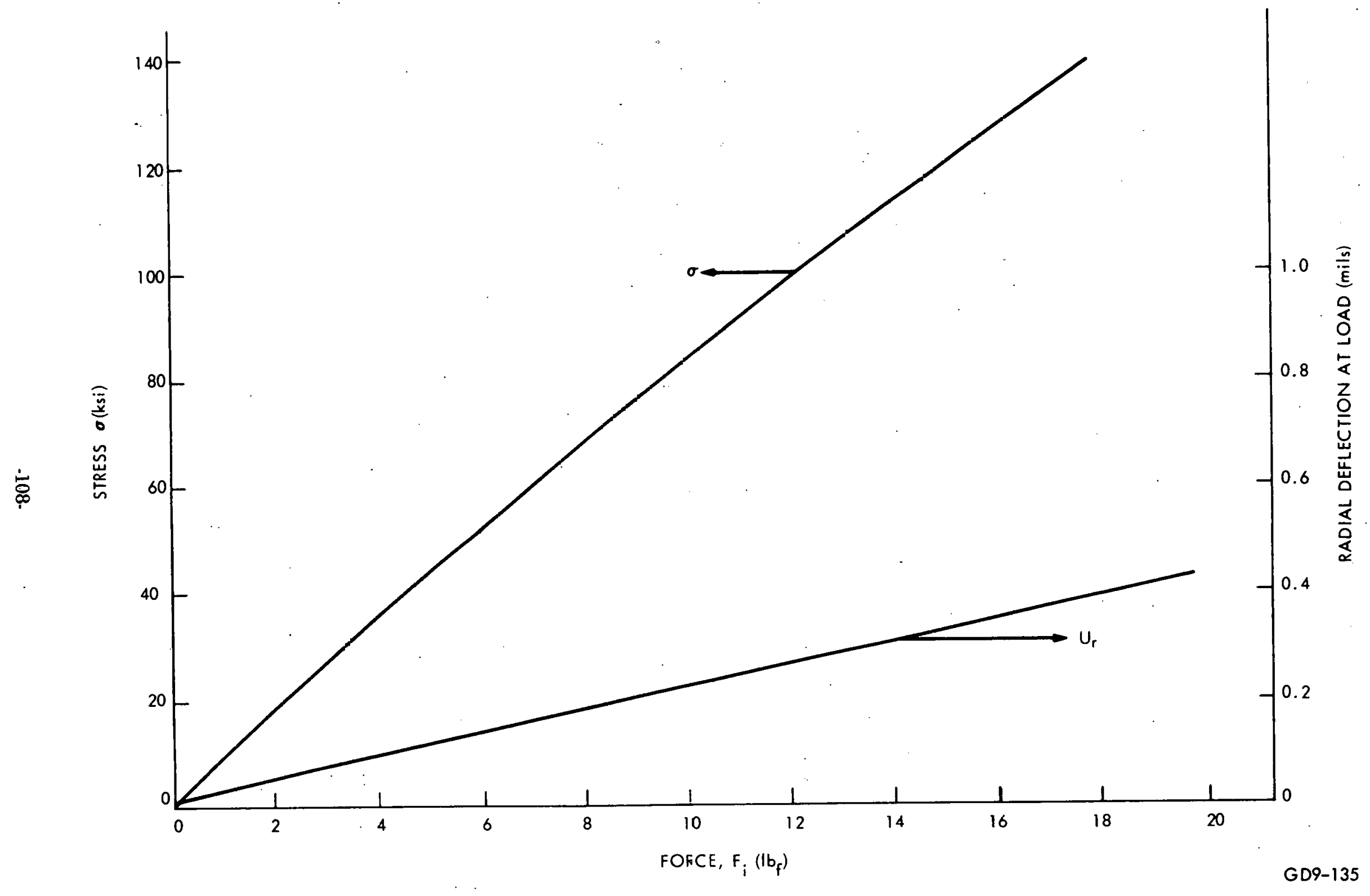

Figure 7-?. Conditions at the Load 


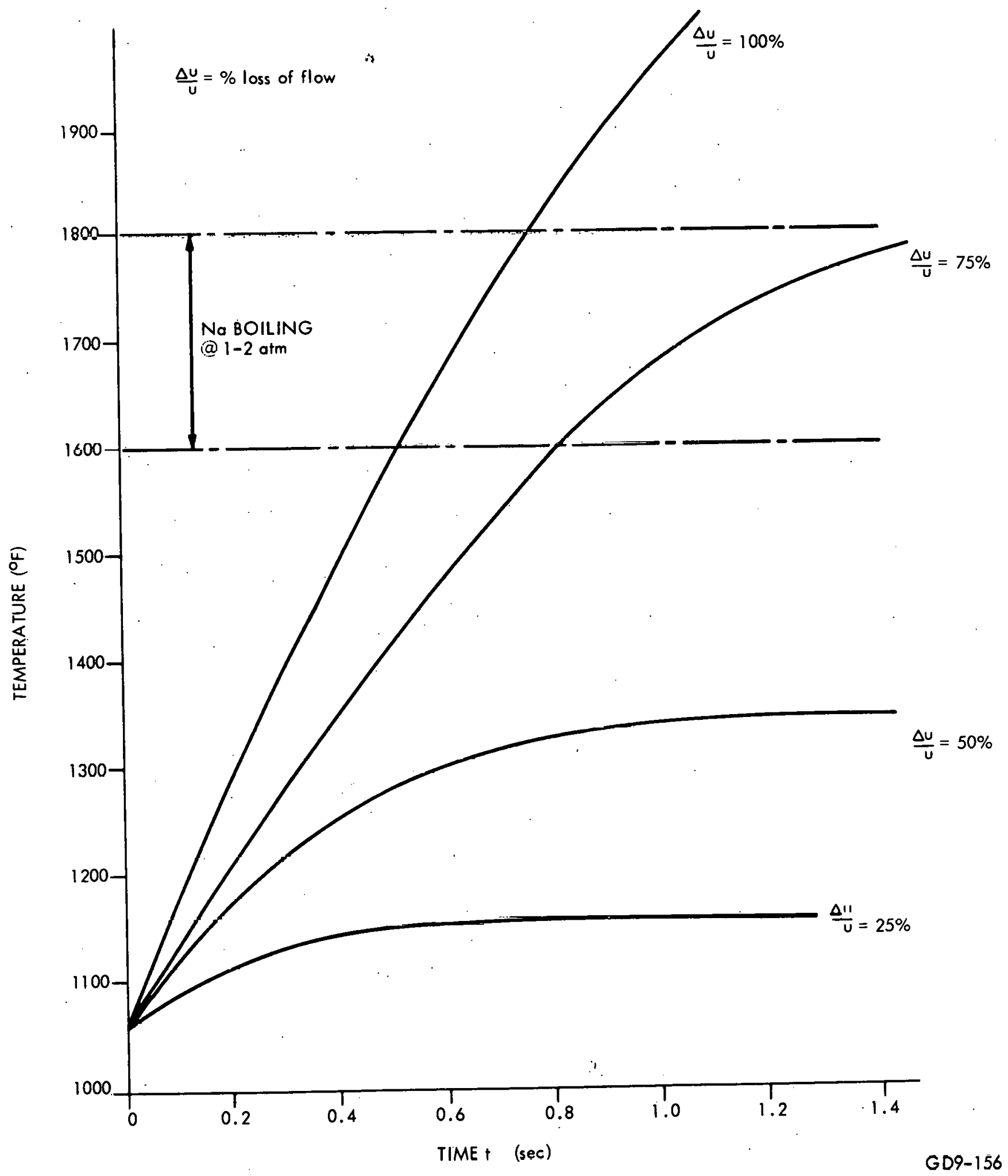

Figure 7-8. Maximum Coolant Temperature for Step Flow Loss 


\subsubsection{Duct Wall Melt-Through}

During the failure of the primary bundle, it is postulated that a layer of molten fuel may be deposited on the duct wall in the primary bundle. Subsequent melt-through of the 2 duct walls between the primary and adjacent bundles represents a mode of breaching the integrity of the adjacent bundle and initiating a failure mechanism.

This problem has been considered before (Ref. 3), under the assumption that the coolant temperature in the adjacent bundle remained constant. This analysis carries the problem one step further, in that the convection effects and heating of the sodium in the adjacent bundle was considered. Of interest was the particular problem as to whether or not the sodium in the adjacent bundle would heat up to voiding conditions before the wall melt-through was completed.

The specific nodal model used for the problem is shown in Figure 7-9. To determine a minimum melt-through time, a 0.3 inch slab of fuel initially at $5000^{\circ} \mathrm{F}$ (which approximates an infinite slab, as shown in reference 3 ), is placed against the duct wall in the primary bundle. The heat transferred across the bundles is absorbed in the coolant in the adjacent bundle that lies between the outer row of pins and the channel wall. The model is axially symmetric for a distance of 3 feet, with power density corresponding to $10.9 \mathrm{~kW} / \mathrm{ft}$, a sodium inlet temperature of $800^{\circ} \mathrm{F}$, and flow rate of $30 \mathrm{ft} / \mathrm{sec}$. The duct walls were asoumed to be initially at $1000^{\circ} \mathrm{F}$.

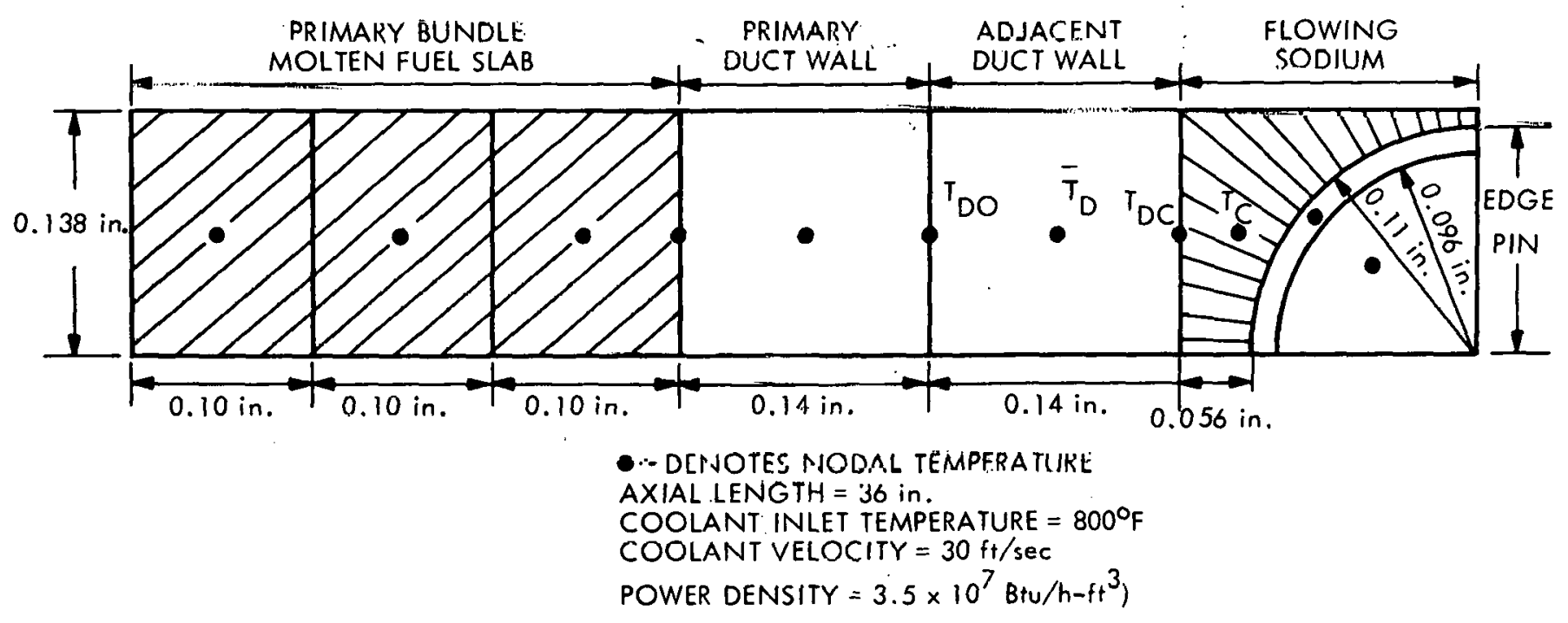

Figure 7-9. Duct Melt-Through Model

GD9-124

The calculation of the nodal temperature as a function of time was pertormed on the transient heat tranofer code, THTD. The time response of the temperatures in the duct wall and sodium in the adjacent bundle are plotted as functions of time in Figure 7.10.

\subsubsection{Vapor Blanketing of the Pin}

For consideration of vapor blankcting effects, it was necessary to determine what length of time a pin cuuld be vapor blanketed (i.e., insulated) before clad damage occurred. It is postulated that vapor from the primary bundle is injected into the adjacent bundle through some breach in the duct wall. The duration of blanketing is not known, as this is a function of what is occurring in the primary bundle.

Therefore, the model chosen was an insulated fuel pin (i.e., all loss of heat transfer to the coolant), and the clad and fuel temperatures are calculated as a function of time. For simplicity, just one node was used in the clad and one in the fuel, as shown in Figure 7-11. The equations for fuel and clad temperature are also shown in Figure 7-11. Driving the pin at 10 and $14 \mathrm{~kW} / \mathrm{ft}$, the temperature and response is plotted in Figure 7-12: 


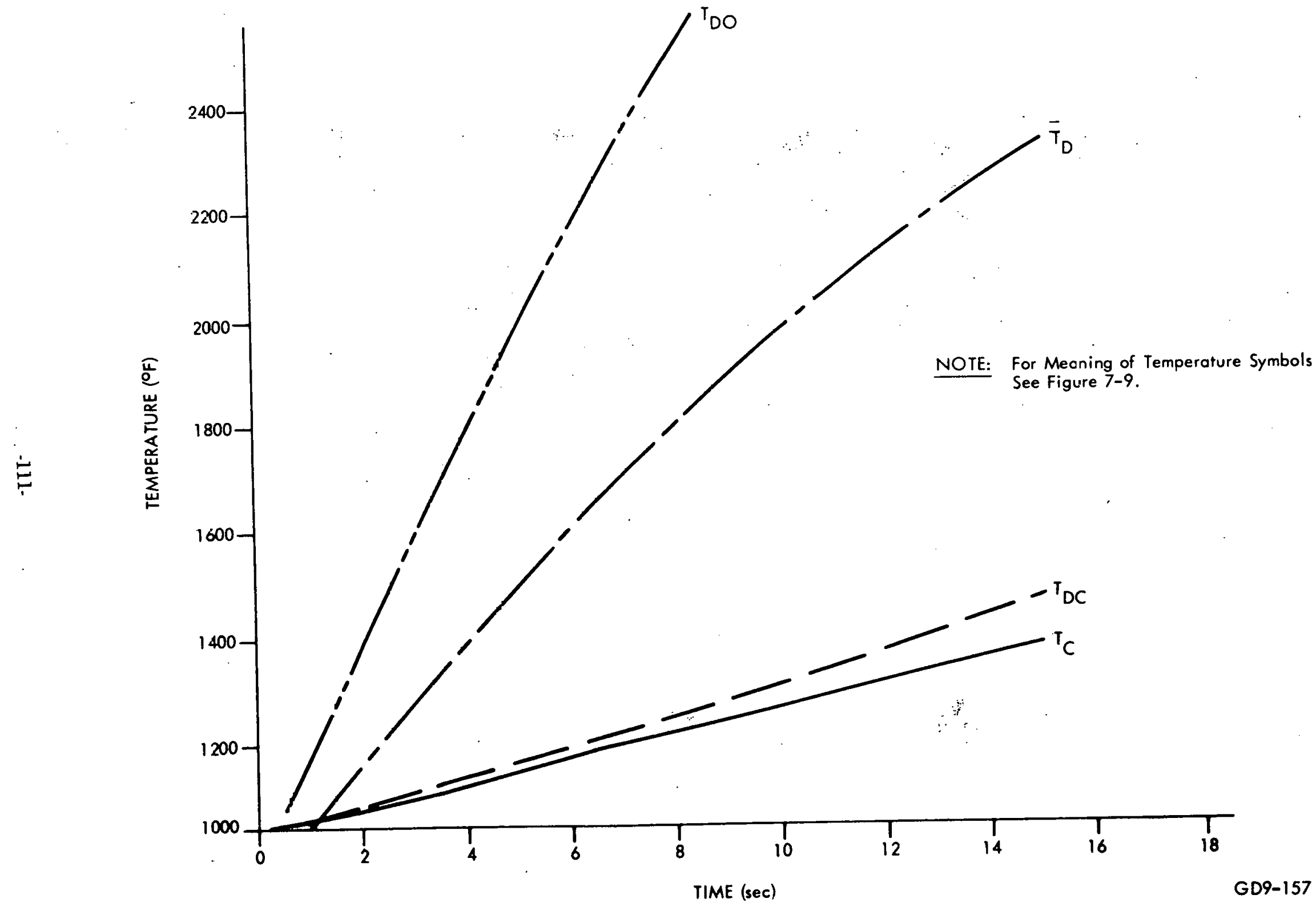

Figure 7-10. Temperature Response for Melt-Through of Duct Wall 


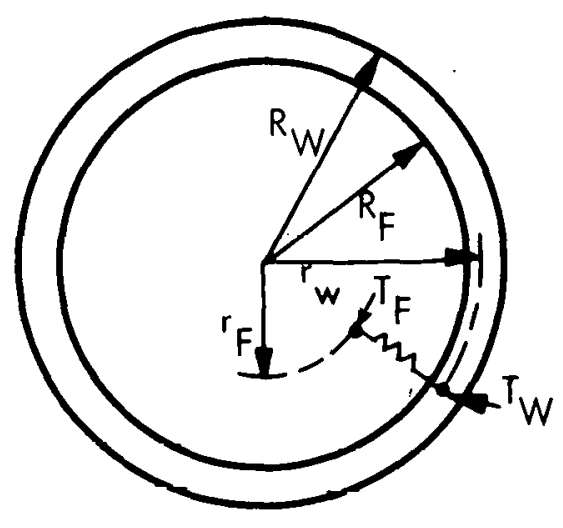

GD9-158

Figure 7-11. Vapor Blanketing Thermal Model

\subsubsection{Temperature of a Local Blockage}

Assuming the integrity of the duct wall in the adjacent bundle has becn breached, it is possihle that debris in the form of pieces of wire. wrap, clad, etc., could enter the adjacent bundle and become lodged between the fuel pins. This now creates a local hot spot between the pins, in that a region of stagnant sodium can bc assumed tu exist downstream from the blorkage, thus starving the blocked region for flow. The model uscd in this section examines lhe lemperaturcs in the etagnant volume. of sodium and the temperatures in the adjacent tuel pins. It is desired lu delirmine if thio region uf stagnant sodium will become hot enongh to cause voiding or clad failure.

The model chosen is shown in Figures 7-13 and 7-14. It consists of six fuel pins and the associated coolant as shown. The model assumes that flow is stopped in the shaded area of coolant channel shown, for an axial length, L. Heat conduction is considered in the radial direction from the pins into stagnant sodium, and conduction out of the stagnant sodium radially to the adjaccnt unblocked channels and also axially to the top and bottom of the blocked sodium. At the bottom of the blockage, a uniform temperature across all of the coolant channels is used. At the top of the blockage, it is assumed that heat is conducted from the blockage to flowing sodium at the temperature of the coolant at this axial position in the unblocked ohannels (this is justified by interchannel mixing effects). The length of the blockage, $L$, was examined as a parameter, since it would be rather difficult to try to determine an actual blockage length. Fiom physical cunsides ations, however, reasonable or realistic values may be dcfined.

The applicable finite difference equations for calculation of the transient nodal iemperaturcs are as follows:

Fuel (F)

$$
\mathrm{T}_{\mathrm{F}}{ }^{\mathrm{j}+1}=\mathrm{T}_{\mathrm{F}}{ }^{\mathrm{j}}+\frac{\dot{q}^{\prime \prime \prime}(\Delta t)}{\rho_{\mathrm{F}} \mathrm{C}_{\mathrm{F}}}-\frac{\mathrm{Y}_{\mathrm{FW}}(\Delta \mathrm{t})}{\rho_{\mathrm{F}} \mathrm{C}_{\mathrm{F}} \mathrm{A}_{\mathrm{F}}}\left(\mathrm{T}_{\mathrm{F}}{ }^{\mathrm{j}}-\mathrm{T}_{\mathrm{W}^{j}}\right)
$$


POWER
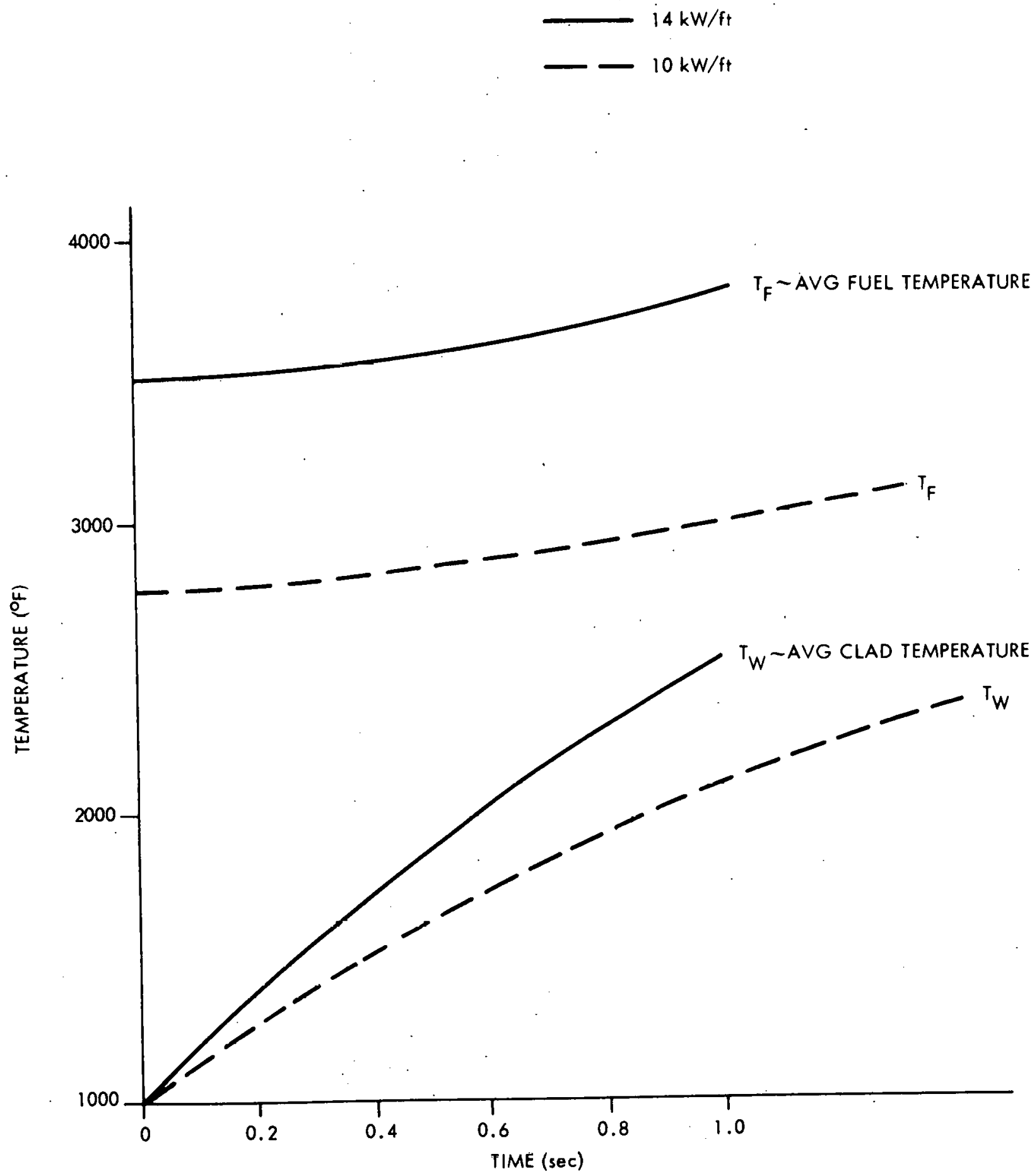

GD9-159

Figure 7-12. Fuel Pin Temperature Response for Vapor Blanketing 
where:

$$
\begin{aligned}
& \mathrm{Y}_{\mathrm{FW}}=\left[\frac{\ln \left(\mathrm{R}_{2} / \mathrm{R}_{1}\right)}{\pi \mathrm{k} F / 3}+\frac{1}{\pi \mathrm{R}_{2} \mathrm{~h}_{\mathrm{G} / 3}}+\frac{\ln \left(\mathrm{R}_{3} / \mathrm{R}_{2}\right)}{\pi \mathrm{k}_{\mathrm{W} / 3}}\right]^{-1} \\
& \rho, \mathrm{c}, \mathrm{k}=\text { density, specific heat, conductivity } \\
& \mathrm{A}_{\mathrm{F}}=\frac{\pi \mathrm{R}_{2}^{2}}{6} \\
& \Delta \mathrm{t}=\text { time increment }
\end{aligned}
$$

Clad (W)

$$
T_{W}^{j+1}=T_{W}{ }^{j}+\frac{Y_{F W}(\Delta t)}{\rho_{W} C_{W} A_{W}}\left(T_{F}^{j}-T_{W}{ }^{j}\right)-\frac{Y_{W C}(\Delta t)}{\rho_{W} C_{W} A_{W}}\left(T_{W}^{j}-T_{B}^{j}\right)
$$

where

$$
\begin{aligned}
& \mathrm{Y}_{W C}=\left[\frac{\ln \left(\mathrm{R}_{4} / \mathrm{R}_{3}\right)}{\pi \mathrm{k}_{\mathrm{w} / 3}}+\frac{\mathrm{R}_{\mathrm{B}}-\mathrm{R}_{4}}{\pi \mathrm{R}_{4} \mathrm{k}_{\mathrm{c} / 3}}\right]^{-1} \\
& \mathrm{~A}_{\mathrm{W}}=\frac{\pi\left(\mathrm{R}_{4}{ }^{2}-\mathrm{R}_{2}{ }^{2}\right)}{6} \\
& \mathrm{R}_{\mathrm{B}}=\frac{\mathrm{P}_{\mathrm{p}}}{2 \text { cus } 30^{\circ}} \\
& \mathrm{P}_{\mathrm{P}}=\text { pin pitch }
\end{aligned}
$$

Blockage (B)

$$
T_{B}{ }^{j+1}=T_{B}^{j}+\frac{3 Y_{W C}(\Delta t)}{\rho_{c} C_{c} A_{c}}\left(T_{W}{ }^{j}-T_{B}^{j}\right)+\frac{Y_{B C}(\Delta t)}{\rho_{c} C_{c} A_{c}}\left(T_{o}^{j}-2 T_{B}{ }^{j}+T_{L}{ }^{j}\right)-\frac{3 Y_{B C}(\Delta t)}{\rho_{c} C_{c} A_{c}}\left(T_{B}{ }^{j}-T_{C}{ }^{j}\right)
$$

where

$$
\begin{aligned}
& Y_{B C}=\frac{2 k_{c}\left(P_{p}-3 R_{4}\right)}{R_{B C}} \\
& R_{B C}=\frac{P_{p}}{2} \tan 30^{\circ} \\
& Y_{B o}=\frac{2 k_{c} A_{B}}{L^{2}} \\
& A_{c}=\frac{1}{2} P_{p}^{2} \cos 60^{\circ}
\end{aligned}
$$


Coolant, adjacent channel (c)

$$
\begin{aligned}
& \mathrm{T}_{\mathbf{c}}^{\mathrm{j}+1}=\mathrm{T}_{\mathrm{c}}^{\mathrm{j}}+\frac{3 \mathrm{Y}_{\mathrm{WC}_{C}(\Delta t)}}{\rho_{c} \mathrm{C}_{c} \mathrm{~A}_{c}}\left(\mathrm{~T}_{\mathrm{W}_{A}} \mathrm{j}_{-} \mathrm{T}_{c}^{\mathrm{j}}\right)-\frac{\mathrm{U}}{\mathrm{L}}(\Delta \mathrm{t})\left(\mathrm{T}_{\mathrm{L}}^{\mathrm{j}}-\mathrm{T}_{\mathrm{o}}\right)+\frac{\mathrm{Y}_{\mathrm{BC}}(\Delta \mathrm{t})}{\rho_{c} \mathrm{C}_{c} \mathrm{~A}_{c}}\left(\mathrm{~T}_{B}{ }^{\mathrm{j}}-\mathrm{T}_{\mathrm{c}}^{\mathrm{j}}\right) \\
& \mathrm{T}_{\mathrm{L}}^{\mathrm{j}+\mathrm{l}}=\mathrm{T}_{\mathrm{o}}+2\left(\mathrm{~T}_{\mathrm{c}}^{\mathrm{jH}}-\mathrm{T}_{\mathrm{o}}\right)
\end{aligned}
$$

Clad, adjacent channel (WA) - use above equation for clad

Fucl, adjacent channel (FA) - use above equation for fuel

The model was then used to calculate the temperatures in the regions shown in Figure 7-13, as functions of time. Initial temperatures were determined by assuming the stagnant sodium to be flowing at its normal rate. An instantaneous flow loss in the blocked region was then assumed and the transient temperatures were calculated by the previously described equations.

Figure 7-15 is a plot iof the stagnant sodium temperature as a function of time for blockage:lengths of $1 / 4 \mathrm{in} ., 1 \mathrm{in}$., and $1 \mathrm{ft}$. The pin was running at $14 \mathrm{~kW} / \mathrm{ft}$ and a $\mathrm{p} / \mathrm{d}$ of 1.24 was used, with coolant flow in the unblocked channel at $30 \mathrm{ft} / \mathrm{sec}$.

Also, the model permits simulation of a blockage larger than one channel. If it is assumed that the adjacent coolant channels are also blocked, there will be no conduction from the primary blocked area to adjacent coolant channels. Therefore a blockage of several channels ean be calculated by dropping the interchannel heat conduction term from the equation for $\mathrm{T}_{B}$.

The stagnant sodium temperature for the case of a multi-channel blockage is plotted in Figure 7-16 for blockage lengths of $\mathrm{L}$ $=1 / 4$ in., 1 in., and $1 \mathrm{ft}$.

\subsubsection{Temperature Response to Bundle Compaction}

If the duct wall fails due to an applied pressure, this pressure will in turn cause crushing on the pin array, as discussed above. The compaction of the pin array implies a reduced coolant area per fuel pin, causing undercooling of the pins. In this section, the temperature of the core is determined as a function of the pitch to diameter ratio and the reduced flow rate (the decrcascd flow area implies an increased flow resistance).

Temperature rises were calculated for interior channels, edge channels and corner channels, as shown in Figure 7-17. The temperature rise across the core is calculated from

$$
\Delta \mathrm{T}=\left(\frac{1}{\rho_{\mathrm{c}} \mathrm{C}_{\mathrm{c}} \mathrm{UA}}\right)\left(\frac{0.948 \mathrm{q}_{\mathrm{c}} \delta}{2 \pi}\right) \mathrm{L}
$$

where $A_{c}=$ coolant area

$$
\begin{aligned}
\mathrm{A}_{\mathrm{c}} & =\sqrt{\frac{3}{4}} \mathrm{P}_{\mathrm{p}}^{2}-\frac{\pi \mathrm{R}^{2}}{2} \text { (interior) } \\
& =\frac{\mathrm{P}_{\mathrm{p}}^{2}}{2}-\frac{\pi \mathrm{R}^{2}}{2} \text { (edge) } \\
& =\frac{1}{4 \sqrt{3}} \mathrm{P}_{\mathrm{p}}^{2}-\frac{\pi \mathrm{R}^{2}}{6} \text { (corner) }
\end{aligned}
$$




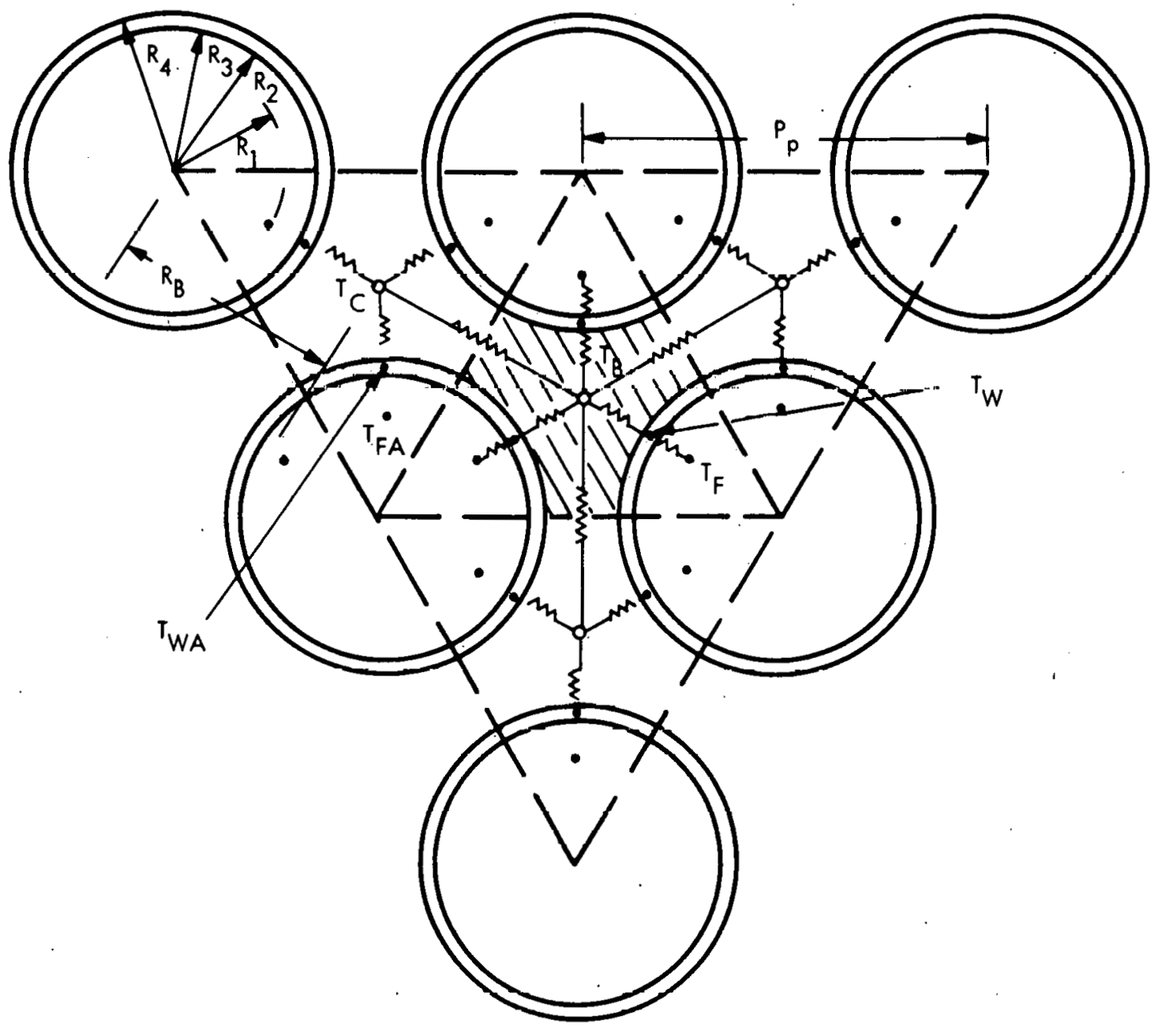

NOTE: Circumferential heat transfer in the fuel pin is neglected

Figure 7-13. Local Blockage - Top View Showing Nodal Structure and Dimensions 


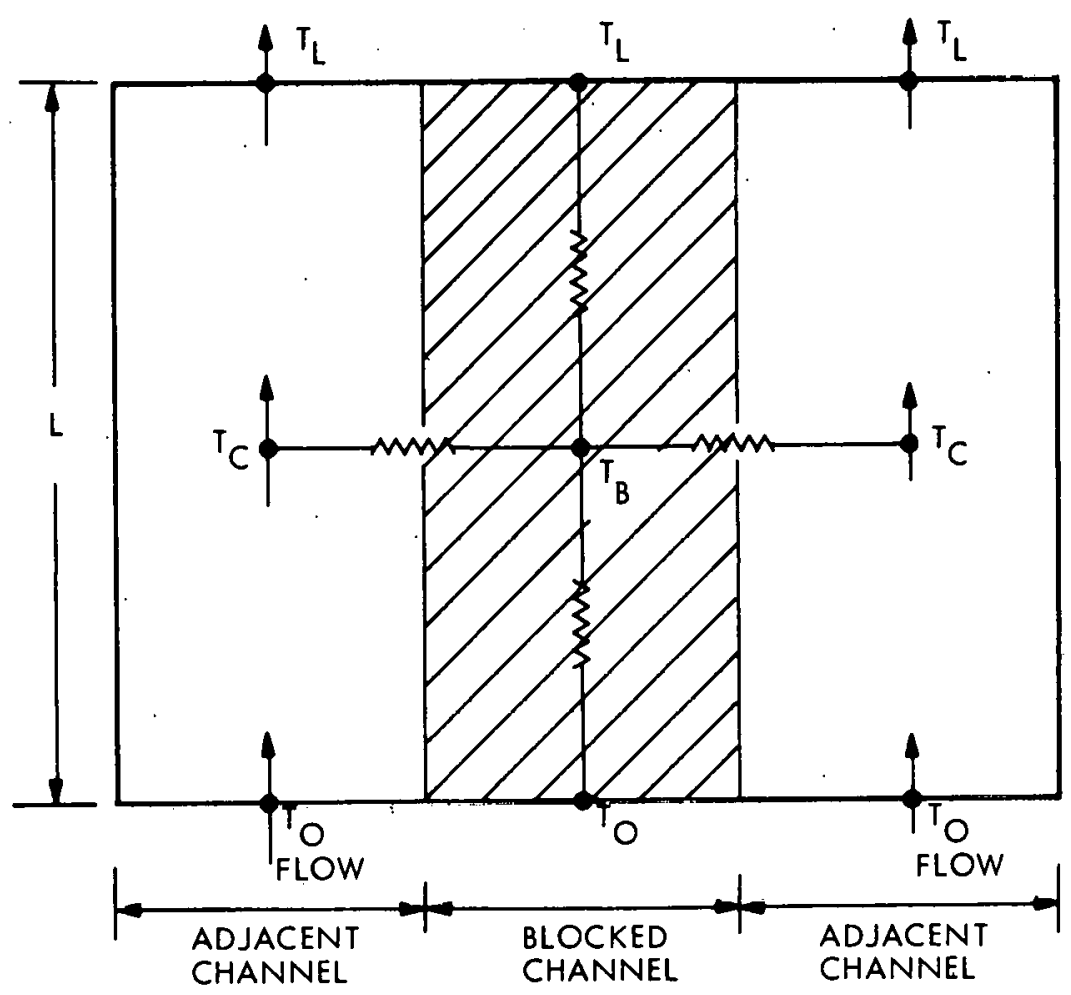

Figure 7-14. Local Blockage - Side View Showing Coolant Conduction Modes

$$
\begin{aligned}
\delta & =\pi \text { (interior) } \\
& =\pi \text { (edge) } \\
& =\pi / 6 \text { (corner) } \\
\mathrm{q}_{\mathrm{L}} & =\text { linear power generation rate }(\mathrm{kW} / \mathrm{ft}) \\
\mathrm{U} & =\text { flow velocity }
\end{aligned}
$$

The flow velocity is calculated, assuming a constant pressure drop for crushed and uncrushed conditions,

$$
\frac{\mathrm{U}}{\mathrm{U}_{\mathrm{o}}}=\sqrt{\left(\frac{\mathrm{D}_{\mathrm{H}}}{\mathrm{D}_{\overline{\mathrm{H}} \mathrm{o}}}\right)\left(\frac{\mathrm{F}_{\mathrm{o}}}{\mathrm{F}}\right)}
$$

where " $0 "=\quad$ uncrushcd conditions

$$
\begin{aligned}
& \mathrm{D}_{\mathrm{H}}=\text { hydraulic diameter } \\
& \mathrm{F}=\text { friction factor } \\
& \dot{F}=0.046 \mathrm{R}_{\mathrm{E}}^{-0.2}
\end{aligned}
$$


GEAP-10059

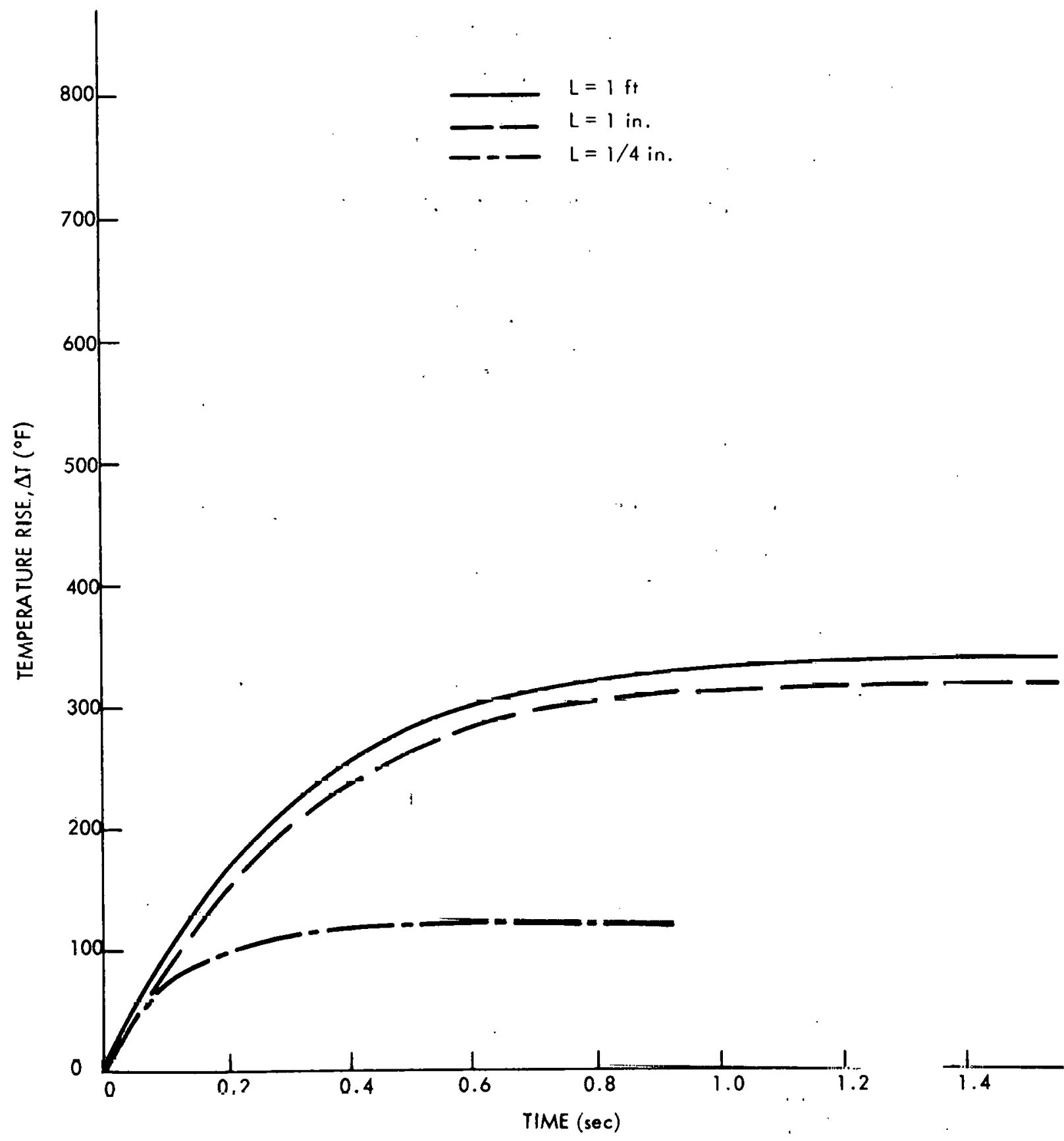

GD9-160

Figure 7-15. Temperature Rise of Stagnant Sodium Single Channel Blockage 


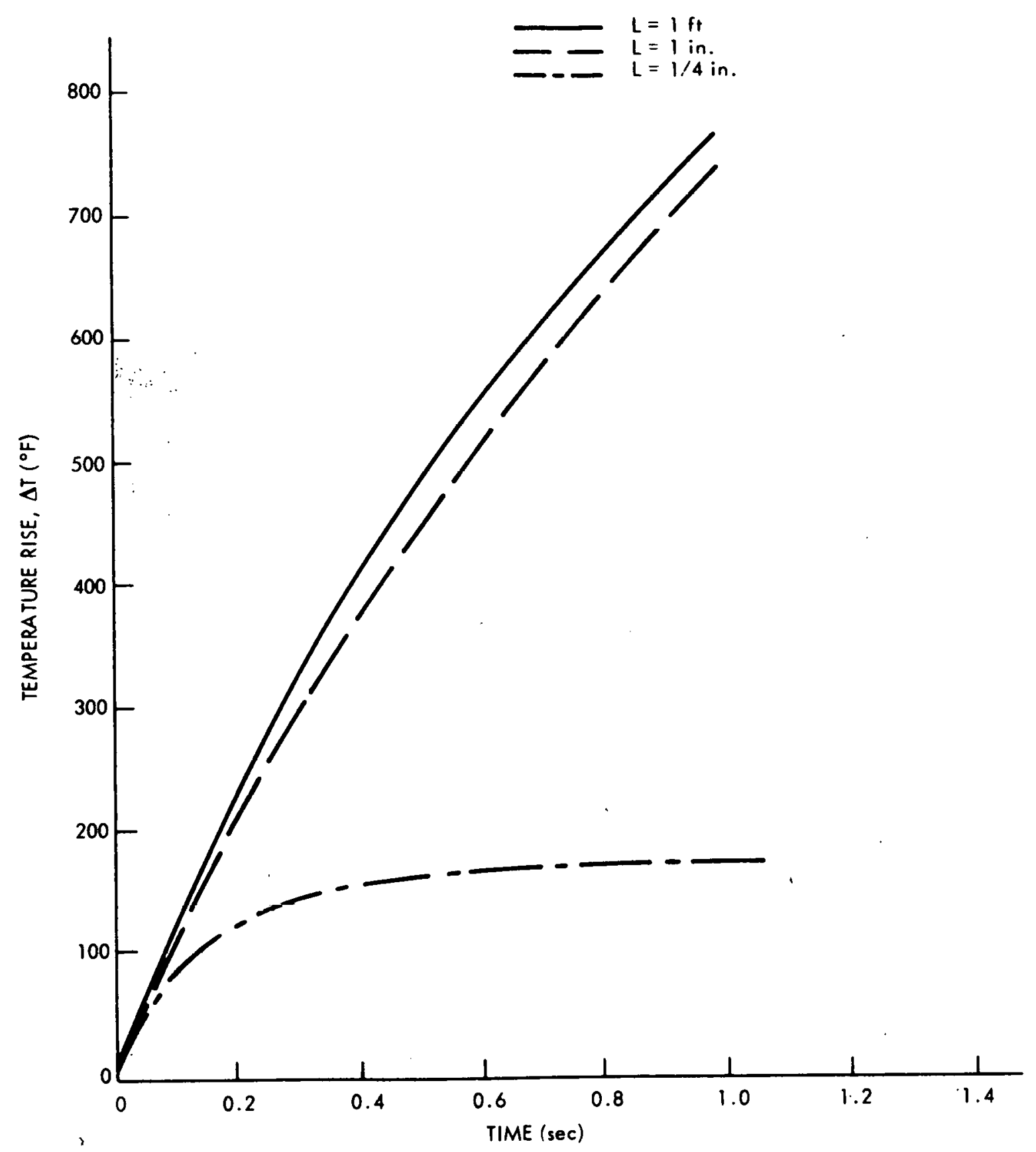

GD9-161

Figure 7-16. Temperature Rise of Stagnant Sodium Multi-Channel Bluckage 


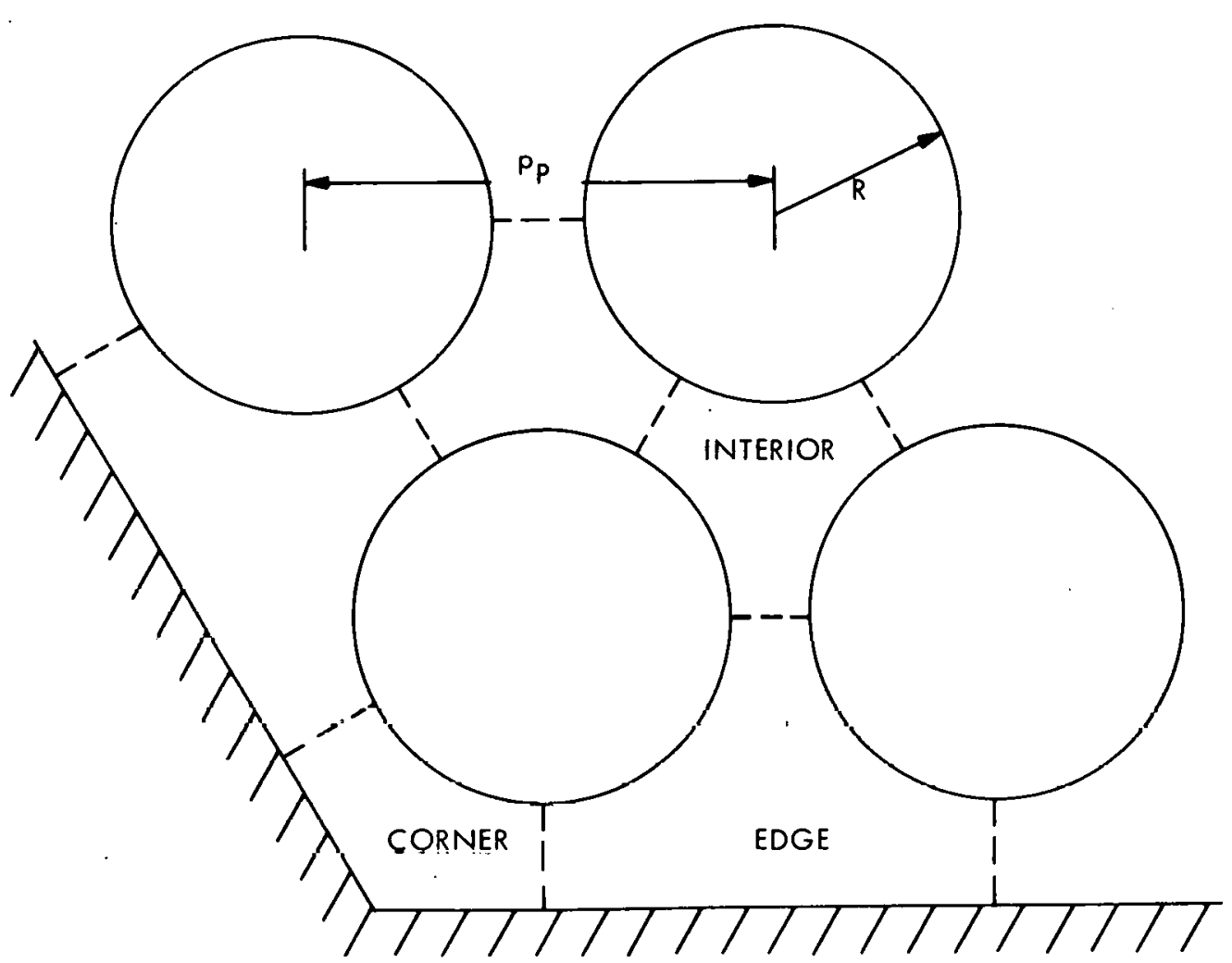

Figure 7-17. Channel Types

The core temperature rise for interior, edge and corner channels is plotted in Figure 7-18 as a function of pitch to diameter ratio, for a power of $10.9 \mathrm{~kW} / \mathrm{ft}$ and an uncrushed flow rate of $30 \mathrm{ft} / \mathrm{sec}$.

\subsubsection{Duration of Vapor Blanketing due to Fission Gas Release}

Due to one of several mechanisms considered previously, the cladding integrity may be ruptured, with a resulting release of the fission gas. The fission gas, as it passes up the channel and is swept out of the core, insulates the fuel pin from any coolant, causing a rise in the clad temperature. The magnitude of the clad temperature rise is determined by the length of time the pin is covered by the gas. It is necessary to determine the duration of blanketing by the fission gas.

Use here is made of a previously developed fission gas release model (Ref. 4). Quoting from these results, a maximum blanket time of 0.12 seconds was calculated. Referring now to Figure 7-12, this implies a clad temperature rise of around $300^{\circ} \mathrm{F}$ for a pin running at $1.4 \mathrm{~kW} / \mathrm{ft}$.

\subsubsection{Results and Discussion}

The mechanical resistance of the bundle to static pressure loading on the duct wall was found tu be quite low. This is due to the fact that (1) a large area is available on the duct wall to apply a pressure, which in turn must be transmitted internally in the pin array through very small local areas at the points of spacer contact, and (2) the fuel, due to its plasticity at high temperature, has a negligible amount of strength, and therefore the strength of the pin array is due to only the cladding.

It was found that pin deformation could be expected with a static loading on the duct wall of around 3 psi. A dynamic analysis of this situation is strongly indicated, because then it would be possible to employ the viscous damping effects of the plastic fuel and also the inertia of the fuel mass in calculating the resistance of the pin array to crushing. 


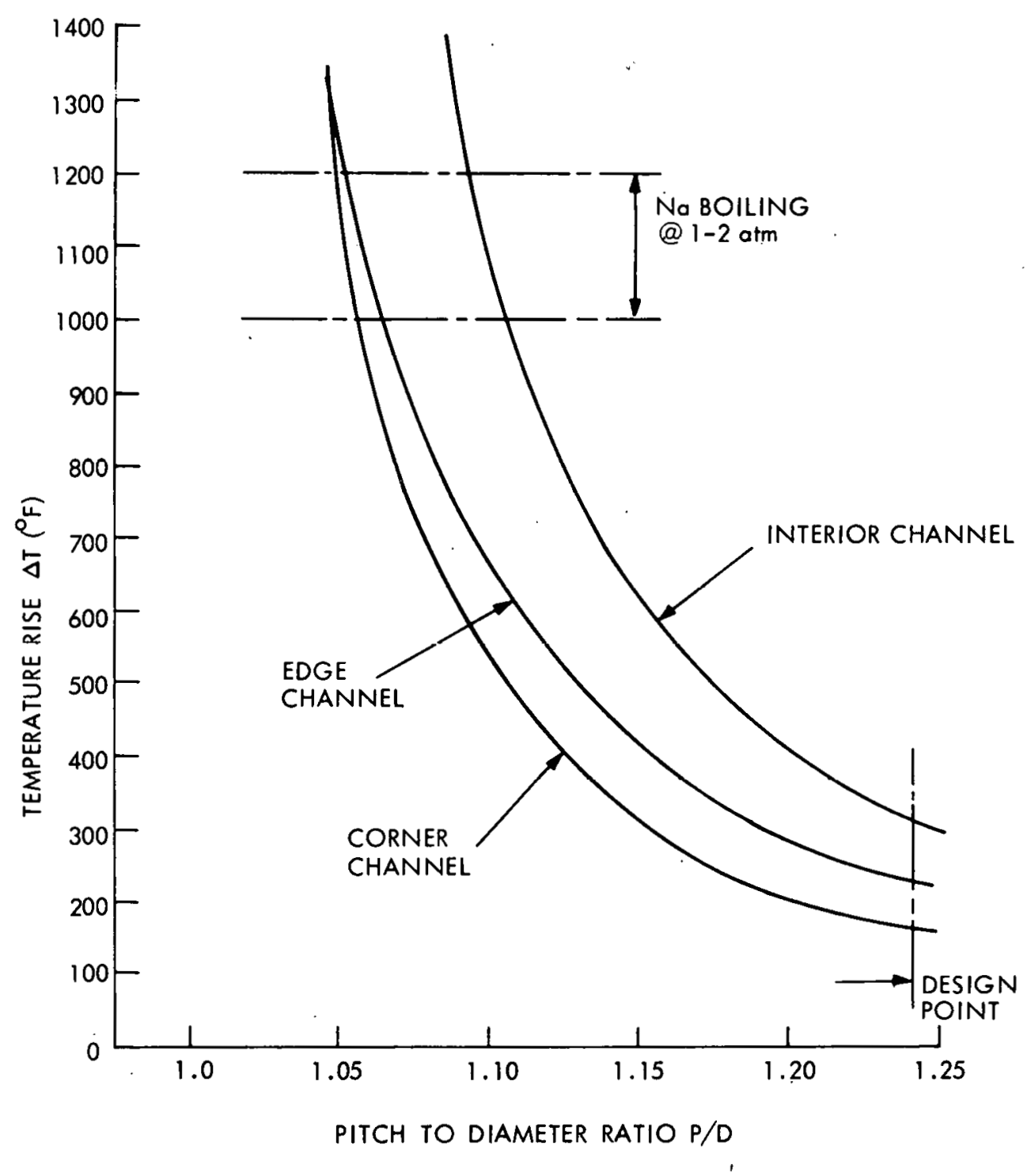

GD9-162

F'igure 7-18. Coolant Temperature Rise Across Core for Crushed Bundle 
Two methods of thermal propagation from the adjacent bundle were considered. Plugging of the bundle inlet and melt-through of the clad wall.

Examining loss of flow accidents due to plugging of the bundle inlet, it was found that the bundle could sustain over a 50\% loss in mass flow rate of the coolant and still not reach voiding conditions. As an upper limit, if total flow loss was experienced, it would require on the order of $0.6-0.8$ seconds to reach voiding conditions, depending on the bundle power.

The analysis of the melt-through of the duct wall by molten fuel indicated that the duct wall represents a very significant heat sink, as it would require on the order of 15 seconds to accomplish the melting of the two walls between the primary and adjacent bundles. It was also found that with coolant flowing in an undisturbed condition in the adjacent bundle, there is little possibility of causing voiding of this coolant by the inter-bundle heat flux. The coolant temperature rise in 15 seconds is only $350^{\circ} \mathrm{F}$.

Having examined methods of breaching the duct wall, the next step was to consider the consequences of exposing the fuel pin array in the adjacent bundle to the voiding and melt down situation in the primary bundle. The llure possibilities here were (1) molten fuel injection (2) vapor injection and (3) debris injection.

The results of interaction of molten fuel and sodium are described in Section 5 , but have not been applied to the molten fuel injection problem discussed here.

The results of vapor injection were examinted by considering the heating up of a fucl pin that was completely insulated from the coolant. It was found that for a pin running at $14 \mathrm{~kW} / \mathrm{ft}$, the clad temperature rise was initially on the order of $1500^{\circ} \mathrm{F} /$ second. If clad rupture may be expected at approximately $1800^{\circ} \mathrm{F}$, Figure $7-1$ would imply failure after about 0.45 seconds of blanketing. The actual length of time the pin is blanketed is a function of what is occurring in the primary bundle.

To examine debris injection, it was assumed a piece of foreign material was lodged in the channel between fuel pins, with a resulting volume of stagnant sodium behind the blockage. The temperature of this stagnant sodium was examined as a function of time for various heights of the sodium blockage. The model included radial conduction from the blockage to adjacent coolant channels (see Figure 7-13) and axial conduction to flowing sodium below and above the blockage (see Figure 7-14). Referring now to Figure 7-15, it was found that the temperature rise of a $1 / 4 \mathrm{in}$. high volume of stagnant sodium between 3 pins was about $120^{\circ} \mathrm{F}$. Looking at longer blockages, i.e., $1 \mathrm{in}$. and $1 \mathrm{ft}$, the maximum temperature rise that could be attained was around $300^{\circ} \mathrm{F}$. Since the $1 \mathrm{in}$. and $1 \mathrm{ft}$ models simulate an "infinitely long" blockage, this says that the radial conduction to the adjacent coolant channels is adequate to keep the sodium below boiling conditions. On the other hand, referring to Figure 7-16, a blockage of several channels was examined by neglecting any heat transfer to the radially adjacent coolant channels. Here it was found that for a $1 / 4$ in. high blockage, the sodium temperature rise was only about $170^{\circ} \mathrm{F}$. In this case the axial conduction maintains the stagnant sodium volume at a relatively low temperature. On the other hand, for very long lengths of blockages, there is essentially no way for the heat to escape from the blockage, and the sodium heats up above boiling conditions. To determine realistic heights for the blockage, it can be said the height of the blockage will be proportional to the number of channels blocked. For just a single channel, $1 / 4 \mathrm{in}$. would probably be an upper limit to the height, as this represents several channel diameters. For a blockage of several channels, the height might conceivably be greater. Now applying these considerations to the previously discussed temperature rises for the blockage as a function of height, it can be said that a very local blockage of just one or two channels should pose no significant overtemperature effects, but there is a possibility of reaching boiling conditions when many pin channels are blocked.

The final area to be examined was internal thermal problems in the adjacent bundle caused by deformation of the pin array from external pressure luading.

Examining the coolant temperature rise across the core as the bundle is uniformly compacted down, it was found that the bundle could be reduced to a pitch to diameter ratio of around 1.1 before voiding conditions would be reached.

The consequences of the release of debris in the form of cladding and wire wrap to form local blockages as the bundle is crushed, parallels the previous discussion on injection of foreign material into the bundle. 
Finally, the problem of pin blanketing due to release of fission gas was considered. The predicted pin blanketing time was approximately 0.12 seconds, implying that the clad temperature rise will be around a maximum of $300^{\circ} \mathrm{F}$ (from Figure 7-12), so that no serious thermal problems should be encountered. A few qualifying remarks should be made about the gas release model, however. In the model, it was assumed that only one pin ruptured within a subassembly, so that the amount of gas released did not change the coolant flow rate through the bundle. Under the conditions hypothesized (gross crushing of the bundle) it is conceivable that the gas in many pins might be released simultaneously, reducing the coolant flow through the bundle and increasing the blanketing time of the pin.

\section{REFERENCES}

1. Roark, R.J., Formulas for Stress and Strain, McGrawHill, Third Edition, 1954.

2. Fast Flux Test Facility Quarterly Technical Report, March 1969, (BNWL-660), p. 7.8.

3. Task I Report of 1000 MWe LMFBR Follow-On Work, June 1968, (GEAP-5618), p. 351.
4. Seventeenth Quarterly Report, Fast Ceramic Development Program, PA-10, February 1966, (GEAP-5098), p. 7-18.

5. Task III and V Report of 1000 MWe LMFBR FollowOn Work, February 1969, (GEAP-5710).

\section{RECOMMENDATIONS}

\subsection{DESIGN IMPLICATIONS}

The state of the art prevents an accurate determination of the consequences of the hypothesized flow blockage accident. The results of this preliminary conservative study indicate that the pressure pulses generated by interaction of hot core materials and cold sodium are of the same order of magnitude as those rcquired to rupture an overheated duct with low ductility $(3 / 2-1 \%)$.

The effect of changing the duct thickness and corner radius was discussed quantitatively in Section 6. While the threshold pressures for rupture increase with increasing duct thickness and corner radius, the energy absorbed at rupture increases only slightly.

Considering the uncertainty of failure mode, duct deformation analysis and material ductility, it is not considered realistic to recornmend either an increased duct thickness or corner radius. The importance of the material ductility need not be emphasized, as it is critical to all core design aspects and is receiving due consideration. This type of hypothetical accident is sensitive to duct ductility.

\subsection{IMPLICATIONS TO SYSTEM INSTR UMENTATION REQUIREMENTS}

The results of this hypothetical accident study show that it appears possible that some damage to adjacent fuel assemblies may occur as early as $\mathbf{2 - 3}$ seconds after a complete flow blockage. This implies that detection and remedial action (reactor scram) may be required to occur in less than three seconds. The instruments currently planned to monitor FFTF core behavior include:

Neutron monitors

Fuel assembly exit thermocouples

Fuel assembly exit flow meters

Fuel assembly exit fission gas samplers.

The reactivity effects of voiding will be between 10 cents (optimum configuration) and 5 cents (entire assembly). This reactivity addition may result in a reactor scram signal, depending on the trip point. The assembly melts and slumps between 4-8 seconds after blockage. A larger reactivity change can be hypothesized due to slumping that will result in a scram signal, but too late to prevent possible damage while at power. 
The thermocouple signal on total flow blockage will not be a sensitive indicator of total loss of flow because the thermocouples are far removed from the hot core region and axial conduction through the sodium is limited, and because of the heat capacity of the cooler reflector and plenum regions which absorbs much of the transient energies associated with the early phases of the accident. In the more realistic case of a partial flow blockage, significant temperature increase may be indicated at the outlet thermocouples. The temperature response would be determined by the degree of partial blockage.

The fuel assembly exit flow meters would give a rapid and clear signal of flow blockage or partial loss of flow. An electromagnetic flowmeter proposed for FFTF should have a very rapid response and should effect a reactor scram in less than 2 seconds.

The FFTF fission gas detection system response time $(\sim 20$ sec) is too slow to be of use in detecting a complete flow blockage early in the accident.

Condensation of sodium vapor created by local boiling or superheat within a fuel assembly may generate an acoustic disturbance that can be detected. If this "noise" can be detected reliably and early in the course of the flow blockage accident, action can be taken by the protection system to minimize the consequences. The boiling detector could provide an additional means of core surveillance, supplementing the present FFTF duct outlet thermocouples and flow meter. A boiling detection system was discussed in General Electric's Final FFTF Backup Design Summary Report, GEAP-5722 (January, 1969). Space considerations and the prediction that the frequency range of interest for detecting boiling is approximately 20 to $60 \mathrm{kHz}$ leads to a detector design with the transducer located at the outlet of the fuel duct. It is estimated that the signal-to-noise ratio is enhanced in this frequency range. The pressure transducer must endure a $1200^{\circ} \mathrm{F}$ and high radiation environment. The noise signal will be propagated along the vertical axis of the duct, with relatively little attenuation in the structure. The reasonant frequency of the transducer should be about $50 \mathrm{kHz}$.

The use of wave guides is an alternate design approach to monitor the boiling noise. The main advantage is that the pressure transducer requires no development, since it operates in a low temperature region. The main disadvantage is that the wave guides complicate the mechanical design of the region above the core. This complication is sufficient that the development of an in-core transducer seems, preferable.
There is a possibility that changes in flow patterns caused by a partial flow blockage may produce measureable changes in the background acoustic noise level. Although this possibility has not been evaluated for feasibility it offers the potential for detecting the blockage before boiling or significant superheat develops. Depending on the signal-tonoise characteristics associated with the changed flow patterns, there is a possibility that a detector developed to monitor sodium vapor collapse might also serve this purpose. A limited evaluation of the feasibility of this approach seems to be warranted.

\subsection{DISCUSSION OF DEVELOPMENT REQUIREMENTS}

\subsubsection{Analytical Tools}

The current state of the art doco not permit signifioant analysis of a flow blockage accident to proceed much beyond the point of initial voiding. Sufficient data and models are not available to describe fully:

- sodium two-phase transient thermal-hydraulics

- molten steel and fuel fragmentation and interaction with sodium

- dynamic duct response to repeated localized pressure pulses

Two general analysis tools that will be available in the near future are ANL's SASIA (Ref. 1) code and General Electric's FREADM code.

ANL's SASIA code will include two-phase coolant thermal hydraulics and a fuel deformation model, but not a fuelsodium interaction model nor a duct deformation calculation.

The FREADM program will define propagation thresholds to permit scoping studies of gross core effects. The multiduct capability should permit application to the question of propagation.

In the area of model development to describe the phenomenon of interest in flow bluckaye accidents, the continuing reactor safety program at ANL holds promise in the areas of sodium two-phase transients, molten core material fragmentation and interaction with sodium, and duct response to dynamic loads. It is clear that progress toward understanding the consequences of extreme flow blockage accidents depends on these individual models as well as their inclusion in an overall accident code. 
Within the current state of the art, this study lacked the definition of scope and funding to explore the following areas:

- dispersed two phase flow axial heat transport and core cooling.

- application of the clad-fuel sodium interaction to existing experimental data for confirmation.

- application of the results of chemical explosive tests to the expected duct hehavior.

In addition the following areas are identified for study in more detail, if additional information is deemed desirable for FFTF.

\subsubsection{Temperature Associated with a Local Blockage}

It would be informative to extend the model of Section 7 to examine the effect of the presence of solid, heatgenerating fuel particles in the coolant, with emphasis on the diameter of the fuel particle.

\subsubsection{Fission Gas Release Model}

The model used in Section 7 for rate of fission gas release from a ruptured fuel pin incorporated the assumption that only one pin failed in the bundle, and thus the amount of gas released did not affect the mass flow rate of the sodium in the bundle.

However, under conditions of gross bundle compaction, it may be more appropriate to assume that the fission gas from many pins will be released simultaneously. This may cause flow choking and significant loss of sodium flow rate in the bundle, with subsequent overheating and void.

\subsection{EXPERIMENTAL PROGRAMS}

An experimental prograni to understand the specific consequences of hypothetical complete, instantaneous flow blockage accidents should consider three types of experiments:

1. simulation with other fluids,

2. out-of-pile tests,

3. in-pile tests of clad and fuel meltdown.

These experiments must fulfill two necds:

- provide information on which to base the analytical models mentioned above.

- confirming tests in the geometry and environment of interest.

\subsubsection{Simulation with Other Fluids}

The base development program at ANL has effectively used other fluids, notably freon, to simulate the expected conditions of transient sodium boiling. Water tests at near atmospheric pressure hold promise for studying the flow regimes involved in the complex geometries of fast reactor cores, particularly the possibility of counter current reentry of liquid along the cold duct wall. To simulate the wall superheat of the sodium system, nominal temperatures less than $1000^{\circ} \mathrm{F}$ are adequate. This test could contribute to development of a transient two-phase flow model applicable to the real geometry of a tube bundle.

\subsubsection{Out-of-Pile Tests}

\subsubsection{Sodium Thermal Hydraulics}

From this accident study it would appear critical to simulate carefully the fuel assembly conditions, in particular,

a. heat flux to coolant as a function of time and space

b. wire wrap spacers (heat capacity and surface area effect)

c. prototypical ratio of heater area to duct wall area

d. reflector and plenum mockup to simulate the transient heat sink (condenser) effect as well as the inertial and frictional flow resistance

e. system simulation to provide inlet and exit plenums at relatively constant pressure.

These tests should provide information on: 1 ) superheat as a function of flow decay rate (velocity), sodium purity and gas concentration, heater surface condition, aging, heat flux, and pressure-temperature history, 2) the expulsion rate which will depend upon whether voiding takes the form of many bubbles or a single bubble, and whether or not liquid sodium remains in the heated region (in the form of a film on the heater or just a volume of sodium trapped between the initial void and the blockage), 3) pressures associated with the voiding to indicate whether or not the initial voiding is likely to clear the blockage, and 4) void detection techniques for use in determining what instrumentation would be best suited for detection of a loss of flow situation in an individual channel.

Out-of-pile tests will not include the effect of ionizing radiation on superheat, and only with difficulty be capable of following the accident into the post voiding region. of clad and fuel meltdown. The planned tests at PNL and ANL are assumed adequate to provide the above information on sodium transient thermal-hydraulics.

\subsection{2 . Mad-Sodium Interactions}

Scoping tests on interactions between hot core materials and the sodium coolant were performed in out-of-pile tests 
in the "shock tube" experiment at TRW system (Ref. 2) and in continuing bench tests at ANL.

Interactions between hot clad and sodium seem to be amenable to out-of-pile testing. Meaningful testing. of interactions between hot fuel and sodium is comparatively complicated due to the lack of internal heat generation in the fuel out-of-pile. Tests of this nature should be aimed at determining the pressure-time history of the pressure wave. If those measurements prove unobtainable, an estimate of the impulse-to-energy ratio of the wave would be useful. If the characteristic pressure-time history of the wave can be obtained, or at least an estimate made of the impulse to energy ratio, it would be a relatively simple task to tailor an explosive charge to reproduce and ascertain the dynamlc duct response as well as the response of adjacent bundles to external pressure loading.

Current phenomenological tests may satisfy the requirements of model development for molten material-sodium interaction; however, sophisticated tests seem necessary to duplicate the geometry and system effects necessary for a complete understanding of this flow blockage accident.

\subsubsection{Structural Tests}

(a) Pin Bundle Crushing

Due to the low mechanical strength of the bundle under static loading conditions, simulation of the bundle response to dynamic loading conditions is required to demonstrate the bundle's resistance to crushing.

Analytic description of the dynamic bundle response is extremely complex and an experimental testing program is thcrcfore recommended.

The testing program would consist of subjecting the bundle to externally applied pressure pulses of varying magnitude and duration. It is suggested that the bundle be filled with water to simulate inertia of the sodium and to provide a medium for transmitting the force through the pin array. The fuel pin array should be simulated.

\section{(b) Duct Deflection Tests}

A development program specifically aimed at understanding the duct response to the possible loading mechanisms is recommended. This should involve experimental confirmation of analytical models for the expected range of pressure histories. Two types of duct deflection tests would appear useful:

- Artifical production of pressure pulses

- Pressure from hot core-sodium interaction.
Both hydraulic loading and explosive loading tests appear useful to confirm models of duct deflection in simulated accidents. Key parameters appear to be:

- Environment of the duct

- Duct ductility and strength

- Shape and magnitude of the pressure loading (duct material strain ratio).

The integral test of duct deformation would be an extension of the molten material-sodium interaction tests. It appears that it may be feasible to mock up sodium reentry into a preheated tube bundle, with the duct at appropriate temperatures and surrounded by dummy ducts. The use of preheating may permit operating with significant molten clad present when reentry is triggered, whoreas eleotrically heating the pins is likely limited by clad melting.

Knowlcdge of mätèriäls propertes under accldent conditions is necessary to model the duct deflections. Important parameters appear to be:

- high fluence

- rapid temperature transients (to $1000^{\circ} \mathrm{F} / \mathrm{sec}$ )

- high strain rates

- strain ratc shapc

- repeated loads near the fracture limit.

Testing for these properties will be limited for some time by the lack of high fluence stainless steel, but early tests under the above conditions are recommended.

\section{(c) In-Pile Interaction Fxperiments (Modeling)}

In-pile tests on hot and molten core material-sodium interactions should be capable of providing a great deal of pertinent information on the consequences of the return of sodium coolant to a hot or molten matrix of clad and fuel. This information is vitally important from the standpoint of failure propagation to adjacent channels.

Small, pseudo-static, in-pile capsules in which nuclear energy is used to heat the fuel and clad, can be used to investigate the consequences of a mocked up loss-of-flow accident. The advantage of the small static capsule approach is the possibility of carefully controlled cunditions during reentry. This type of capsule can be designed to provide a very strong test vehicle for scoping tests of the interaction process.

An alternate method for studying the interaction phenomenon is in a forced flow capsule. In this case, steady state conditions can be maintained for an appropriate period prior to the flow transient. Voiding can be initiated 
by simply reducing flow. In this case, as in the case of the static capsule, initial tests should be small (single pins) and well controlled to eliminate uncertainties resulting from a complicated geometry. In tests of this type, the initial voiding as well as the consequences of reentry can be studied in a single test.

Instrumentation capable of providing complete information on the interaction problem may not be readily available, especially in the severe environment of an operating reactor. Because of this, the measurement requirements are broken into two categories: 1) instrumentation to measure the pressure and velocity perturbations associated with the initial voiding and subsequent vapor expansion; 2) techniques for determining the magnitude of any shock waves which may be generated. The response of existing instrumentation should be adequate for measurement in the first category. The high pressure and short time constant associated with a shockwave makes meaningful direct measurements very difficult. It is anticipated that measurement of the effect of the shock wave would prove most fruitful. This information may be obtained through post irradiation measurement of the plastic deformation of the duct surrounding the fuel pin. An indication of the sequerce of events can be obtained through direct monitoring of strain gauges mounted on the duct. This technique may be supplemented by high speed pressure transducers if adequate transducers are available.

Attention should be directed to the same requirements as defined under the out-of-pile test.

(d) In-Pile Flow Blockage Experiments, Integral Tests Specific information on the consequences of flow blockage can be obtained with in-pile tests similar to those described under "in-pile interaction experiments." In this case, the capsule should contain several fuel pins (3-7.) and the fuel and blanket regions mocked up quite accurately. Some method should be devised for determining, in situ, how and where sodium reentry occurs. Even without this capability, post irradiation examinations should reveal a great deal about the mechanism of sodium reentry.

All of the requirements for simulation, stated for the out-of-pile and in-pile tests should be applied here, also. These final tests should be capable of following the accident from initiation, through reentry to the final core material-sodium interaction.

The recommended series of development tests based on this study is described in Table 8-1.

\section{Table 8-1 \\ RECOMMENDED EXPERIMENTAL PROGRAM}

\section{Recommended Test}

1. Flow regime simulation

2. Molten clad-sodium interaction (modeling tests)

3. Hot and/or molten-clad-sodium interaction (prototype geometry)

4. Pin bundle crushing

5. Duct deflection

6. Molten fuel and clad-sodium interaction.(modeling tests)

7. Molten fuel "lad-sudium intcraction (losb-of-flow integral tests)

\section{Description}

Prototype geometry, water tests, voiding and reentry

Shock tube tests to characterize pressure. pulses

Out-of-pile rod bundle (electrical heated or preheated) duct response measured

Mechanical strength measurements of a simulated pin bundle

Out-of-pile, hydraulic and explosive loading of hexagonal ducts (ductile and brittle ducts)

In-pile pseudo-static and/or forced flow capsules, single pins, parametric studies

In-pile, prototype geometry, 3-7 pins. 


\section{REFERENCES}

1. Fischer, G.J., et al., Fast Reactor Accident Study Code, SASIA, Conf-690401 Proceedings of Conference on "The Effective Use of Computers in the Nuclear Industry, Knoxville, Tenn., April 21-23, 1969.

2. Annual Summary Report, 1965, (STL 372-30). 


\section{Appendix A \\ MATERIAL PROPERTIES}

The following is a compilation of material properties used in this study. The properties of irradiated steel under the conditions expected in this transient are generally not available. For purposes of discussion, the relationships between elongation and temperature, and elongation and fluence have been assumed, while recognizing the uncertainties shown by the scatter of existing data. The influence of the real temperature distribution, temperature history, strain history, and strain rates on the steel elongation are unknown but are not expected to be of major significance (probably less than a factor of two, while overall uncertainty is a factor of 10 ).

Figure

\section{LIST OF ILLUSTRATIONS}

Number

A-1a

A-ib

A-1c

A-2a

A-2b

A-3a

A-3b

A- $4 a$

A- 4 b

A-5

A-6

A-7

A-8a

A-8b

A-8c

A.9

A-10a

A-10b

A-10c

Liquid Sodium-Density versus 'l'emperature

Liquid Sodium-Specific Heat versus Temperature

Liquid Sodium-Thermal Conductivity versus Temperature

T.iquid Sodium-Thermal Diffusivity versus Temperature

Liquid Sodium-Viscosity versus Temperature

Liquid Sodium-Volume Expansion versus Temperature Liquid Sodium-Surface Tension versus Temperature

Sodium Vapor-Specific Heat versus Temperature

Sodium Vapor-Heat of Vaporization versus Temperature

Sodium Vapor-Vapor Pressure (psia) versus Temperature

Sodium Vapor-Vapor Pressure (atms) versus Temperature

Saturated Sodium Vapor-Specific Volume at Saturation versus Temperature

Saturated Sodium Vapor-Viscosity versus Temperature

Saturated Sodium Vapor-Specific Heat versus Temperature

Saturated Sodium Vapor-Thermal Conductivity versus Temperature

A-11a

A-11b

Super Heated Sodium Vapor-Density versus Tempcrature

A-11c

Type 316 Stainless Steel-Density versus Temperature

Type 316 Stainless Steel-Specific Heat versus Temperature

Type 316 Stainless Steel-Thermal Conductivity versus Temperature

A-12a

A-12b

Type 316 Stainless Steel-Thermal Diffusivity versus Temperature

Type 316 Stainless Steel-Poisson's Ratio versus Temperature

Type 316 Stainless Steel-Modulus of Elasticity versus Temperature

A-13

Type 316 Stainless Steel-Volume Expansion versus Temperature

Type 316 Stainless Steel-Coefficient of Expansion versus Temperature

A.14

Type 316 Stainless Steel-Some Mechanical Properties versus Temperature

A-15

A.16

A-17

A-18

Type 304 and 316 Stainless Steel-Yield Strength versus Temperature

Type 316 Stainless Steel-Yield Strength versus Fluence

Type 316 Stuinless Stcel-Ultimate Stress versus Temperalure

Type 316 Stainless Steel-Ultimate Stress versus Fluence

Type 316 Stainless Steel-Percent Elongation versus Fluence

A.19

A-20

Mixed-Oxide Fuel-Thermal Conductivity versus Temperature

Mixed-Oxide Fuel-Specific Heat vcrsus Temperature

A-21

Mixed-Oxide Fuel-Linear Thermal Expansion versus Temperature

A-22

Mixed-Oxide Fuel-Völumetric Thermal Expansion versus Temperature 
GEAP-10059

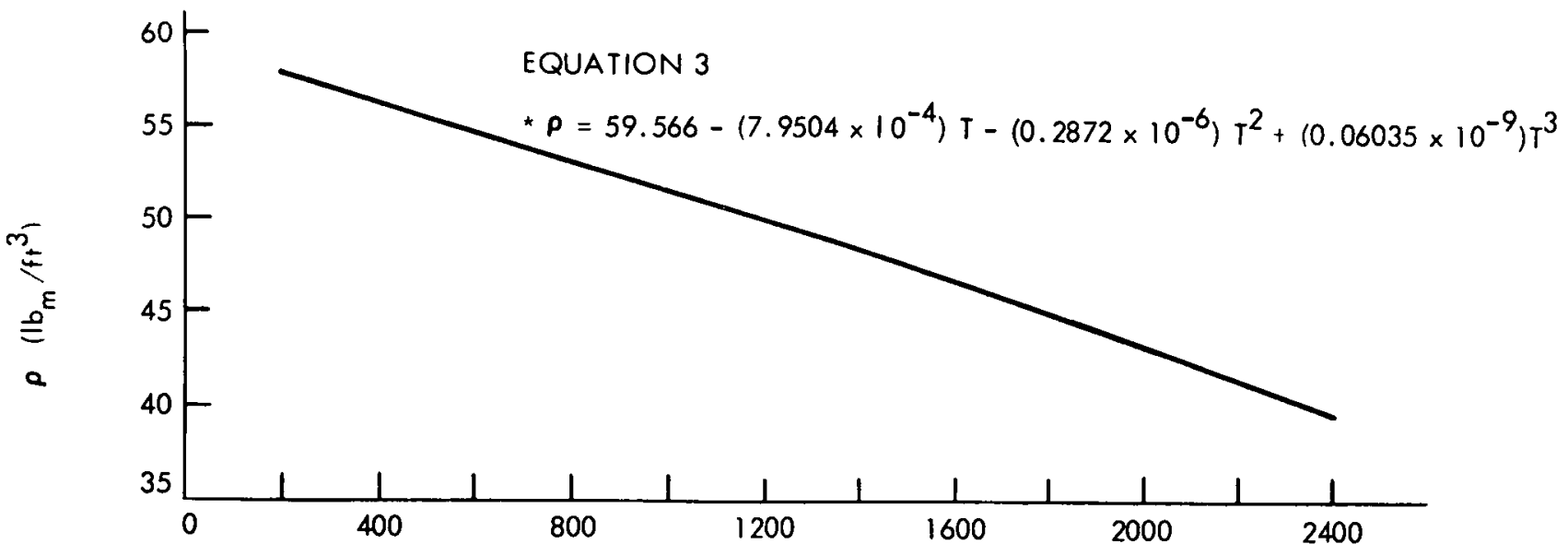

Figure A-la. Liquid Sodium-Density versus Temperature

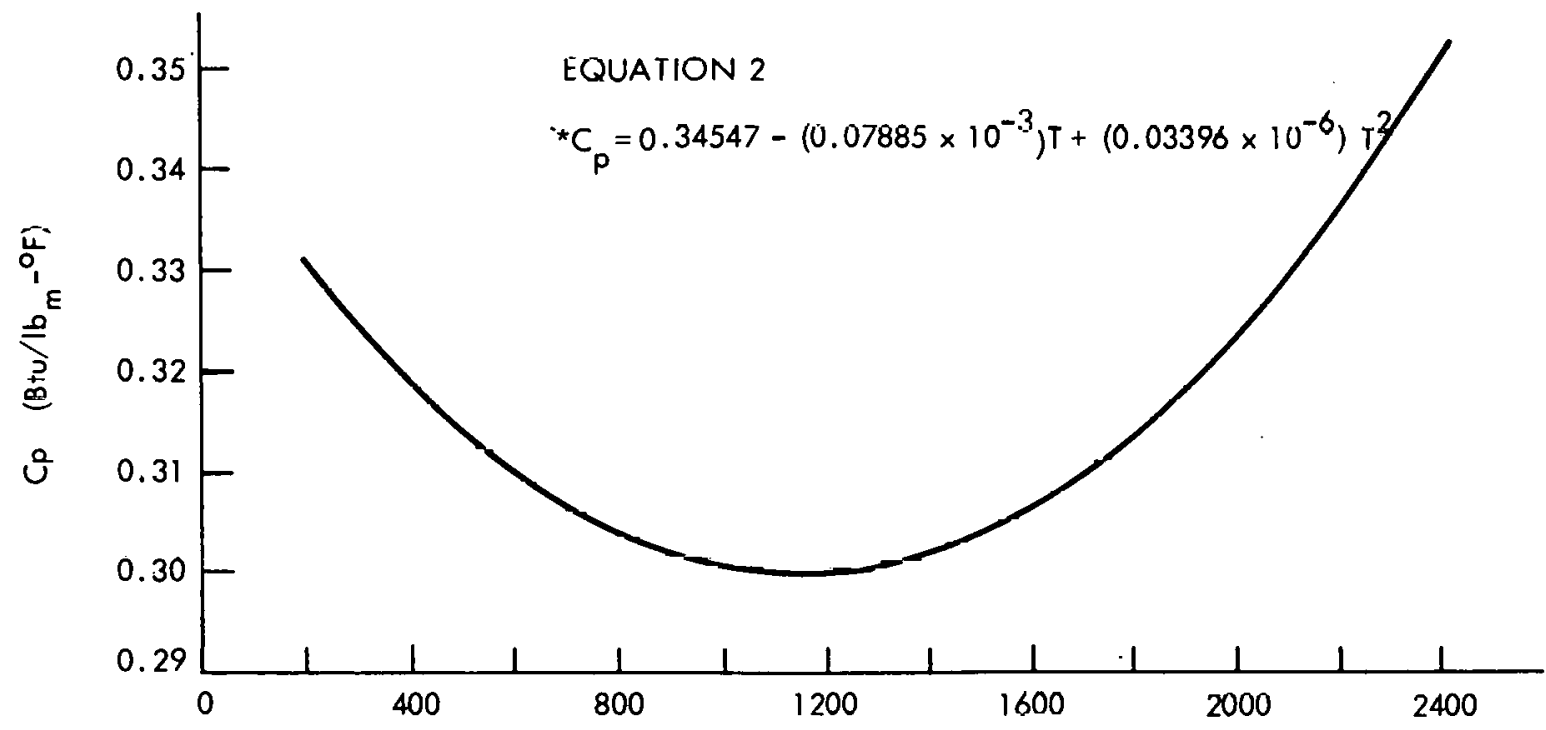

Figure A-1b. Liquid Sodium-Specific Heat versus Temperature

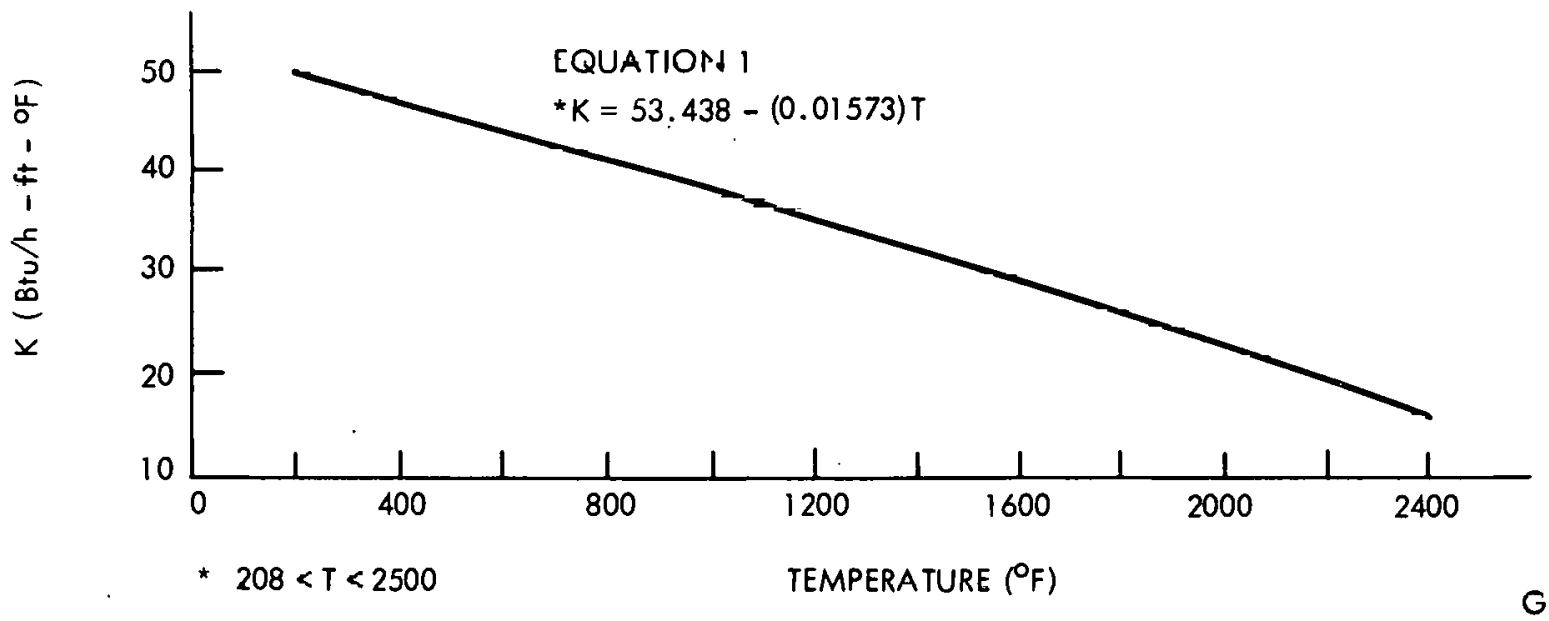

Figure A-1. Liquid Sodium-Thermal Conductivity versus Temperature 


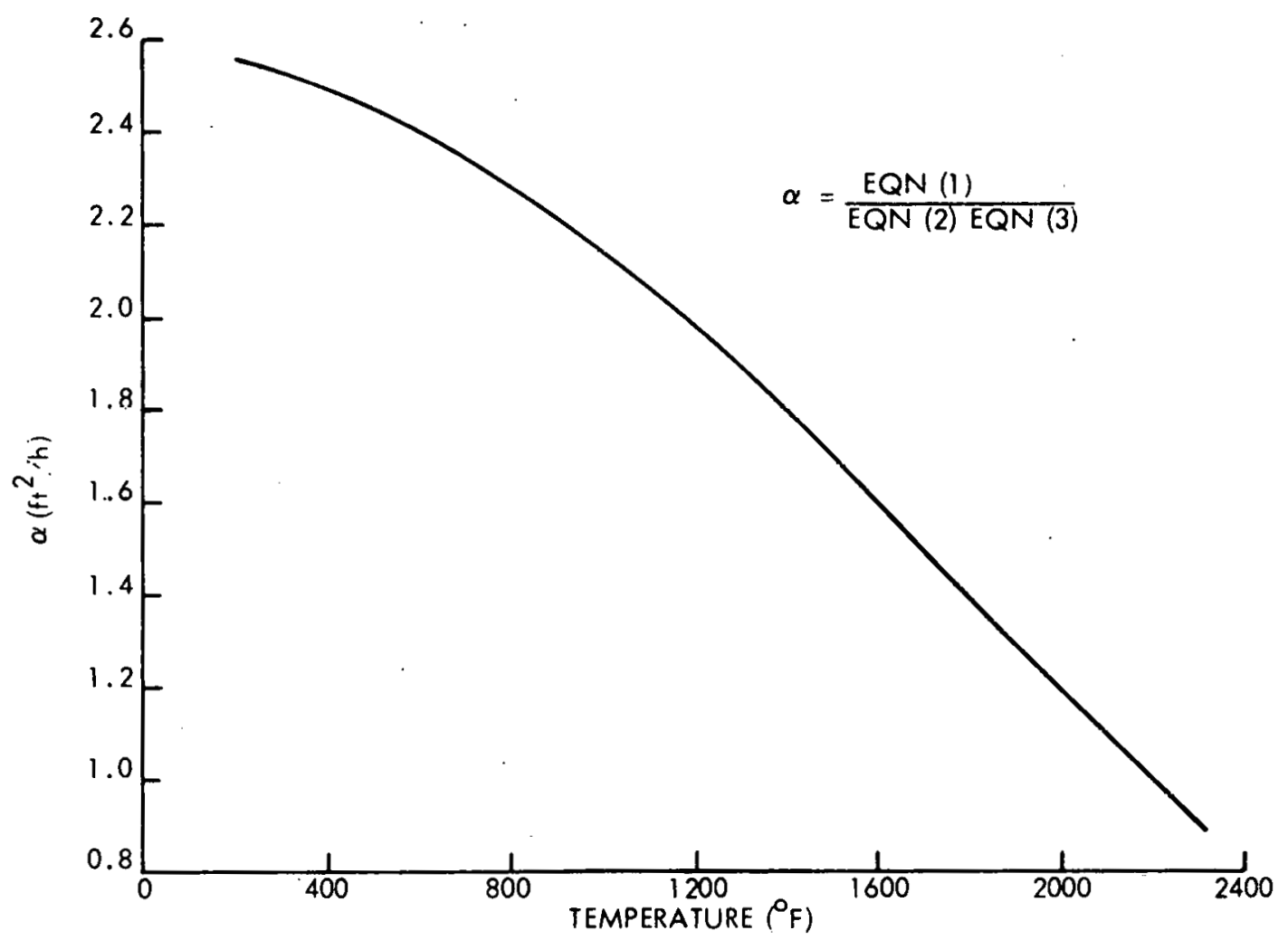

Figure A-2a. . Liquid Sodium-Thermal Diffusivity versus Temperature

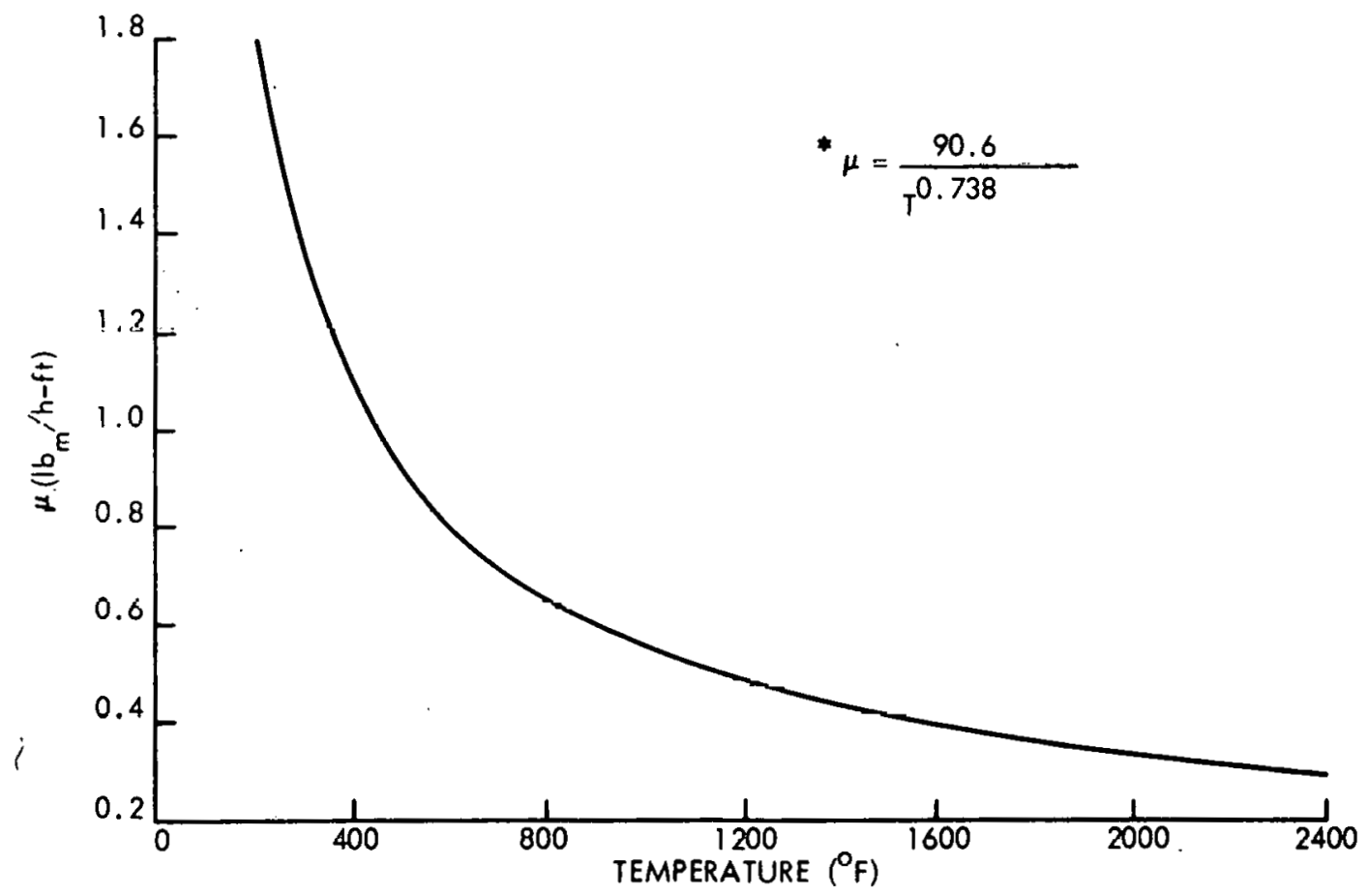

* $208<\mathrm{T}<2500$

G09-131

Figure A-2b. Liquid Sodium-Viscosity versus Temperature 


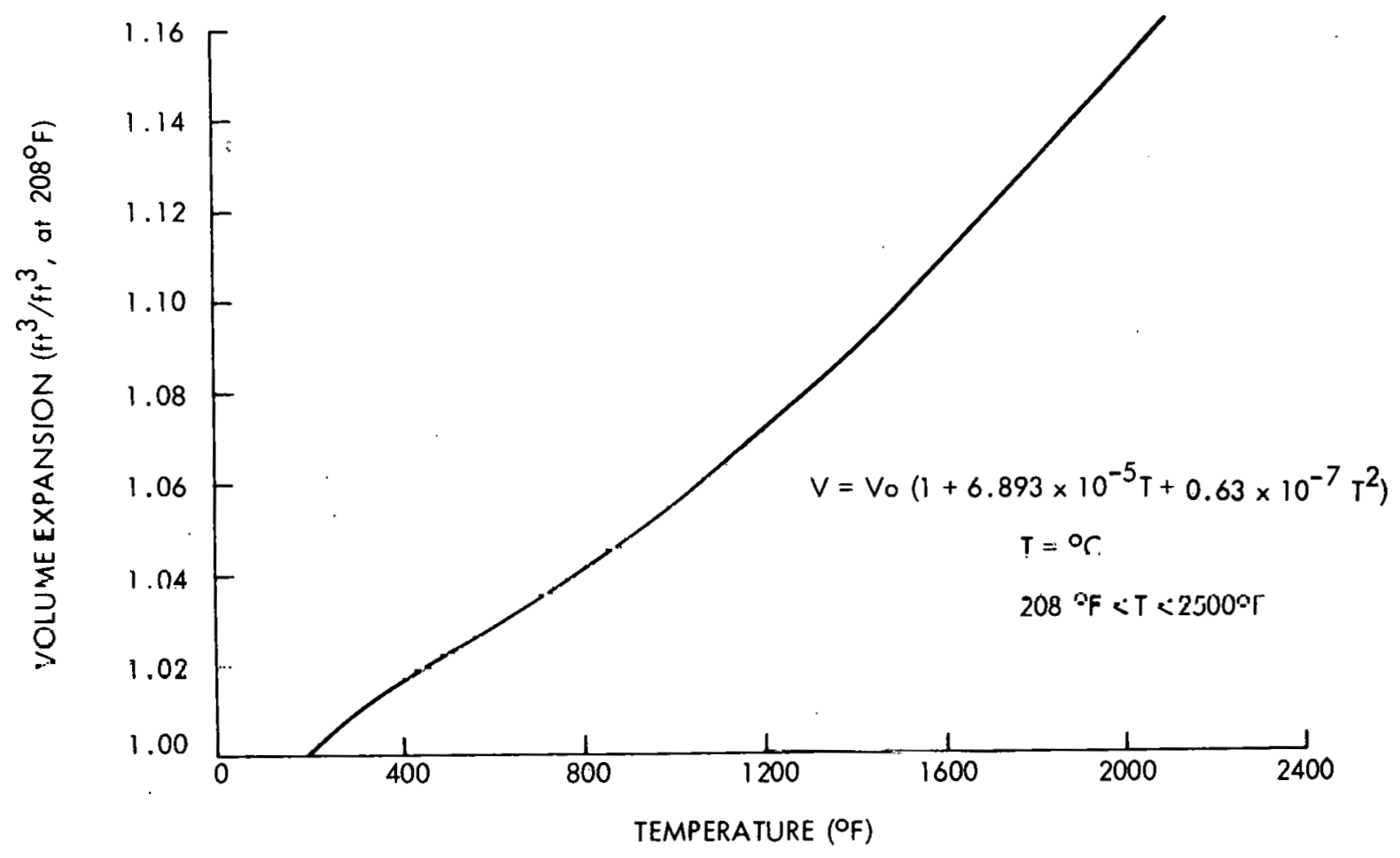

Figure A-3a. Liquid Sodium-Volume Expansion versus Temperature

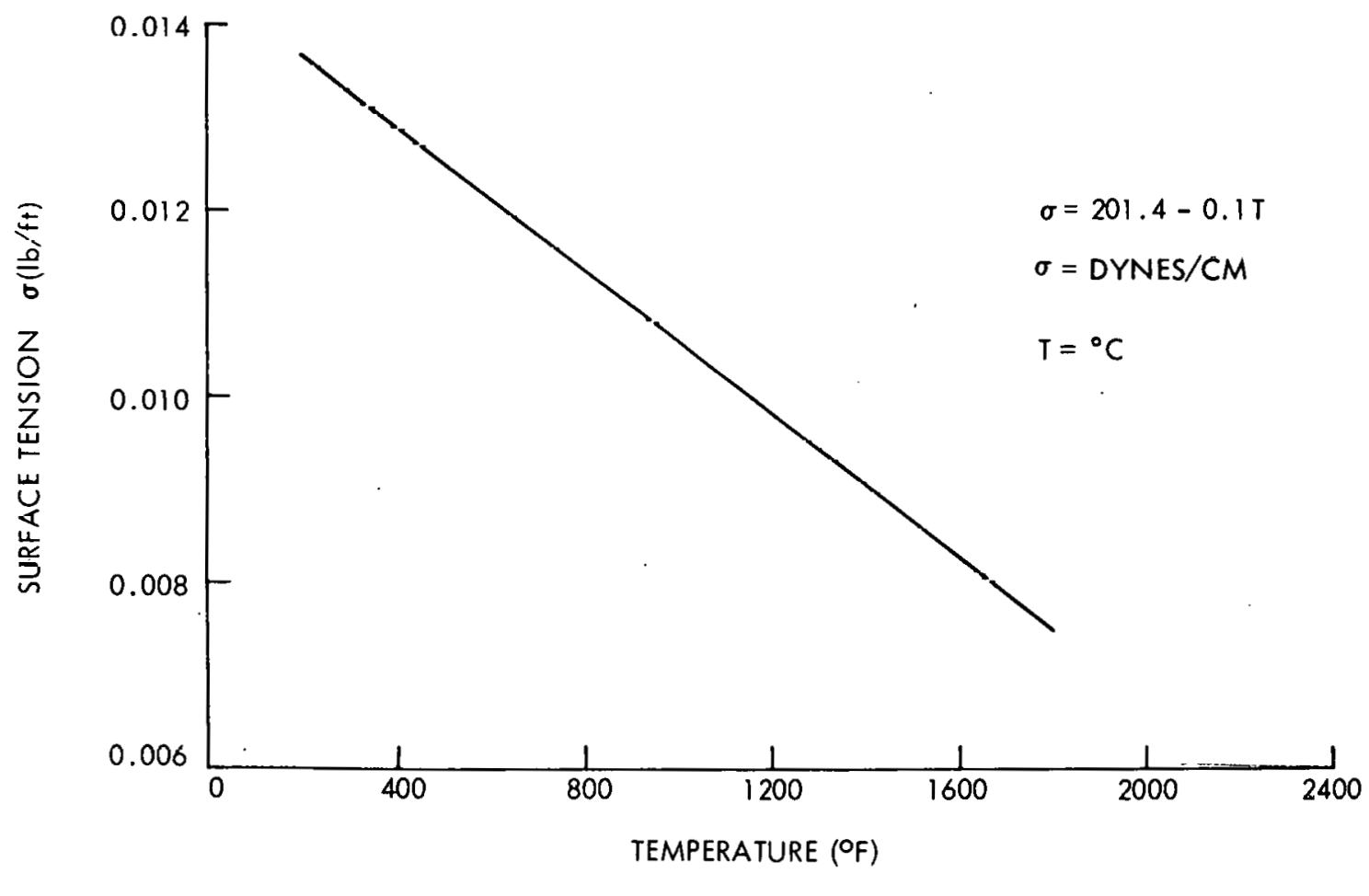

Figure A-3b. Liquid Sodium-Surface Tension versus Temperature 


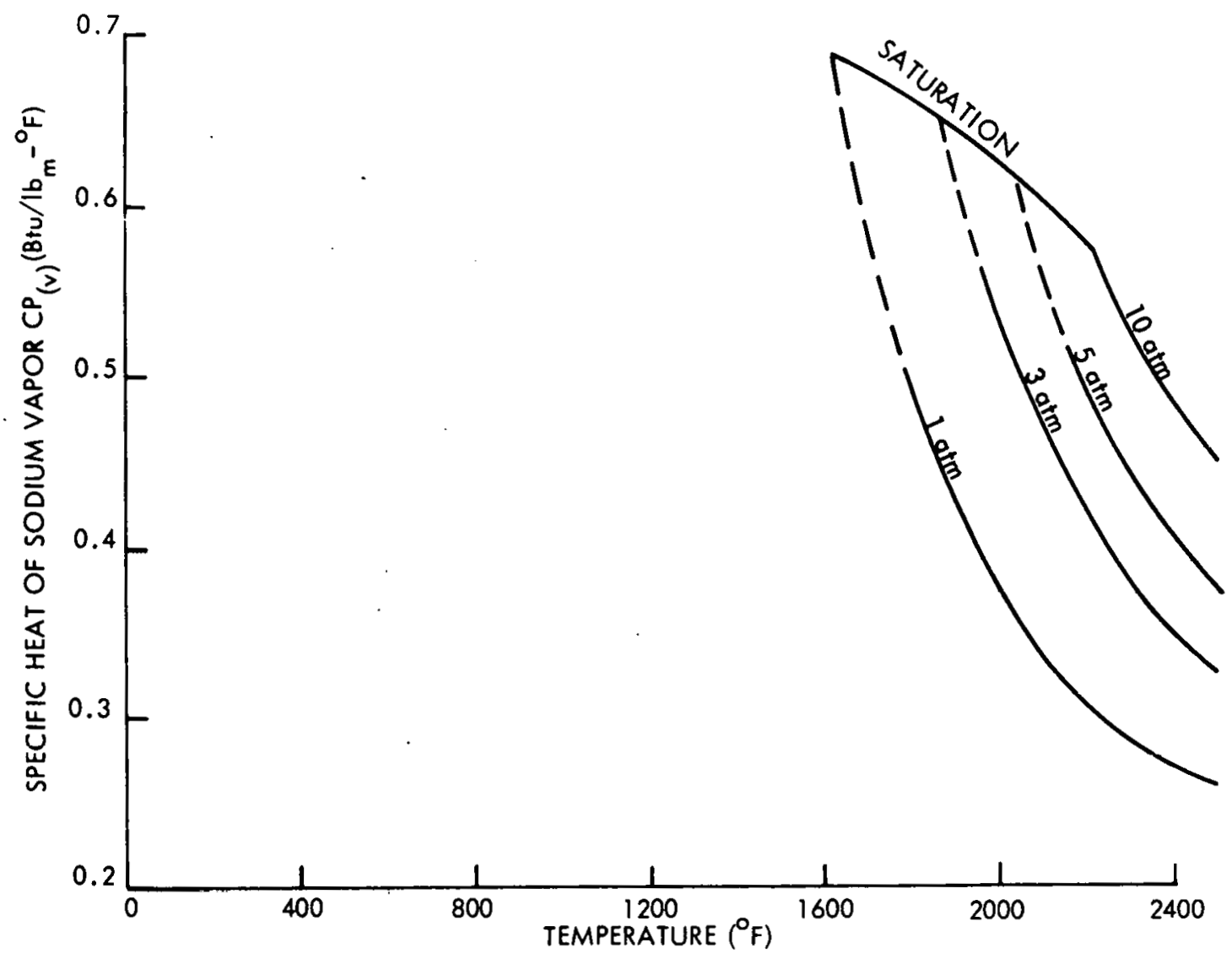

Figure A-4a. Sodium Vapor-Specific Heat versus Temperature

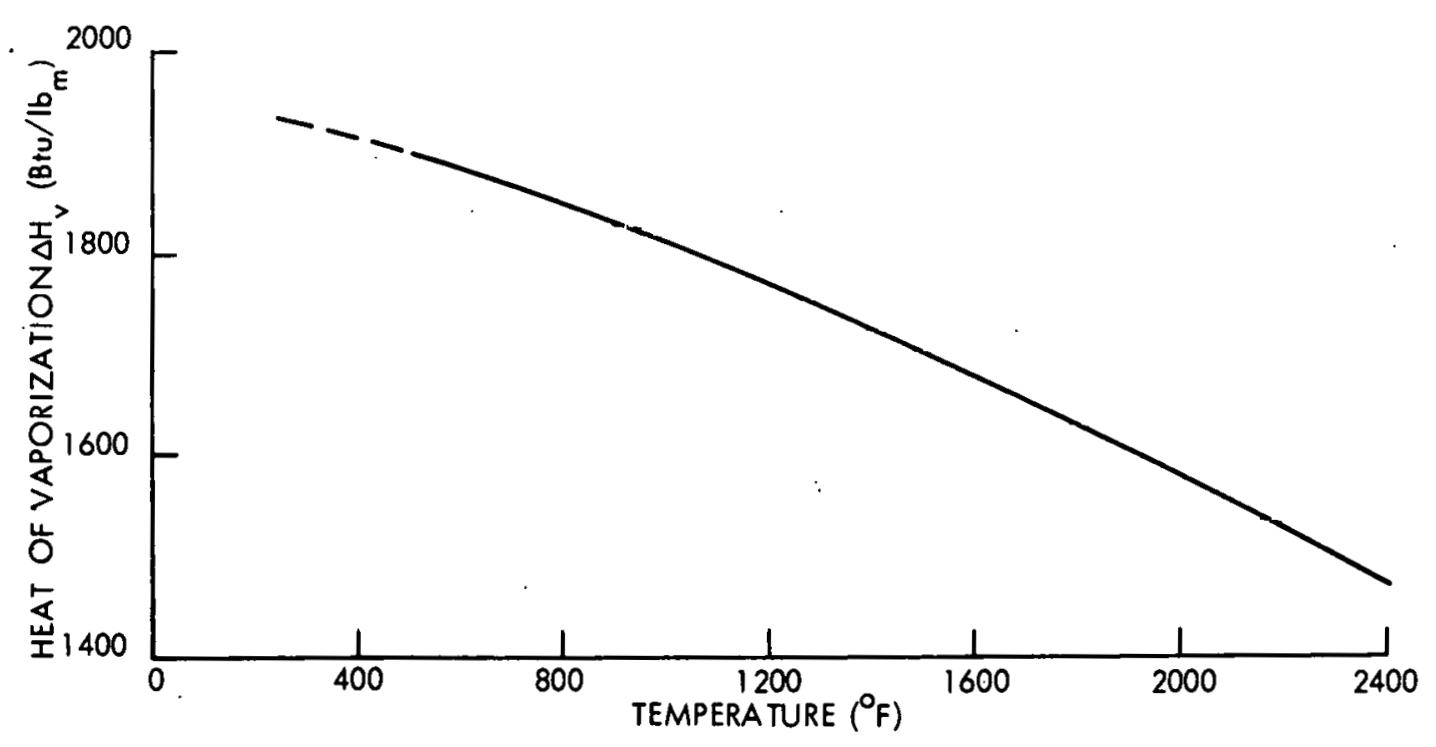

GD9-151

Figure A-4b. Sodium Vapor-Heat of Vaporization versus Temperature 


\section{GEAP-10059}

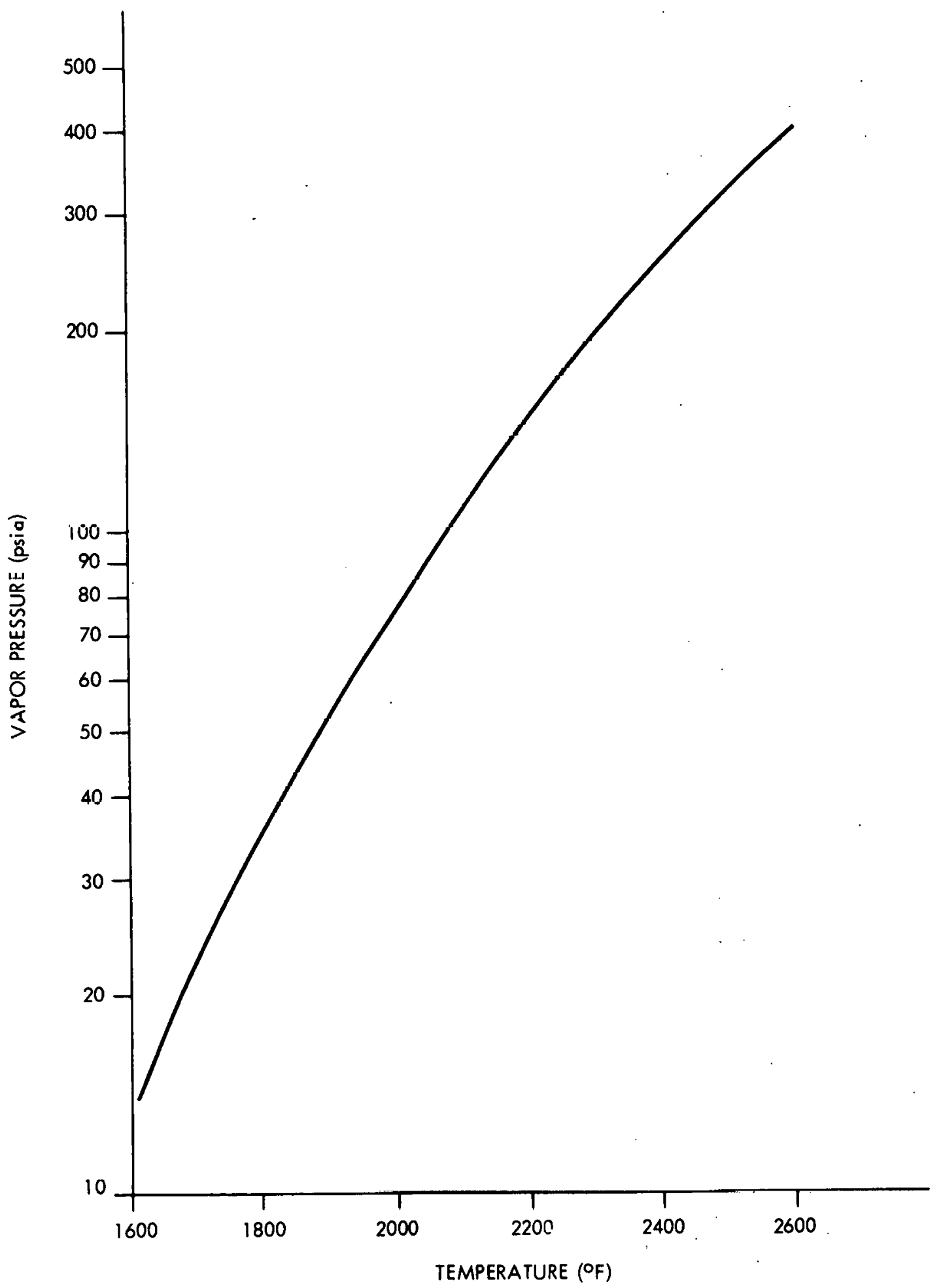

GD9-152

Figure A-5. Sodium Vapor-Vapor Pressure (psia) versus. Temperature 
GEAP-10059

TEMPERATURE $\left({ }^{\circ} \mathrm{F}\right)$

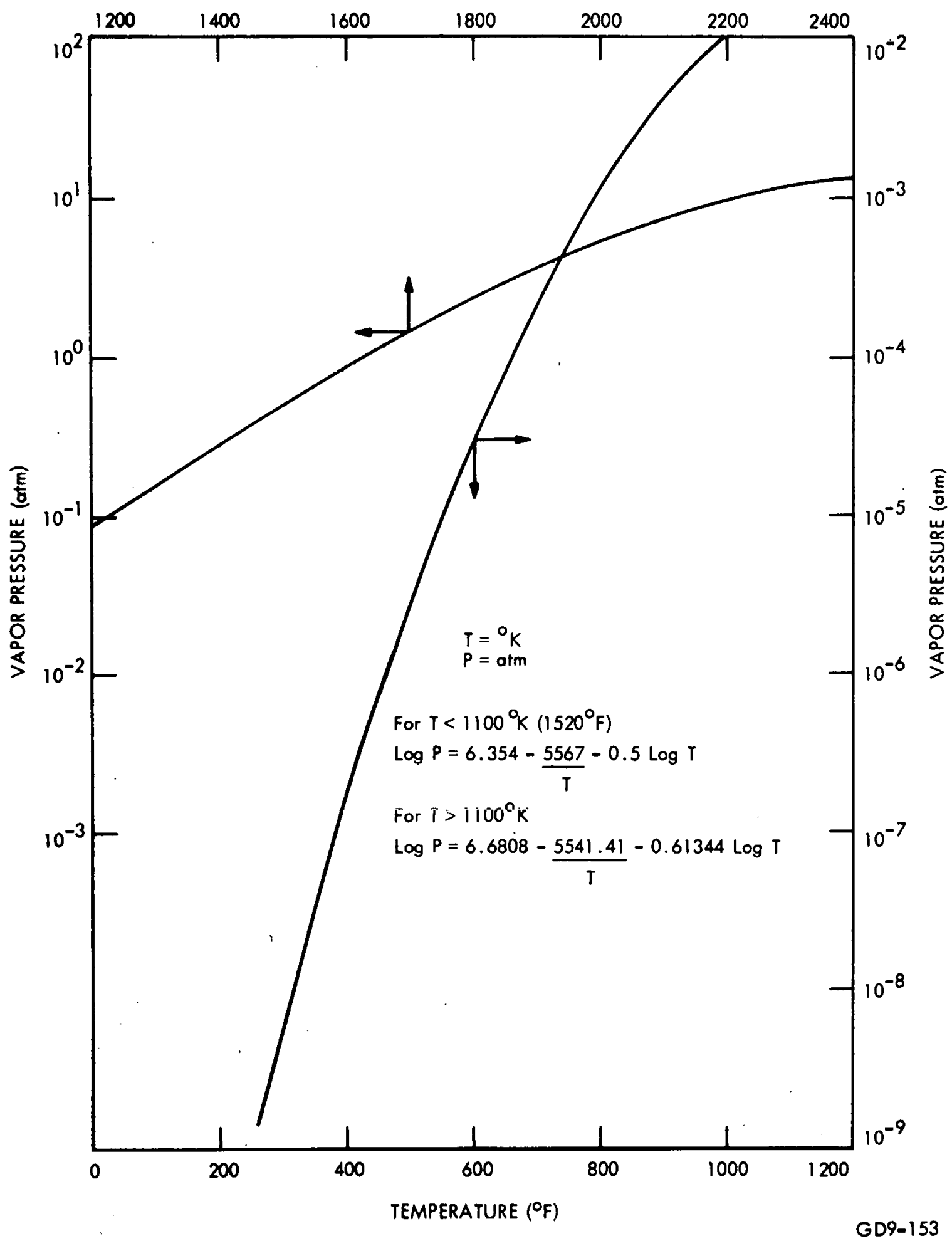

Figure A-6. Sodium Vapor-Vapor Pressure (atms) versus Temperature 
GEAP-10059

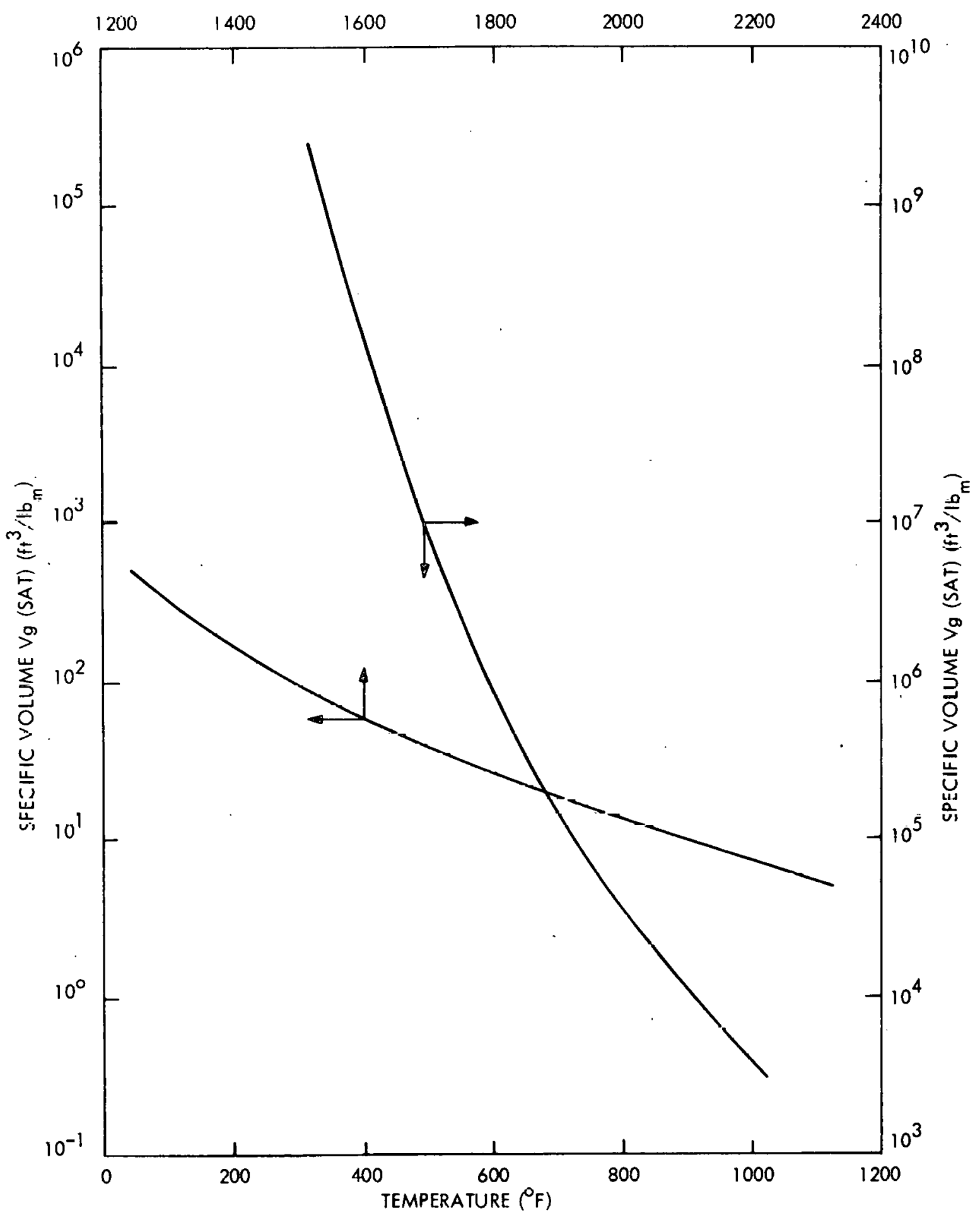

GD9-164

Figure A-7. Saturated Sodium Vapor-Specific Volume at Saturation versus Temperature 


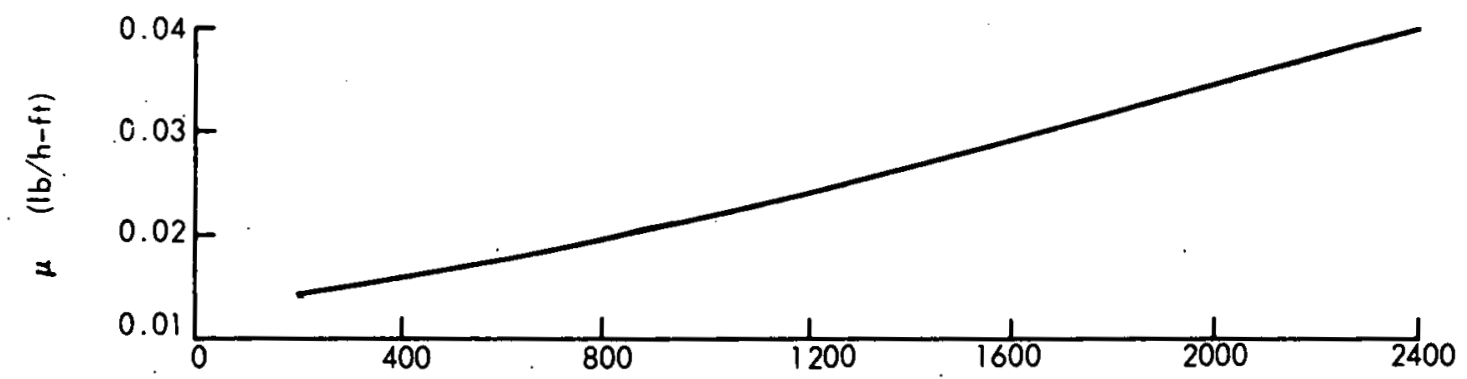

Figure A-8a Saturated Sodium Vapor-Viscosity versus Temperature

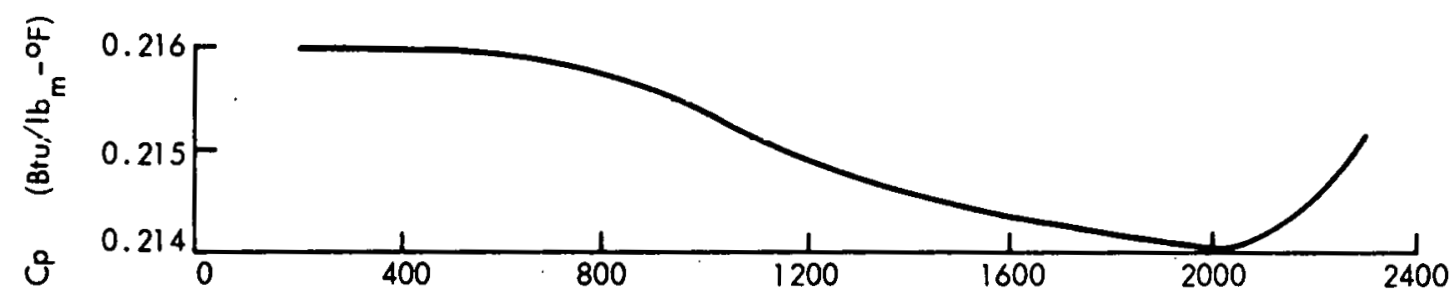

Figure A-8b. Saturated Sodium Vapor-Specific Heat versus Temperature

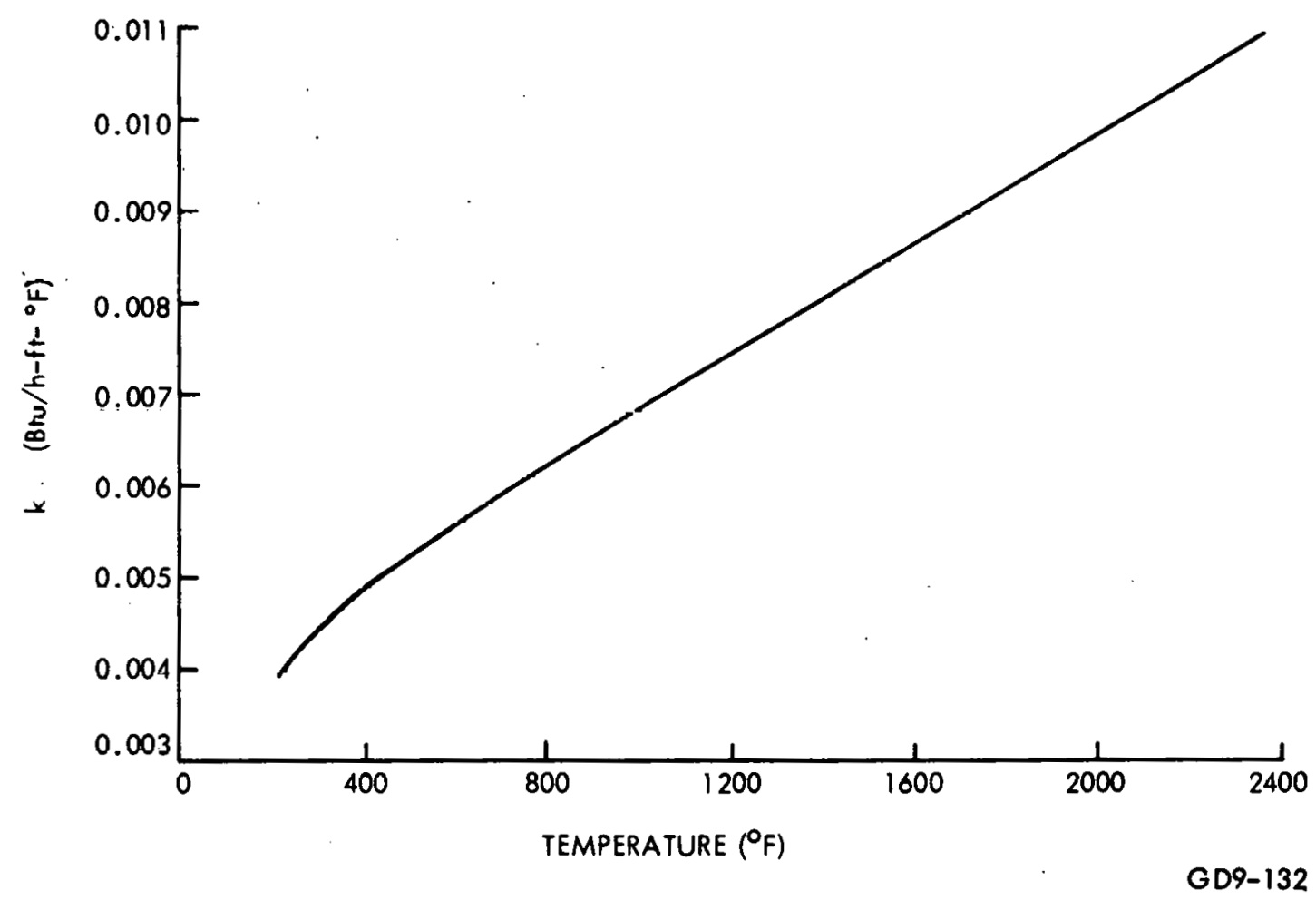

Figure A-8c. Saturated Sodium Vapor-Thermal Conductivity versus T'emperature 


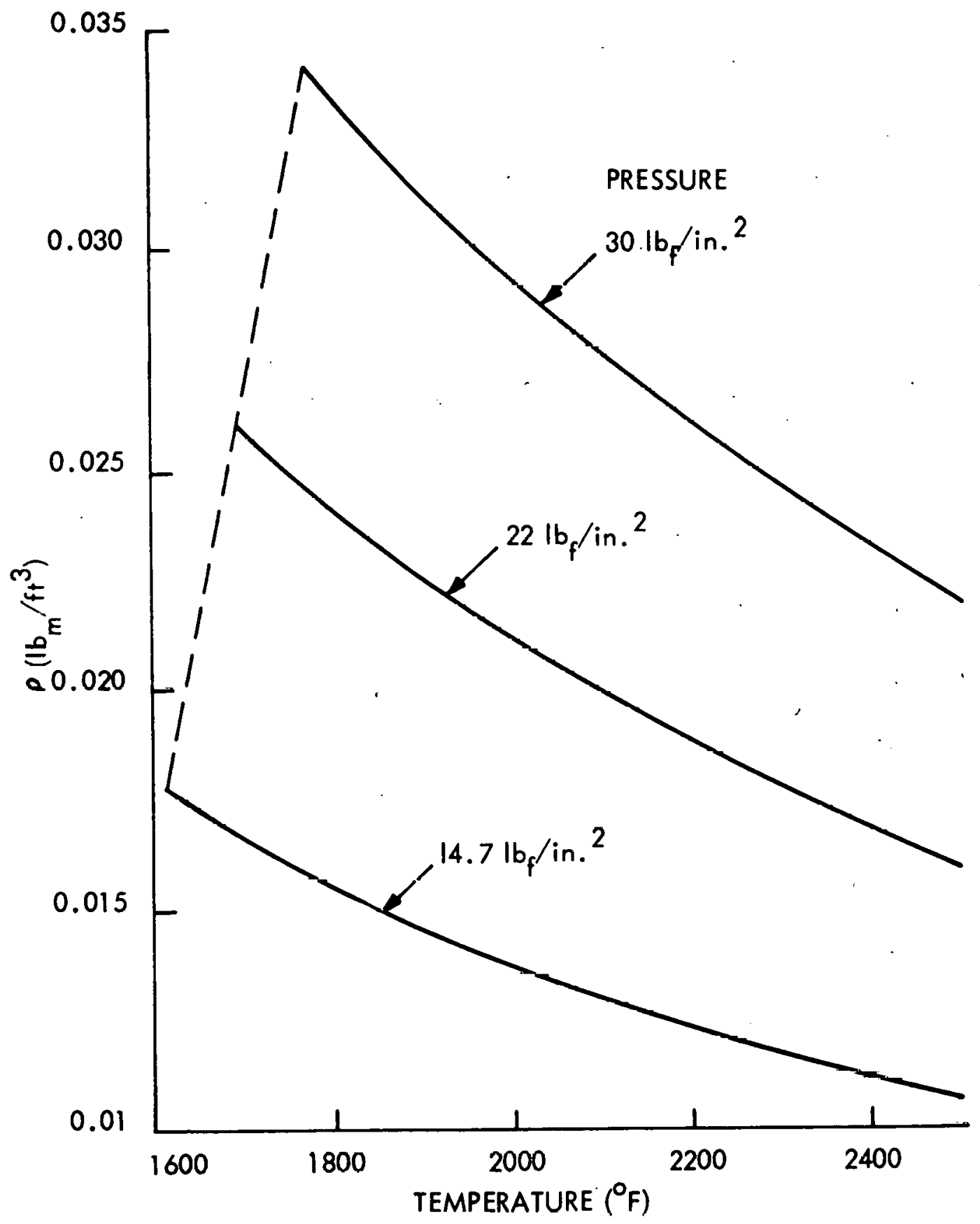

GD9-133

Figure A-9. Supcr Heated Sodium Vapor-Density versus Temperature 


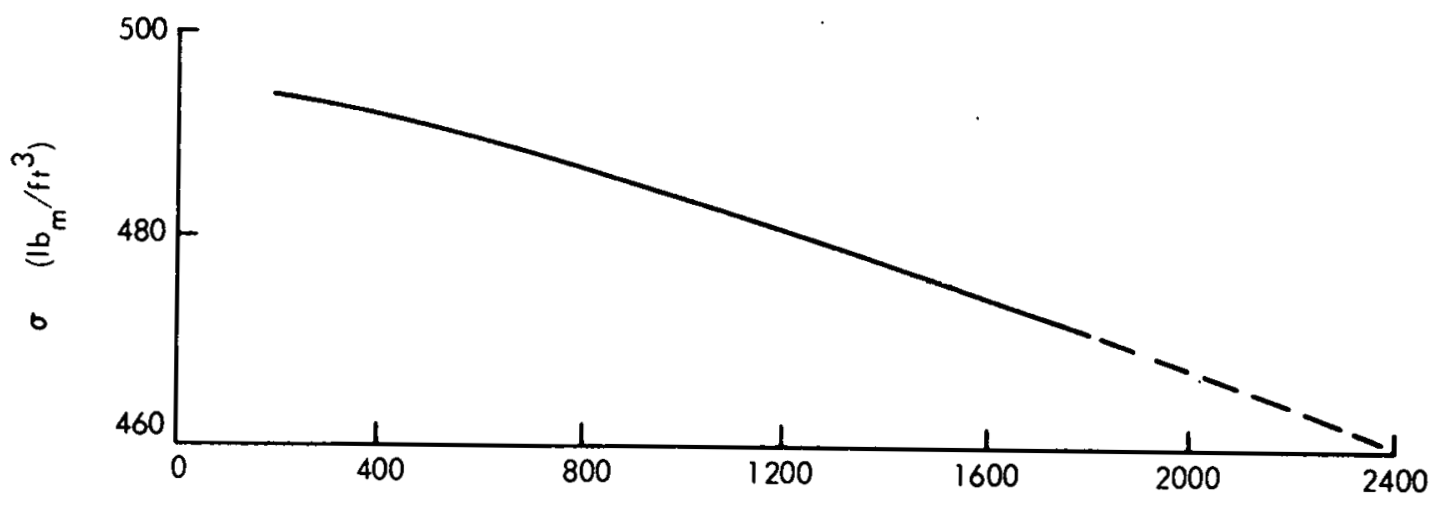

Figure A-10a. Type 316 Stainless Steel-Density versus Temperature

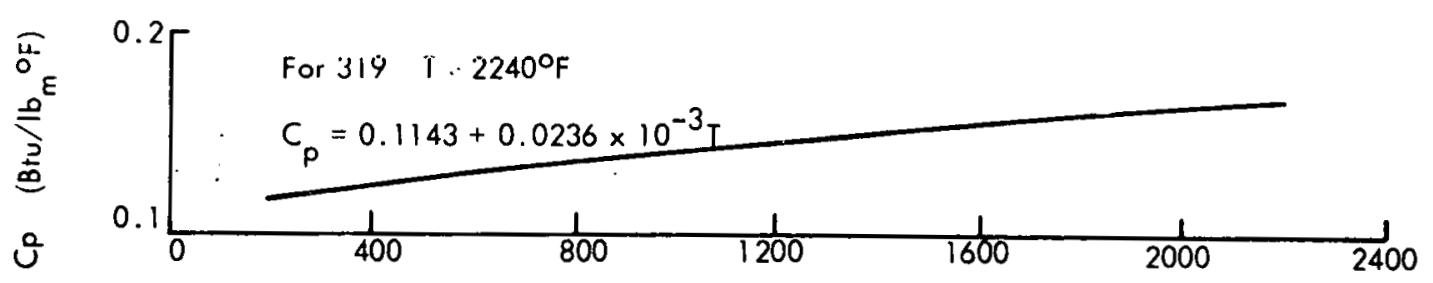

Figure A-10b. Type 316 Stainless Steel-Specific Heat versus Temperature

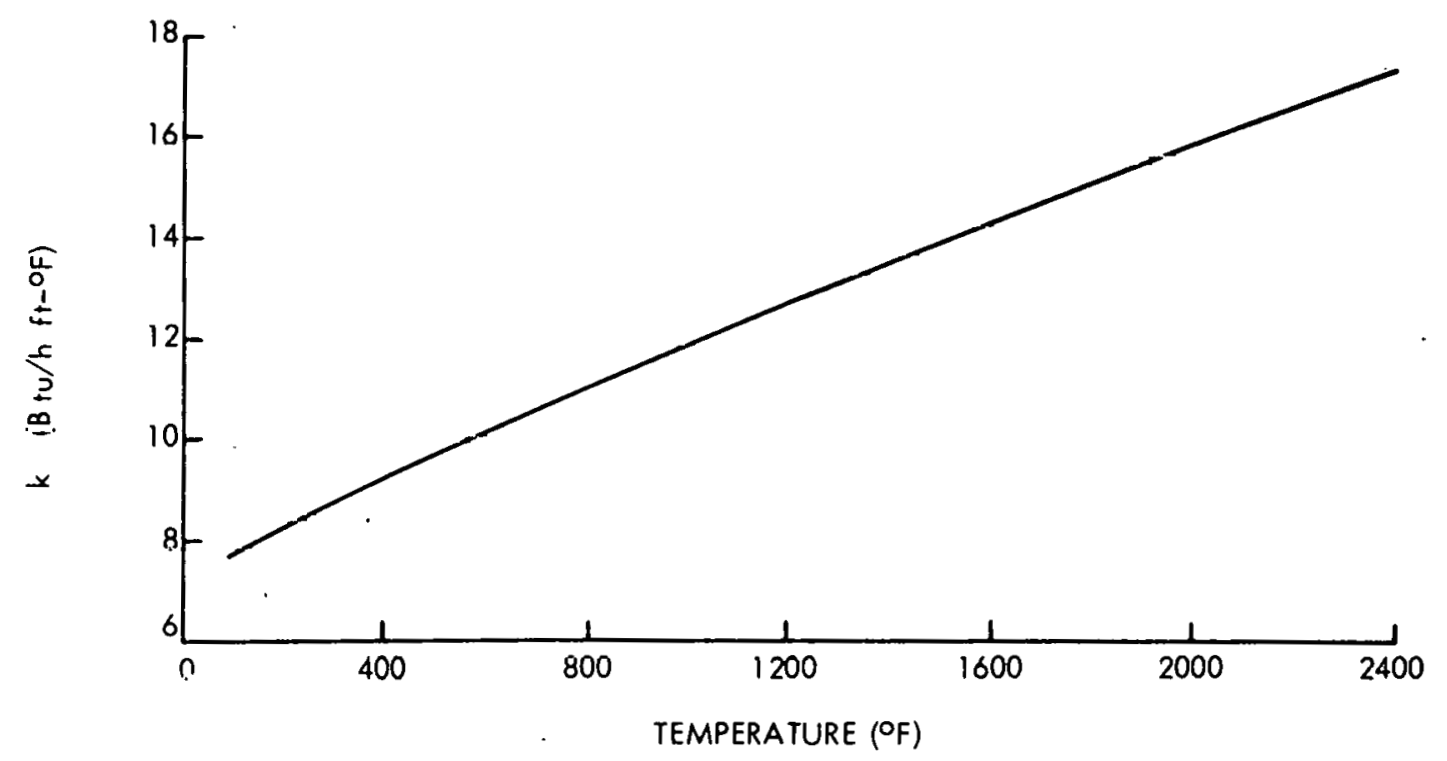

GD9-13A

Figure A-10c. Type 316 Stainless Steel-Thermal Conductivity versus Temperature 


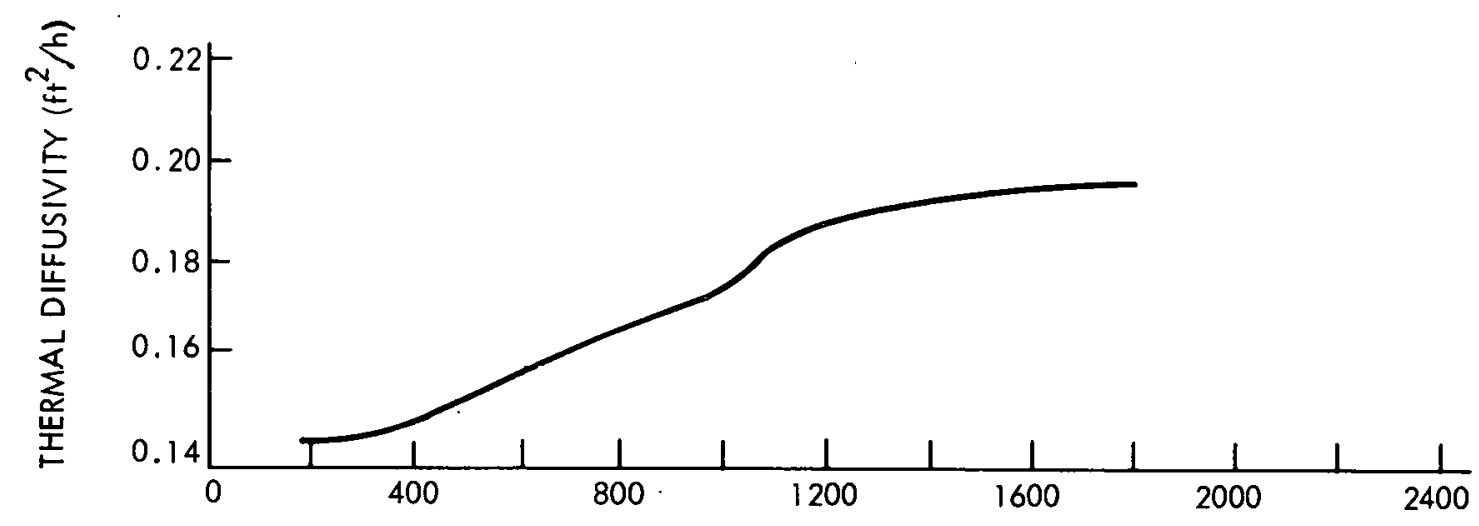

Figure A-11a. Type 316 Stainless Steel-Thermal Diffusivity versus Temperature

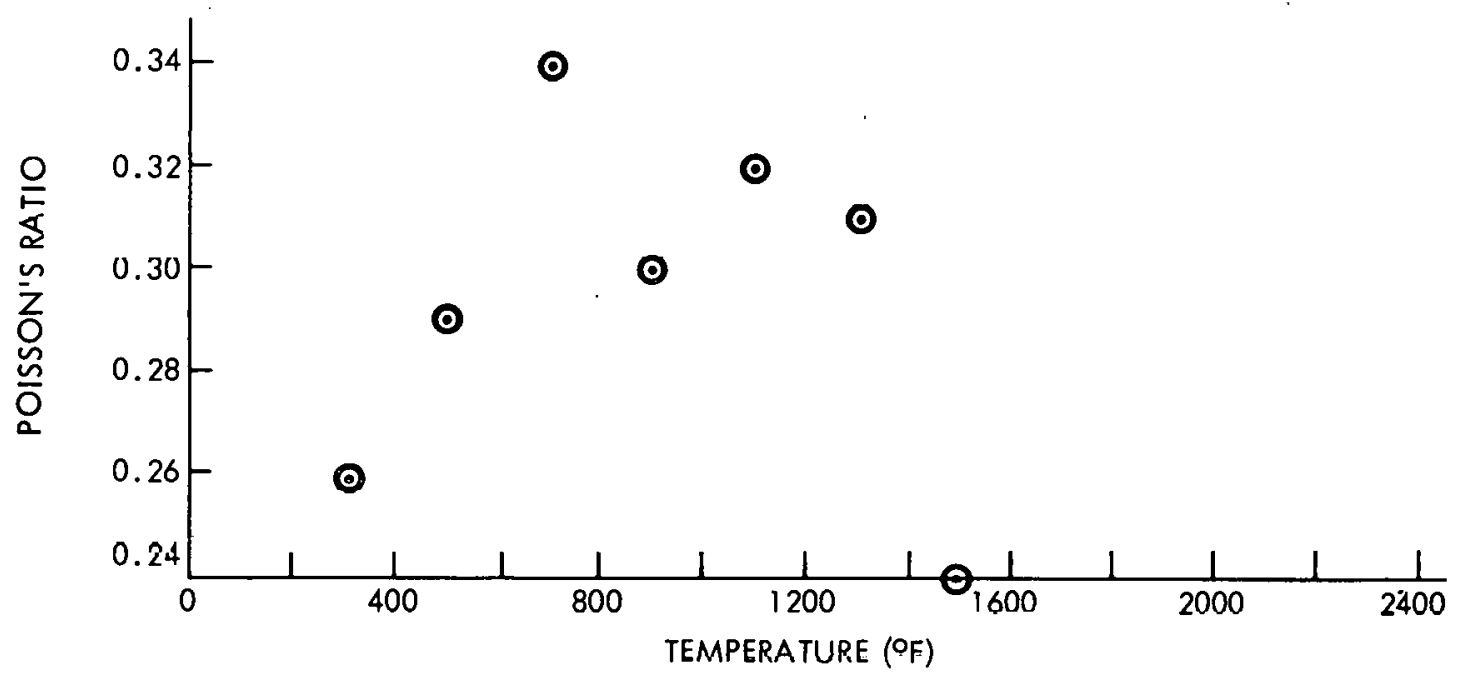

Figure A-11b. Type 316 Stainless Steel-Poisson's Ratio versus Temperature

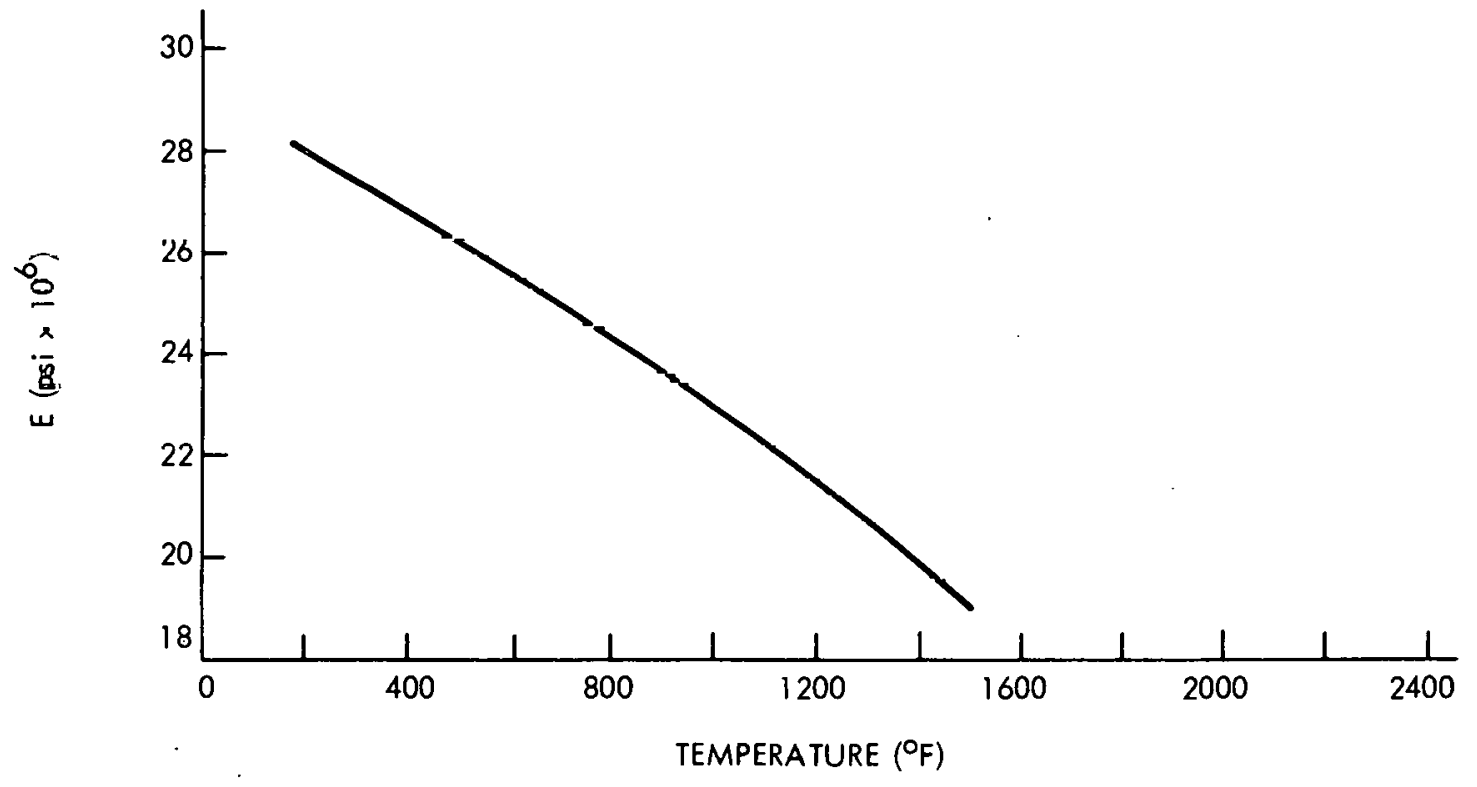

Figure A-11c. Type 316 Stainless Steel-Modulus of Elasticity versus Temperature 


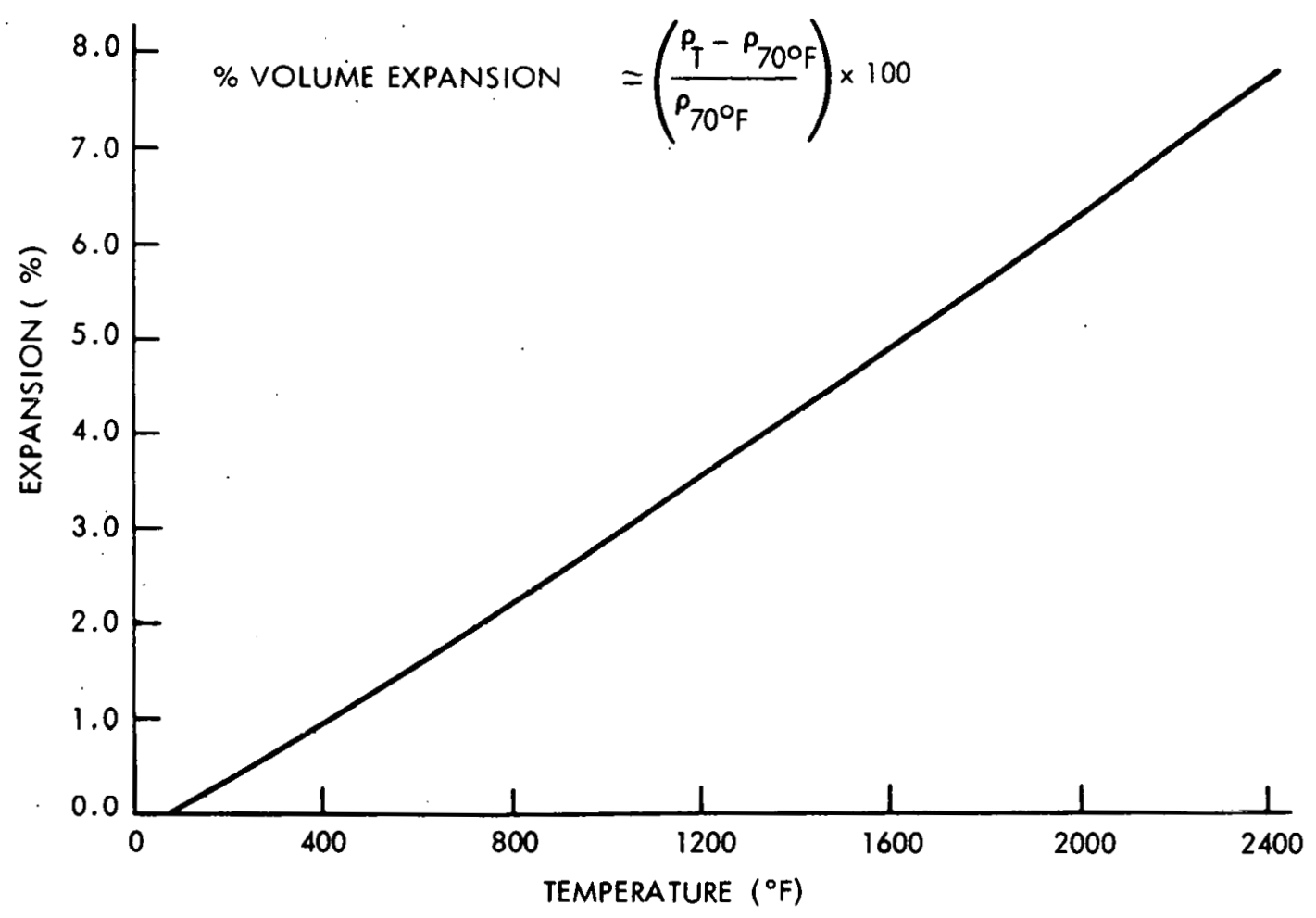

Figure A-12a. Type 316 Stainless Steel-Volume Expansion versus Temperature

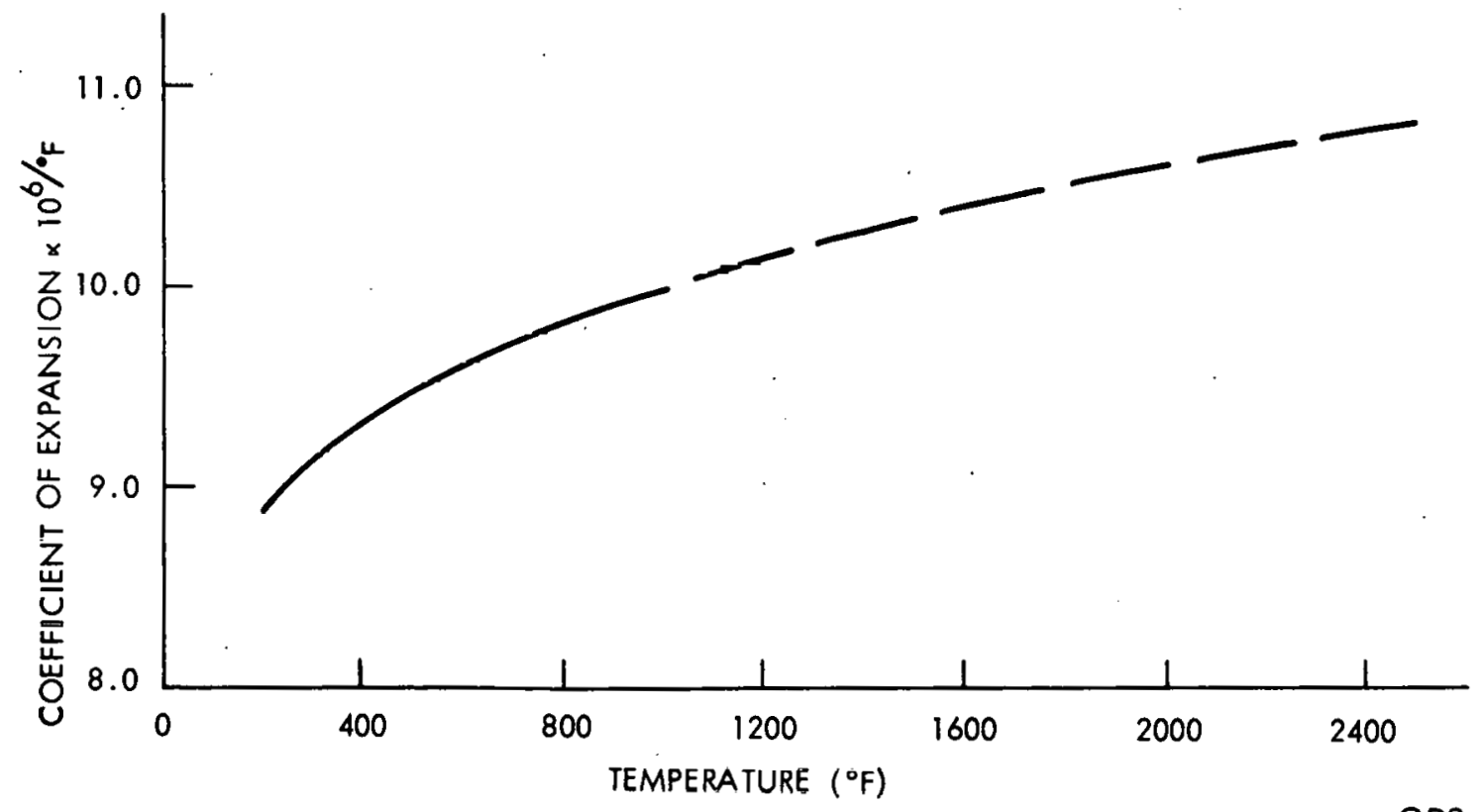

GD9-14C

Figure A-12b. Type 316 Stainless Steel-Coefficient of Expansion versus Temperature 


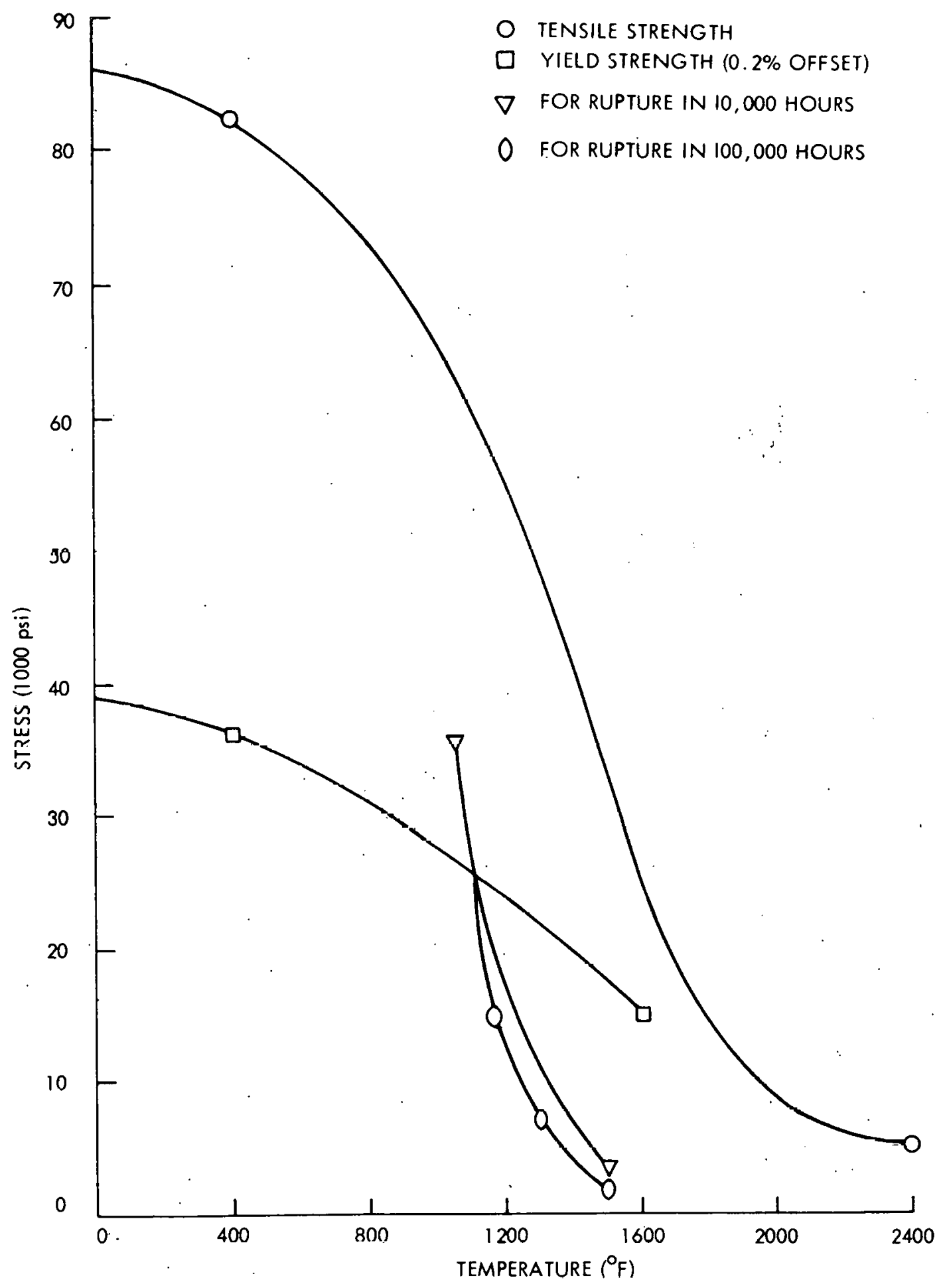

GD9-172

Figure A-13. Type 316 Stainless Steel-Some Mechanical Properties versus Temperature 


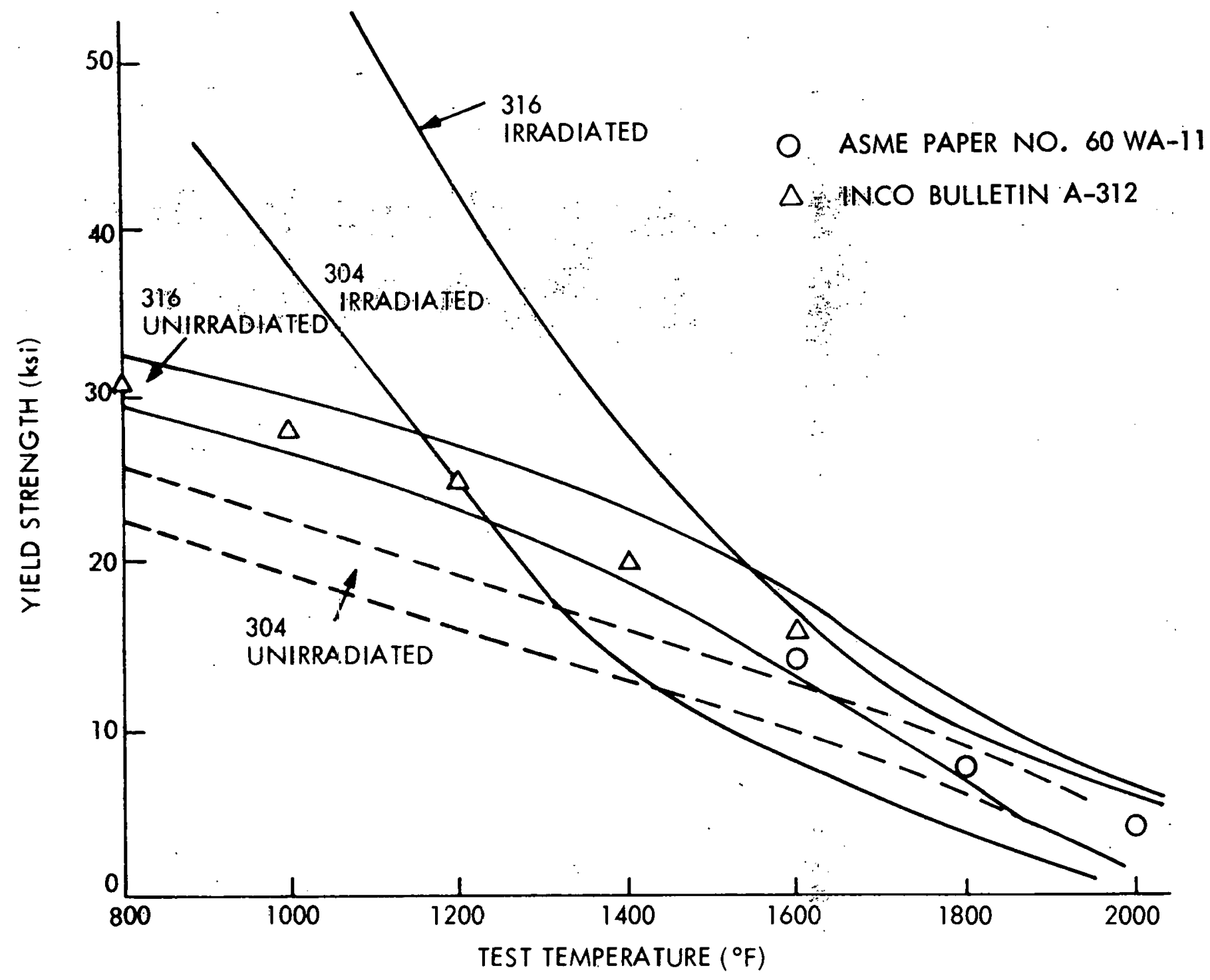

Figure A-14. Type 304 and 316 Stainless Steel-Yield Strength versus Temperature 


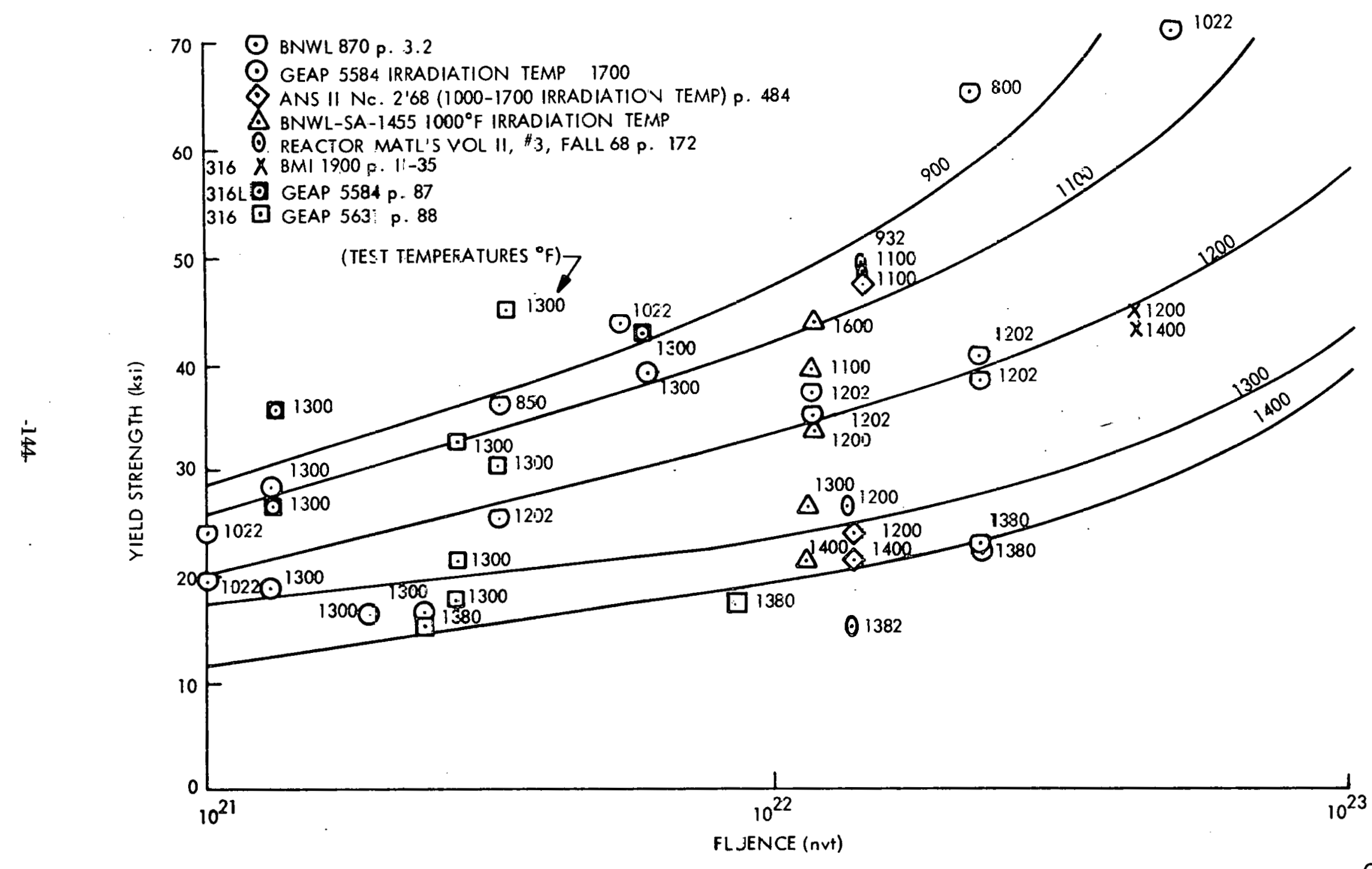

Figure A-15. Type 316 Stainiess Steel-Yield Strength versus Fluence 
GEAP-10059

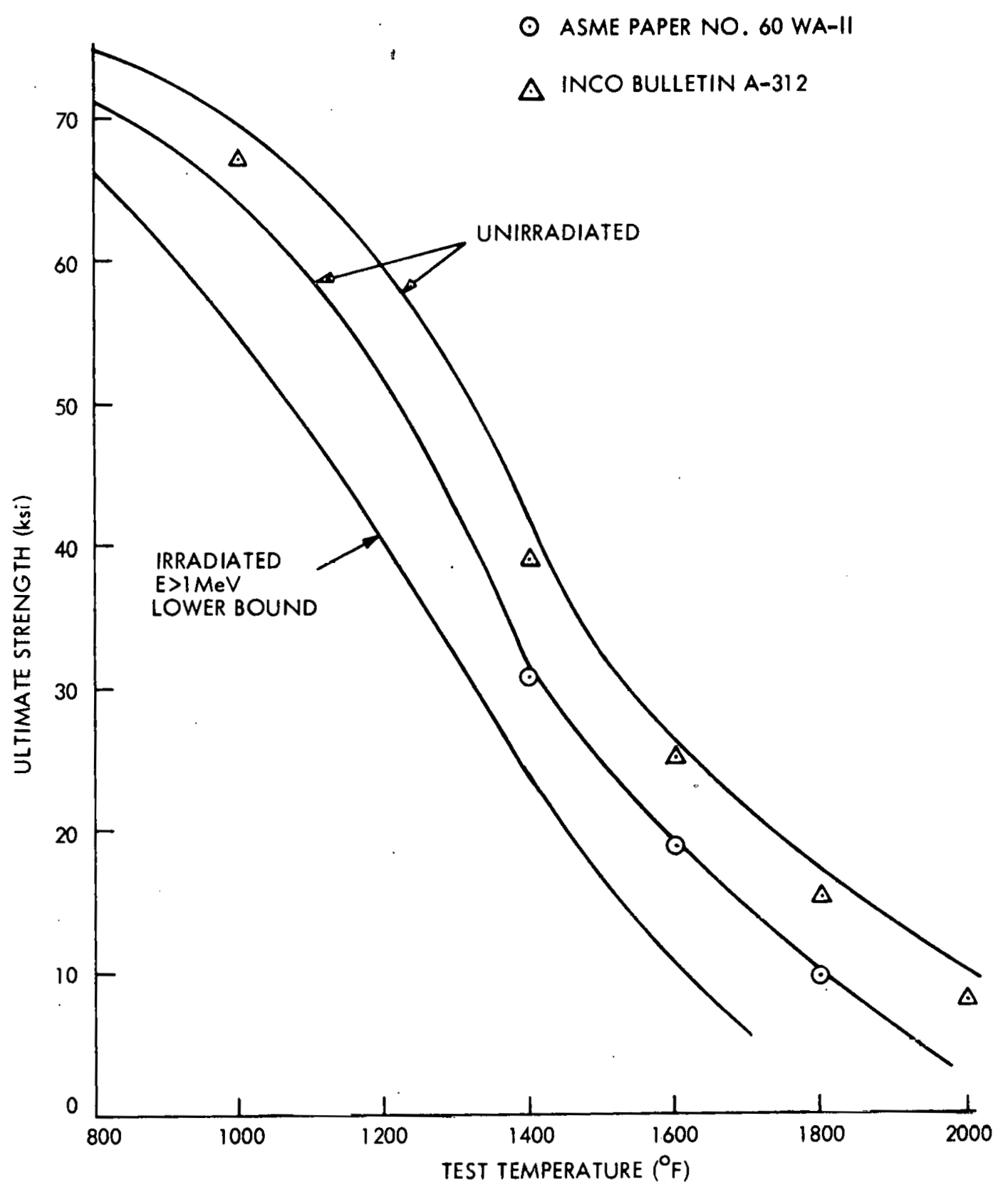

GD9-170

Figure A-16. Type 316 Stainless Steel-Ultimate Stress versus Temperature 


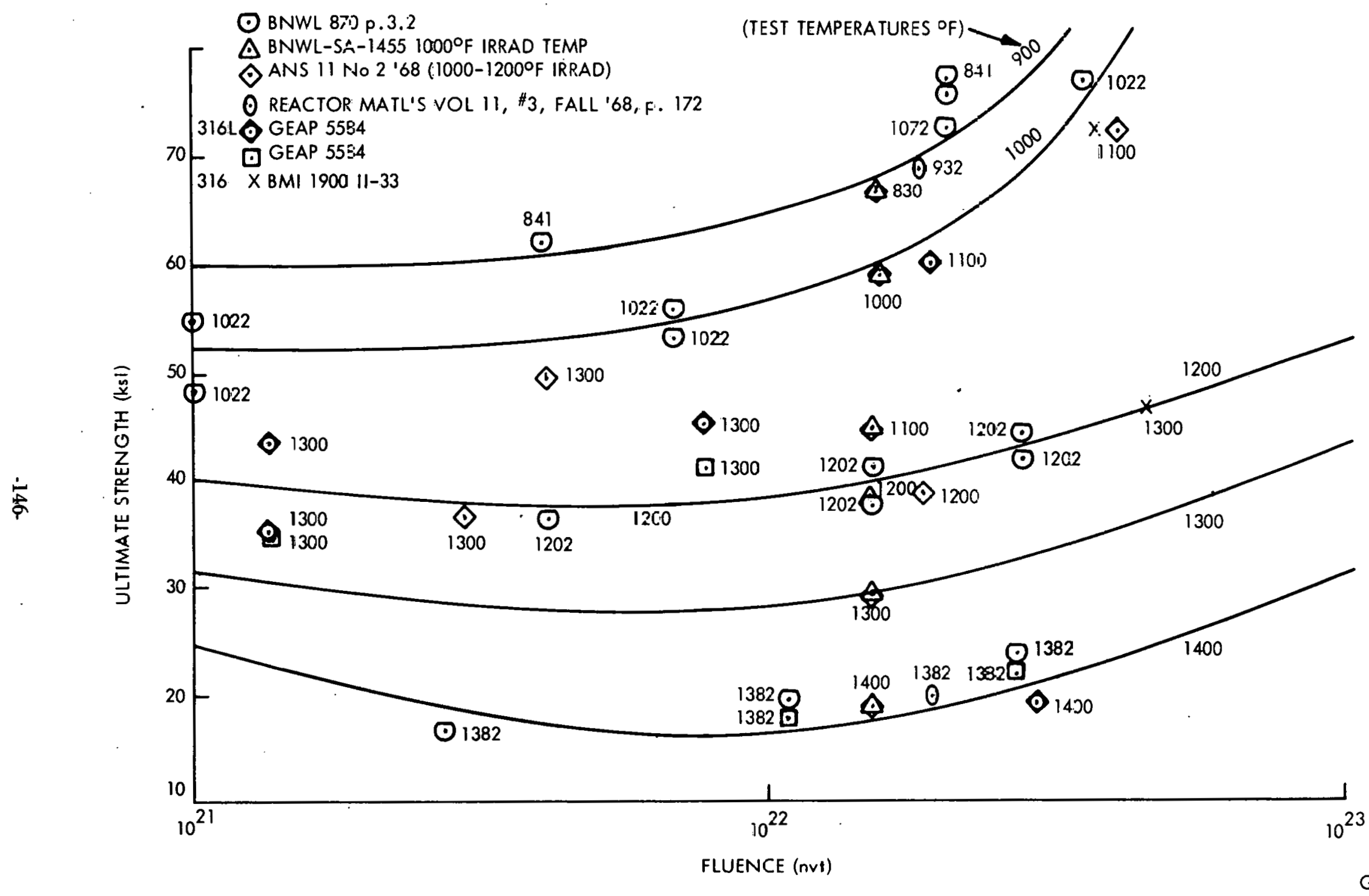

Figure A-17. Type 316 Stainless Steel-Ultimate Stress vers.ts Fluence 


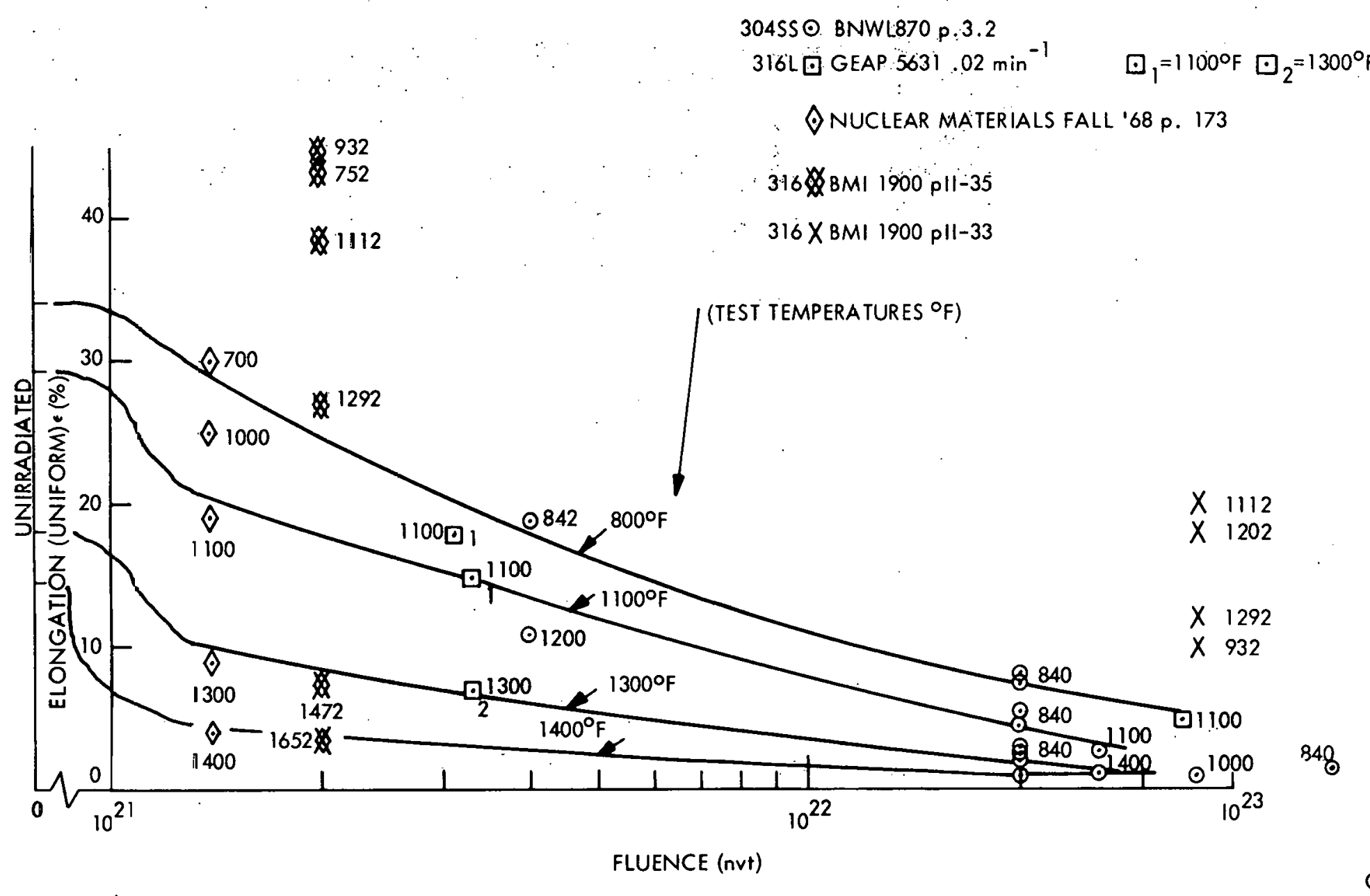

GD9-136

Figure A-18. Type 316 Stainless Steel-Percent Elongation versus Fluence 


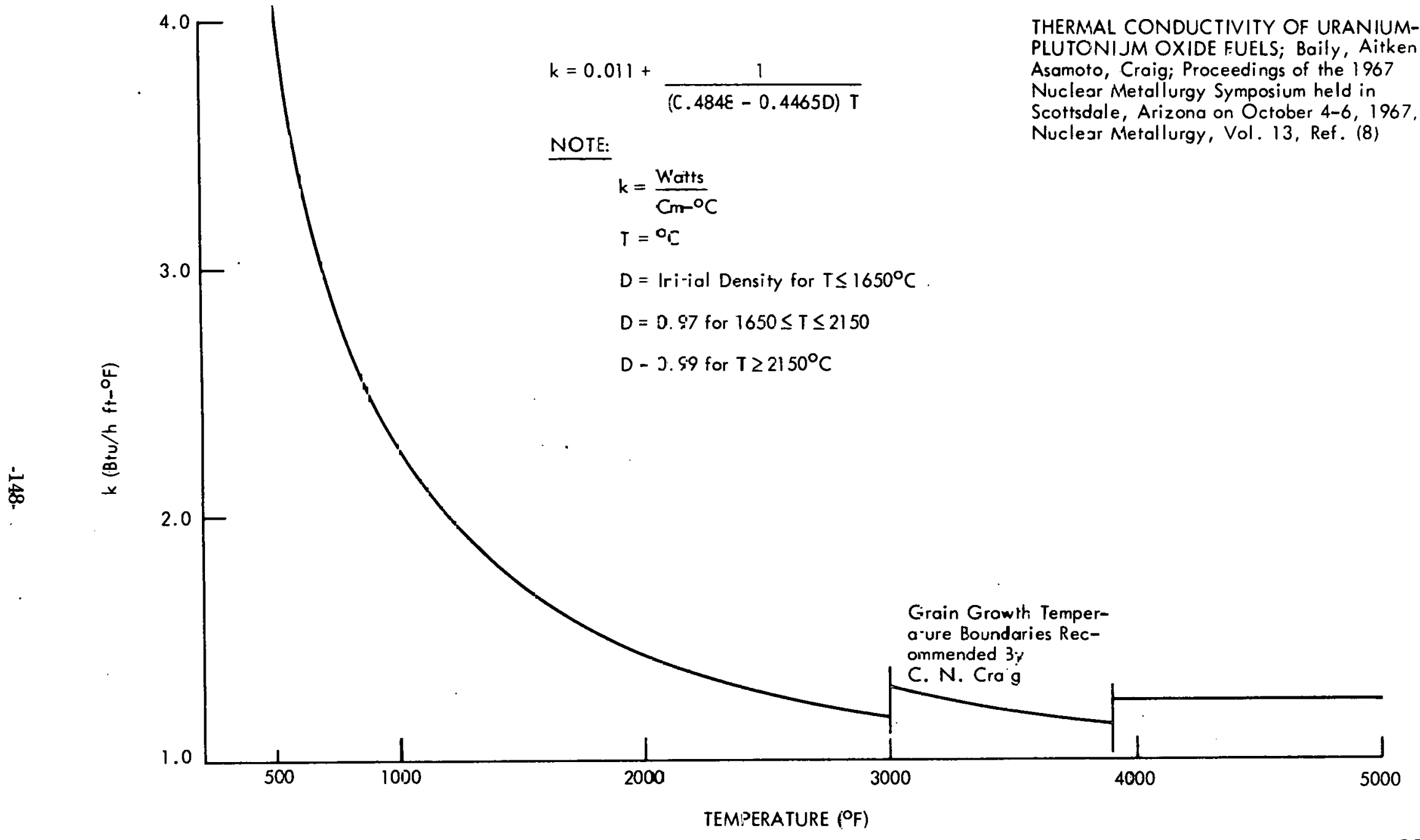




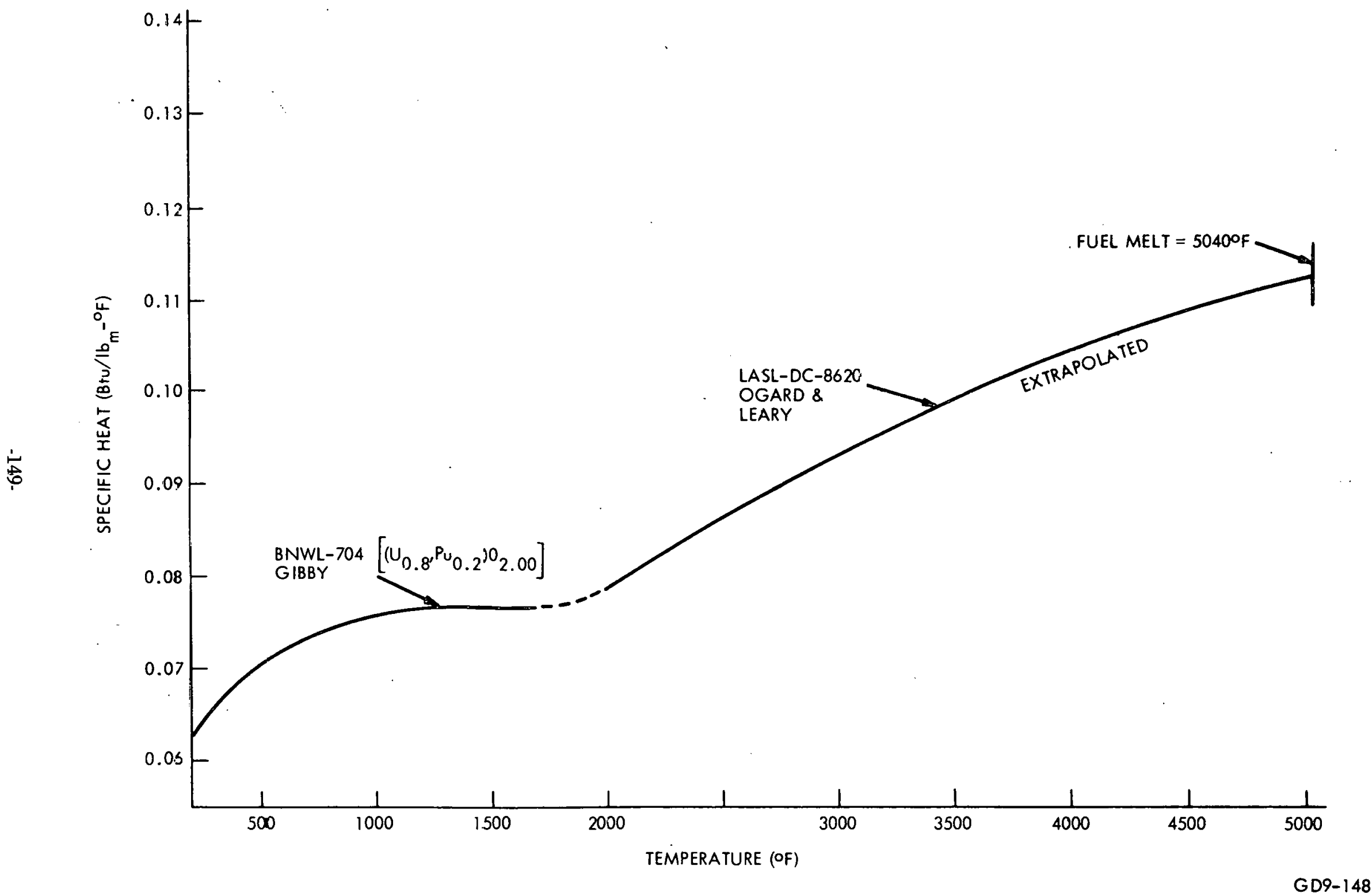




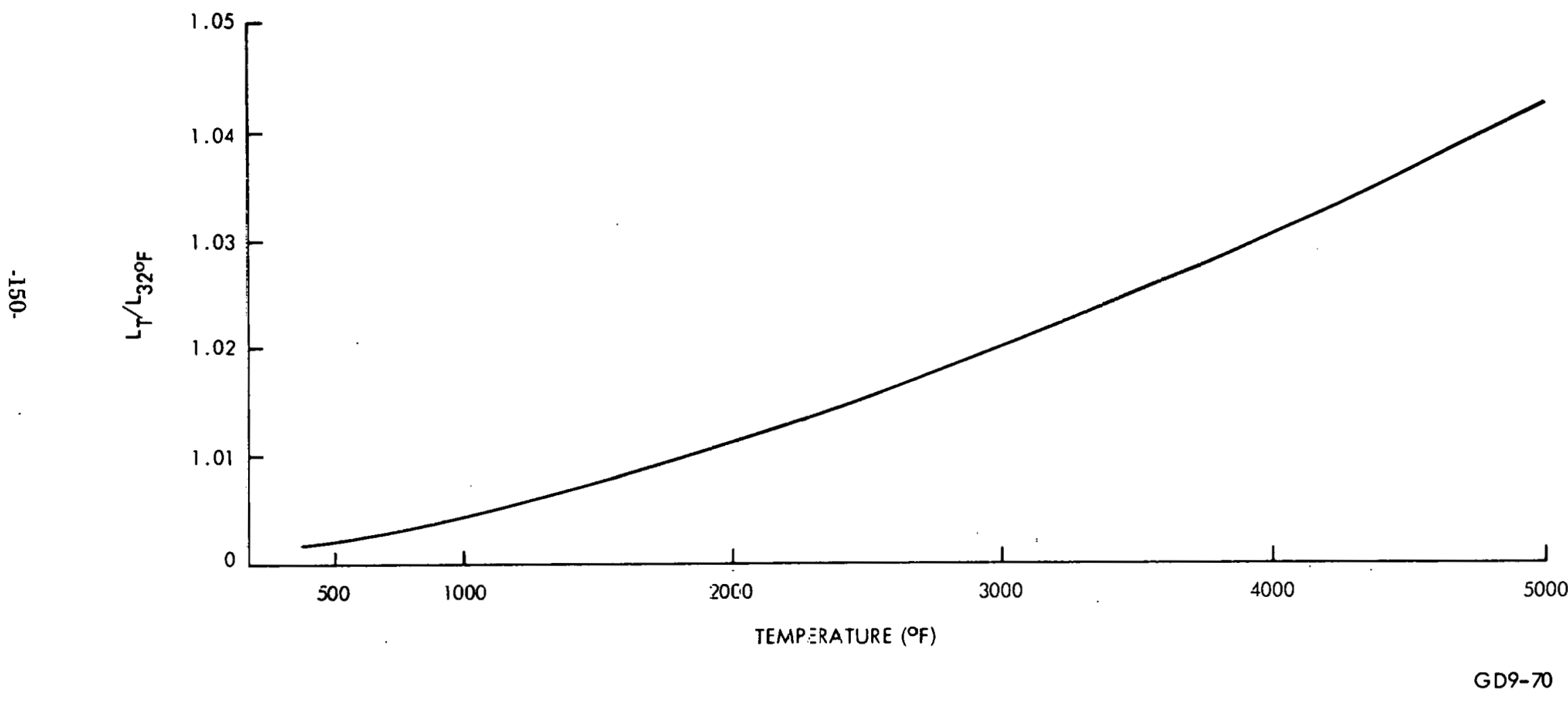

Figure A-21. Mixed-Oxide Fuel-Linear Thermal Expansion versus Temperature 


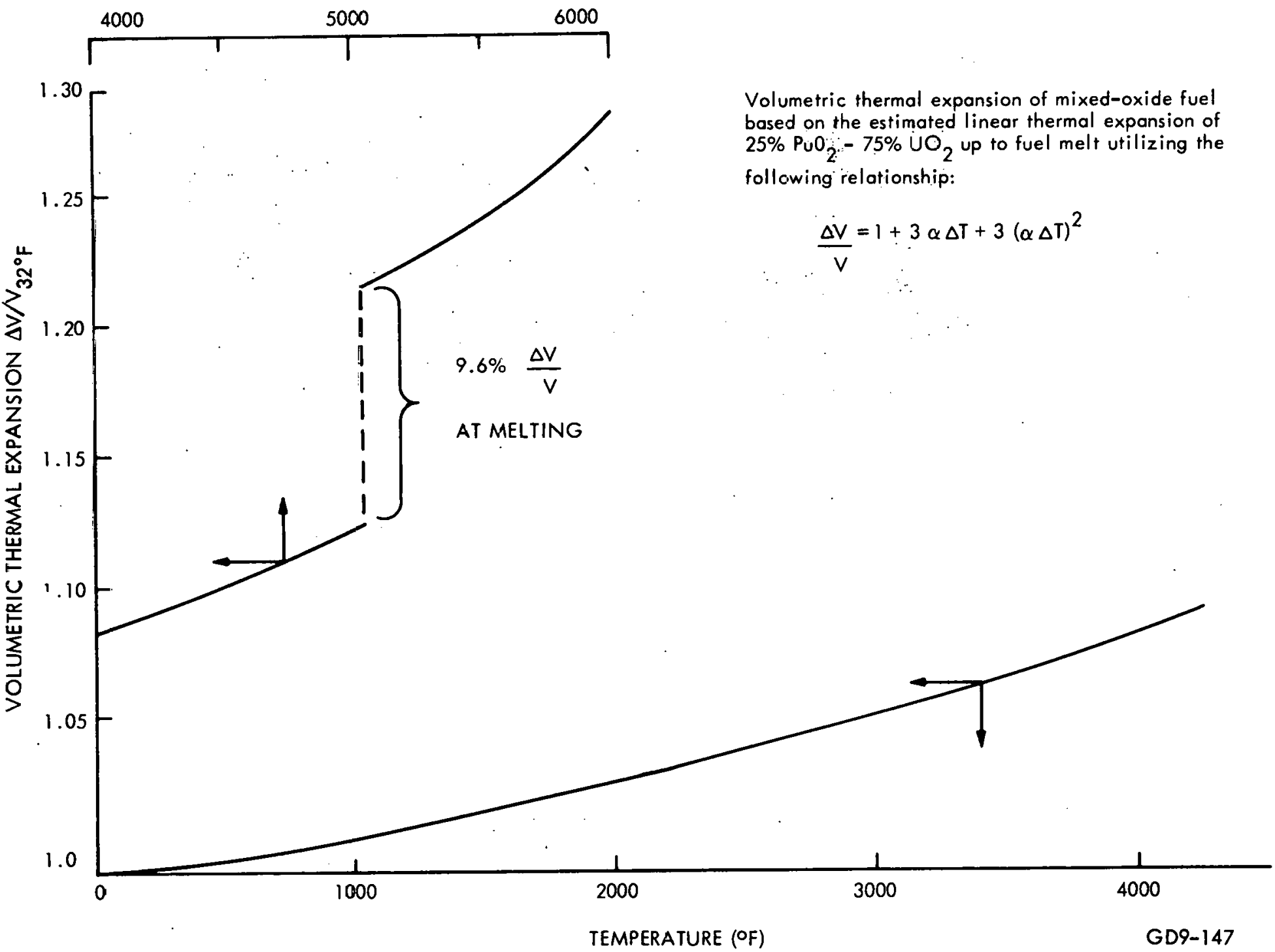

Figure 4-22. Mixed-Oxide Fuel-Volumetric Thermal Expansion versus Temperature 
Figures 1 - 9

SODIUM
Melting Point . . . . . . . . $208.1^{\circ} \mathrm{F}$

Boiling Point . . . . . . . . . . $1618.5^{\circ} \mathrm{F}$

Volume Increase on Melting _ . . . . . . 2.71\%

Latent Heat of Fusion . . . . . . . . $48.69 \mathrm{Btu} / \mathrm{lb}$

Latent Heat of Vaporization of the Boiling Point . . . . . . $1574 \mathrm{Btu} / \mathrm{lb}$

Critical Temperature . . . . . $2573 \pm 350 \mathrm{~K}$

Critical Pressure . . . . . . . . . $350 \pm 70 \mathrm{~atm}$

Critical Volume . . . . $0.116 \pm 0.023 \mathrm{liter} / \mathrm{gm}$-mole

Values in this figure are taken from Ref. 2.
DATA PERTAINING TO FIGURES 10A - 18

316 SS

Melting Point . . . . . . 2500-2550 ${ }^{\circ} \mathrm{F}$

Latent Heat of Fusion . . . . . . . . $122 \mathrm{Btu} / \mathrm{lb}_{\mathrm{m}}$

DATA PERTAINING TO FIGURES 19 - 22

$\left(\mathrm{U}_{0.2}-\mathrm{Pu}_{0.8}\right){ }_{1.98}$

Melting Temperatures (8) . . . . . . . 5040 50

Latent Heat of Fusion (9) $\ldots \ldots \ldots$

\section{REFERENCES}

1. Golden, G.H., and Tokar, J.V., Thermophysical Prop: erties of Sodium, August 1967, (ANL-7323).

2. Preliminary draft of the revised Sodium and $\mathrm{NaK}$ Engineering Handbook, (To be published).

3. Dunning, E.L., The Thermodynamic and Transport Properties of Sodium and Sodium Vapor, October 1960, (ANL-6246).

4. Mechanical and Physical Properties of Austenitic Chromium - Nickel Stainless Steels at Ambient I'emperatures, The International Nickel Company, Inc., Bulletin A311, 1963.

5. Mechanical and Physical Properties of the Austenitic Chromium - Nickel Stainless Steels at Elevated Temperatures, 'l'he International IVickel Liompany, Inc., Bulletin A312, 1963.
6. Thermodynamic and Transport Properties of Gases, Liquids, and Solids, Papers presented at the ASME Symposium on Thermal Properties, Purdue University, February 1959.

7. Furman, D.E., Thermal Expansion Characteristics of Stainless Steels Between $-300^{\circ}$ and $1000^{\circ} \mathrm{F}$. Journal of Metals, Transactions AIME, 188, (April 1950).

8. Bailey, Aitken, Asumoto, and Craig, Thermal Conductivity of Uranium - Plutonium Oxide Fuels, A paper prcparcd for the Nuclear Metallurgy Sympusium, American Institute of Mining, Metallurgical and Petroleum Engineers, Camelback Inn, Phoenix, Arizona, Nuclear Metallurgy, 13, (October 1967).

9. Bailey, W.E., and Spalaris, C.N., Contributions to the Fuel Properties Evaluation Section of the High Tem. perature F'uels Committee Meeting, Los Ángeles, December 1968. 


\section{Appendix B \\ INCIPIENT SUPERHEAT ESTIMATE FOR FFTF}

Calculations have been performed to determine the incipient superheat expected in the FFTF under the conditions set forth for the Molten Fuel-Sodium-Duct Interaction study.

The results presented were obtained using the method advanced by J. C. Chen.* In this model the superheat can be related to the saturation temperature at the boiling. pressure and the saturation temperature at the vapor pressure by (nomenclature listing is at end of this appendix):

$$
\Delta \mathrm{T}_{\mathrm{s}}=\mathrm{T}-\mathrm{T}_{\mathrm{s}}
$$

The vapor pressure is defined by

$$
\mathrm{P}_{\mathrm{v}}=\Delta \mathrm{P}_{\mathrm{s}}+\mathrm{P}
$$

where

$$
\begin{aligned}
& \Delta \mathrm{P}_{\mathrm{s}}=\frac{\sigma}{\sigma^{\prime}} \frac{\left(\mathrm{P}^{\prime}-\mathrm{P}_{\mathrm{v}}{ }^{\prime}\right)}{\cos \theta}-\frac{\mathrm{G}_{\mathrm{o}}}{\mathrm{r}_{\mathrm{d}}}\left[\frac{\mathrm{T}}{(1+2 \tan \theta)}+\frac{\sigma}{\sigma^{\prime}} \frac{\mathrm{T}}{\mathrm{F}(\theta) \cos \theta}\right] \\
& \mathrm{F}(\theta)=1-(\tan \theta)(1 / \cos \theta)^{3}(1-\sin \theta)^{2}(2+\sin \theta)
\end{aligned}
$$

and $r_{d}$ must be determined by solving the cubic equation:

$$
\mathbf{r}_{\mathbf{d}}{ }^{3}-\frac{2 \sigma^{\prime}}{\left(\mathbf{P}^{\prime}-\mathbf{P}_{v}{ }^{\prime}\right)} \cos \theta \mathbf{r}_{\mathbf{d}}{ }^{2}-\frac{\mathrm{G}_{\mathrm{o}} \mathrm{T}^{\prime}}{\left(\mathrm{P}^{\prime}-\mathrm{P}_{\mathrm{v}}{ }^{\prime}\right) \mathbf{F}(\theta)}=0
$$

The results obtained assumed the following deactivation conditions:

\section{Case 1 (Bottom of Core)}

$$
\begin{aligned}
& \mathrm{P}^{\prime}=90 \mathrm{psia} \\
& \mathrm{P}_{\mathbf{v}}^{\prime}=0.0069 \mathrm{psia} \\
& \mathrm{T}^{\prime}=740^{\circ} \mathrm{F}=1200^{\circ} \mathrm{R} \\
& \sigma^{\prime}=9.62 \times 10^{-4} \mathrm{lb} / \mathrm{in} .
\end{aligned}
$$

Case 2 (Middle of Core)

$$
\begin{aligned}
& \mathrm{P}^{\prime}=73.3 \mathrm{psia} \\
& \mathrm{P}_{\mathrm{v}}^{\prime}=0.0735 \mathrm{psia} \\
& \mathrm{I}^{\prime}=920^{\circ} \mathrm{F}=1980^{\circ} \mathrm{R} \\
& \sigma^{\prime}=.9 .03 \times 10^{-4} \mathrm{lb} / \mathrm{in} .
\end{aligned}
$$

* Chen, J. C., "Incipient Boiling Superheats in Liquid Metals," J. of H. T., August 1968, pp 303-312. 
Case 3 (Top of Core)

$$
\begin{aligned}
& \mathrm{P}^{\prime}=67 \mathrm{psia} \\
& \mathrm{P}_{\mathrm{v}}^{\prime}=0.279 \mathrm{psia} \\
& \mathrm{T}^{\prime}=1100^{\circ} \mathrm{F}=1560^{\circ} \mathrm{R} \\
& \sigma^{\prime}=8.47 \times 10^{-4} \mathrm{lb} / \mathrm{in} .
\end{aligned}
$$

The conditions at which boiling occurs were assumed to be:

$$
\begin{aligned}
& \mathrm{P}=23.4 \mathrm{psia} \\
& \mathrm{T}_{\mathbf{8}}=1720^{\circ} \mathrm{F}=2180^{\circ} \mathrm{R} \\
& \sigma \quad=6.49 \times 10^{-4} \mathrm{lb} / \mathrm{in} .
\end{aligned}
$$

The incipient superheat was calculated using Equations (1-5) for the three core positions for two conditions. An upper limit was established by setting the half-apex angle, $(\theta)$, to zero and empirical constant, $G_{0}$, to zero. A lower limit was determined by retaining a zero half-apex angle and a value of $10^{-16}$ for $G_{0}$. These limit lines are shown as a function of core position in Figure B-1 as temperature at incipient boiling.

According to the reference, the assumption of zero half-apex angle most nearly represents the incipient superheat for real surfaces. The empirical constant, $G_{o}$, is in reality a dimensional variable measuring the amount of gas trapped in a cavity and would vary with the surface condition and method in which the gas fills the cavities. Using $G_{o}$ as an empirical constant alleviates the difficulties in determining these conditions. Small variations should not cause significant variations in the required superheat.

The results present give an indication of the expected superheat under laboratory conditions. Some of the variables which would affect these values are:

1. Amuunt of diosolìed gascis

2. Radiation effects

3. Amount of entrained gases

4. Sodium impurity due to particle entrainment

5. Sodium velocity.

The first two effects should be quite small in that they will affect the boiling only when high superheate are othcrwisc obtainable. The effect of entrained gases will normally be small due to a low level of entrainment during normal operation. Consideration of entrained particles would result in additional nucleation sites, but the amount of particles required to canse. a significant increase in the nucleation site population cannot be readily determined. Early BNL results indicate a rapid decrease in superheat with sodium velocity increase from the static condition.

Therefore, although one may predict high superheats analytically, one would expect much lower values in the practical siluation. 


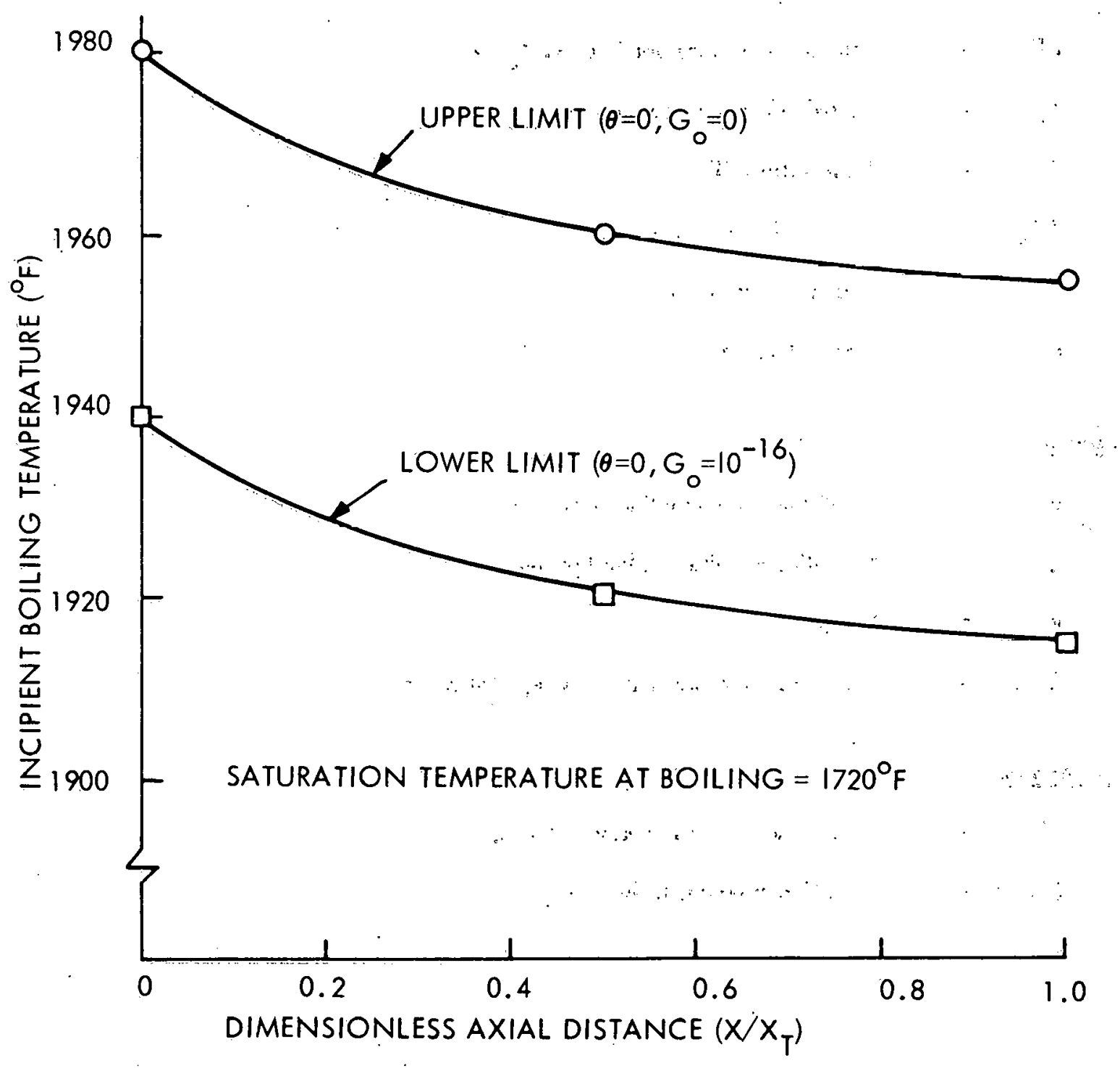

GD9-177

Figure B-1. Incipient Boiling Temperature versus Position in Core 


\section{NOMENCLATURE LIST}

\section{Symbols}

\begin{tabular}{|c|c|c|}
\hline $\mathrm{G}_{\mathbf{0}}$ & $=$ & Empirical constant dependent upon surface and filling conditions. \\
\hline $\mathbf{P}$ & $=$ & Pressure, psia \\
\hline$\Delta \mathrm{P}_{\mathrm{s}}$ & $=$ & Superpressure corresponding to $\Delta \mathrm{T}_{\mathrm{s}}$, psi \\
\hline $\mathbf{r}_{\mathbf{d}}$ & $=$ & Wetted radius of cavity, in. $"$ \\
\hline $\mathrm{T}$ & $=$ & Temperature, ${ }^{\circ} \mathrm{R}$ \\
\hline$\Delta \mathrm{T}_{\mathrm{s}}$ & - & Inciplent boiling superheat. \\
\hline$\theta$ & $=$ & Half-apex angle of cavity \\
\hline$\sigma$ & $=$ & Surface tension \\
\hline
\end{tabular}

\section{Subscripts}

$$
\begin{array}{lll}
\mathrm{o} & = & \text { Condition at initial filling of cavities } \\
\mathrm{s} & = & \text { Saturation condition at local pressure } \\
\mathrm{v} & =\ldots \ldots & \text { Vapor }
\end{array}
$$

\section{Superscripts}
(') =
Deactivation condition prior to boiling
(none) $=$
Condition at boiling incipience 


\section{Appendix C \\ PLENUM TEMAPERATURES}

Transient heat transfer calculations were performed to estimate the plenum temperature following voiding and the subsequent sodium temperatures on reentry. The lack of a coupled two-phase flow-heat transfer code required separate calculation of the liquid slug displacement.

The liquid slug displacement calculations are described in Appendix D. Iteration between the heat transfer and displacement calculations permitted a crude estimate to be made of the plenum and sodium temperatures.

The results of this study showed that the reentering sodium temperature follows closely the local clad temperature. As a consequence, the vapor pressure retarding reentry and leading to revoiding is characterized closely by the saturation pressure at the clad temperatures. The further conclusion is that plenum heating due to heat transport from the core leads to plenum saturation pressures higher than the driving pressure above the core. This effectively prohibits slug reentry from the top of the core and is in agreement with experiments and other industry comments. The results of the plenum and sodium thermal transients is included here to support this conclusion.

Three types of transients were run on the "NAAC" code. These are:

1. Plenum and Reflector Transients (PT)

2. Core and Plenum Transients (CT)

3. Core Reentry Transients (RT)

\section{C.1 PLENUM AND REFLECTOR TRANSIENTS}

The reflector and plenum were modeled as a steel pin surrounded by a sodium annulus sized to give the correct ratio of steel-to-sodium heat capacity. Inlet temperature and velocity were then programmed to vary with time to simulate the axial movement of the hot sodium slug into the reflector and plenum region. The code is not programmed to treat an intermittent slug of coolant, requiring cross plotting of the clad temperature just after a particular slug length has been ejected. The reflector temperatures are represented by the cladding temperature and the average of the interior steel. This difference shows the delay in heating the interior steel of the reflector pin and the high surface temperature just after voiding. If heat transfer were stopped after the liquid slug passed, the surface and interior temperatures would converge toward their average value. The plenum cladding temperature is represented by its bulk average temperature, assuming no heat transfer to the fission gas and helium within the plenum. The plenum temperature model is shown in Figure C-1. The results are shown in Figures C-2 through C-7.

\section{C.2 CORE AND PLENUM TRANSIENTS}

Because of limitations with modifying the "N $\Lambda \mathrm{AC}$ " program, the transients of the core reflector and plenum were based on the model shown in Figure C-8. The reflector and plenum are simulated as being filled with fuel but producing no power. This provides the correct core transient and simulates the reflector and plenum quite well for the rapid expulsions of interest at high superheat. At constant power, the transient simulates a sudden complete loss of flow followed after a specific delay by a coolant velocity transient taken from Appendix D.

The clad temperatures in the plcnum and reflector are quite similar tn those of the plenum transient cases. The energy transport to the plenum region must be about the same. The principal effect of interest is the shifting of the temperature profile in the core due to the axial transport of heat from the hot center to the colder portions near the core edge. This effect raiscs the clad temperature at the core boundary. Continuation of voiding into the two phase region would accentuate the axial transport of heat, lowering the center temperatures initially and raising the clad temperatures near the core edge. Boiling and condensation then tend to equalize all surface temperatures. This effect was not studied due to lack of a suitable tool, but leads to the conclusinn that reflector and plenum temperatures will be much too high to permit slug flow reentry. The results are shown in Figures C-9 through C-14. 


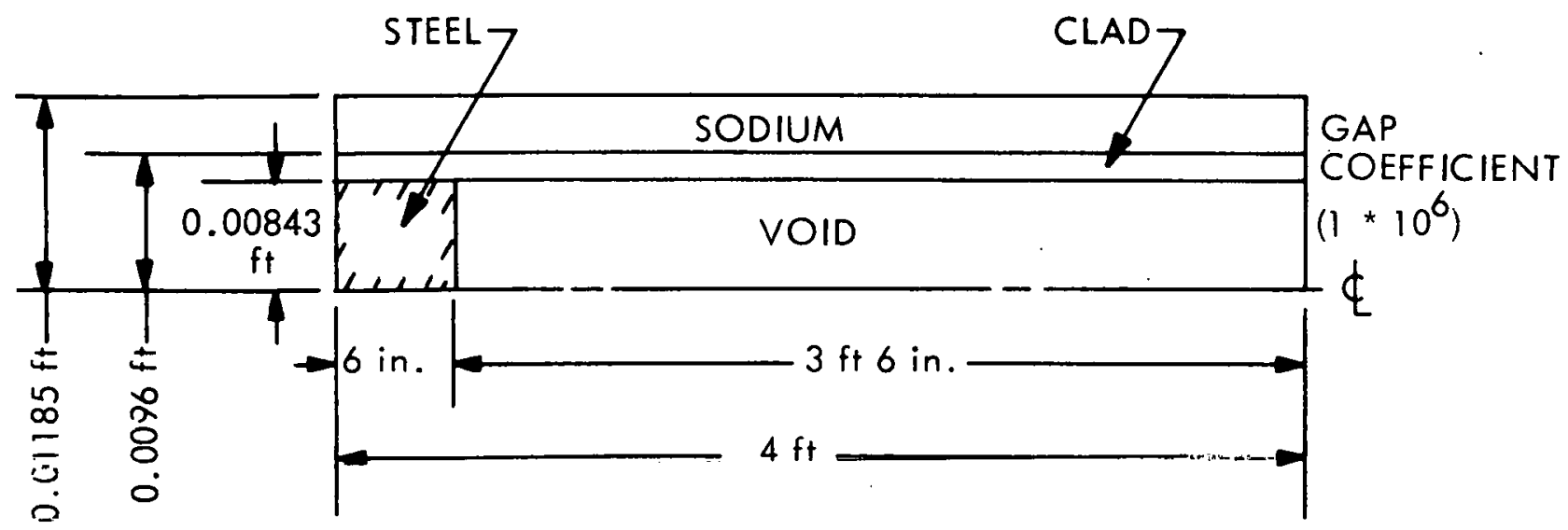

GD9-168

Figure C-1. Plenum Temperature Model

\section{C.3 CORE REENTRY TRANSIENTS}

To observe the sodium temperature transient on reentry, it was necessary to reverse the "NAAC" geometry, letting the slad nodes represent sodium and vice-versa. This is required because the code does not handle a reversed flow situation and it is necessary to simulate the clad as moving into the sodium with the appropriate temperatures. The result of the transient showed that the sodium slug interface temperature follows closely the clad temperature and should result in rapid vapor production to slow reentry and cause revoiding. The key assumption is that the sodium wets the hot clad. Actually the leading edge would proceed through the heat transfer regimes of conduction, nucleate boiling and film boiling as it travels up the clad lemperalure prufile.

Because of the extremely large change of volume on vaporization, the boiling at the leading edge of the slug will pressure the core rapidly and halt reentry. The reentry case was run at constant velocity during reentry $(20 \mathrm{fps})$ and did not simulate the secondary voiding which would occur. The model is shown in Figure C-15. The results are given in Figure C-16. 


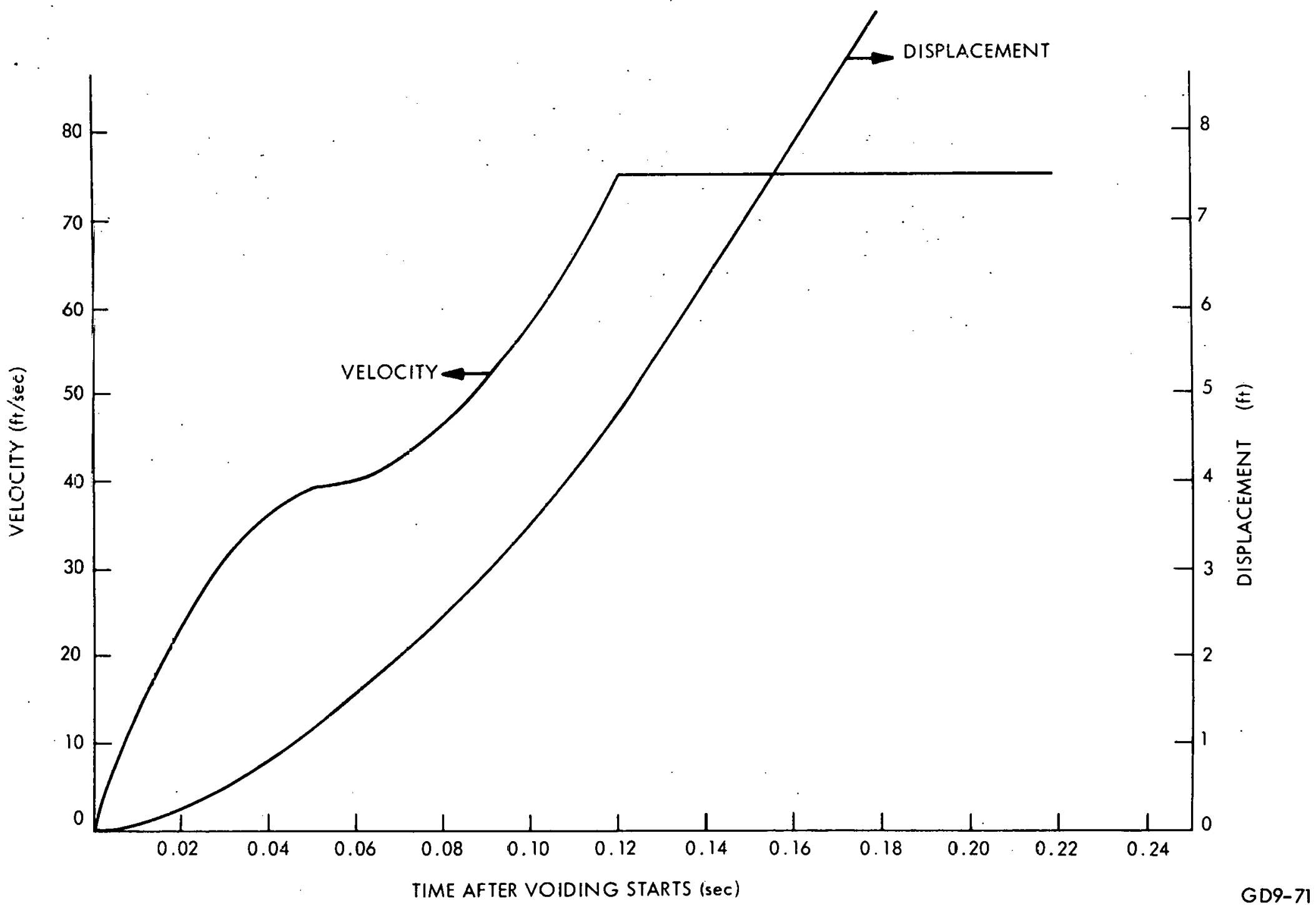

Figure C-2. Voiding Velocity and Displacement $400^{\circ} \mathrm{F}$ Superheat Case PT-2 


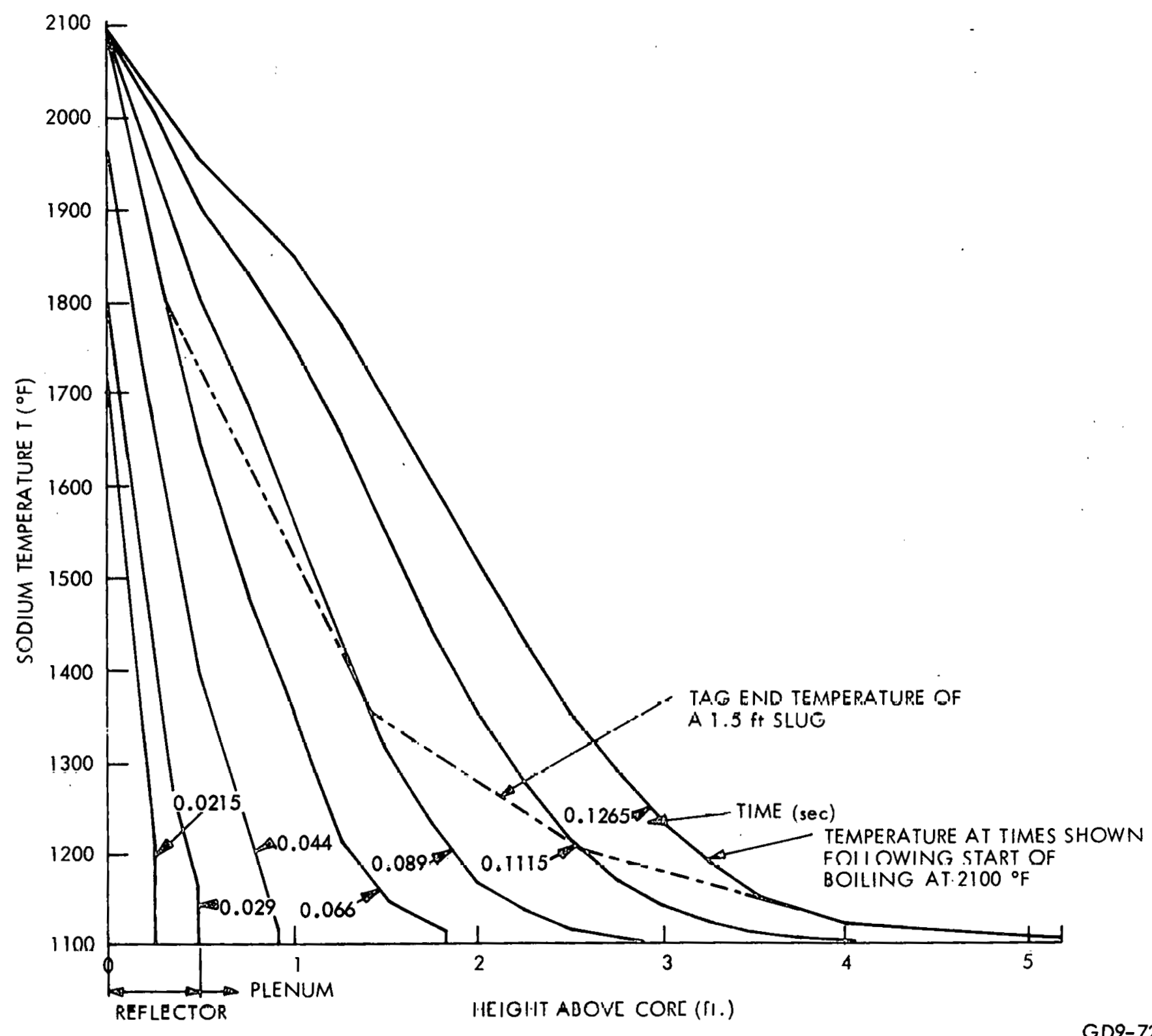

Figure C-3. Sodium Temperature in Plenum Region Following Voiding $400^{\circ} \mathrm{H}^{\prime}$ Superheat Case PT'-2 


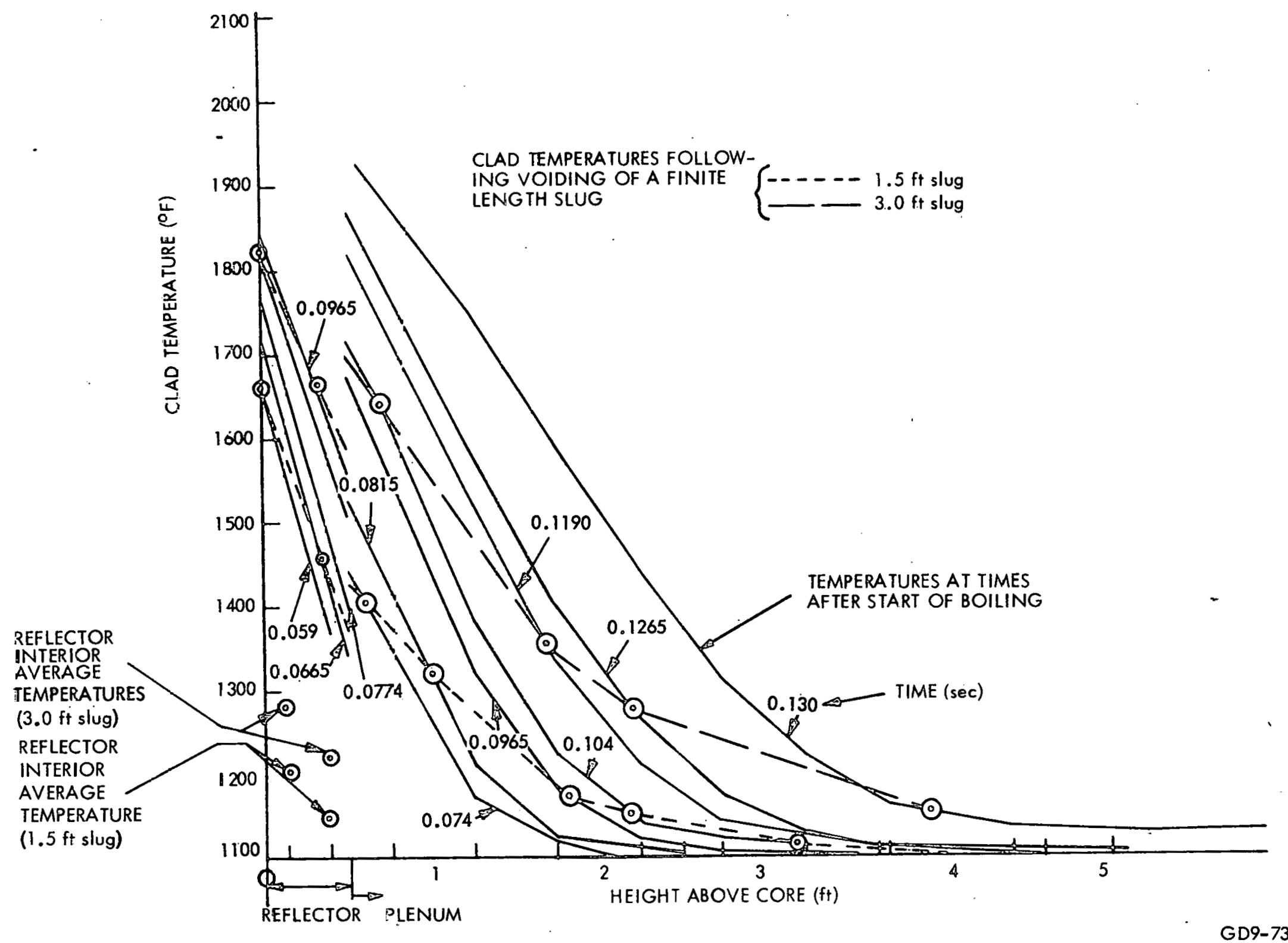

Figure C-4. Clad Temperatures in Plenum Region Following Voiding $400^{\circ}$ F Superheat Case PT-2 


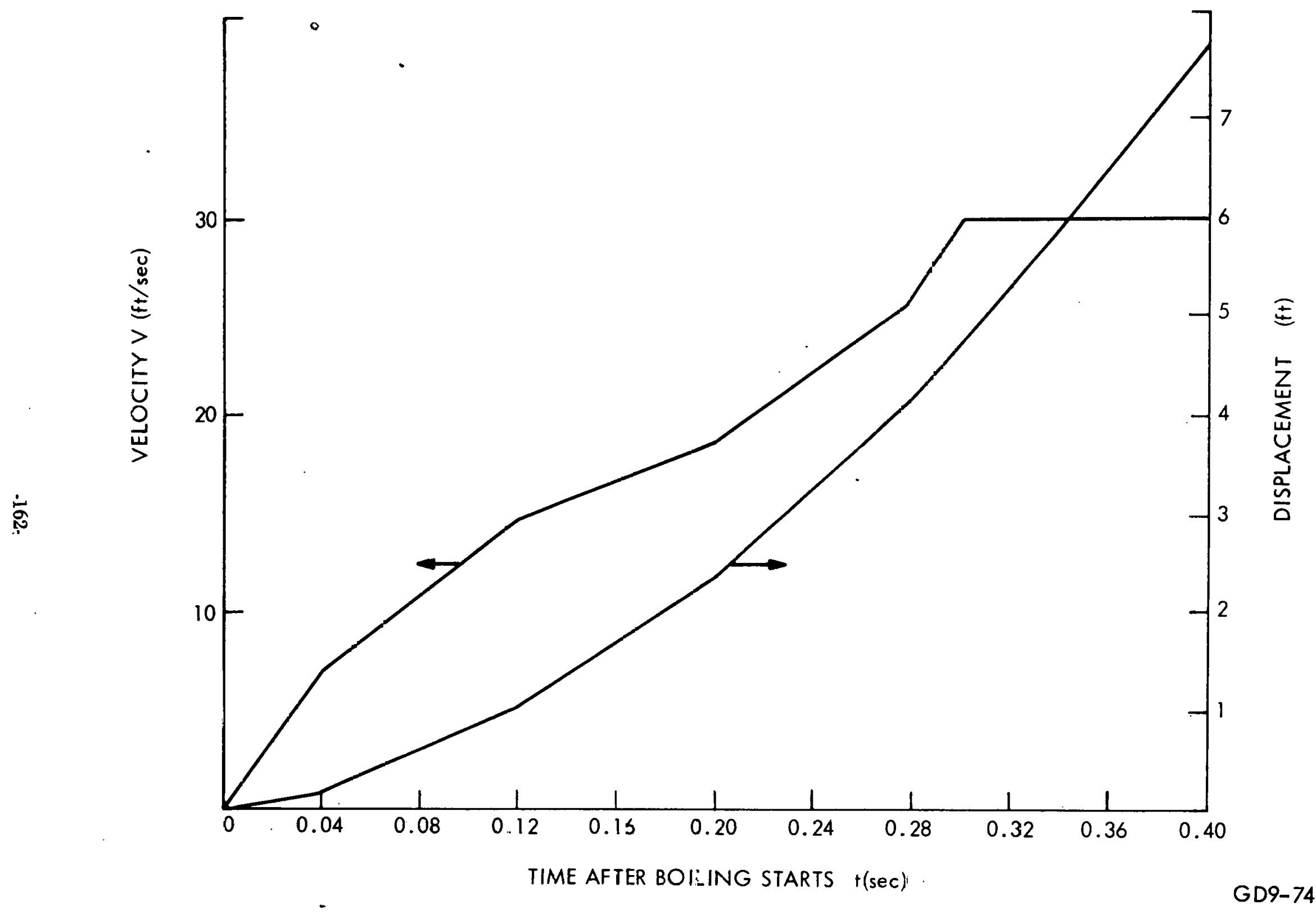

Figure C-5. Voiding Velocity and Displacement $100^{\circ}$ F Superkeat Case PT-3 


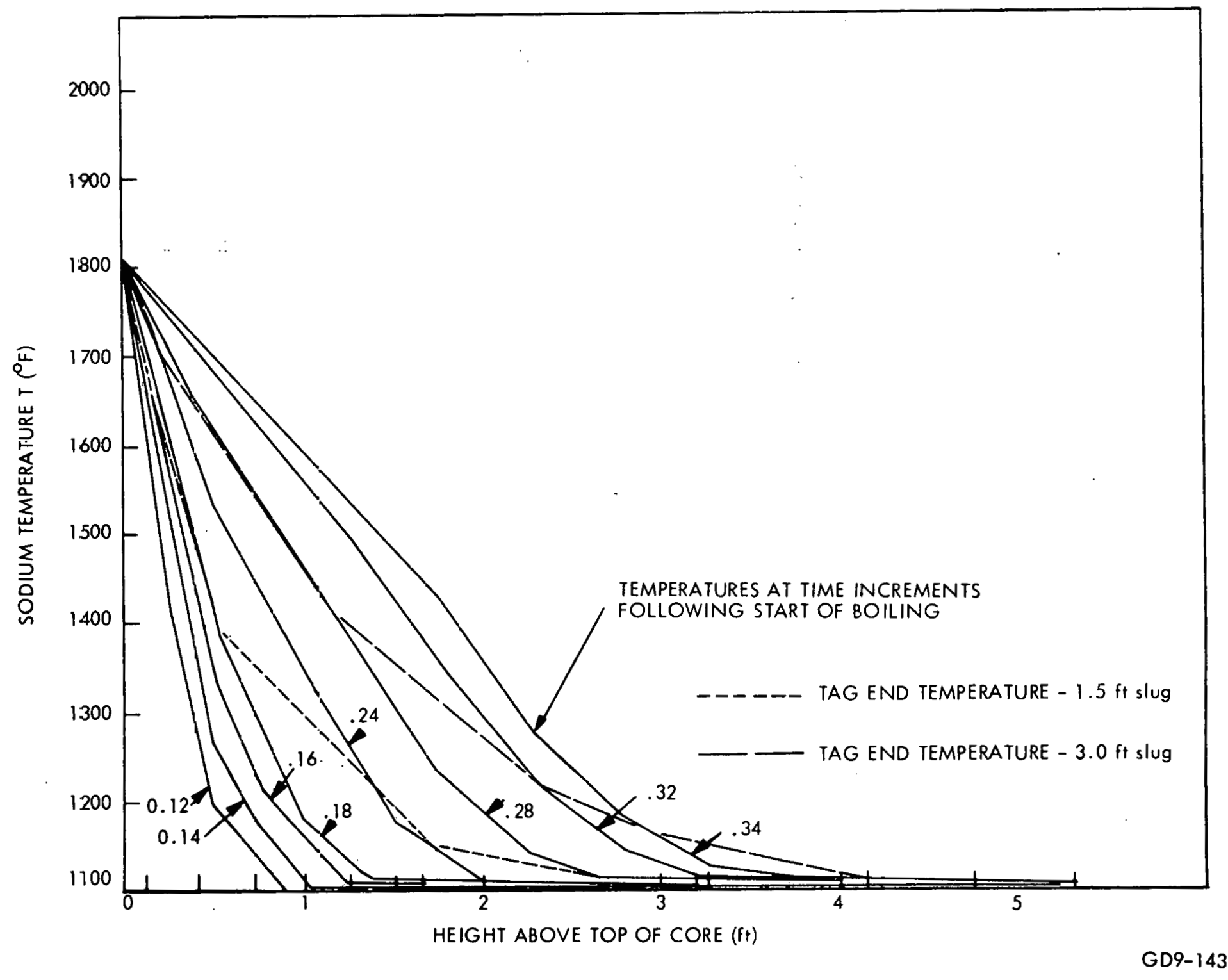

Figure C-6. Sodium Temperatures in Plenum Following Voiding $100^{\circ} \mathrm{F}$ Superheat Case PT-3 


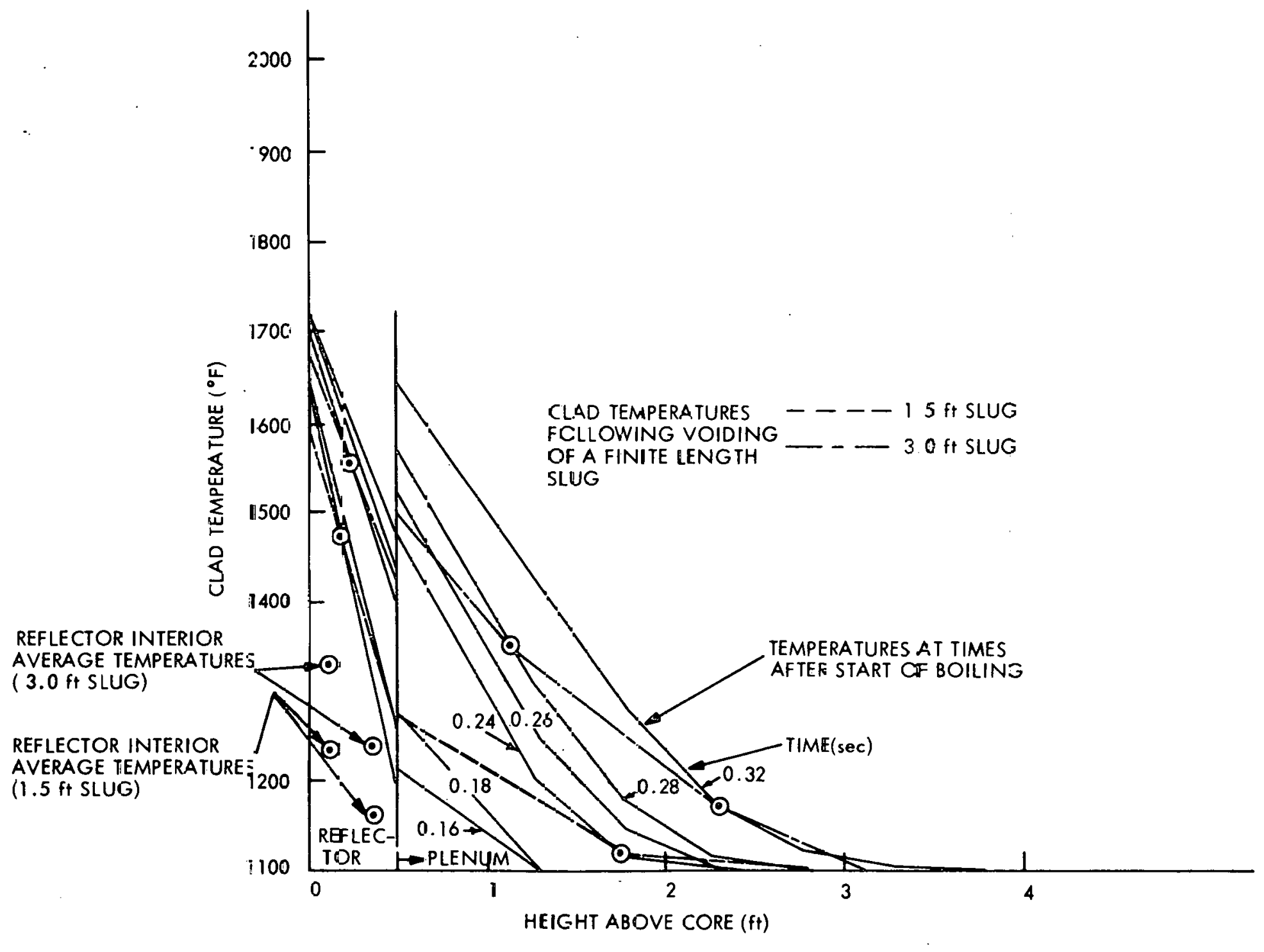
$100^{\circ} \mathrm{F}$ Superheas Case PT-3 


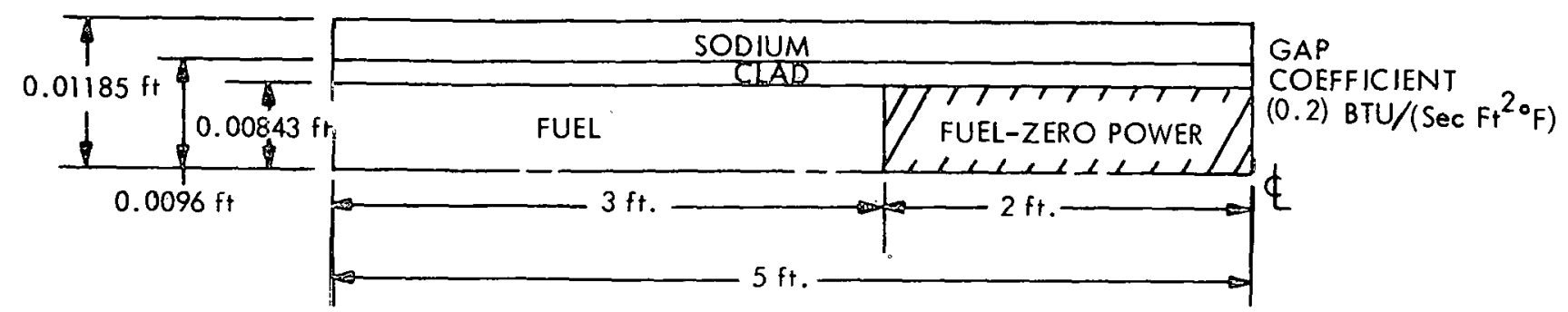

GD9-75

Figure C-8. Core Temperature Model 


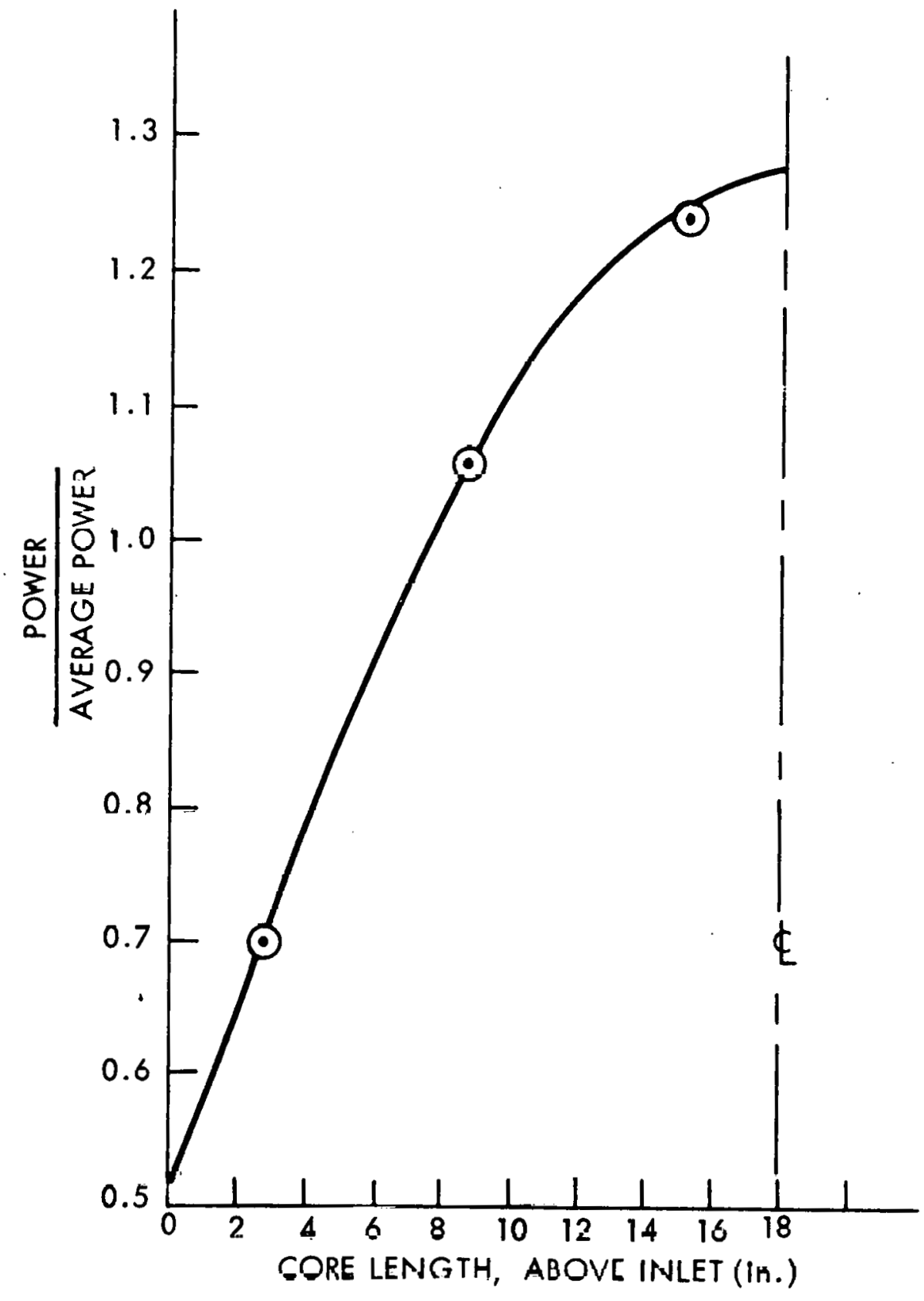

Figure C-9. Power Distribution-Core and Plenum Transient 


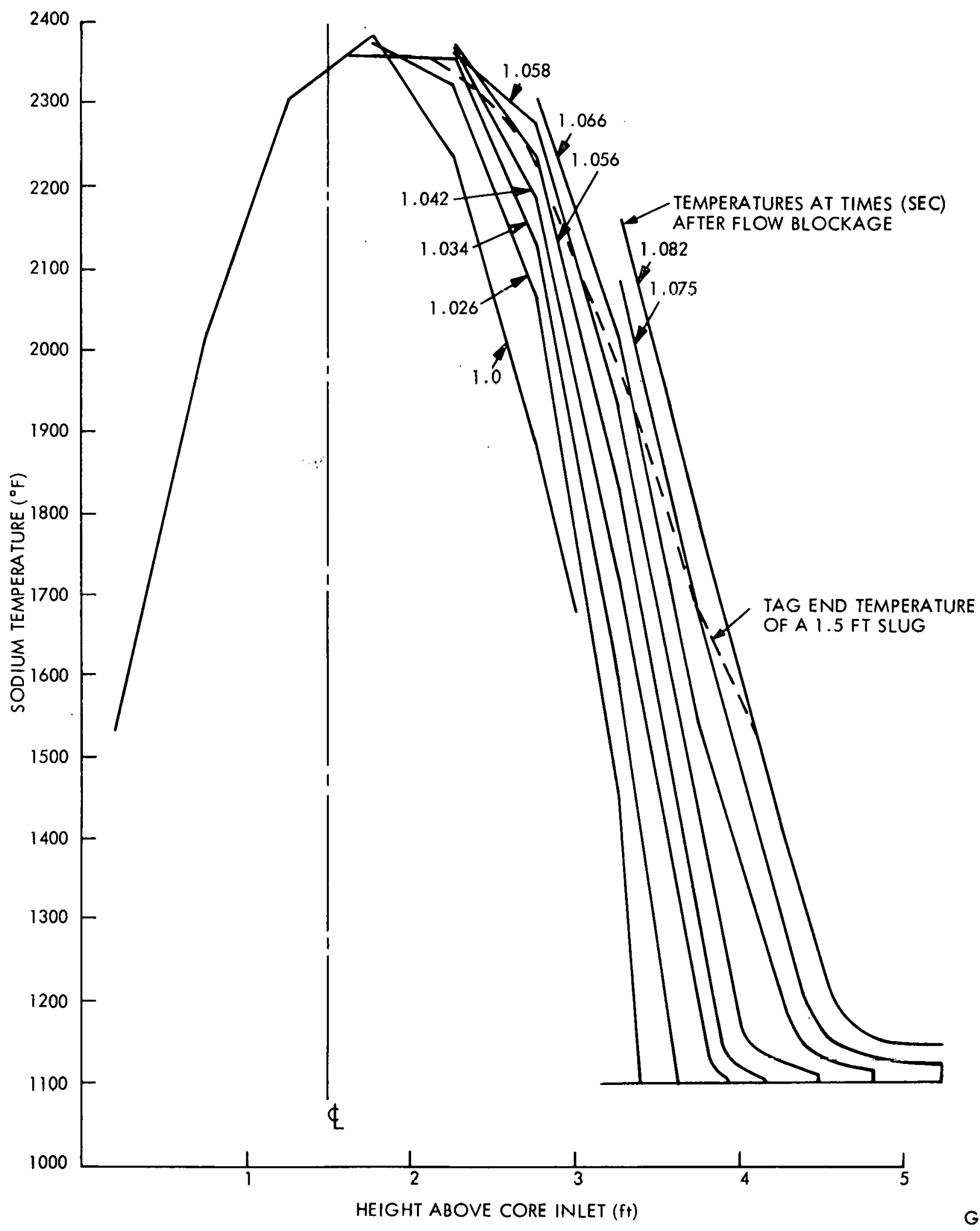

Figure C-10. Sodium Temperatures Case CT.1 $700^{\circ}$ F Superheat 


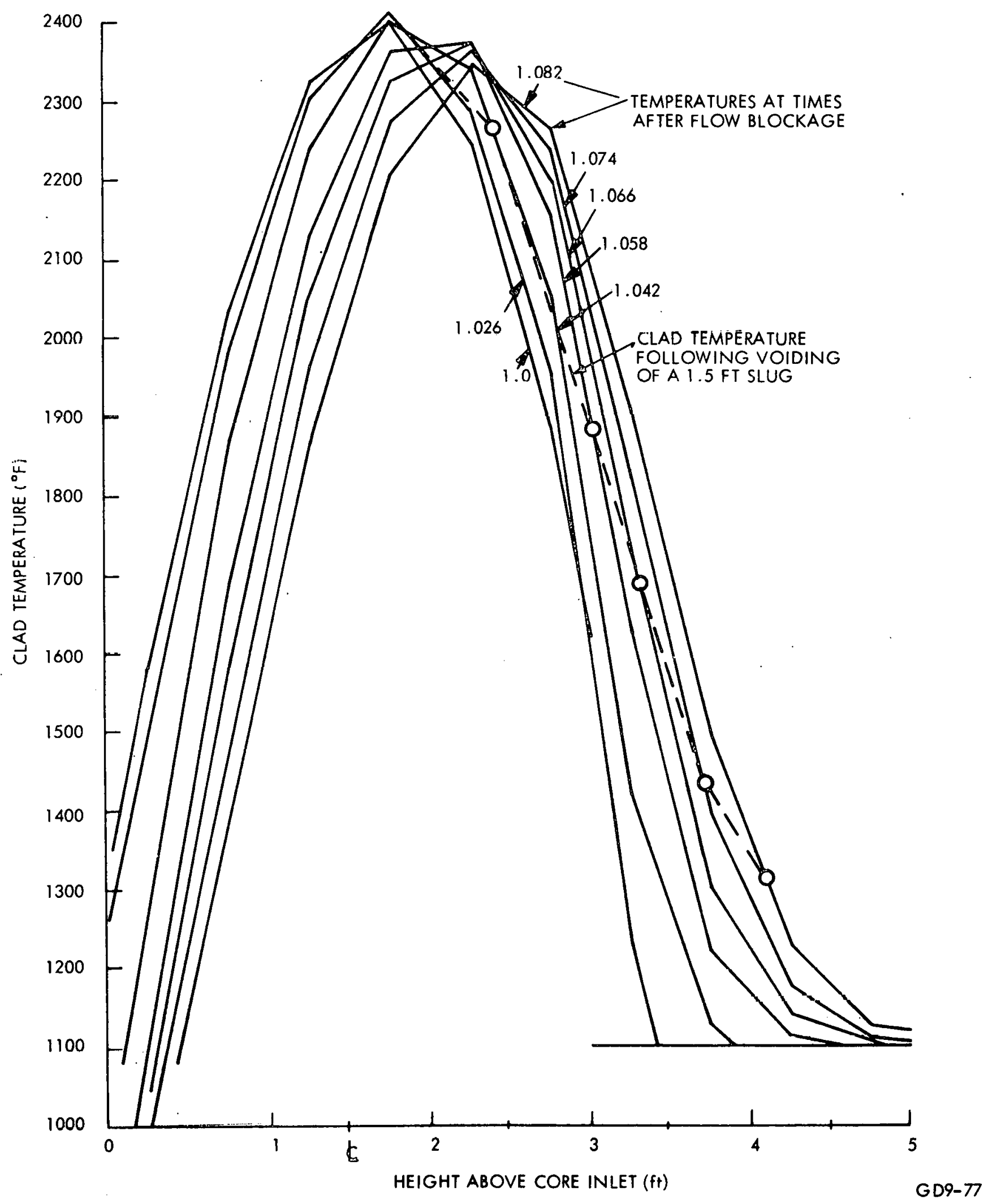

Figure C-11. Clad A verage Temperature Case CT-1 $700^{\circ} \mathrm{F}$ Superheat 


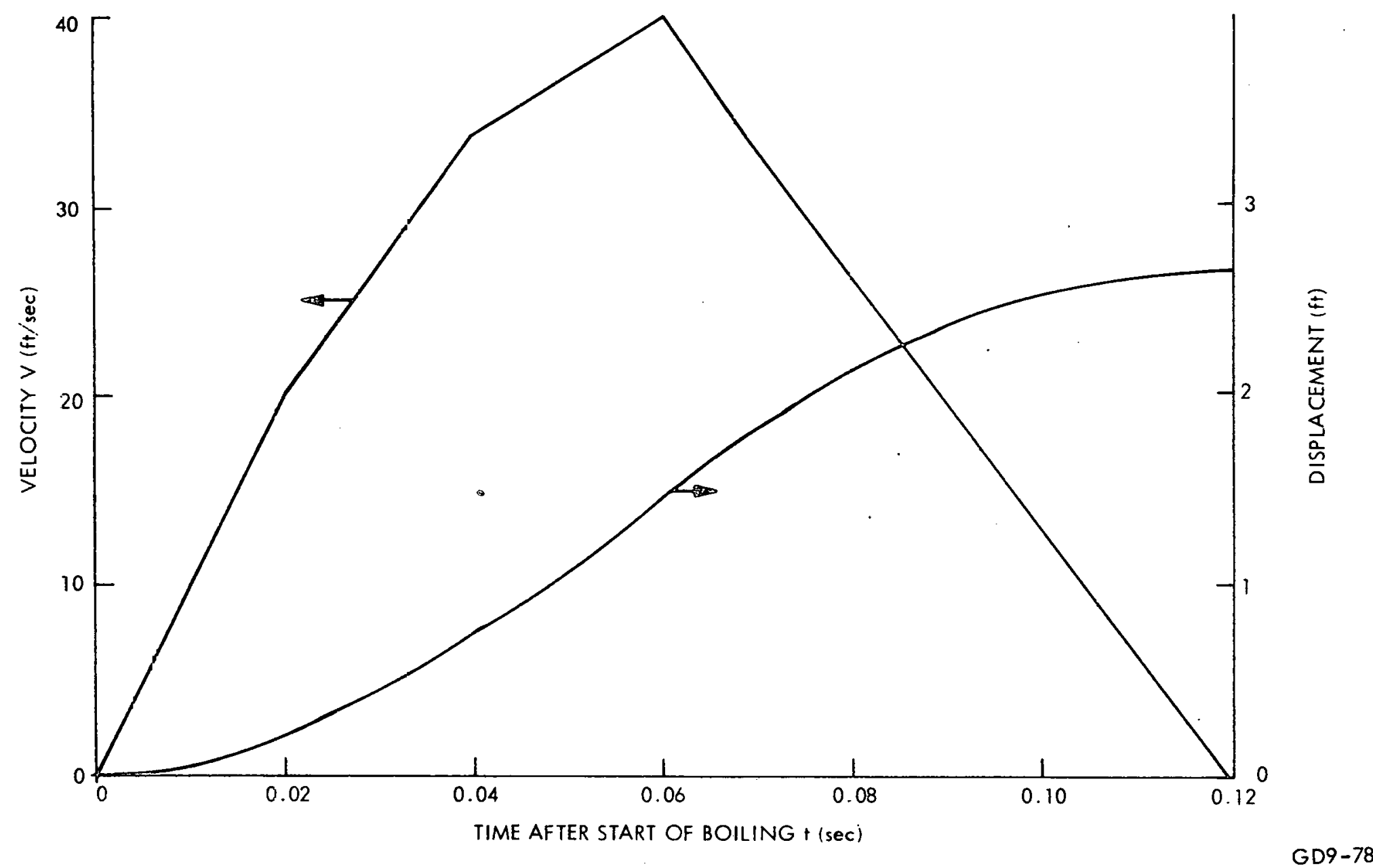

Figure C-12. Voiding Velocity and Displacement $400^{\circ}$ F Superheat Case CT-2 


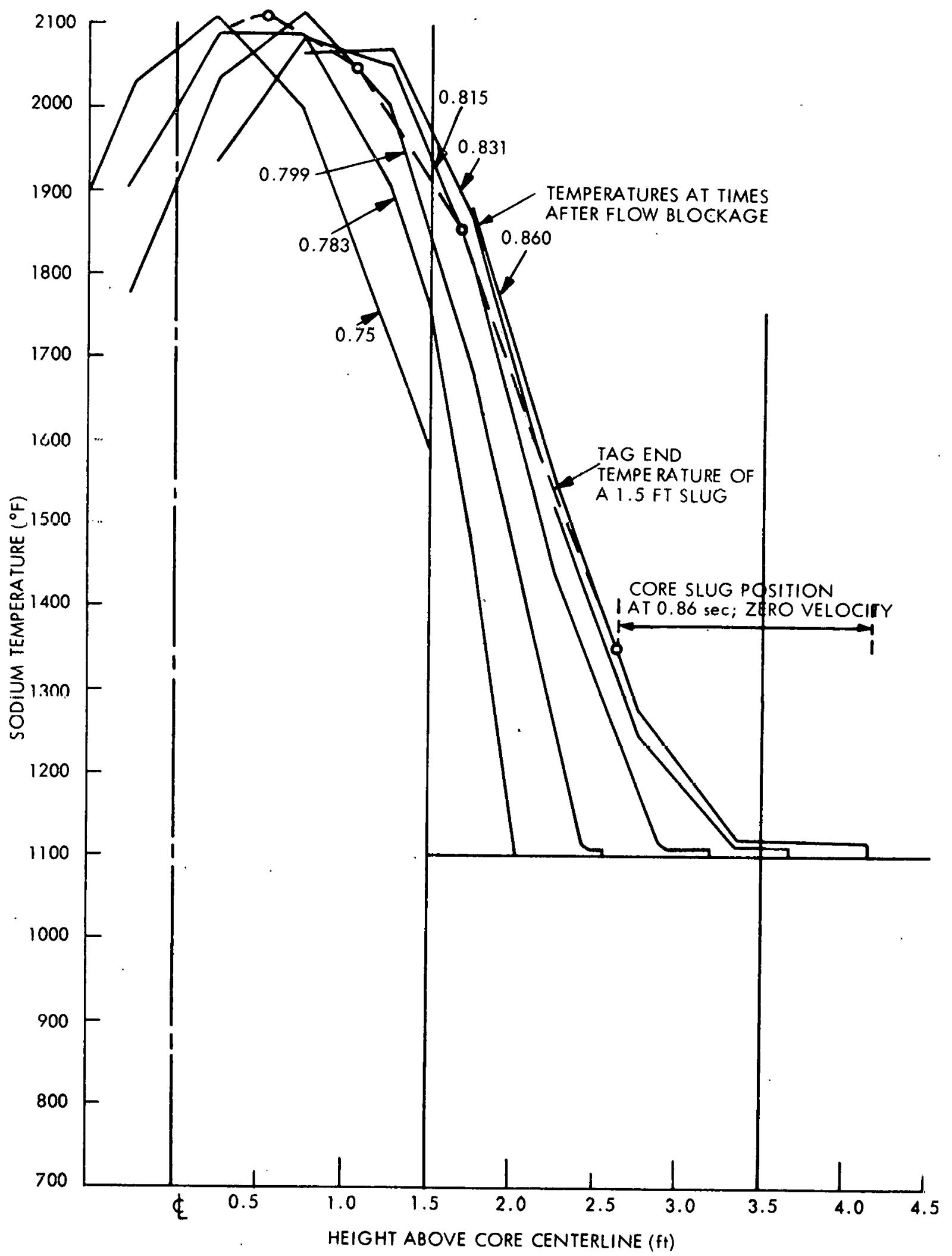

GD9-80

Figure C-13. Sodium Temperatures Case CT-2 $400^{\circ}$ F Superheat 


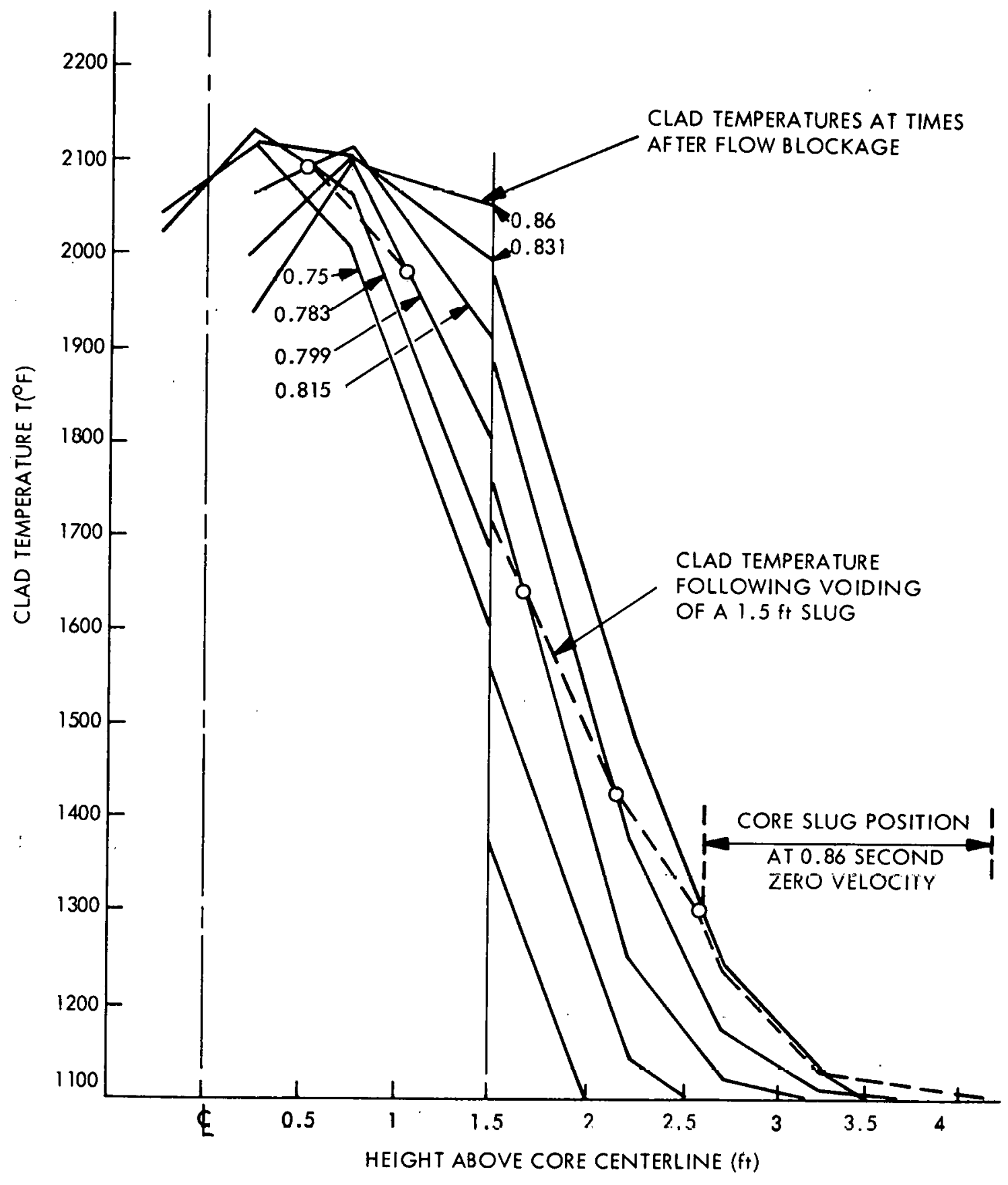

GD9-81

Figure C-14. Clad Temperatures Following Voiding $400^{\circ} \mathrm{F}$ 'Superheat Case ('I'-2 


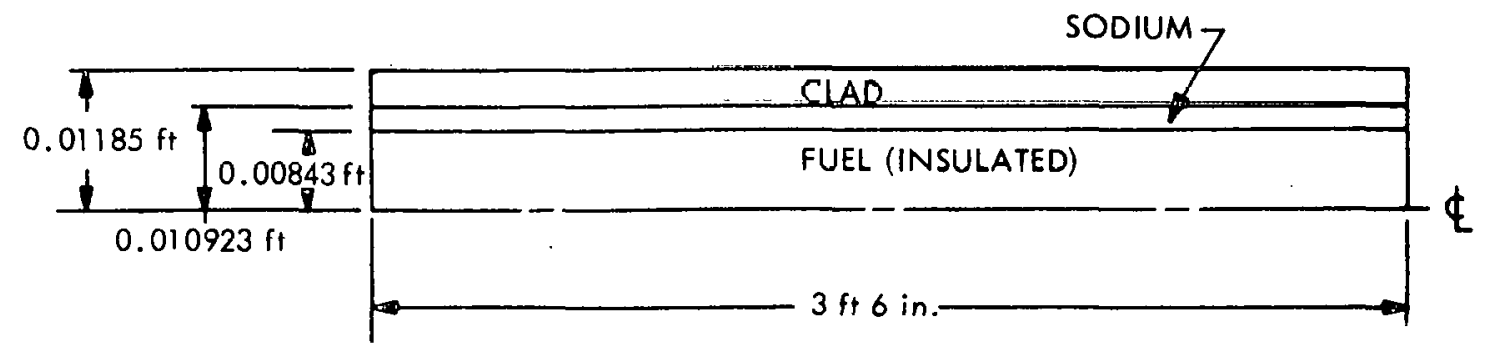

GD9-167

Figure C-15. Reentry Temperature Model 
GEAP-10059

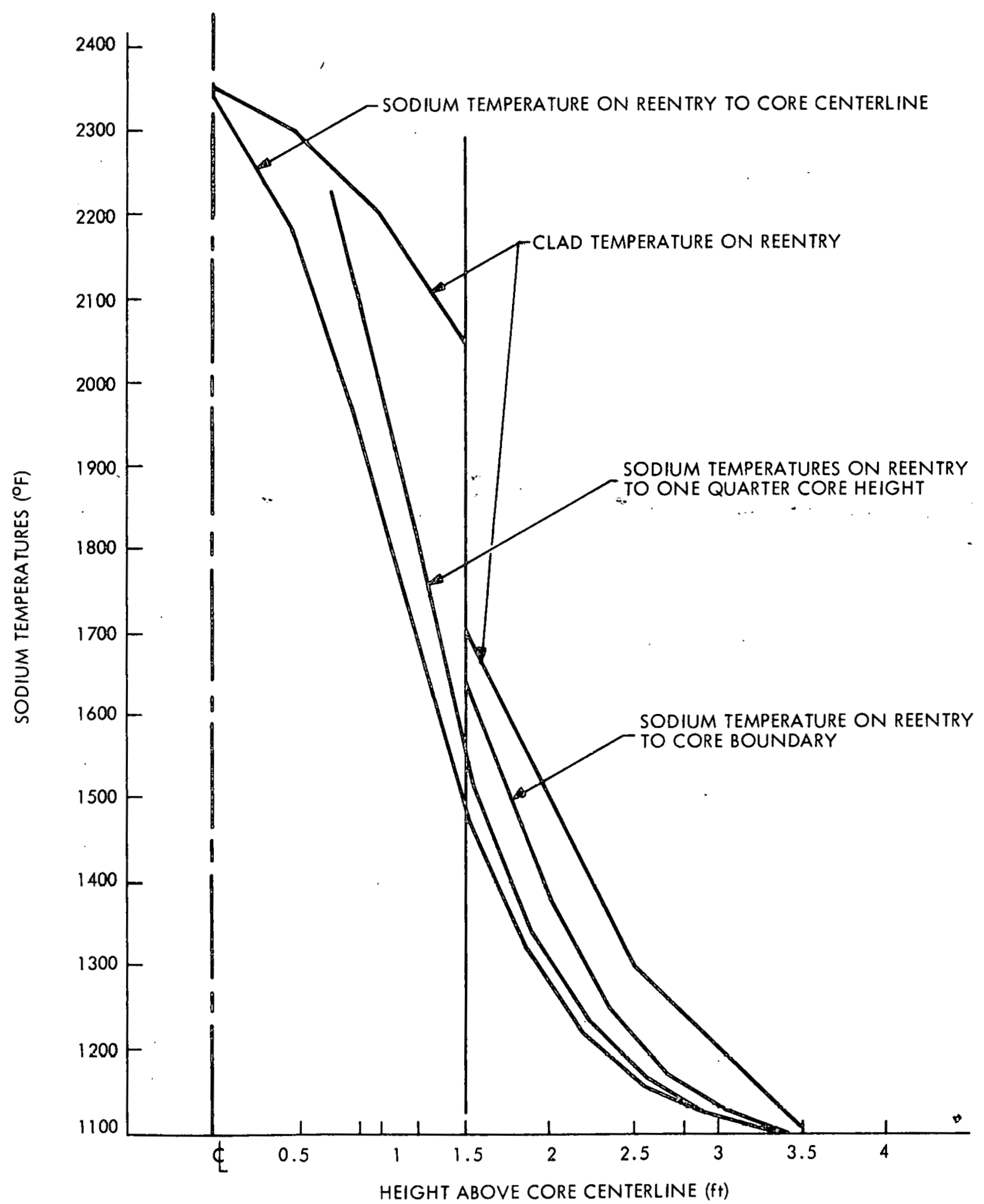

HEIGHT ABOVE CORE CENTERLINE (ft)

Figure C-16. Reentry Coolant Temperatures 


\section{Appendix D \\ SLUG VOIDING AND REENTRY}

This appendix contains the results of a parameter study of slug voiding and reentry. Newton's second law relating forces on a body and the resultant acceleration is used to calculate the acceleration of the liquid slug, the effects of frictional losses, orifice losses, area variations, and jetting into the outlet plenum are included. The driving pressures are determined from the difference between the plenum pressure (23 psia) and the pressure at the liquid vapor interface as determined in Appendix C. Figure D-1 shows the model and nomenclature used and the basic equation.

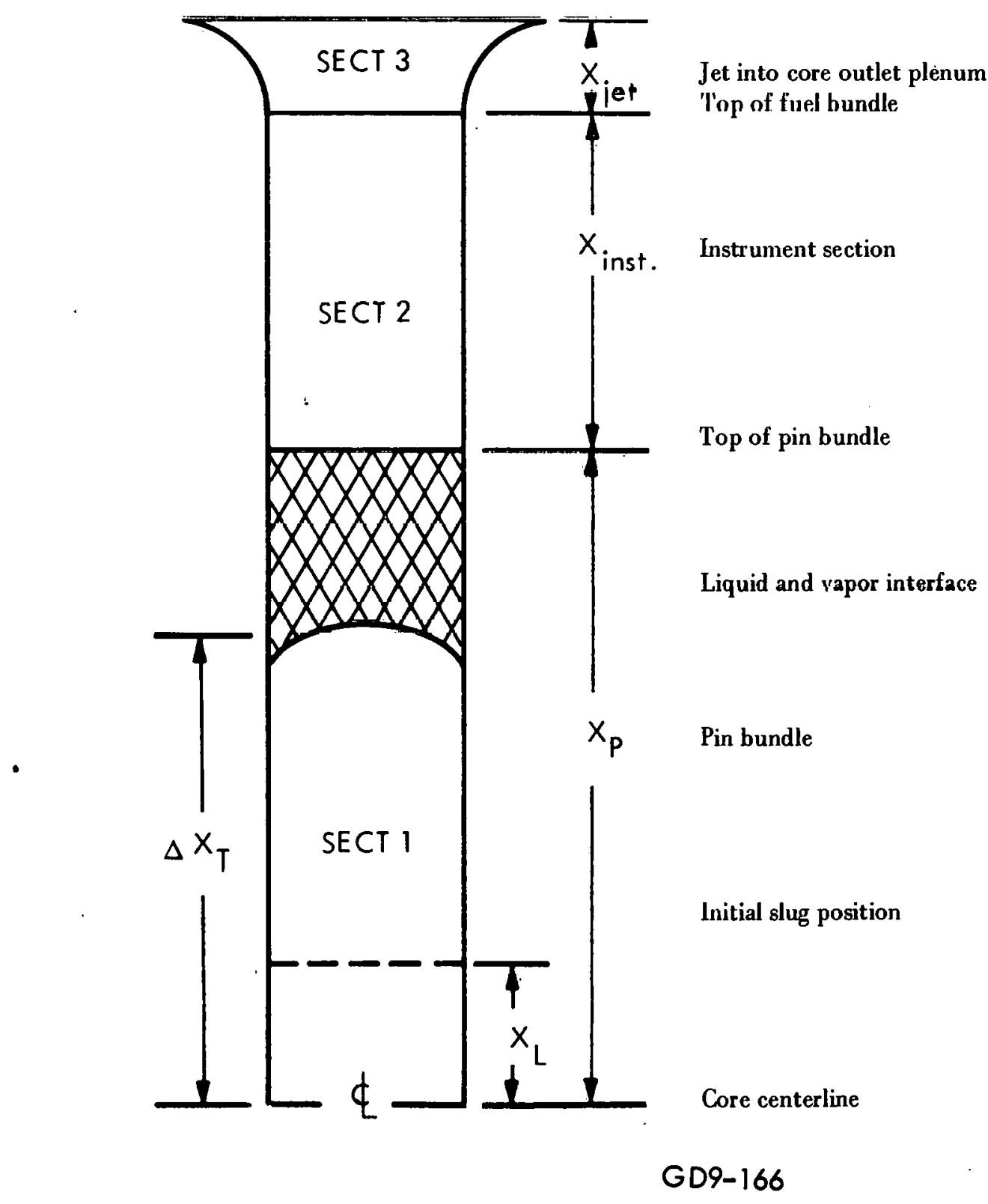

Figure D-1. Slug Flow Model 
Assumption: All orifice losses are lumped at bundle exit.

Sect 1

$$
\begin{aligned}
& m a=F \\
& \ddot{X}_{\mathrm{T}}\left[\mathrm{X}_{\mathrm{p}}-\Delta \mathrm{X}_{\mathrm{T}}+\frac{\mathrm{Ac}}{\mathrm{A}_{\text {inst }}}\left(\mathrm{X}_{\text {inst }}+\mathrm{X}_{\text {jet }}\right)\right] \frac{\rho}{\mathrm{g}}=144\left(\mathrm{P}_{\text {vap }}-\mathrm{P}_{\text {top }}\right) \\
& -C_{\text {orf }} \frac{\rho}{2 g} \cdot \dot{X}_{\mathrm{T}}^{2}-\frac{\mathrm{f}}{\mathrm{D}_{\mathrm{H}}} \frac{\rho}{2 \mathrm{~g}} \dot{\mathrm{X}}_{\mathrm{T}}^{2}\left(\mathrm{X}_{\mathrm{p}}-\Delta \mathrm{X}_{\mathrm{T}}\right)-\rho\left(\mathrm{X}_{\text {inst }}+\mathrm{X}_{\mathrm{p}}-\Delta \mathrm{X}_{\mathrm{T}}\right)
\end{aligned}
$$

Sect 2

When gas reaches Section 2 , the following changes are made in ahove equation:

$$
\frac{\mathrm{Ac}}{\mathrm{A}_{\text {inst }}}=1.0, \dot{\mathrm{X}}_{\mathrm{T}}=\frac{1}{2} \dot{\mathrm{X}}_{\mathrm{T}}, \mathrm{C}_{\text {orf }}=4 \mathrm{C}_{\text {orf }}, \mathrm{f}=0.0
$$

\section{Results}

The following listing briefly describes the cases calculated. The results are given in Figures D-2 through D-12. All cases but the last assume an initial sodium superheat of $400^{\circ} \mathrm{F}$ which causes voiding of the core in both directions and leads to rapid slug flow reentry into a dry core. The last case calculates the effect of reentry following low superheat voiding in which the core temperatures and resultant sodium pressures increase by 50 psi during each voiding and reentry cycle. All results show that reentry of the slug into the hot core is calculated only under the assumption of lower pressures in the plenum than can reasonably be expected from the temperature transients in Appendix C.

\section{Description of Cases}

Case 1: UPPER SLUG. Voiding at variable pressure. $\left(400^{\circ} \mathrm{F}\right.$ initial superheat)

Case 2: UPPER SLUG. Same as Case 1 but with new pressure profile. $\left(400^{\circ} \mathrm{F}\right.$ initial superheat)

Case 3: IJPPER. SL.IJG. Voiding and reentry with separate pressure tables for each.

Case 4: UPPER SLUG. Reentry from jet. Same pressure table as Case 3.

Case 5: LOWER SLUG. Ejection and reentry past core centerline. Reentry pressure constant ( 5 psi). New pressure table for voiding.

Case 6: LOWER SLUG. Pin length of $27 \mathrm{in.}$ Voiding (6a) at 107 psia. Reentry (6b) at 23.4 psia.

Case 7: LOWER SLUG. Pin length of 51 in. Voiding (7a) at 107 psia. Reentry (7b) at 23.4 psia.

Case 8: UPPER SLUG. Voiding at $400^{\circ} \mathrm{F}$ superheat (constant pressure) when orifice coefficient is quadrupled.

Case 9: UPPER SLUG. Same as Case 3 except orifice coefficient is quadrupled.

Case 10: UPPER SLUG. Modification of Case 4. Voiding pressure increases 50 psi with each successive voiding. 


\section{GEAP-10059}

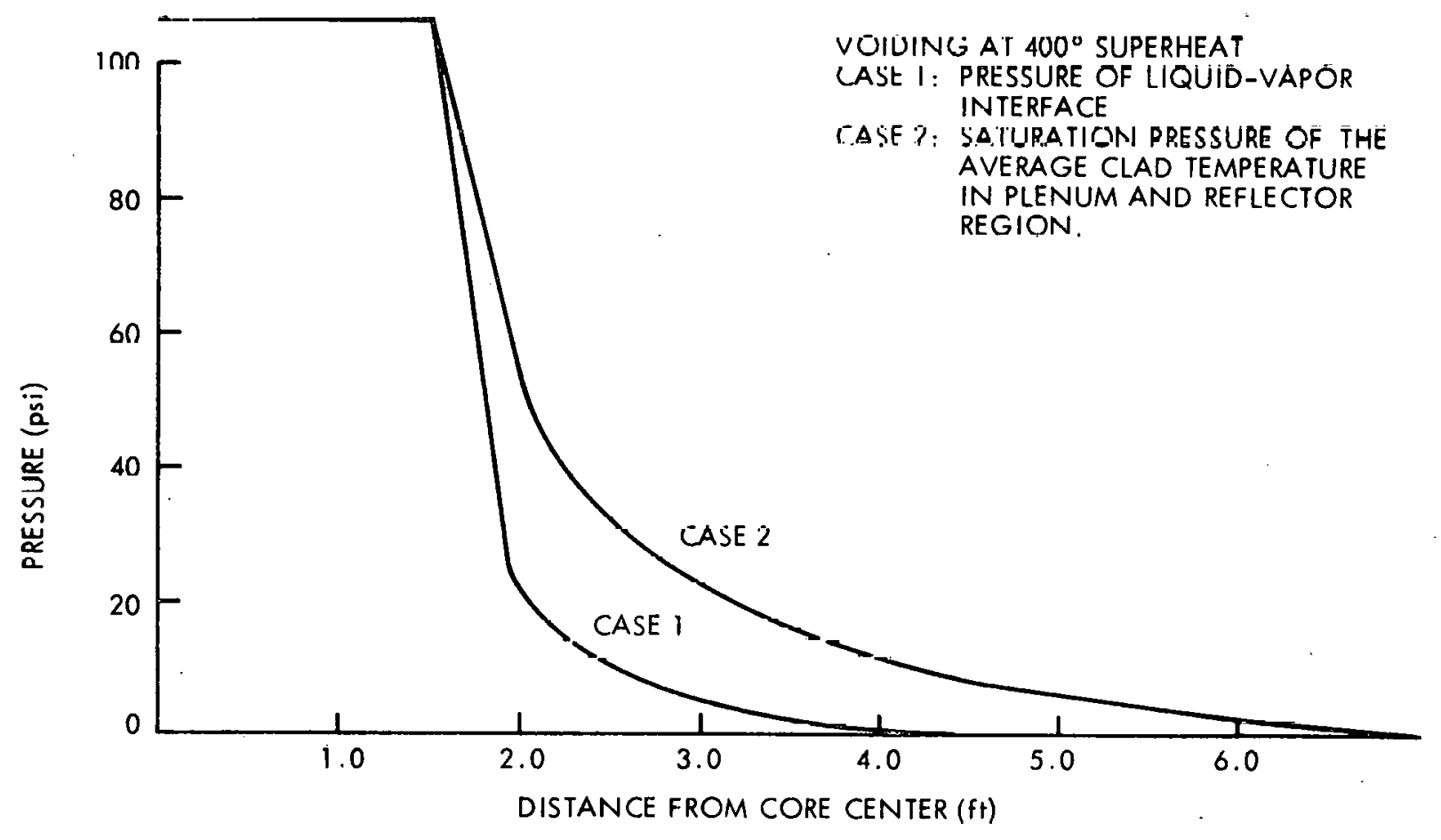

GD9-83

Figure D-2. Prossuro Tablo for Caoeo 1 and 1 


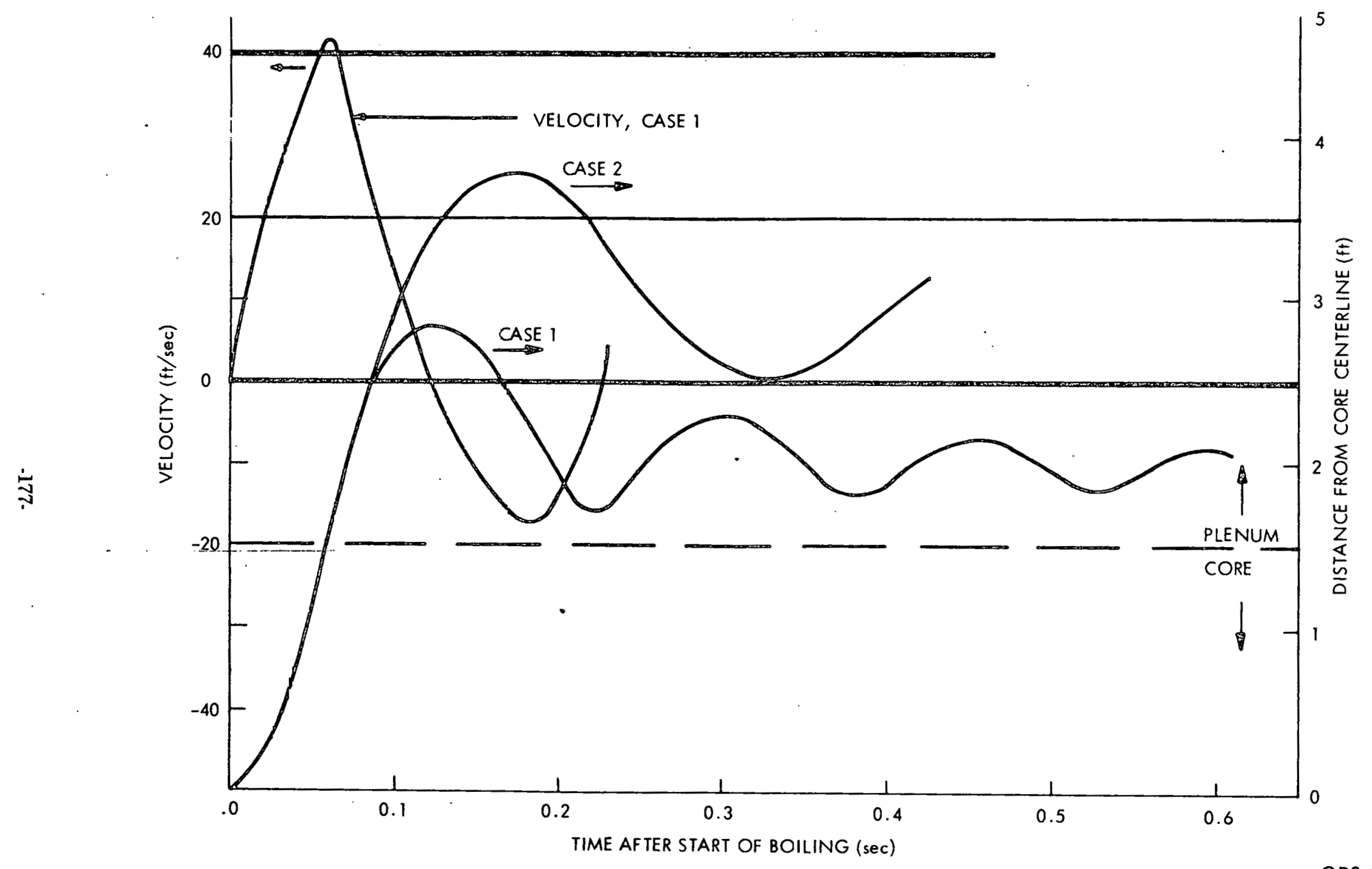




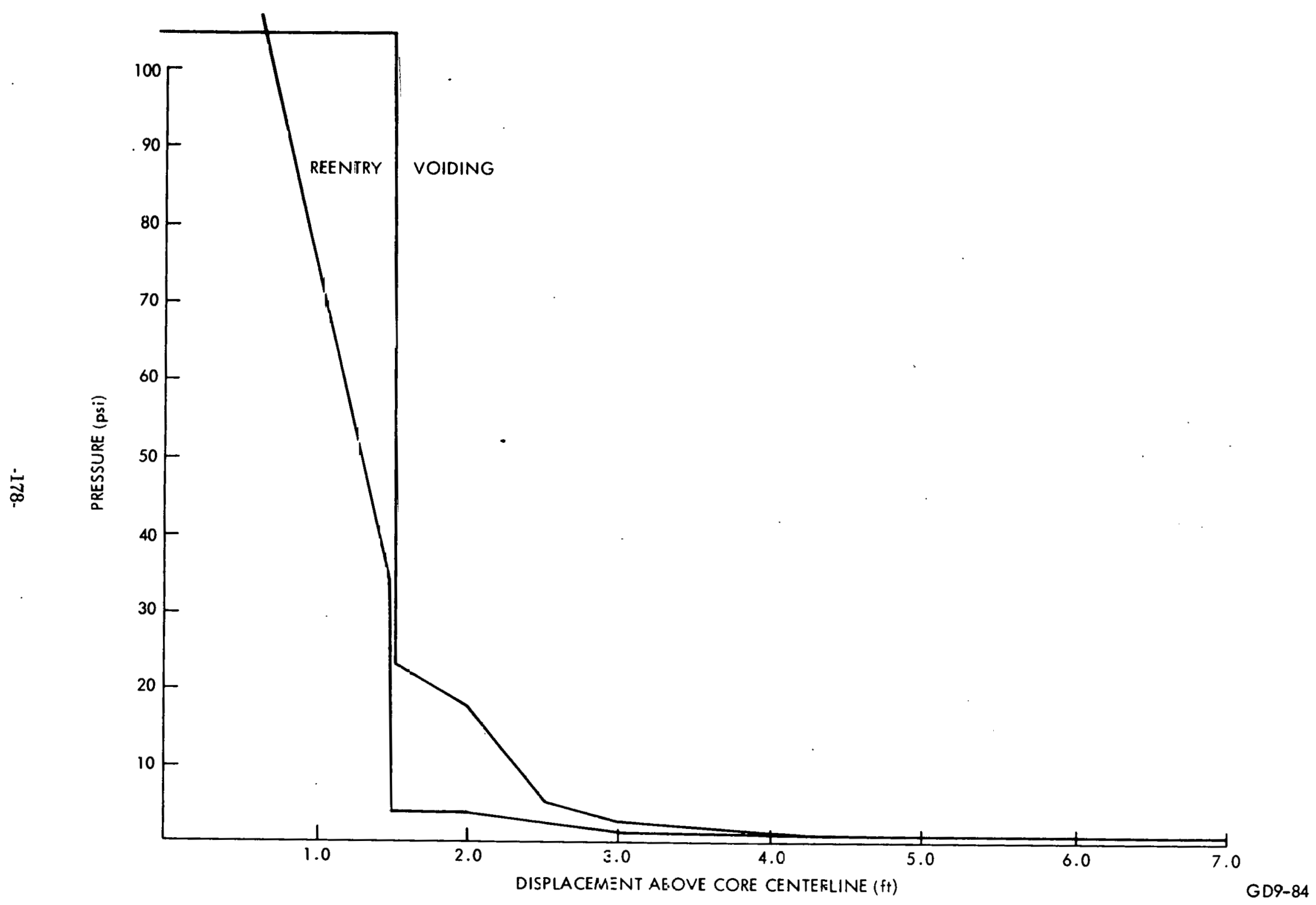

Figure D-4. Pressure for Cases 3, 4, and 9 


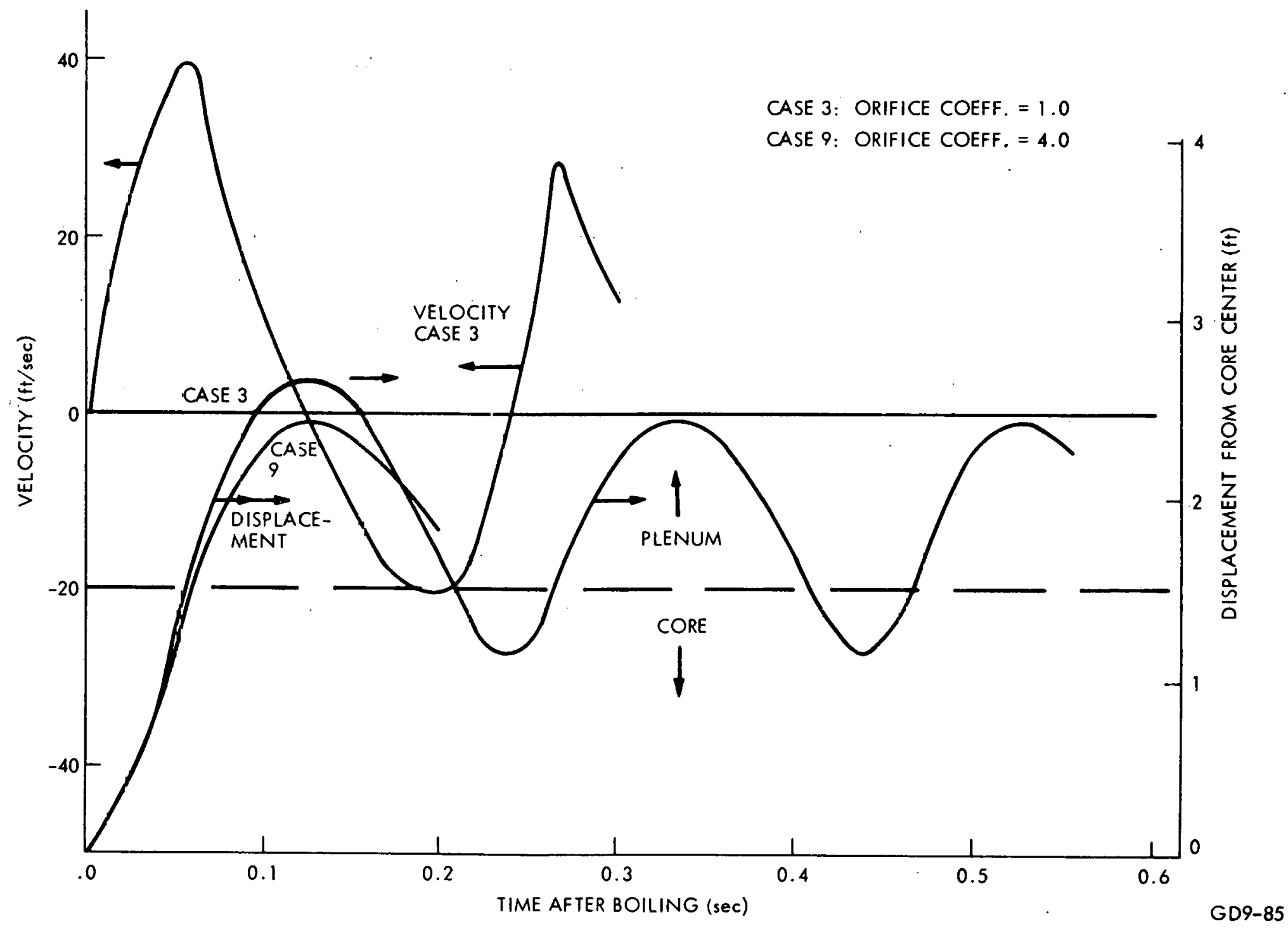

Figure D-5. Coolant Voiding and Reentry $400^{\circ}$ F Superheat 


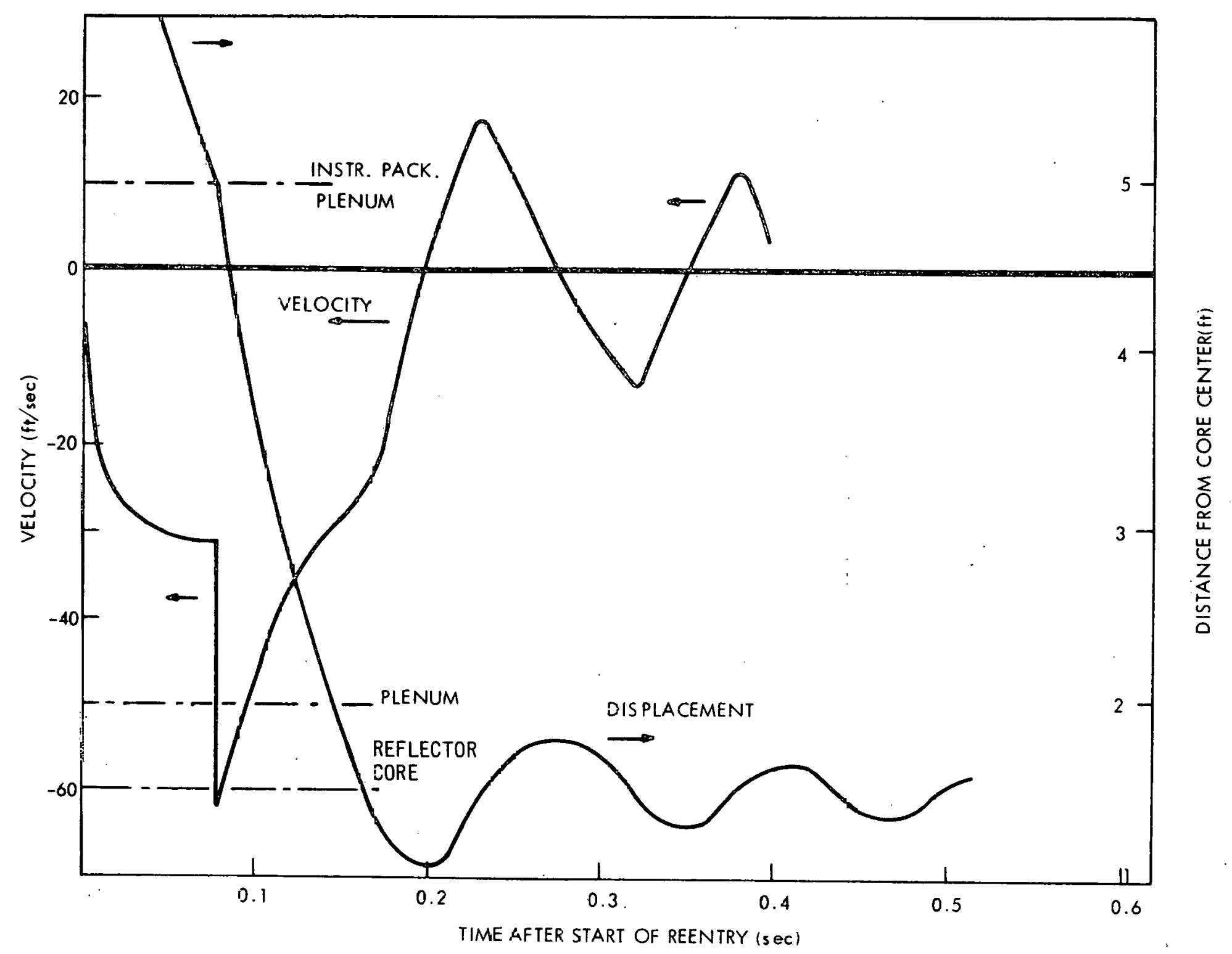




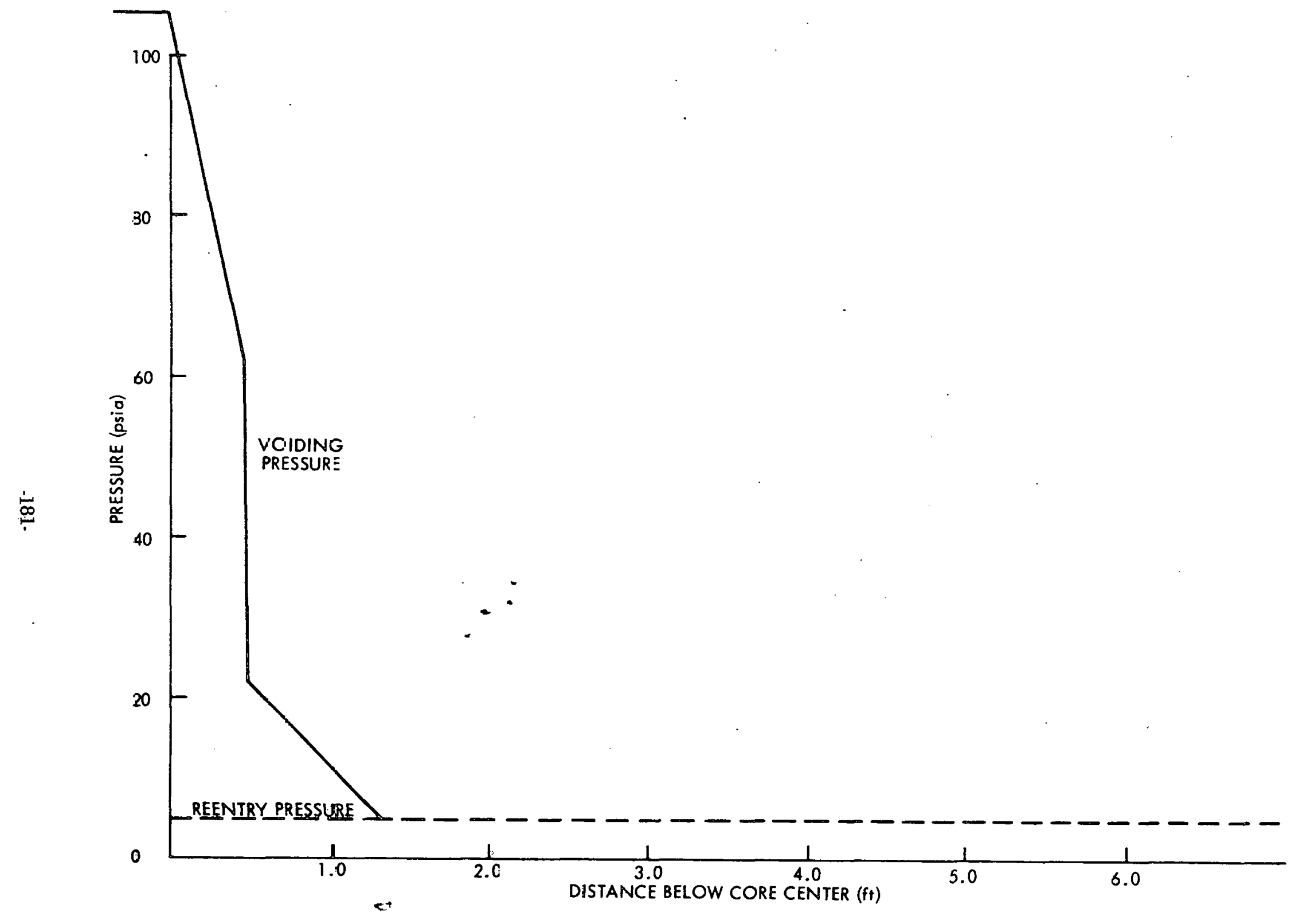

Figure D-7. Pressure Table for Case 5 Lower Slug Voiding 


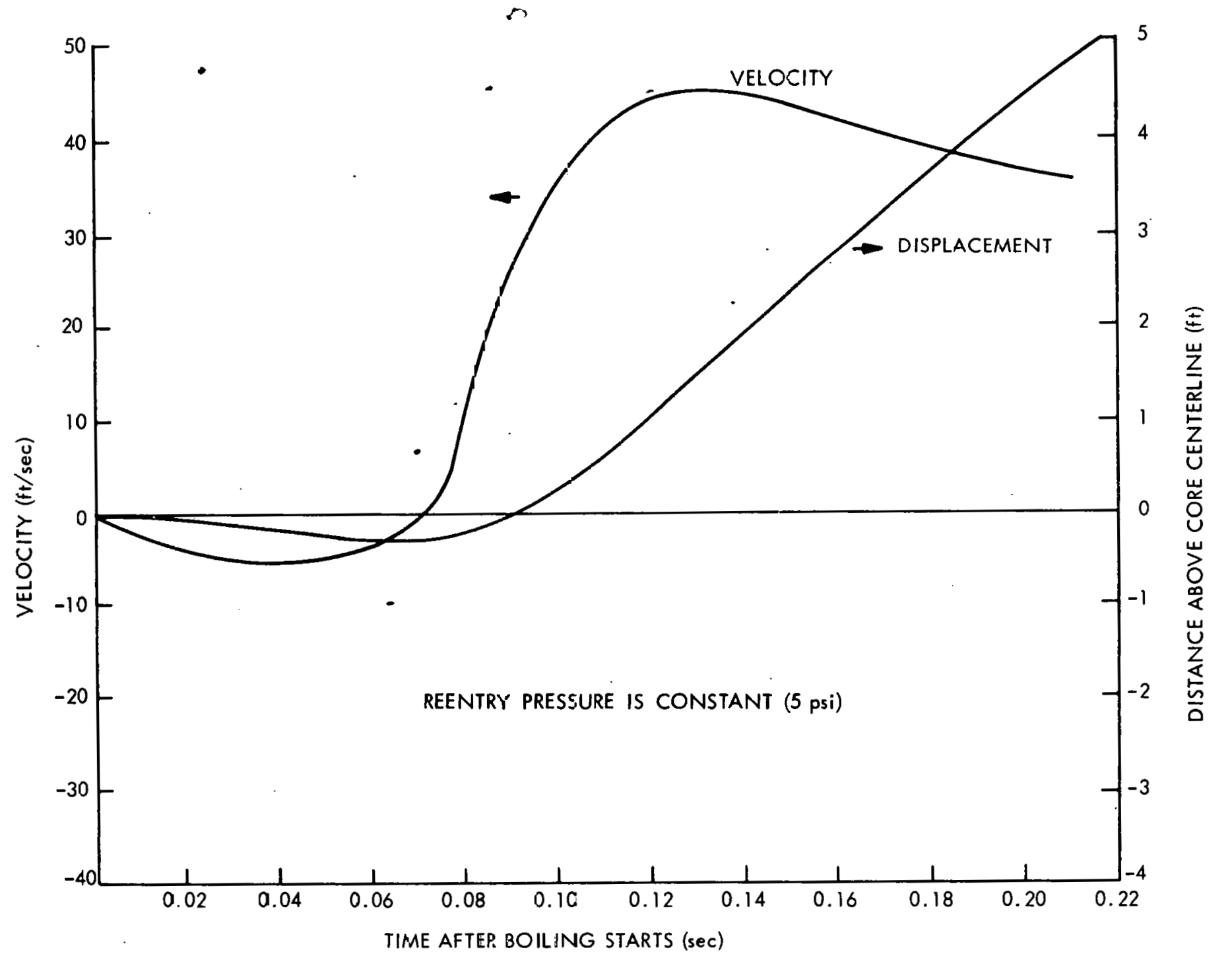

Figure D-8. Case 5: Lower Slug Eiection and Reentry Past Core Centerline 


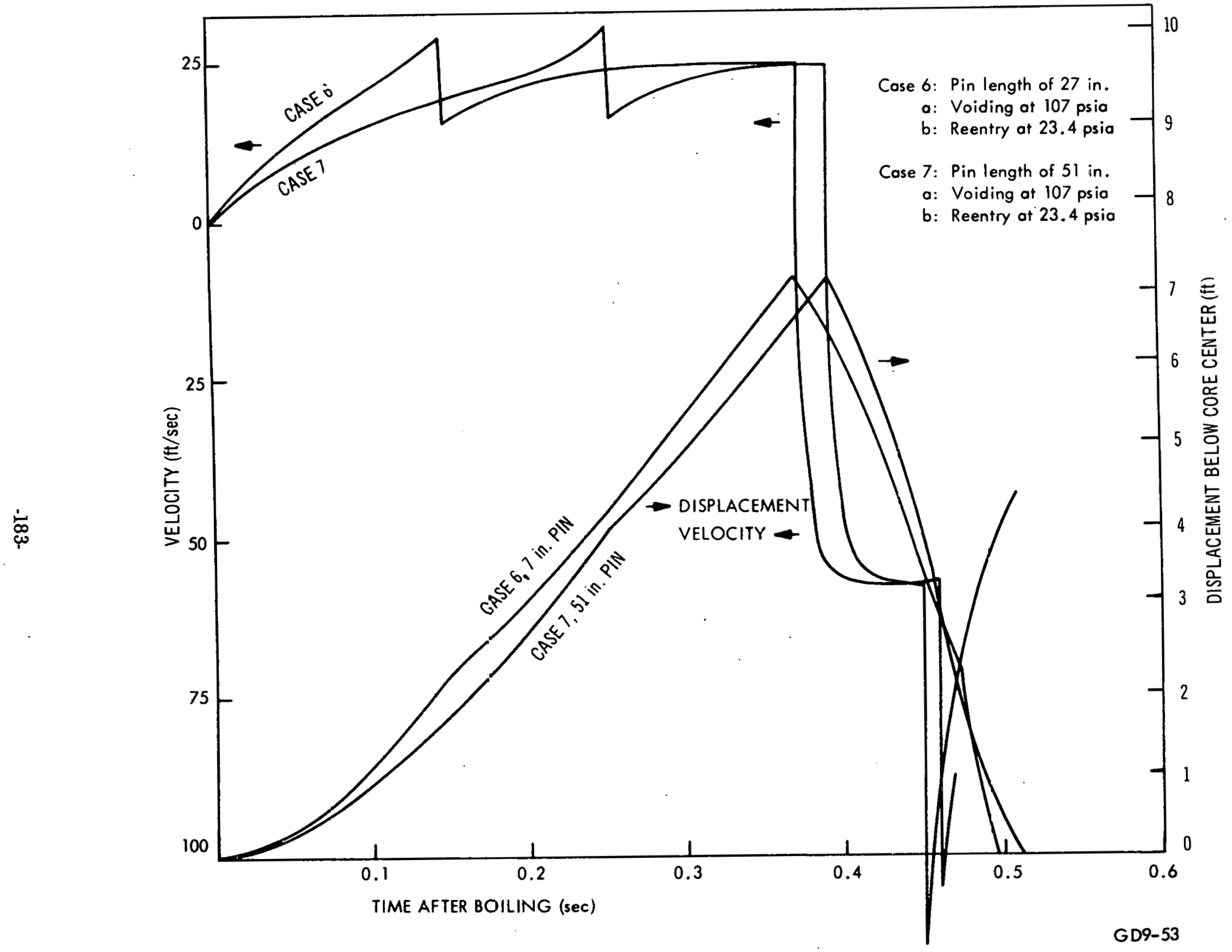

Figure D-9. Cases 6 and 7: Lower Shug Voiding and Reentry 


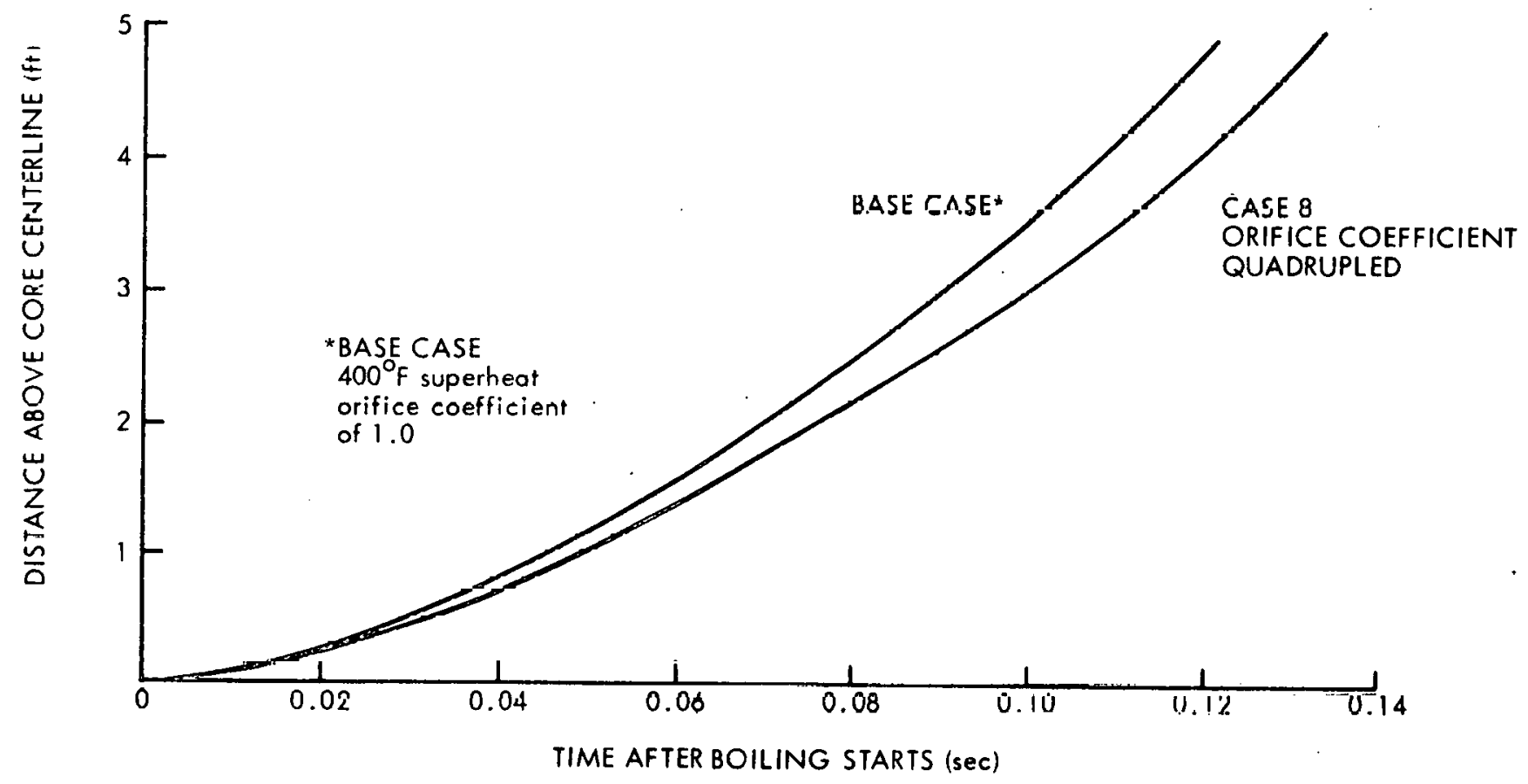

GD9-55

Figure D-10. Voiding at Constant Pressure (107 psi) $400^{\circ}$ F Initial Superheat 


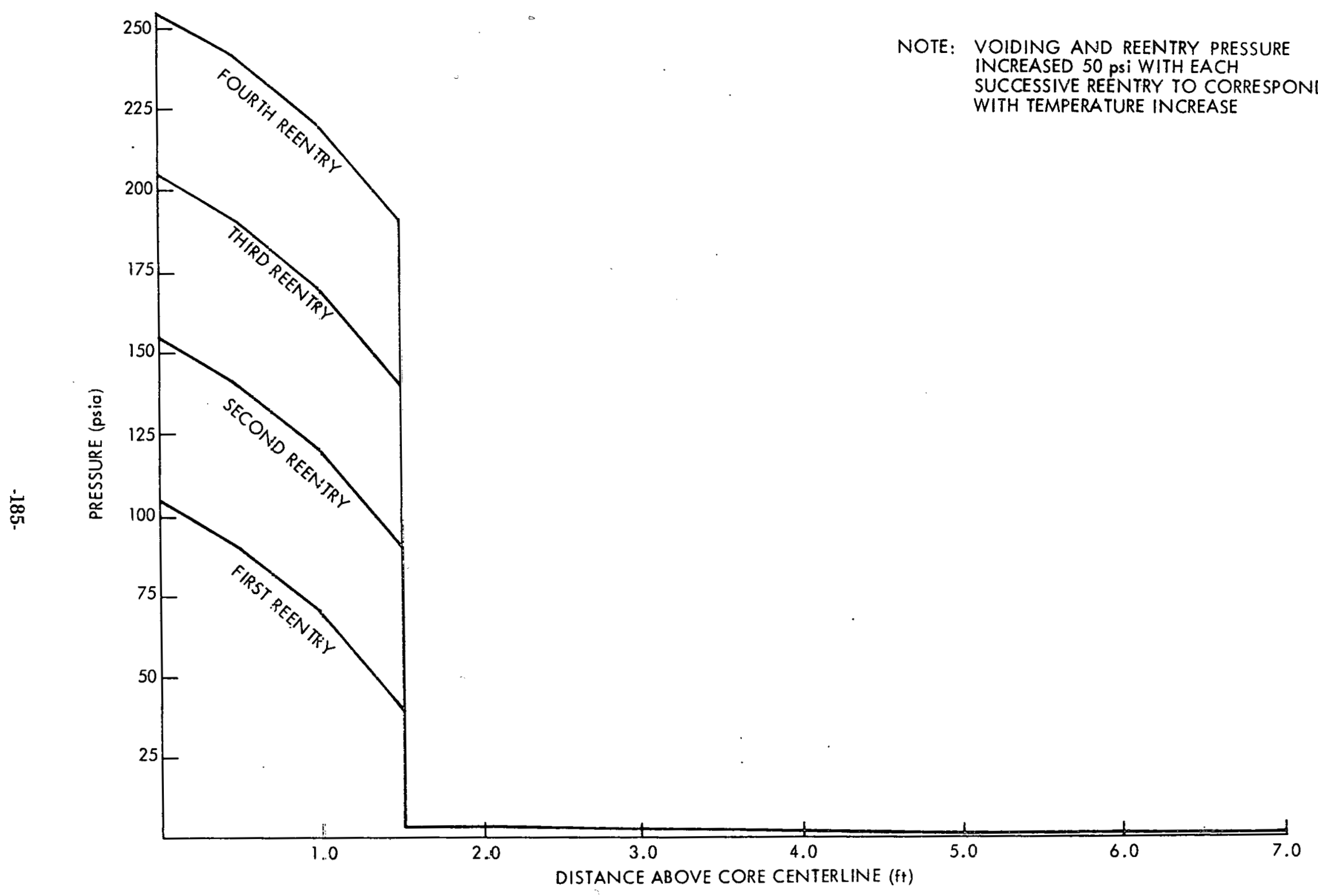




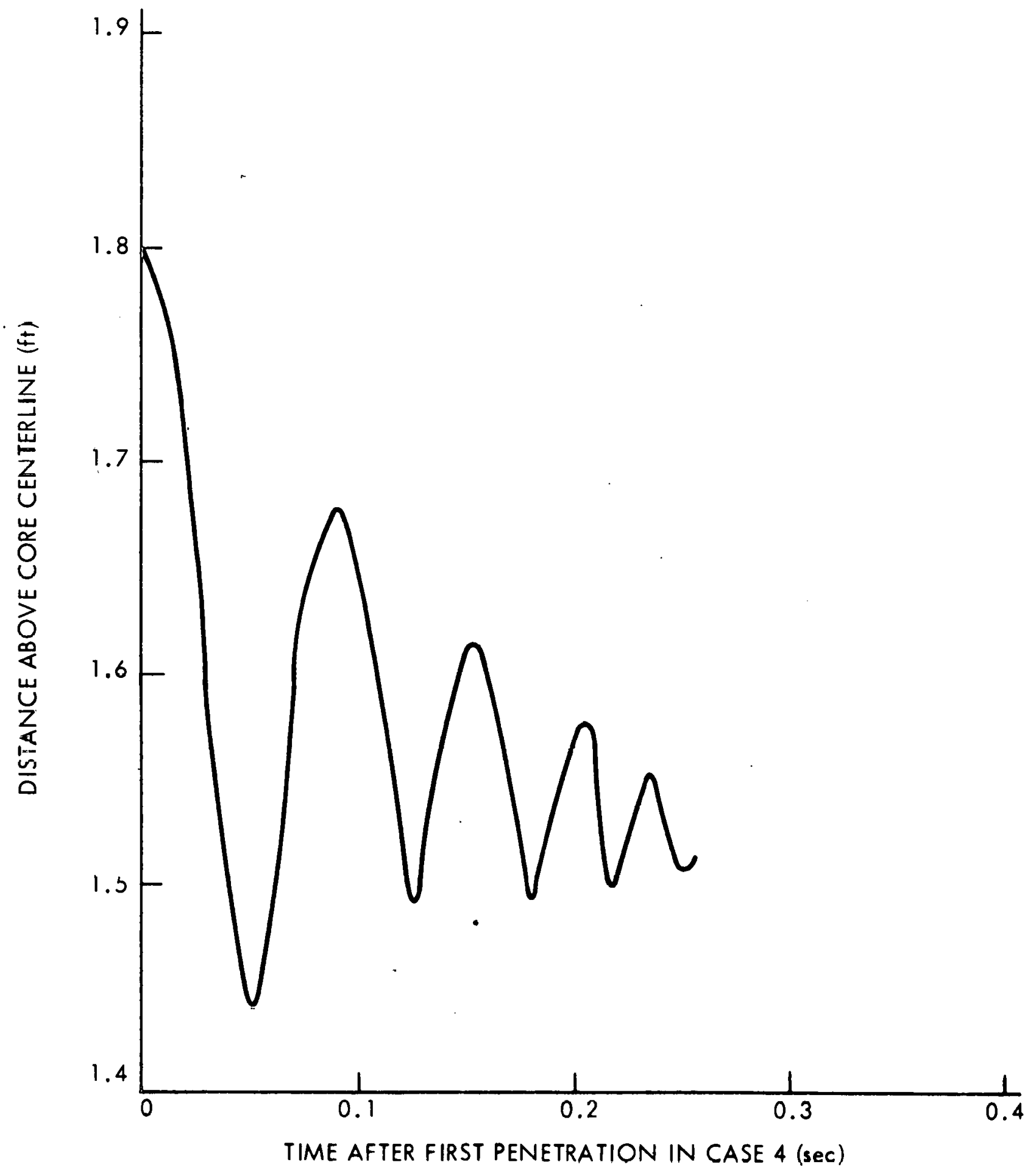

5

Figure D-12. Case 10: Continuation of Case 4 with Core Pressure Increasing 50 psi on Each Successive Reentry 


\section{Appendix E DUCT DEFLECTIONS}

The appendix contains the derivation of the moment, stresses, and deflection equations for a flat plate in the elastic and plastic regime. These equations were used in a time share computer program to calculate the energy absorbed in the duct. The results are discussed in Section 6.

Elastic Deflections:

The following details the equations used to describe the duct response in the purely elastic domain.

Using the geometry and nomenclature given on Figure 6-12, a simple force balance gives:

$$
\mathrm{W}_{\mathrm{A}}=\text { ap }\left[\frac{2}{\sqrt{3}}-\beta\left(\frac{2}{\sqrt{3}}-1\right)\right]
$$

and

$$
W_{B}=\mathbf{a p}
$$

where

$W$ is the unit force in duct wall

and

$$
\beta \quad=\frac{\mathrm{R}}{\mathrm{a}}=\frac{0.225}{2.2375}=0.1005
$$

substituting for a and $\beta$ gives:

$$
\begin{aligned}
& W_{A}=2.5489 \cdot p \\
& W_{B}=2.2375 \cdot p
\end{aligned}
$$

The meinlbrane otrowess in tho duct wall are:

$$
\begin{aligned}
& \sigma_{\text {mem }_{A}}=\frac{W_{A}}{T}=\frac{p \cdot 2.5489}{0.14}=18.206 \cdot p \\
& \sigma_{\text {mem }_{B}}=\frac{W_{B}}{T}=\frac{p \cdot 2.2375}{0.14}=16.239 \cdot p
\end{aligned}
$$

Applying Castigliano's theorem using only the strain energy in bending results in the following expressions for the moments:

$$
M_{B}=\frac{a^{2} p}{6-\beta(6-\pi \sqrt{3})}\left(\frac{(1-\beta)^{3}}{3}-\frac{\beta(1-\beta)}{2 \sqrt{3}}[\beta(7 \pi-12 \sqrt{3})-\pi]\right)
$$

and

$$
M_{A}=a^{2} p \cdot\left(\frac{(1-\beta)}{6}[1-\beta(7-4 \sqrt{3})]\right)-M_{B}
$$


Substitution of the actual values for a and $\beta$ into these two expressions yields the following relationship bctween bending moments and internal differential pressure:

$$
\begin{aligned}
& M_{B}=p \cdot 0.27072 \\
& M_{A}=p \cdot 0.474422
\end{aligned}
$$

The extreme fiber stresses for a linear stress distribution are calculated by the conventional equation:

$$
\sigma_{b}=\frac{M_{C}}{I}=\frac{M \cdot \frac{T}{2}}{\frac{1}{12} b \cdot T^{3}}=\frac{6 M}{T^{2}}
$$

Effect of the curvature on shifting of the neutral axis is tabulated in Figure 6-14 in terms of a stress correction factor $\mathrm{K}_{\mathrm{i}}$ and $\mathrm{K}_{\mathrm{o}}$ which represents the ratio of the actual stress to stress computed by the ordinary flexure formula for a flat beam. $\mathrm{K}_{\mathrm{i}}$ refers to the concave side and $K_{0}$ to the convex side.

For a ratio $\frac{T}{R}=0.6225$ Figure 6-14 gives

$$
\mathrm{K}_{\mathrm{o}}=0.8125
$$

and

$$
\mathrm{K}_{\mathrm{i}}=1.273
$$

therefore

$$
\begin{array}{ll}
\sigma_{\text {hyp }}=1.273 \cdot \sigma_{\text {lin. }} & \text { (tension) } \\
\sigma_{\text {hyp }}=0.8125 \cdot \sigma_{\text {lin. }} & \text { (compression) }
\end{array}
$$

where $\sigma_{\text {hyp }}$ is stress for a hyperbolic stress distribution.

Applying these results, the total stress in the duct wall can now he momputed for cross sectione $\Lambda \cdot \Lambda$; B-B shown in Figure 6:12.

$$
\begin{aligned}
& \sigma_{\text {tot }_{A}}=\sigma_{\text {hyp }}+\sigma_{\text {mem }_{A}}=1.273 \cdot \frac{6 \mathrm{M}_{\mathrm{A}}}{\mathrm{T}^{2}}+18.21 \cdot \mathrm{p} \\
& \sigma_{\text {tot }_{\mathrm{B}}}=\sigma_{\text {bend }_{\mathrm{B}}}+\sigma_{\text {mem }_{\mathrm{B}}}=\frac{6 \cdot \mathrm{M}_{\mathrm{B}}}{\mathrm{T}^{2}}+16.23 \cdot \mathrm{p}
\end{aligned}
$$

substituting for $M_{A}, M_{B}$, and $T$ gives:

Corner: $\quad \sigma_{\text {tot }_{A}}=(184.89+18.21) \cdot p=203.10 \mathrm{p}$

Mid-side: $\quad \sigma_{\text {tot }_{\mathrm{B}}}=(82.87+16.23) \cdot \mathrm{p}=99.10 \mathrm{p}$ 
This result indicates a tension-stress concentration on the inside of the duct-corner (cross section A-A). Accordingly this is where the duct is most likely to fail when strained by internal pressure.

\section{Deflections Beyond the Elastic Limit}

Relationships are developed for deflection of a duct wall when the elastic limit is exceeded. The principal assumptions are a straight beam model and no strain hardening beyond the elastic limit (idealized stress-strain curve). The length of the straight beam cquals the length of the neutral axis between two adjacent corners when the corner radius is zero.

This subsection derives a relationship between the moment and the radius of curvature when the elastic limit is exceeded.

Figure E-1 shows the model used in this analysis

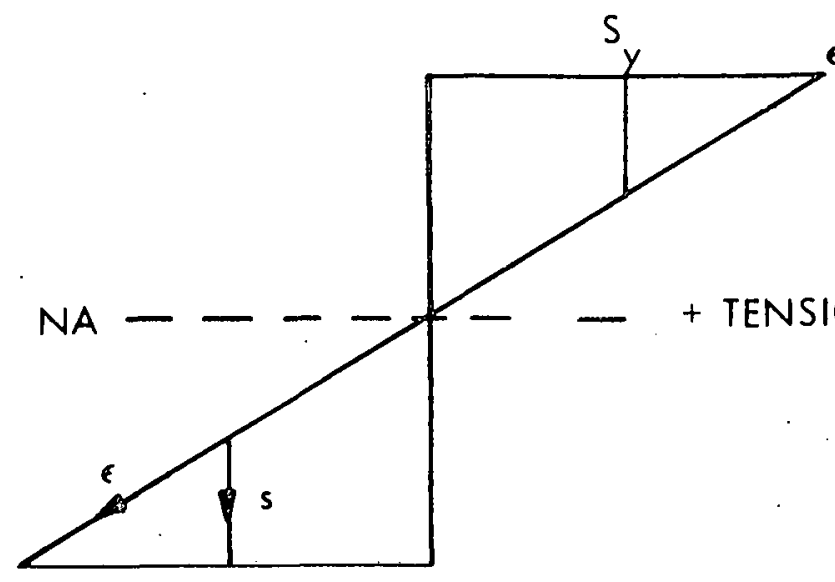

BENDING

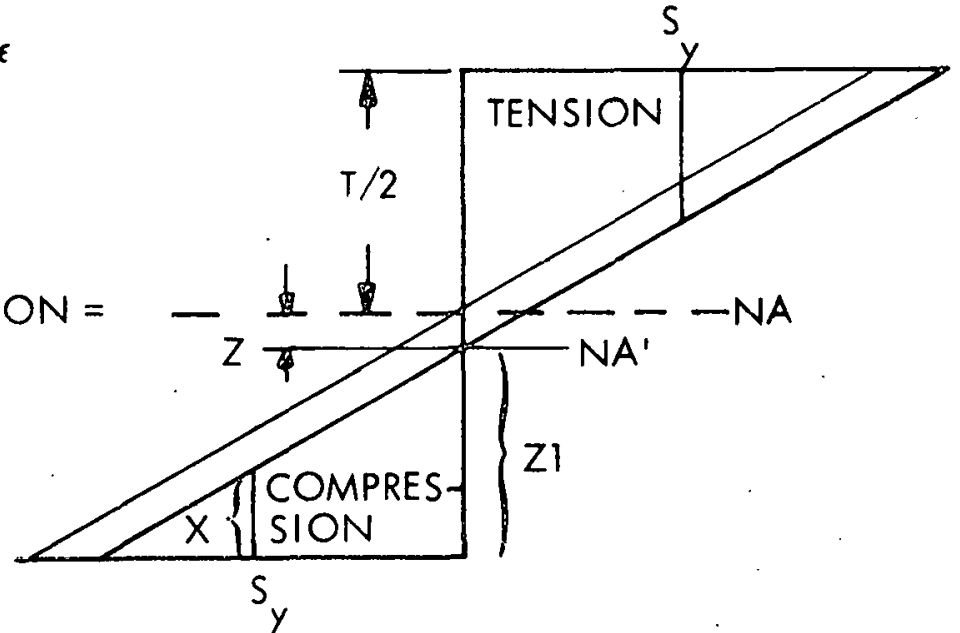

BENDING \& TENSION

Figure E-1. Flat Plate Stress Distributions

The darkened area must equal the tensile force

$$
\begin{aligned}
& Z \cdot 2 \cdot S=P \cdot a \\
& Z=\frac{P \cdot a}{2 \cdot S} \text { (inch) }
\end{aligned}
$$

The moment with respect to the new neutral axis is twice the moment of the compression-side.

$$
M=2 \cdot S\left[X(T / 2-Z-X / 2)+(T / 2-Z-X)^{2} \cdot \frac{1}{3}\right]
$$

This gives:

$$
\begin{array}{ll}
M_{u}=2 \cdot S \cdot \frac{(T / 2-Z)^{2}}{2}=S \cdot(T / 2-Z)^{2} & (X=T / 2-Z) \\
M_{y}=2 \cdot S \cdot \frac{1}{3} \cdot(T / 2-Z)=\frac{2}{3} S(T / 2-Z)^{2} & (X=0)
\end{array}
$$

$\mathrm{X}$ is the part of the duct that yields in compression. 
Defining $(T / 2-Z)=Z 1$

We can write:

$$
\begin{aligned}
& M=2 \cdot S\left[X(Z 1-X / 2)+\frac{1}{3}(Z 1-X)^{2}\right] \\
& \frac{M}{2 S}=Z 1 \cdot X-\frac{X^{2}}{2}+\frac{1}{3} Z^{2}-\frac{2}{3} Z 1 \cdot X+\frac{1}{3} X^{2} \\
& \frac{3 M}{S}=6 Z 1 \cdot X-3 X^{2}+2 Z^{2}-4 Z 1 X+2 X^{2} \\
& X^{2}-2 Z 1 X-\left(2 Z^{2}-\frac{3 M}{S}\right)=0 \\
& X=Z 1 \pm \sqrt{Z 1^{2}+2 l^{2}-\frac{3 M}{S}}=7.1-\sqrt{3\left(Z^{2}-\frac{M}{S}\right)}
\end{aligned}
$$

Radius of eurvature:

$$
\begin{aligned}
r & =\frac{7.1-X}{\epsilon y} \\
\frac{1}{r} & =\frac{\mathrm{d}^{2} \mathrm{y}}{\mathrm{dx}^{2}}=\frac{M}{E I}
\end{aligned}
$$

Substituting for $\mathrm{X}$

$$
\begin{aligned}
& \frac{\mathrm{d}^{2} \mathrm{y}}{d x^{2}}=\frac{1}{r}=\frac{{ }^{\top} y}{Z 1-X}=\frac{{ }^{6} y}{Z 1-Z 1+\sqrt{3\left(Z 1^{2}-\frac{M}{S}\right)}} \\
& \frac{d^{2} y}{d x^{2}}=\frac{S}{E} \cdot \frac{1}{\sqrt{3\left(Z 1^{2}-M / S\right)}}
\end{aligned}
$$

Assuming the case where a plastic hinge has developed at the ends and at the middle of the beam as pictured in Figure E-2.

$$
\begin{array}{ll}
M_{1-2}=\frac{p L 3}{2}\left(\frac{X^{2}}{L 3}-X\right)+M_{u} & M_{u}=S(T / 2-Z)^{2}=S \cdot Z^{2} \\
M_{2-3}=\frac{p L 5}{2}\left(\frac{X^{\prime 2}}{L 5}-X^{\prime}\right)+M_{y} & M_{y}=\frac{2}{3} S(T / 2-Z)^{2}=\frac{2}{3} S \cdot Z^{2}\left(M_{3-4}{ }_{\max }=M_{u}=-\frac{p L 7^{2}}{8}-M_{y}\right) \\
M_{3-4}=\frac{p \cdot L 7}{2}\left(\frac{X^{\prime \prime}}{L 7}-X^{\prime \prime}\right)-M_{y} &
\end{array}
$$



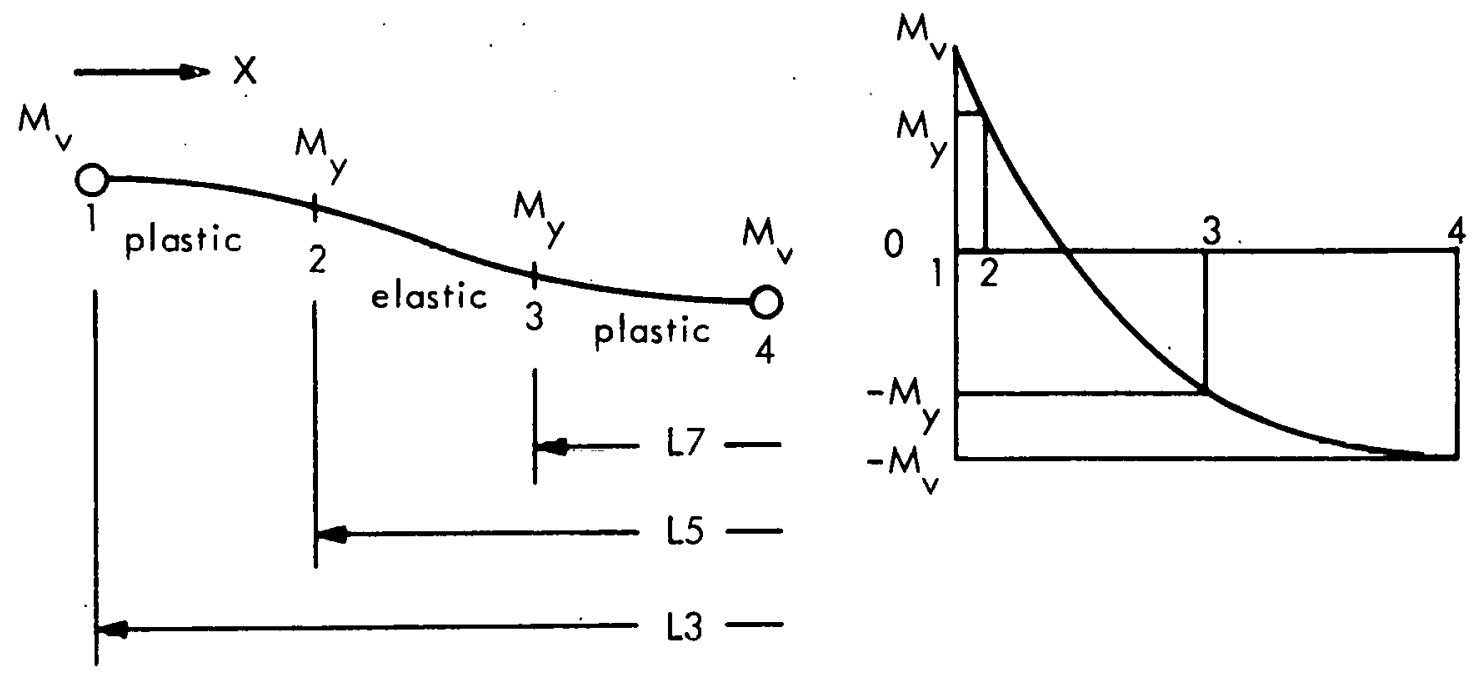

Figure E-2. Flat Plate

Substituting and reducing,

$$
\begin{aligned}
& \frac{\mathrm{d}^{2} \mathrm{y}}{\mathrm{dx} \mathrm{x}^{2}}=\frac{\mathrm{s}}{\mathrm{E}} \frac{\mathrm{l}}{\left.\sqrt{3\left(\mathrm{Zl}^{2}-\frac{\mathrm{l}}{\mathrm{S}}\left[\frac{\mathrm{pL} 3}{2}\left(\frac{\mathrm{x}^{2}}{\mathrm{~L} 3}-\mathrm{X}\right)+\mathrm{S} \cdot \mathrm{Z1}^{2}\right]\right.}\right)} \\
& \frac{d_{-y}^{2} y}{d x^{2}}=\frac{S}{E} \frac{1}{\sqrt{3\left(z 1^{2}-\frac{p X^{2}}{2 S}+\frac{P L 3 X}{2 S}-21^{2}\right)}} \\
& \frac{d^{2} y}{d x^{2}}=\frac{S}{E} \frac{1}{\sqrt{\frac{3 P L 3}{2 S} X-\frac{3 p}{2 S} X^{2}}}=\frac{S}{E} \frac{1}{\sqrt{\frac{3 p}{2 S}}} \cdot \frac{1}{\sqrt{L 3 \cdot X-X^{2}}}
\end{aligned}
$$

Let

$$
\begin{aligned}
& \frac{S}{E} \cdot \frac{l}{\sqrt{\frac{3 p}{2 S}}}=K 4 \\
& \frac{d^{2} y}{d x^{2}}=K 4 \cdot \frac{1}{\sqrt{L 3 X-X^{2}}} \\
& \frac{d y}{d x}=K 4 \int_{1}^{2} \frac{d x}{\sqrt{L 3 X-X^{2}}} \quad\left[\text { we know: } \int \frac{d x}{\sqrt{2 a x-X^{2}}}=\cos ^{-1}\left(\frac{a-x}{|a|}\right)\right]
\end{aligned}
$$


if $a=\frac{L 3}{2}$ then $\frac{d y}{d x}=K 4 \cdot \cos ^{-1}\left(\frac{L 3 / 2-X}{L 3 / 2}\right)$

the slope for the plastic portion $1-2$ of Figure E-2 is $\frac{\mathrm{dy}}{\mathrm{dx}}=\mathrm{K} 4 \cdot\left[\cos ^{-1}\left(1-\frac{2 \mathrm{X}}{\mathrm{L} 3}\right)+\mathrm{Cl}\right]$ boundary condition: $\frac{d y}{d x}=0$ when $X=0$

$$
\begin{aligned}
& \cos ^{-1} 1+\mathrm{Cl}=0 \text { or } \mathrm{Cl}=0 \\
& \frac{\mathrm{dy}}{\mathrm{dx}}=\mathrm{K} 4 \cdot \cos ^{-1}\left(1-\frac{2 \mathrm{X}}{\mathrm{L} 3}\right)
\end{aligned}
$$

defleotion: $y^{-K}-\int_{1}^{3} \operatorname{cosi}^{-1}\left(1-\frac{2 X}{L 3}\right) d x$

substituting $f=1-\frac{2 X}{L 3}$ we have $d f=-\frac{2}{L 3} d x$ or $d x=-\frac{L 3}{2} d f$

this gives:

$$
\begin{aligned}
& y=K 4 \cdot\left(-\frac{L 3}{2}\right) \int \cos ^{-1} f \cdot d f \\
& y=-K 4 \cdot \frac{L 3}{2}\left[f \cos ^{-1} f-\sqrt{1-f^{2}}\right]
\end{aligned}
$$

recalling that $\mathrm{f}=\left(1-\frac{2 \mathrm{X}}{\mathrm{L} 3}\right)$

wc obtain:

$$
\begin{aligned}
& \mathrm{y}=-\mathrm{K} 4 \cdot \frac{\mathrm{L} 3}{2}\left[\left(1-\frac{2 \mathrm{X}}{\mathrm{L} 3}\right) \cdot \cos ^{-1}\left(1-\frac{2 \mathrm{X}}{\mathrm{L} 3}\right)-\sqrt{\frac{4 \mathrm{X}}{\mathrm{L} 3}-\left(\frac{2 \mathrm{X}}{\mathrm{L} 3}\right)^{2}}+\mathrm{C} 2\right] \\
& \mathrm{y}=\mathrm{K} 4 \cdot \frac{\mathrm{L} 3}{2}\left[2 \sqrt{\frac{\mathrm{X}}{\mathrm{L} 3}-\left(\frac{\mathrm{X}}{\mathrm{L} 3}\right)^{2}}-\left(1=\frac{2 \mathrm{X}}{\mathrm{L} 3}\right) \cdot \cos ^{-1}\left(1-\frac{2 \mathrm{X}}{\mathrm{L} 3}\right)+\mathrm{C} 2\right]
\end{aligned}
$$

Boundary Condition:

$$
\begin{aligned}
& y=0 \text { when } X=0 \\
& 0=-\cos ^{-1} 1+C 2 \therefore C 2=0 \\
& y=K 4 \cdot \frac{L 3}{2}\left[2 \sqrt{\frac{X}{L 3}-\left(\frac{X}{L 3}\right)^{2}}-\left(1-\frac{2 X}{L 3}\right) \cdot \cos ^{-1}\left(1-\frac{2 X}{L 3}\right)\right]
\end{aligned}
$$

the plastic deflection in region 1-2 is:

$$
y=K 4\left[\sqrt{X(L 3-X)}-\left(\frac{L 3}{2}-X\right) \cdot \cos ^{-1}\left(1-\frac{2 X}{L 3}\right)\right]
$$


Minimum internal pressure to produce plastic hinges at 1 and 4.

$$
\begin{aligned}
& M_{3-4}=\frac{\mathrm{pL} 3}{2}\left(\frac{\mathrm{X}^{2}}{\mathrm{~L} 3}-\mathrm{X}\right)+\mathrm{M}_{\mathrm{u}}=-\mathrm{M}_{\mathrm{u}} \quad\left(\mathrm{X}=\frac{\mathrm{L} 3}{2}\right): \mathrm{M}_{\mathrm{u}}=\mathrm{S} \cdot(\mathrm{T} / 2-\mathrm{Z})^{2} \\
& \mathrm{p}=\frac{16 \mathrm{M}_{\mathrm{u}}}{\mathrm{L}^{2}}=\frac{16 \cdot \mathrm{S}(\mathrm{T} / 2-\mathrm{Z})^{2}}{\mathrm{~L}^{2}} \\
& \mathrm{M}_{2}=\mathrm{M}_{\text {yield }}=\frac{2}{3} \cdot \mathrm{S} \cdot(\mathrm{T} / 2-\mathrm{Z})^{2} \quad \text { where } \mathrm{Z}=\frac{\mathrm{P} \cdot \mathrm{a}}{2 \cdot \mathrm{S}} \\
& \mathrm{M}_{1-2}=\frac{\mathrm{pL} 3}{2}\left(\frac{\mathrm{X} 1^{2}}{\mathrm{~L} 3}-\mathrm{Xl}\right)+\mathrm{M}_{\mathrm{u}}=\mathrm{M}_{\mathrm{y}} \\
& \quad \frac{\mathrm{pL} 3}{2}\left(\frac{\mathrm{X} 1^{2}}{\mathrm{~L} 3}-\mathrm{X} 1\right)=-\frac{1}{3} \mathrm{~S} \cdot \mathrm{Zl}^{2}
\end{aligned}
$$

solve for $\mathrm{Xl}$ :

$$
\begin{aligned}
& \mathrm{Xl}^{2}-\mathrm{L} 3 \mathrm{X} 1+\frac{2}{3} \cdot \frac{\mathrm{S}}{\mathrm{P}} \cdot \mathrm{Z1}^{2}=0 \\
& \mathrm{X} 1=\frac{\mathrm{L} 3}{2}-\sqrt{\left(\frac{\mathrm{L} 3}{2}\right)^{2}-\frac{2}{3} \frac{\mathrm{S}}{\mathrm{P}} \cdot \mathrm{Z1}^{2}}
\end{aligned}
$$

The moment equals yield moment a distance Xl from the supports making,

$$
\mathrm{L} 5=\mathrm{L} 3-2 \mathrm{Xl}
$$

and the moment:

$$
M=\frac{p L 5}{2}\left(\frac{X^{2}}{L 5}-X\right)+M_{y}
$$

and we have:

$$
\frac{d^{2} y}{d x^{2}}=\frac{1}{E I} \cdot M
$$

slope:

$$
\begin{aligned}
& \frac{d y}{d x}=\frac{1}{E I} \int M d x=\frac{1}{E I} \int\left[\frac{p L 5}{2}\left(\frac{X^{2}}{L 5}-X\right)+M_{y} \cdot\right] d x \\
& \frac{d y}{d x}=\frac{1}{E I}\left[\frac{p L 5}{2}\left(\frac{X^{3}}{3 L 5}-\frac{X^{2}}{2}\right)+M_{y} \cdot X\right]+C 3
\end{aligned}
$$

where $\mathrm{C} 3$ has to equal the slope for the plastic region at $\mathrm{X}_{2}$

$$
\frac{d y}{d x}=\left\{\frac{1}{E I}\left[\frac{p L 5}{2}\left(\frac{X^{3}}{3 L 5}-\frac{X^{2}}{2}\right)+M_{y} \cdot X\right]+\left|K 4 \cdot \cos ^{-1}\left(1-\frac{2 X}{L 3}\right)\right|_{X=X_{2}}\right\}
$$


deflection:

$$
\begin{aligned}
& y=\int\left\{\frac{1}{E I}\left[\frac{p L 5}{2}\left(\frac{X^{3}}{3 L 5}-\frac{X^{2}}{2}\right)+M_{y} \cdot X\right]+\left|K 4 \cdot \cos ^{-1}\left(1-\frac{2 X}{L 3}\right)\right|\right\} d x \\
& y=\frac{1}{E I}\left[\frac{p L 5}{2}\left(\frac{X^{4}}{12 L 5}-\frac{X^{3}}{6}\right)+M_{y} \cdot \frac{X^{2}}{2}\right]+S\left(X_{2}\right) \cdot X+C 3
\end{aligned}
$$

where C3 is $y\left(X_{2}\right)$

Length of the plastic region at center $=\mathrm{L} 7$

$$
\begin{aligned}
M= & \frac{p L 5}{2}\left(\frac{X_{2}^{2}}{L 5}-X_{2}\right)+M_{y}=-M_{y} \\
& X_{2}^{2} \quad L 5 \cdot X_{y}+\frac{4 M_{y}}{p}=0 \\
& X_{2}=\frac{L 5}{2}-\sqrt{\left(\frac{L 5}{2}\right)^{2}-\frac{4 M_{y}}{p}}
\end{aligned}
$$

This makes L7 $=\mathrm{L} 5-2 \cdot \mathrm{X}_{2}$

The moment $\mathrm{M}_{3-4}$

$$
\begin{aligned}
M & =\frac{p L 7}{2}\left(\frac{X^{2}}{L 7}-X\right)-M_{y} \quad\left(M_{y}<M<M_{u}\right) \\
\frac{d^{2} y}{d x^{2}} & \equiv \frac{s}{E} \frac{1}{\sqrt{3\left(Z 1^{2}-1 M 1 / S\right)}} \quad M-\frac{P L 7}{2}\left(\frac{X^{2}}{L 7}-X\right)-I M_{y} \\
\frac{d y}{d x} & -\int_{3}^{4} \frac{S}{E} \frac{d x}{\left.\sqrt{3\left(Z 1^{2}-\frac{1}{S}\left[\frac{P L 7}{2}\left(\frac{X^{2}}{L 7}-X\right)-M_{y}\right]\right.}\right)} \quad M_{y}=\frac{2}{3} S \cdot Z^{2} \\
& =\int_{3}^{4} \frac{S}{E} \frac{d x}{\sqrt{3 \cdot\left[1^{2}-\frac{P X^{2}}{2 S}+\frac{P \cdot L 7 \cdot X}{2 S}+\frac{2}{3} Z 1^{2}\right]}} \\
& =\frac{S}{E} \int_{3}^{4} \frac{d x}{\sqrt{5 Z 1^{2}-\frac{3 P}{2 S} X^{2}+\frac{3 P \cdot L 7}{2 S} X}}
\end{aligned}
$$


Let $5 Z 1^{2}=a$

$$
\begin{aligned}
& \frac{3 P \cdot L 7}{2 S}=b \\
& \frac{3 P}{2 S}=c \\
& \frac{d y}{d x}=\frac{S}{E} \int_{3}^{4} \frac{d x}{\sqrt{a+b x-c x^{2}}}
\end{aligned}
$$

or:

$$
\frac{S}{E} \int \frac{d x}{\sqrt{a+b x-c x^{2}}}=\frac{S}{E} \frac{1}{\sqrt{c}}\left[\sin ^{-1}\left(\frac{2 c x-b}{\sqrt{b^{2}+4 a c}}\right)+C 1\right]
$$

Boundary Condition:

$$
\frac{d y}{d x}=0 \text { when } x=0 \text {. }
$$

this makes $\mathrm{Cl}=\sin ^{-1}\left(\frac{\mathrm{b}}{\sqrt{\mathrm{b}^{2}+4 \mathrm{ac}}}\right)$

$$
\begin{aligned}
\frac{d y}{d x} & =\frac{S}{E} \frac{1}{\sqrt{c}}\left(\sin ^{-1} \frac{b}{\sqrt{b^{2}+4 a c}}+\sin ^{-1} \frac{2 c x-b}{\sqrt{b^{2}+4 a c}}\right)+C 3 \\
K 4 & =\frac{S}{E} \frac{1}{\sqrt{c}} \\
y & =K 4 \int\left(\sin ^{-1} \frac{b}{\sqrt{b^{2}+4 a c}}+\sin ^{-1} \frac{2 c x-b}{\sqrt{b^{2}+4 a 0}}\right) d x+\int C 3 d x+C 4 \\
y & =K 4\left[X \cdot \sin ^{-1} \frac{b}{\sqrt{b^{2}+4 a c}}+\int \sin ^{-1} \frac{2 c x-b}{\sqrt{b^{2}+4 a c}} d x\right]+C 3 \cdot X+C 4
\end{aligned}
$$

substituting: $f=\frac{2 c x-b}{\sqrt{b^{2}+4 a c}}$

$$
\begin{aligned}
& d f=\frac{2 c}{\sqrt{b^{2}+4 a c}} d x \text { or } d x=\frac{1}{2 c} \sqrt{b^{2}+4 a c} d f \\
& y_{1}=K \dot{4} \frac{1}{2 c} \sqrt{b^{2}+4 a c} \int \sin ^{-1} f d f
\end{aligned}
$$


calling $\mathrm{K} 4 \cdot \frac{1}{2 \mathrm{c}} \sqrt{\mathrm{b}^{2}+4 \mathrm{ac}}=\mathrm{K} 5$ we have

$$
\begin{aligned}
& y_{1}=K 5\left[f \sin ^{-1} f+\sqrt{1-f^{2}}\right] \\
& y_{1}=K 5\left[\frac{2 c x-b}{\sqrt{b^{2}+4 a c}} \cdot \sin ^{-1} \frac{2 c x-b}{\sqrt{b^{2}+4 a c}}+\sqrt{1-\left(\frac{2 c x-b}{\sqrt{b^{2}+4 a c}}\right)^{2}}\right]
\end{aligned}
$$

calling $\frac{2 c x-b}{\sqrt{b^{2}+4 a c}}=D 3$ and $\frac{-b}{\sqrt{b^{2}+4 a c}}=F 3$

We have:

$$
\mathrm{y}=\mathrm{K} 4 \cdot \mathrm{X} \cdot \sin ^{-1}(\mathrm{~F} 3)+\mathrm{K} 5 \cdot\left[\mathrm{D} 3 \cdot \sin ^{-1} \mathrm{D} 3+\sqrt{1-\mathrm{D} 3 \uparrow 2}\right]+\mathrm{C} 3 \cdot \mathrm{X}+\mathrm{C} 4
$$

This expression is used in Section 6 in computing the energy absorbed in the duct.

The following equations summarize the results of this appendix.

The expressions for the deflections in the three different regions of the duct wall are

Plastic:

$$
y_{1-2}=K 4\left[\sqrt{X(L .3-X)}-\left(\frac{L 3}{2}-X\right) \cdot \cos ^{-1}\left(1-\frac{2 \cdot X}{L 3}\right)\right]
$$

where

$$
K 4=\frac{S}{E} \cdot \frac{1}{\sqrt{\frac{3 p}{2 S}}}
$$

Elastic:

$$
y_{2-3}=\frac{I}{E I}\left[\frac{p \cdot L 5}{2}\left(\frac{X^{4}}{12 \cdot L 5}-\frac{X^{3}}{6}\right)+M_{y} \cdot \frac{X^{2}}{2}\right]+S\left(X_{2}\right) \cdot X+C 3
$$

where

$$
S\left(\mathrm{X}_{2}\right)=\text { slope at point } 2,
$$

and

$$
\text { C3 = deflection at point } 2 \text {. }
$$


Plastic:

$$
\mathrm{y}_{3-4}=\mathrm{K} 4 \cdot \mathrm{X} \cdot \sin ^{-1}(\mathrm{~F} 3)+\mathrm{K} 5 \times\left[\mathrm{D} 3 \cdot \sin ^{-1} \mathrm{D} 3+\sqrt{1-\mathrm{D} 3^{2}}\right]+\mathrm{C} 3 \cdot \mathrm{X}+\mathrm{C} 4
$$

where

$$
\mathrm{K} 5=\mathrm{K} 4 \cdot \frac{\mathrm{l}}{2 \mathrm{c}} \sqrt{\mathrm{b}^{2}+4 \mathrm{ac}}
$$

and

$$
\begin{aligned}
& \mathrm{a}=5 \cdot \mathrm{Z1}^{2} \\
& \mathrm{~b}=\frac{3 \mathrm{p} \cdot \mathrm{L} 7}{2 \mathrm{~S}} \\
& \mathrm{C}=\frac{3 \mathrm{p}}{2 \mathrm{~S}} \\
& \mathrm{F3}=\frac{-\mathrm{b}}{\sqrt{\mathrm{b}^{2}+4 \mathrm{ac}}} \\
& \mathrm{D} 3=\frac{2 \mathrm{cx}-\mathrm{b}}{\sqrt{\mathrm{b}^{2}+4 \mathrm{ac}}} \\
& \mathrm{C} 3=\text { slope at } 3 \\
& \mathrm{C} 4=\text { deflection at } 3
\end{aligned}
$$




\section{ACKNOWLEDGMENTS}

The following personnel made a substantial contribution to the work described in this report:

Thermal Hydraulic Analysis, D.L. Wilmer, R.C. Thompson, H.T. Matsuo, S.D. Weber; Sodium Superheat and Voiding Analysis, K.W. Cook, W.G. Meinhardt; Sodium-Core Material Interaction Analysis, H.C. Pfefferlen; Local Failure Propagation Analysis, D.J. Bender; Structural Analysis, J.M. Cole, F.T. Frydenbo, J.R. Punches, D. Langley.

\section{DIS'I'RIBU'I'ION}

Parific Northwest Laboratory

FF'I'F' Project

P.O. Box 220

Richland, Washington 99352

Attn: Supervisor of Configurations Contract 